\title{
Regulación de la citoquinesis por Rgf1 y la ruta de integridad
}

TESIS DOCTORAL

Tomás Edreira González

2019

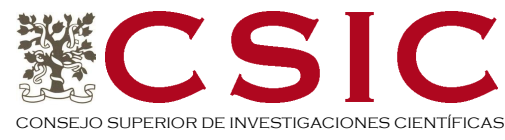

VNiVERSiDAD

1:

and

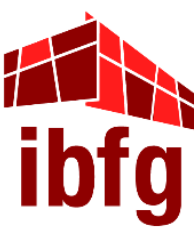

INSTITUTO DE BIOLOGÍA FUNCIONAL Y GENÓMICA 



\section{UNIVERSIDAD DE SALAMANCA \\ DEPARTAMENTO DE \\ MICROBIOLOGÍA Y GENÉTICA}

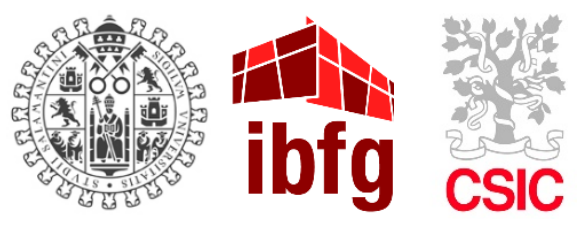

Yolanda Sánchez Martín, Profesora Titular del Departamento de Microbiología y Genética de la Universidad de Salamanca,

\section{CERTIFICA:}

Que la memoria titulada Regulación de la citoquinesis por Rgf1 y la ruta de integridad presentada por D. Tomás Edreira González para optar al título de Doctor por la Universidad de Salamanca, dentro del programa de Doctorado en Biología Funcional y Genómica, ha sido realizada bajo mi dirección en el Instituto de Biología Funcional y Génomica (IBFG), centro mixto de la Universidad de Salamanca (USAL) y del Consejo Superior de Investigaciones Científicas (CSIC).

Y para autorizar su presentación y evaluación por el tribunal correspondiente, expido el presente certificado en Salamanca, a 21 de octubre de 2019.

Dra. Yolanda Sánchez Martín 



\section{ÍNDICE}

\section{Introducción}

Schizosaccharomyces pombe: organismo modelo para el estudio del ciclo y la morfogénesis celular ...................................................................................................................

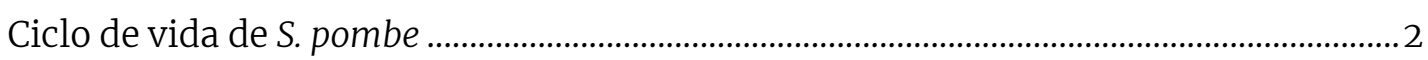

Ciclo celular y ciclo morfogenético de S. pombe …...........................................................

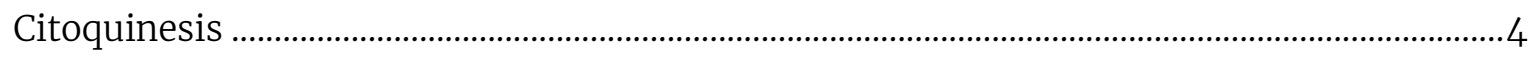

Establecimiento del plano de división............................................................................

Ensamblaje del anillo contráctil .............................................................................................

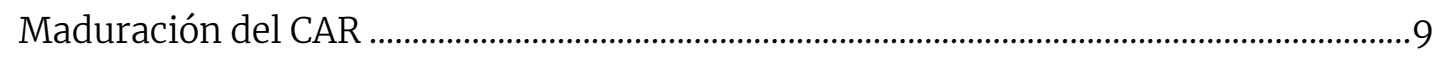

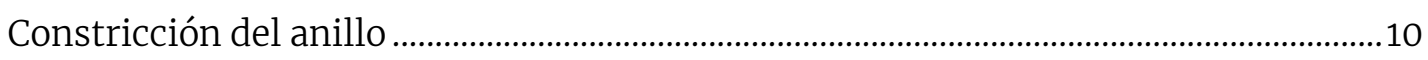

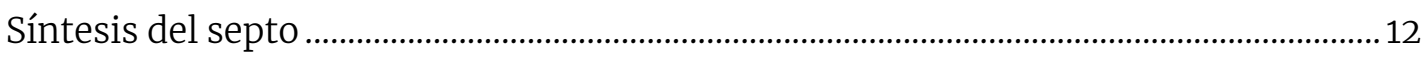

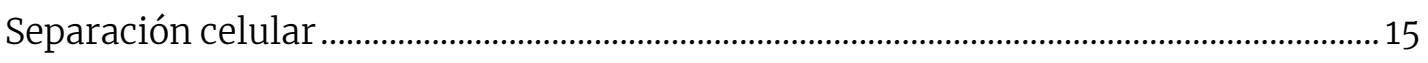

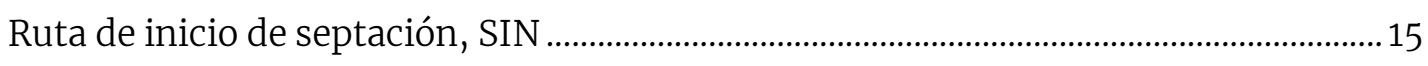

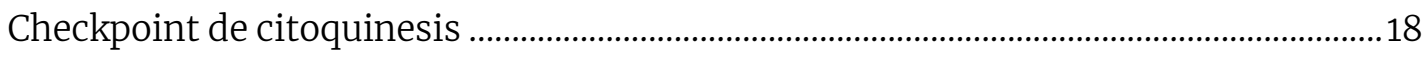

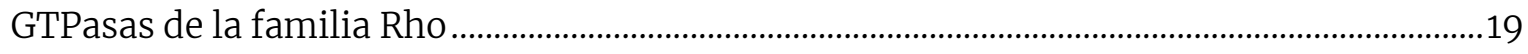

Regulación de las GTPasas de la familia Rho …………………………………............... 20

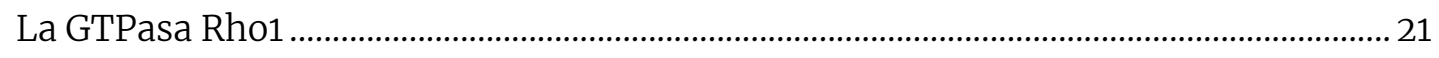

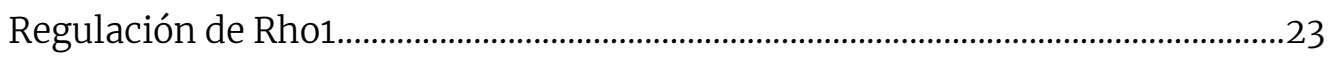

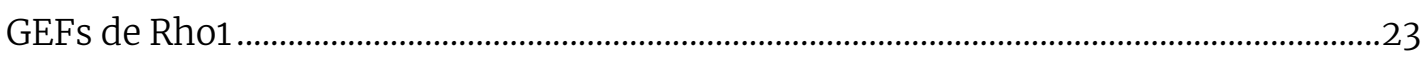

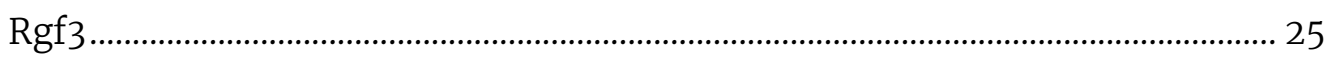

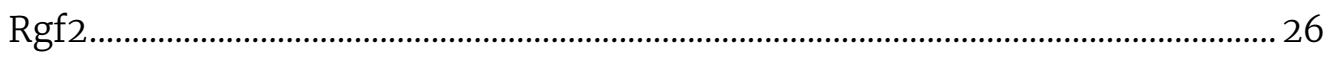

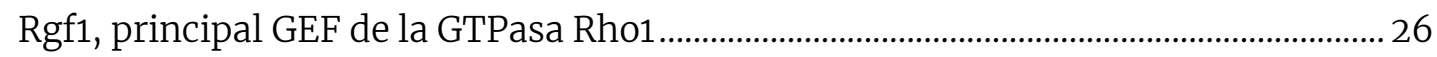

Rgf1 es necesario en el mantenimiento de la integridad celular y

crecimiento bipolar ..................................................................................................... 27

Rgf1 participa en la tolerancia al estrés replicativo.................................................. 28

Rgf1 está involucrado en la reparación de daño en el DNA...................................... 29

Rgf1 es un activador de la ruta de integridad celular ................................................ 30

Respuesta celular a estrés: Rutas de MAPK.................................................................................... 31

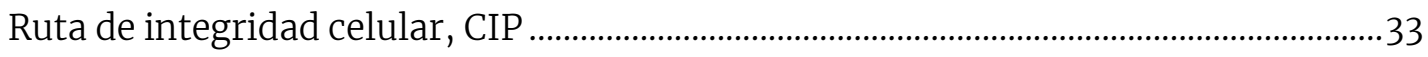

Sensores y reguladores positivos .............................................................................. 34

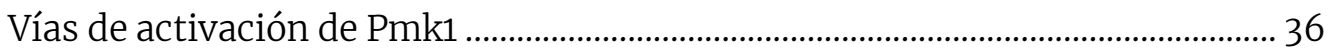




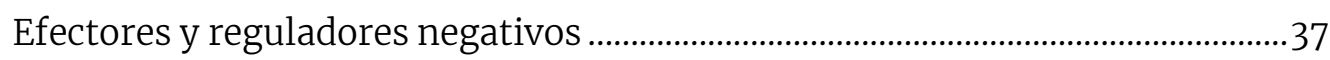

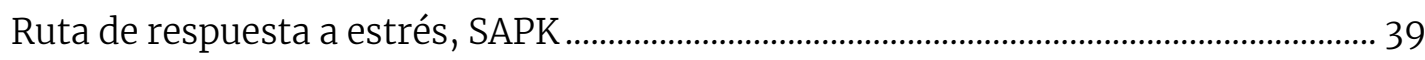

\section{Objetivos}

Resultados

Rgf1 se localiza junto al anillo contráctil de actomiosina .........................................................4 45

La localización de Rgf1 en el septo depende de su interacción con los componentes del CAR.

El blankophor produce un retraso de la citoquinesis ausente en parte en el mutante $\operatorname{rgf} 1 \triangle$

El inicio de la septación y de la constricción del CAR están desacoplados en presencia de blankophor

El blankophor retrasa específicamente el inicio de la constricción del CAR

La ruta de integridad celular es necesaria para retrasar la constricción del CAR en respuesta a blankophor 64

componentes de la ruta CIP que participan en la respuesta a blankophor. 67

Otros estreses que activan la ruta CIP también retrasan la constricción del CAR 68

El blankophor, la caspofungina, la cafeína y el $\mathrm{KCl}$ inducen defectos de separación celular en el mutante pmk1 $\Delta$.

Relación de la miosina con el retraso causado por el estrés en septación..................................75

Relación de la actina con el retraso causado por el estrés en septación.......................................77

Clp1 y el checkpoint de citoquinesis frente al bloqueo por blakophor .......................................... 79

La ruta SIN como mediador del bloqueo del CAR frente al estrés en septación .......................83

\section{Discusión}

\section{Conclusiones}

\section{Materiales y Métodos}

Cepas de Schizosaccharomyces pombe 103

Métodos genéticos 106

Conjugación 106

Aislamiento de ascosporas al azar 107

Reacción en cadena de la polimerasa (PCR) 107

Condiciones de cultivo 108

Inducción de estrés 109 Ensayo de crecimiento en gota 
ÍNDICE | VII

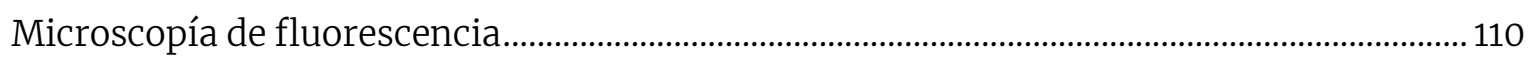

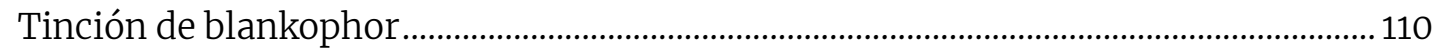

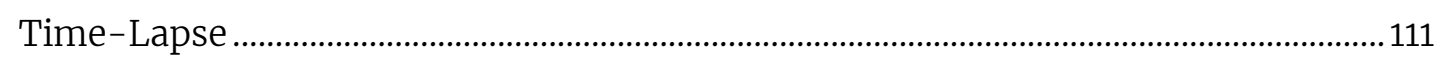

Análisis y presentación de datos............................................................................................... 112

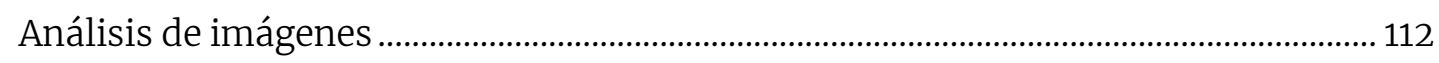

Representación gráfica y análisis de datos ..........................................................................113

$\begin{array}{ll}\text { Bibliografía } & 115\end{array}$ 



\section{ACRÓNIMOS}

\begin{tabular}{|c|c|}
\hline AMP & Adenosín monofosfato \\
\hline $\mathrm{BP}$ & Blankophor \\
\hline CAR & Anillo contráctil de actomiosina (Contractile actomyosin ring) \\
\hline $\mathrm{CDK}$ & Kinasa Dependiente de Ciclina (Ciclin dependent kinase) \\
\hline CIP & Ruta de integridad celular (Cell integrity pathway) \\
\hline $\mathrm{CNH}$ & Dominio con homología a la kinasa Citron (Citron kinase homology) \\
\hline $\mathrm{CPT}$ & Camptotecina \\
\hline Csp & Caspofungina \\
\hline DEM & Malonato de dietilo (Diethyl maleate) \\
\hline DEP & Dominio con homología a Dishevelled, Egl-10 y Pleckstrin \\
\hline $\mathrm{DH}$ & Dominio con homología a Dbl (Dbl homology) \\
\hline DNA & Ácido desoxirribonucleico \\
\hline dNTP & Desoxirribonucleótido trifosfato \\
\hline DO & Densidad Óptica \\
\hline DSB & Roturas de doble cadena (Double-strand break) \\
\hline F-BAR & Fes/CIP4 homology-Bin/Amphiphysin/Rvs \\
\hline $\mathrm{FH} 2$ & Dominio con homología a formina (Formin homology 2) \\
\hline GAP & Activador de la actividad GTPasa (GTPase activating protein) \\
\hline GDI & Inhibidor de la disociación de GDP (GDP dissociation inhibitor) \\
\hline GEF & Factor intercambiador de guanina (Guanine exchange factor) \\
\hline GFP & Proteína verde fluorescente (Green fluorescent protein) \\
\hline GPI & Glicosilfosfatidilinositol \\
\hline GTP & Guanina 5' trifosfato \\
\hline HR & Recombinación Homóloga (Homologous recombination) \\
\hline $\mathrm{HU}$ & Hidroxiurea \\
\hline IQGAP & Proteína con motivo IQ (Iso/Leu y Gln) y dominio GAP \\
\hline LatA & Latrunculina A \\
\hline MAPK & $\begin{array}{l}\text { Proteína kinasa activada por mitógenos (Mitogen-activated protein } \\
\text { kinase) }\end{array}$ \\
\hline MAPKK & MAP kinasa kinasa \\
\hline MAPKKK & MAP kinasa kinasa kinasa \\
\hline
\end{tabular}


MBC Metil benzimidazol-2-ilcarbamato

MEA Medio agar extracto de malta (Malt extract agar)

miRNA Micro RNA

MM Medio Mínimo

MOR Ruta de morfogénesis (Morphogenesis Orb6 network)

mRNA RNA mensajero

NES Secuencia de Exporte Nuclear (Nuclear export signal)

NETO Inicio del crecimiento por el polo nuevo (New end take off)

NHEJ Unión de extremos no homólogos (Non homologous end joining)

NLS Secuencia de localización nuclear (Nuclear localization sequence)

OETO Inicio del crecimiento por el polo viejo (Old end take off)

PCR Reacción en cadena de la polimerasa (Polimerase chain reaction)

PH Dominio con homología a Pleckstrin (Pleckstrin homology)

Phl Fleomicina

PKC Proteína kinasa C (Protein kinase C)

PDK Kinasa dependiente de fosfoinosítidos (Phosphoinositide-dependent kinase)

RNA Ácido ribonucleico

SAPK Ruta de respuesta a estrés (Stress activated protein kinase)

SCPR Modelo de búsqueda, captura, tirón y liberación (Search, capture, pull and release)

SD Desviación estándar (Standard deviation)

$\mathrm{SH} 3 \quad$ Dominio con homología a Src (Src homology domain 3)

SIN Ruta de inicio de la septación (Septation initiation network)

SPB Cuerpo polar del huso (Spindle Pole Body)

BGS $\quad \beta$-Glucán sintasa

t-BOOH Hidroperóxido de terc-butilo (tert-butyl hydroperoxide)

TOR Ruta diana de rapamicina (Target of rapamycin)

UV Ultravioleta

vic Viable en presencia de inmunosopresor e iones cloruro (viable in the presence of immunosuppressant and chlorine ion)

YES Medio rico para S. pombe (Yeast extract supplemented) 


\section{1}

\section{INTRODUCCIÓN}

\section{Schizosaccharomyces pombe: ORGANISMO MODELO PARA EL ESTUDIO DEL CICLO Y LA MORFOGÉNESIS CELULAR}

La levadura Schizosaccharomyces pombe es un hongo unicelular perteneciente al filo Ascomycota, que se definen por la presencia de un asca o saco que contiene las esporas de germinación en su interior. Fue descrita por primera vez por P. Lindner en 1893, quién la aisló de una cerveza de mijo del este de África. Su nombre taxonómico para el género hace referencia a que se trata de una levadura (-saccharomyces) y que se divide por fisión (schizo-) (Figura 1). En cuanto a la

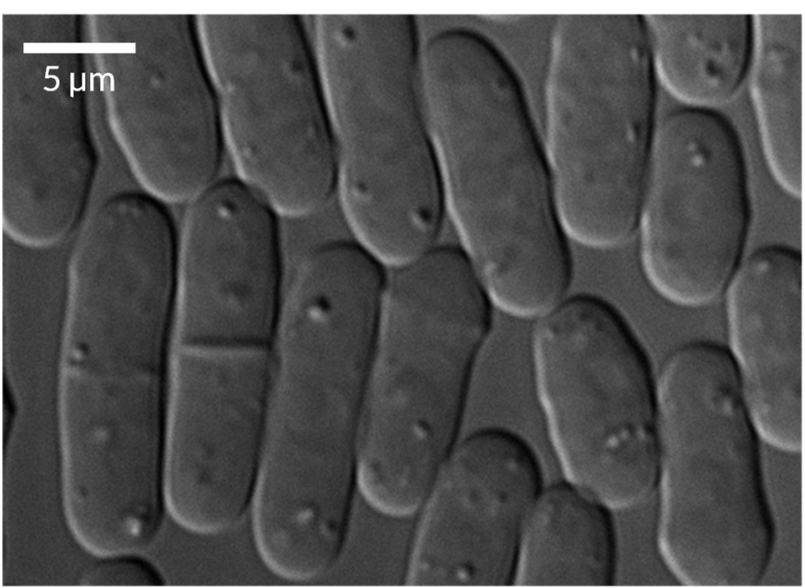

Figura 1 Imagen de la levadura de fisión Schizosaccharomyces pombe obtenida por microscopía Nomarski. especie, la palabra pombe proviene del vocablo suajili para cerveza. La mayoría de cepas, tanto silvestres como mutantes, empleadas hoy en día en el laboratorio derivan de una especie homotálica h90 aislada en Francia en 1921 por A. Ostewalder a partir de mosto, de la que se obtuvieron posteriormente cepas heterotálicas con dos tipos sexuales opuestos, $\mathrm{h}^{+} \mathrm{y} \mathrm{h}^{-}$(Egel 2013). En la década de 1940 Urs Leupold caracterizó genéticamente a $S$. pombe, gracias al aislamiento de mutantes en diversos procesos y la elaboración de los primeros mapas cromosómicos. 
Entre los años 1950 y 1970 Murdoch Mitchison identificó en la fisiología de S. pombe un buen modelo para desarrollar sus estudios sobre el crecimiento y la división celular (Fantes \& Hoffman 2016). Ya en la década de 1970 Paul Nurse combinó el empleo de los métodos genéticos de Leupold con el trabajo sobre crecimiento de Mitchison para describir el control del ciclo celular y la existencia de un mecanismo de control universal en eucariotas (Nurse 1990). S. pombe es fácil de manipular en el laboratorio, no es patógeno, presenta un ciclo de vida y un ciclo sexual de corta duración y es susceptible de análisis genético clásico y molecular (Hoffman et al. 2015; Lock et al. 2019).

\section{Ciclo de vida de S. pombe}

S. pombe es un organismo con un ciclo de vida haplodiplonte (Figura 2). Durante la fase haploide las células presentan una forma cilíndrica, y al nacer tienen un tamaño aproximado de $4 \mu \mathrm{m}$ de diámetro y 7-8 $\mu \mathrm{m}$ de longitud. Durante el crecimiento las células mantienen un diámetro constante y aumentan en longitud hasta alcanzar $14 \mu \mathrm{m}$, que es el tamaño al que se dividen.

La reproducción vegetativa se produce por fisión transversal mediante la formación de un septo perpendicular al eje mayor de la célula, que tras la citoquinesis se disuelve dando lugar a dos células hijas de idéntico tamaño. Las cepas de S. pombe utilizadas en el laboratorio se pueden mantener de forma continua en estado haploide, distinguiendo dos tipos sexuales, $h^{+} y$ $h^{-}$(Leupold 1949).

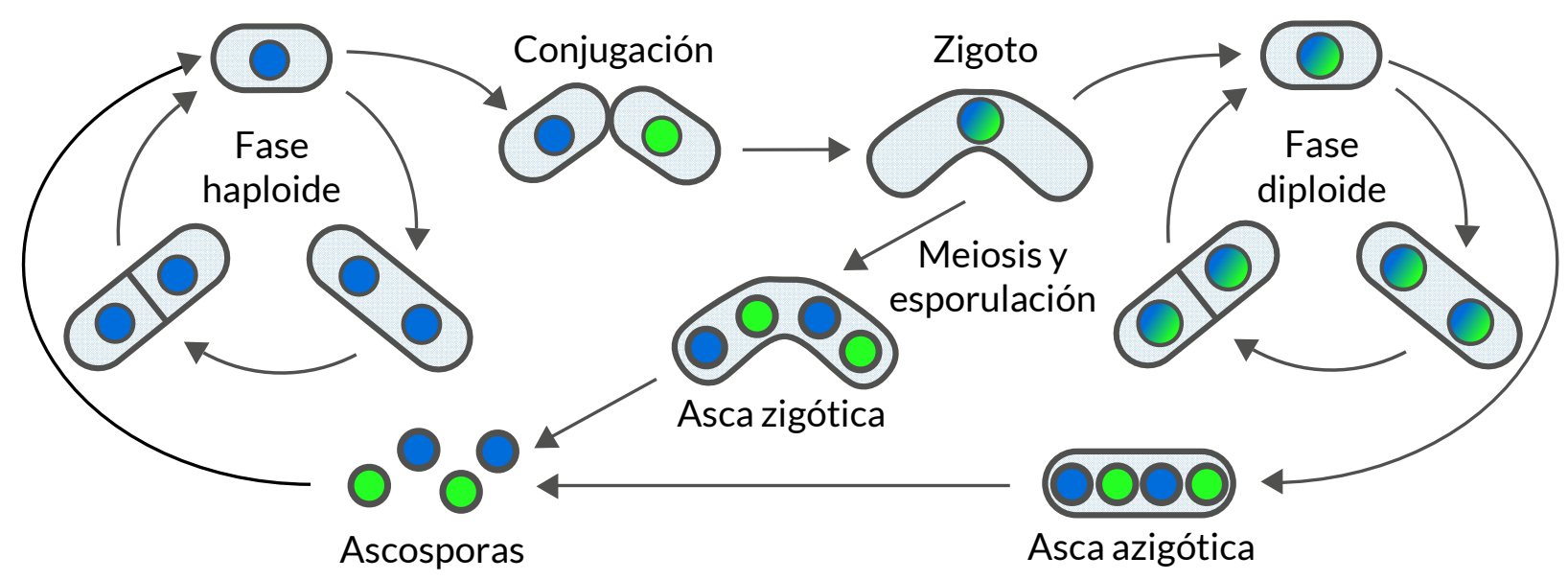

Figura 2 Ciclo de vida haplodiplonte de Schizosaccharomyces pombe. Adaptada de (Sabatinos \& Forsburg 2010). 
En medios desfavorables, especialmente carentes de nitrógeno, las células haploides secretan feromonas características de su tipo sexual y producen receptores para la hormona del tipo sexual complementario, cuya unión, de haber células de ambos tipos sexuales, desencadena el proceso de conjugación. Éste comienza con la formación de una proyección denominada schmoo en un extremo de la célula hacia la célula de tipo sexual complementario hasta que ambas entran en contacto y se fusionan para formar un zigoto diploide (Merlini et al. 2013).

Estos zigotos son células inestables que en medios pobres entran en meiosis, aunque pueden ser mantenidos como células diploides si se reinoculan inmediatamente en un medio rico; estas células diploides presentan un tamaño mayor que las haploides, siendo de 11-14 $\mu \mathrm{m}$ de longitud al formarse y de 20-25 $\mu \mathrm{m}$ antes de la división. Si no se mantienen como células diploides se desencadena el proceso meiótico que da lugar a cuatro núcleos haploides, cada uno de los cuales quedará incluido en el interior de una espora, y éstas a su vez en el interior de un asca zigótica. Finalmente, la pared del asca se rompe liberando las cuatro esporas haploides, que permanecerán latentes hasta encontrar las condiciones favorables para germinar, reiniciando así el ciclo (Yamashita et al. 2017).

\section{Ciclo celular y ciclo morfogenético de S. pombe}

En S. pombe el crecimiento se produce de forma polarizada y asimétrica, y está coordinado temporalmente con la progresión del ciclo celular. En condiciones normales de crecimiento las células de S. pombe presentan un ciclo celular eucariota típico que comprende las fases G1, S, G2 y la fase $M$.

La fase G1 es muy corta y supone un intervalo entre la mitosis y la replicación de los cromosomas caracterizado por la síntesis de RNA y proteínas necesarias para la duplicación del DNA. En este punto, si la disponibilidad de nutrientes es limitada, las células pueden iniciar el ciclo sexual; en caso contrario entran en fase $S$, comenzando la replicación del DNA de forma simultánea en varios puntos del genoma (Harigaya \& Yamamoto 2007).

La fase G2 es la más amplia dentro del ciclo celular y llega a abarcar hasta el 70\% del ciclo. Tras la división celular, las células inician el crecimiento por el polo viejo, aquel que ya existía en la célula madre antes de la división. A este momento en el que las células crecen por un único polo se le conoce con el nombre de OETO (Old End Take Off). El crecimiento monopolar continúa hasta un punto de la fase G2 en el que se activa el crecimiento por el polo nuevo (aquel generado durante la división celular). Tras esta transición conocida como NETO (New End Take Off) la célula incrementa su tamaño mediante la extensión de ambos polos por igual (Mitchison \& Nurse 1985) (Figura 3). 


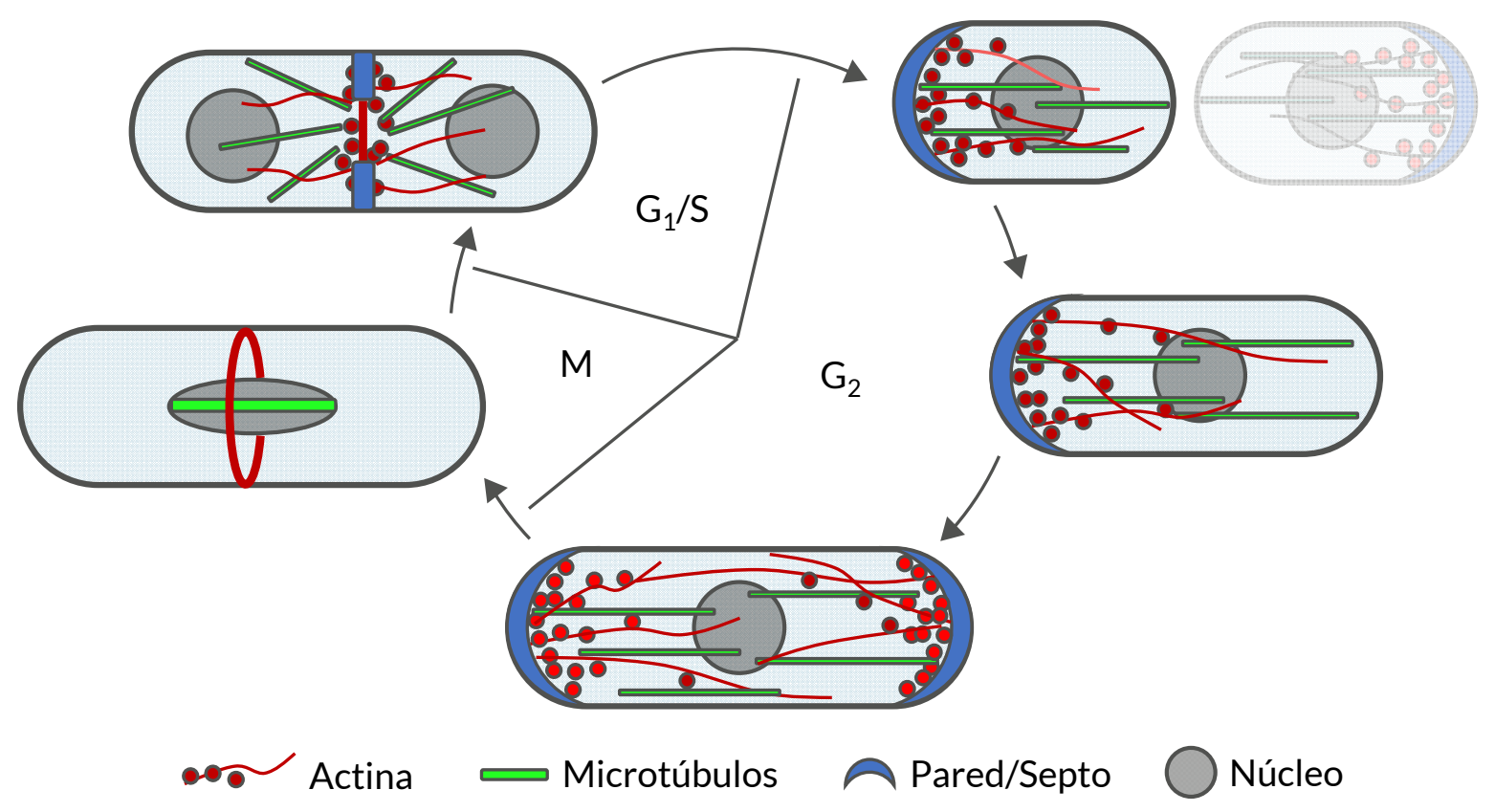

Figura 3 Ciclo celular y morfogenético de S. pombe. Adaptada de (Chang \& Martin 2009)

El crecimiento bipolar en G2 prosigue hasta que la célula alcanza un tamaño crítico y entra en mitosis (fase M) (Wood \& Nurse 2015). En esta etapa se produce la condensación de los cromosomas, la formación del huso mitótico y la segregación de las cromátidas hermanas a ambos polos celulares. La mitosis de S. pombe es cerrada en tanto que se conserva la integridad de la envuelta nuclear (Gu \& Oliferenko 2015) y va seguida por la citoquinesis.

\section{CITOQUINESIS}

La citoquinesis es la parte del proceso de división celular que produce la separación física del citoplasma de una célula madre para originar dos células hijas. Esta división tiene lugar en las últimas etapas de la segregación nuclear y se basa en la formación previa de un anillo constituido por actina y miosina, que al contraerse sirve de guía para la placa de división (Glotzer 2017).

Esto es cierto al menos de forma general en amebas, hongos y animales, ya que otras ramas de los eucariotas como las plantas utilizan mecanismos diferentes debido a que carecen de miosina II (Pollard 2017); incluso S. pombe emplea un segundo proceso de división celular, la esporulación, que no involucra la contracción de un anillo (Shimoda 2004). Sin embargo, este mecanismo aparece únicamente tras la división meiótica y queda fuera del alcance de este trabajo en el que estudiamos la citoquinesis vegetativa o mitótica de S. pombe, que sí emplea un anillo contráctil de actomiosina además de la formación del septo de división (Balasubramanian et al. 2004; Roncero \& Sánchez 2010; Cortés et al. 2016a). 
La maquinaria de división se ensambla con la entrada en mitosis a través de la señalización por la kinasa Plo1 (Bähler et al. 1998; Tanaka et al. 2001). Una serie de nodos coalescen durante prometafase hasta formar el anillo contráctil de actomiosina (CAR) en el plano medio de la célula (revisado en (Willet etal. 2015; Cheffings et al. 2016; Rincon \& Paoletti 2016)). Este posicionamiento integra señales de la geometría celular y la localización del núcleo para asegurar la segregación correcta del material genético y la distribución equitativa de material citoplasmático. Al final de anafase, cuando se produce la segregación nuclear con la elongación del huso mitótico, ensamblado desde los SPBs (Spindle Pole Bodies), comienza la constricción del anillo, que va acompañada de la síntesis del septo (Figura 4) (revisado en (Hercyk et al. 2019; Salas-Pino \& Daga 2019).

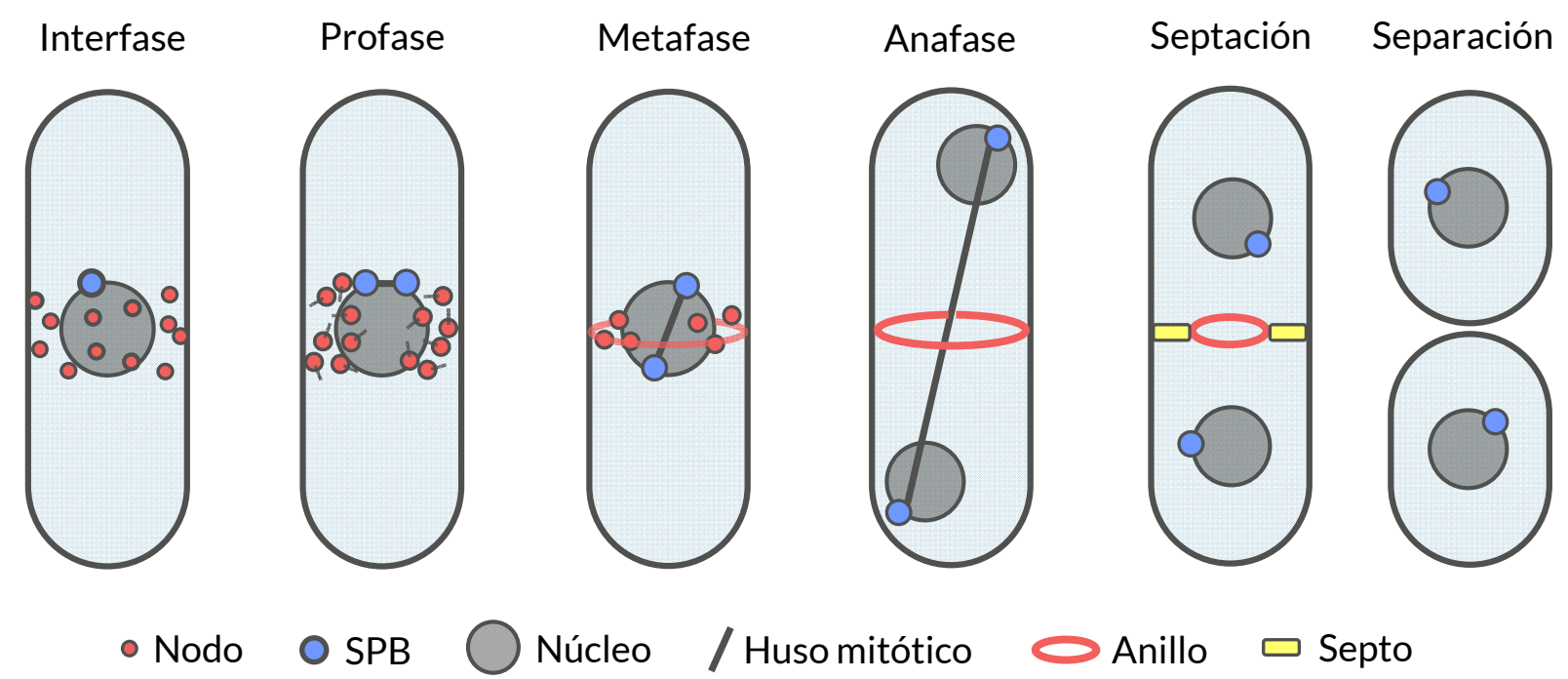

Figura 4 Ensamblaje y constricción de la maquinaria citoquinética referidas a las etapas mitóticas. Adaptada de (Simanis 2015)

\section{Establecimiento del plano de división}

En S. pombe el plano de división se establece de forma transversal en el centro de la célula. Un primer mecanismo determina esta región durante la fase G2 a través del posicionamiento de los precursores del anillo contráctil en la zona media de la célula. Estos precursores son agrupaciones de proteínas conocidas como nodos que se unen a la membrana plasmática. El componente principal de estos nodos es la kinasa Cdr2, que sirve de organizador gracias a su capacidad para unirse a membranas y formar complejos. Durante interfase una fracción de Mid1, quien también se une a membranas y oligomeriza, interacciona con Cdr2 y juntos promueven el reclutamiento de otros componentes a los nodos. Aquí se incluyen las kinasas de ciclo Wee1 y su 
inhibidor Cdr1, que contribuyen al control del tamaño celular (Moseley et al. 2009), y otros nodos interfásicos que permanecen tras la separación celular (Akamatsu et al. 2014) formados por la proteína de unión a membrana Blt1 (Guzman-Vendrell et al. 2013), la kinesina Klp8 (Kashiwazaki et al. 2019), el Rho-GEF Gef2 (Ye et al. 2012) y la proteína asociada Nod1 (Jourdain et al. 2013; Zhu et al. 2013).

El posicionamiento de estos nodos, y por tanto finalmente del anillo, está restringido a la región media de la célula gracias a señales que emanan de los dos polos y que inhiben su formación fuera del centro celular, donde esta señal es menor. La kinasa Pom1 genera parte de esta señal de inhibición (Celton-Morizur et al. 2006; Padte et al. 2006) (Figura 5A). Pom1 establece un gradiente de concentración desde la membrana de los polos, donde está más concentrada, hacia el centro celular gracias al transporte polarizado mediado por los factores de polaridad Tea1 y Tea4. Pom1 se asocia a la membrana de los polos después de ser desfosforilada por el complejo fosfatasa Tea4-Dis2, y se va desprendiendo de la membrana mediante un mecanismo de autofosforilación (Hachet et al. 2011; Hersch et al. 2015).

A

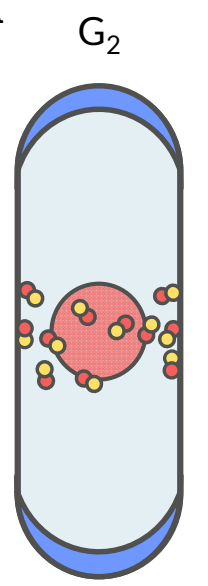

$\mathrm{G}_{2} / \mathrm{M}$

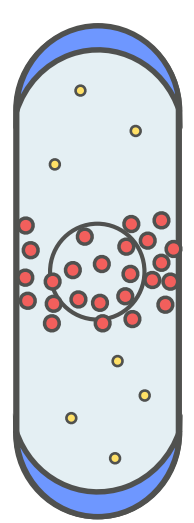

O Mid1
M

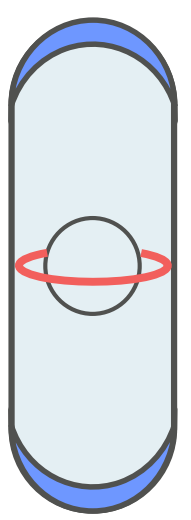

O Cdr2
B

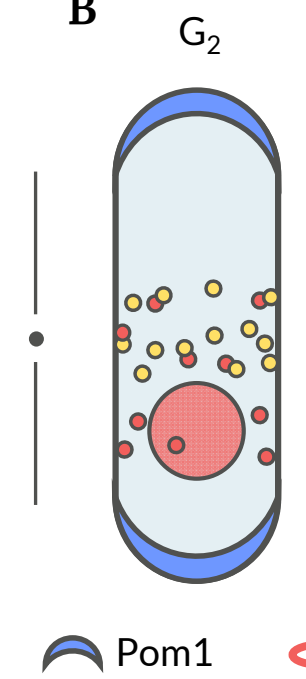

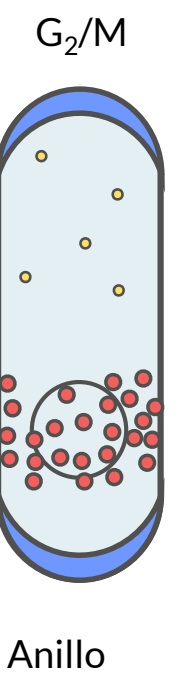

M

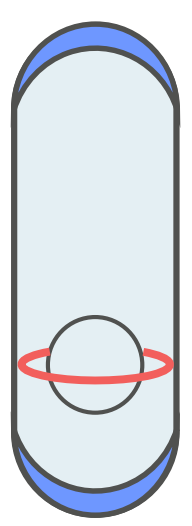

Figura 5 Modelos de establecimiento del plano de división. (A) El gradiente de Pom1 desde los polos restringe la formación de los nodos de Cdr2 al centro celular. (B) Mid1 se asocia a la membrana en la zona circundante al núcleo, incluso si este se encuentra desplazado. Adaptada de (Almonacid et al. 2009)

Pom1 bloquea la formación de los nodos citoquinéticos mediante la fosforilación de Cdr2 (Moseley et al. 2009; Hachet et al. 2011), lo que reduce la asociación de esta kinasa con la membrana y también con Mid1, y afecta a su capacidad de formar nodos estables (Rincon et al. 2014). En los polos de la célula la concentración de Pom1, y por tanto su actividad inhibitoria, es alta, lo que favorece el posicionamiento de los precursores del anillo en la zona central. A pesar 
de este mecanismo las células pom1 $\Delta$ siguen excluyendo la formación de los nodos en el polo de crecimiento (son monopolares), indicando la existencia de otros factores que restringen esta distribución (Celton-Morizur et al. 2006; Moseley et al. 2009).

El segundo aspecto que establece la localización del plano de división es la posición del núcleo en el interior celular (Figura 5B). Generalmente este mecanismo pasa desapercibido ya que los microtúbulos longitudinales anclados a la envuelta nuclear ejercen fuerzas de empuje desde los polos de la célula, que se equilibran colocando el núcleo en el medio, donde se localizan los nodos. Sin embargo, se puede desplazar la posición del núcleo empleando fuerzas de centrifugación, y esto modifica el establecimiento del anillo, que se ensambla allá donde se ha movido el núcleo (Daga \& Chang 2005).

Este mecanismo depende de la fracción nuclear de Mid1. Aunque Mid1 se encuentra en nodos durante la fase G2 también se acumula en el núcleo; con la entrada en mitosis la kinasa Plo1 induce la liberación masiva de Mid1 del núcleo y su acumulación en forma de nodos en la región de membrana plasmática próxima al núcleo en ese momento (Almonacid et al. 2009, 2011). Este mecanismo de posicionamiento es dominante sobre el de exclusión de los polos en tanto que el desplazamiento del núcleo es suficiente para modificar el establecimiento del plano de división.

\section{Ensamblaje del anillo contráctil}

En la transición G2/M, Plo1 fosforila a la fracción nuclear de Mid1 e induce su liberación, así como la formación de nodos en la membrana y el reclutamiento del resto de componentes del anillo de manera ordenada. En este proceso también participa Gef2. Mid1 recluta por un lado a la proteína IQGAP de andamiaje Rng2 y a la cadena ligera de la miosina II, Cdc4, la cual a su vez promueve el reclutamiento de las subunidades pesada, Myo2, y reguladora, Rlc1, de la miosina II. Esto ocurre 10 minutos antes de la separación de los SPBs, evento que se emplea de referencia como el punto cero de la entrada en mitosis.

A continuación, Mid1 recluta a Cdc15, proteína F-BAR de unión a membrana, y a otras proteínas del anillo que interaccionan con Blt1 y Rng1 (Wu et al. 2006; Vavylonis et al. 2008; Laporte et al. 2011). Cdc15 y el módulo de la miosina II reclutan a la formina Cdc12, el principal nucleador de actina, que ensambla filamentos lineales de actina desde los nodos citoquinéticos. La formina For3 también es reclutada al sitio de división por Cdc15 y, aunque su actividad es prescindible e insuficiente para la formación del anillo, podría servir como en mecanismo de refuerzo (Willet et al. 2015).

La formación de filamentos de actina es una de las dos partes implicadas en el modelo de ensamblaje del anillo SCPR (Search, Capture, Pull and Release). Según este modelo los filamentos 
de actina nucleados desde un nodo por la formina Cdc12 serían capturados por las miosinas II de otros nodos próximos. La formina sirve además de anclaje del filamento al nodo mientras la actividad motriz de la miosina tira de estos filamentos, generando la fuerza que mueve los nodos y los aproxima unos a otros (Vavylonis et al. 2008). Seguidamente, los filamentos de actina son liberados de la miosina por distintos mecanismos que implican a la cofilina Adf1, que corta los filamentos de actina estocásticamente permitiendo la nucleación de nuevos filamentos (Chen \& Pollard 2011), la disociación de la miosina del filamento, o el recambio de forminas y miosinas de los nodos (Figura 6).

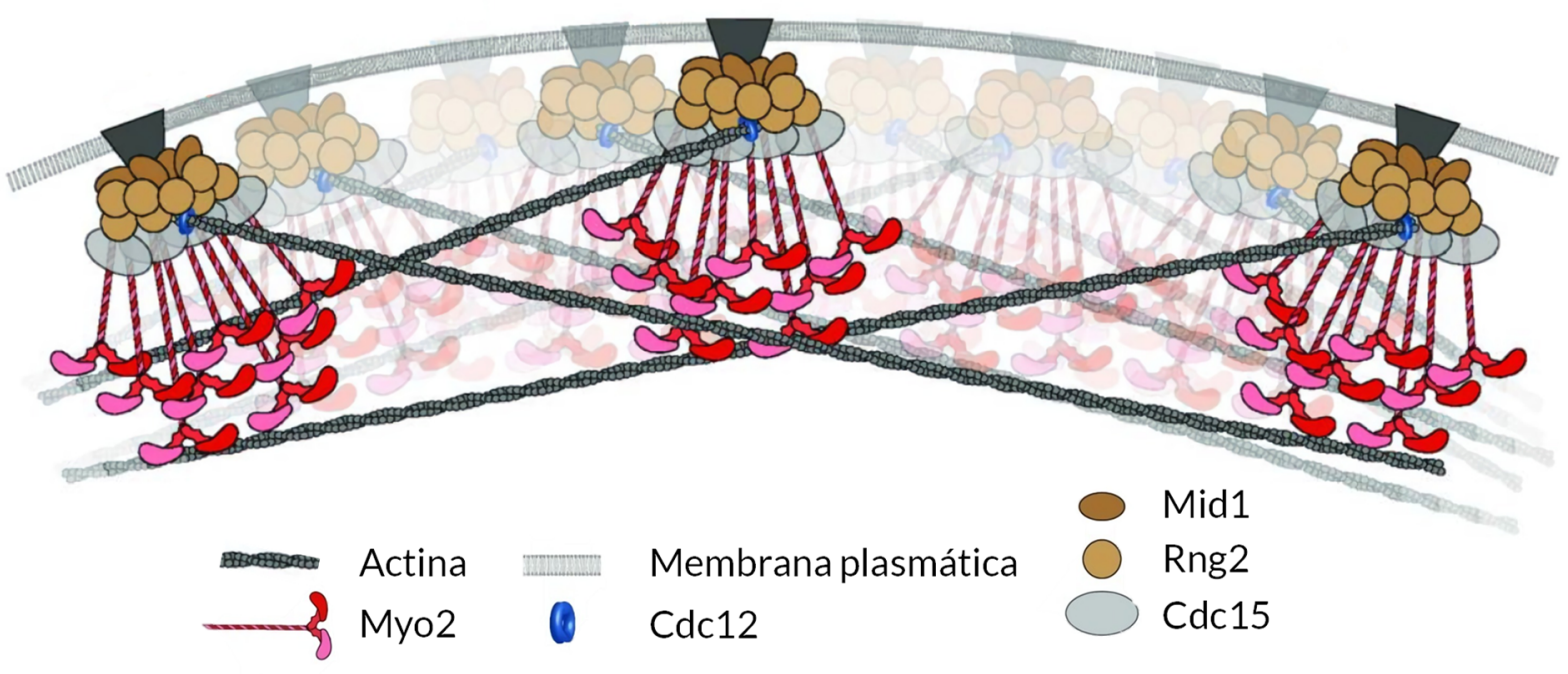

Figura 6 Modelo de organización de los nodos en el anillo contráctil. Cada nodo ensambla y ancla un filamento de actina a través de su formina. Traducida de (O’Shaughnessy \& Thiyagarajan 2018).

Finalmente, proteínas como Ain1 y Fim1, que refuerzan las estructuras de actina, son reclutadas al comienzo de la condensación de los nodos y contribuyen a la formación del anillo (Laporte et al. 2012). También son importantes la tropomiosina Cdc8, que estabiliza los filamentos de actina y su asociación con Myo2, y la miosina V Myo51, que se localiza en los nodos y aumenta la fuerza producida por Myo2 (Stark et al. 2010; Laplante et al. 2015). Aun siendo Mid1 el principal reclutador de los componentes del anillo las células mid1 $\Delta$ siguen siendo capaces de formar anillos. Estos anillos se forman a través de un mecanismo diferente al SCPR que depende de la activación de la ruta SIN (Septation Initiation Network) y de Cdc15 (Hachet \& Simanis 2008; Huang et al. 2008). Durante el ensamblaje, Cdr2 se disocia de los nodos. Su disociación está 
controlada por la ruta SIN, que de esta forma podría borrar la información posicional de la célula madre para permitir su reposicionamiento de acuerdo con la nueva geometría de las células hijas (Pu et al. 2015; Rincon et al. 2017).

\section{Maduración del CAR}

Después del ensamblaje viene un periodo de maduración en el que, a pesar de no haber cambio en la forma ni en el tamaño del anillo, se reclutan algunas proteínas y se liberan otras antes de que se inicie la constricción (Pelham \& Chang 2002; Roberts-Galbraith et al. 2009). Durante la etapa de maduración llega más Cdc15 al anillo, así como otras dos proteínas con dominio F-BAR, Imp2 y Rga7 (Roberts-Galbraith et al. 2009; Martín-García et al. 2014). Imp2 y Cdc15 reclutan otras proteínas como Fic1, Pxl1 y Rgf3.

La paxilina Pxl1 participa en la estabilidad y la constricción del CAR y coopera con la glucán sintasa Bgs1 en la formación del septo (Cortés et al. 2015; Martín-García et al. 2018). La localización de Bgs1 en la zona de división durante maduración depende, entre otras, de Cdc15 (Arasada \& Pollard 2014) y de Sbg1, proteína integral de membrana que también llega en esta etapa (Davidson et al. 2016; Sethi et al. 2016). Rgf3 es el principal activador de la GTPasa Rho1 durante la síntesis del $\beta$-glucano del septo (Tajadura et al. 2004) e interacciona con el dominio SH3 de Cdc15 y de Imp2 (Ren et al. 2015). La localización de Rgf3 también depende de la arrestina Art1, con quien interactúa físicamente y en cuyo mutante la maduración y constricción son más lentas (Davidson et al. 2015). Rga7 es reclutado a la membrana por la proteína coiled-coil Rng10 también en esta etapa, y ambas regulan la localización de la $\beta$-glucán sintasa Bgs 4 durante la septación (Liu et al. 2016, 2019).

La miosina II no convencional Myp2 también aparece en el anillo durante la maduración (Laplante et al. 2015). Myp2 no es tan importante para la constricción como Myo2 (Palani et al. 2017; Zambon etal. 2017), pero contribuye a la estabilidad y constricción del anillo, especialmente bajo situaciones de estrés (O'Shaughnessy \& Thiyagarajan 2018; Okada et al. 2019). Finalmente, Mid1 se disocia del anillo antes de iniciar la constricción en un proceso mediado por la fosforilación por la kinasa Sid2 (Willet et al. 2019). Tanto Mid1 como Cdr2 dejarían el anillo para eliminar la información posicional marcada en la célula madre que ya está en citoquinesis (ver apartado anterior).

La duración de la etapa de maduración es variable y puede ser acortada o alargada de acuerdo a variaciones en la etapa previa de ensamblaje o formación. Por ejemplo, los mutantes myo2-E1 (Coffman et al. 2009), cdc8-27 (Stark et al. 2010), o el apagado de rng2+ (Tebbs \& Pollard 2013) tardan más tiempo en ensamblar el anillo y pasan seguidamente por una fase de 
maduración corta antes de la contracción. Por el contrario, las células con dos copias de myo2 ${ }^{+}$ forman el CAR de forma prematura y alargan la fase de maduración (Stark et al. 2010).

Otras proteínas cuya función es menos conocida también aparecen en el anillo durante maduración. Cykz llega al CAR al comienzo de maduración y se mantiene en el septo después de la constricción (Pollard et al. 2012). Cyk3 interacciona con Cdc15 (Roberts-Galbraith et al. 2010) y con Fic1 (Bohnert \& Gould 2012), mientras que el mutante cyk3 $\Delta$ presenta retraso en el inicio de la constricción del anillo y defectos en la separación celular (Pollard et al. 2012). Spa2 y Pos1 aparecen en el anillo hacia el final de la etapa de maduración. Spaz interacciona con el dominio SH3 de Cdc15 y es necesaria para el reclutamiento de Pos1. Sus respectivas deleciones originan leves defectos en septación y de pérdida de polaridad (Ren et al. 2015). Recientemente se ha descrito que Pkd2, un receptor de potencial transitorio putativo, aparecería en la zona de división en la transición maduración/constricción y cuyo mutante tiene una constricción más rápida, presumiblemente por una reducida presión de turgencia (Morris et al. 2019).

\section{Constricción del anillo}

Tras la formación y maduración el anillo está listo para iniciar la constricción. El CAR presenta entonces una estructura en contacto con la membrana plasmática que se extiende con una circunferencia de unos $11 \mu \mathrm{m}$ (3.5 $\mu \mathrm{m}$ de diámetro) y $125 \mathrm{~nm}$ de ancho de sección (Swulius et al. 2018). La composición del anillo no es uniforme, sino que se estructura en capas (Figura 7). En la sección próxima a la membrana (entre los o y $80 \mathrm{~nm}$ ) se encuentran las proteínas de andamiaje que se unen a la membrana incluyendo las proteínas F-BAR Cdc15, Imp2 y Rga7, las septinas, la formina Cdc12 y el extremo C-terminal de la miosina Myo2.

A continuación (80-160 nm) se localizan proteínas de señalización (GTPasas y sus reguladores, kinasas y fosfatasas) como Sid2, Clp1 y Rgf3 y otras proteínas accesorias de andamiaje, o que se unen a través de los dominios SH3 de las proteínas de anclaje y que son críticas para la integridad del anillo como Rng2, Pxl1 y Fic1. En la región más distante de la membrana (200 nm) están los filamentos de actina y las proteínas de unión a actina incluyendo los dominios motores de las miosinas Myo2, Myp2 y Myo51 (McDonald et al. 2017).

Mientras que las proteínas en las secciones medias y distales a la membrana tienen una distribución más homogénea (McDonald et al. 2017), con los filamentos de actina dispuestos de forma relativamente empaquetada y paralelos a la membrana (Swulius et al. 2018), las proteínas en la zona proximal a la membrana plasmática se agrupan en estructuras que recuerdan a los nodos y que se van aproximando entre sí a medida que se cierra el anillo (Swulius et al. 2018). 


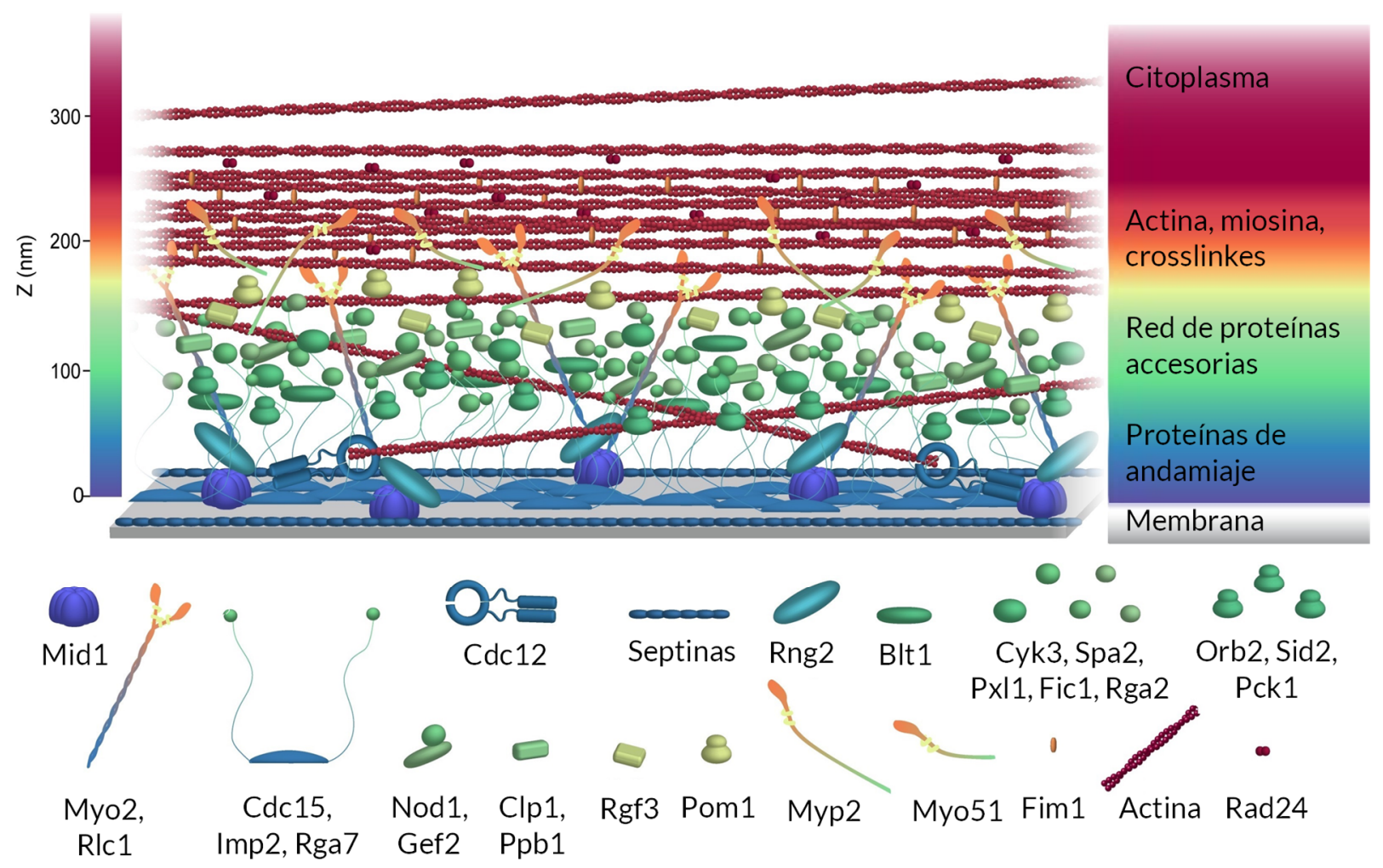

Figura 7 Modelo de la arquitectura molecular del anillo contráctil. Las proteínas están coloreadas en base a su localización en Z. Traducida de (McDonald et al. 2017).

El CAR, lejos de ser una estructura estática, sufre una remodelación constante. Sus componentes como Cdc15, Myo2, Myp2 y Cdc12 tienen tiempos de recambio muy rápidos y la actina está siendo constantemente polimerizada por la actividad de las forminas y la profilina Cdc3, y despolimerizada por la actividad de la cofilina (O'Shaughnessy \& Thiyagarajan 2018). A medida que se contrae, el anillo se vuelve más pequeño y se va despojando de sus componentes. El número de moléculas de actina y formina cae de forma proporcional a la circunferencia del anillo, por lo que su concentración permanece constante (Courtemanche et al. 2016), mientras que la liberación de Myo2 y Myp2 es menor y su densidad va aumentando a medida que avanza la constricción (Wu \& Pollard 2005). Esta remodelación es necesaria para asegurar la homeostasis del anillo y evitar la agregación de sus componentes (Chew et al. 2017).

La constricción del CAR está íntimamente ligada a la síntesis del septo; el análisis del papel individual del anillo de actomiosina en este proceso y su mecanismo de constricción ha sido posible gracias al empleo de protoplastos y los sistemas semi-in vitro. Los protoplastos son células a las que se les elimina la pared celular mediante digestión enzimática (Stachowiak et al. 2014). Los sistemas semi-in vitro conocidos como "fantasmas celulares" utilizan protoplastos permeabilizados para eliminar el material citoplásmico (Mangione \& Gould 2019). La pérdida de la pared vuelve a las células redondeadas, y el anillo, al no tener anclaje, se desliza por la 
membrana durante la constricción. Aun con sus particularidades no fisiológicas estos métodos han permitido medir la tensión ejercida por el CAR (O'Shaughnessy \& Thiyagarajan 2018; Pollard \& O'Shaughnessy 2019).

Las medidas de tensión junto los números de moléculas de los principales componentes del anillo, su velocidad de recambio, su localización y sus propiedades conocidas, son incorporados en simulaciones matemáticas que buscan predecir los mecanismos moleculares que permitan alcanzar dicha tensión (Stachowiak et al. 2014; O'Shaughnessy \& Thiyagarajan 2018; Pollard \& O'Shaughnessy 2019). De acuerdo a estos modelos, las forminas nuclean cada uno de los filamentos de actina y los anclan a través de los extremos barbados a los nodos de la membrana; las miosinas se unen a estos filamentos y tiran de ellos de forma paralela al anillo, tensándolos. La fuerza motriz de las miosinas junto al anclaje lateral de los filamentos de actina mediado por las forminas proporcionaría la tensión necesaria para el cierre del anillo, siguiendo un mecanismo similar al del ensamblaje del CAR. En estos modelos Myo2 y Cdc12 se localizan en los nodos unidos a la membrana, mientras que Myp2 contribuye a la tensión incluso sin anclaje a través de la unión únicamente a los filamentos de actina. Los modelos también explican cómo el rápido recambio medido en los componentes del CAR, que excede a la velocidad de constricción, permite la remodelación del mismo a medida que se contrae sin perder organización o funcionalidad (Cheffings et al. 2019).

\section{Síntesis del septo}

S. pombe, como otras levaduras, posee una estructura polisacarídica denominada pared celular que envuelve a la célula y le permite mantener su alta presión de turgencia interna de $1.5 \mathrm{MPa}$ (Chang 2017). Esta presión de turgencia ejerce una fuerza hacia el exterior que empuja a la membrana contra la pared, y es la pared quien contrarresta esta fuerza con sus propiedades mecánicas (Atilgan et al. 2015). La invaginación del surco citoquinético requiere pues de fuerzas que sobrepasen la presión de turgencia. De acuerdo con esto, se ha visto que la adición de bajas concentraciones de sorbitol aumenta la velocidad de constricción del anillo, lo cual se podría explicar por una reducción de la presión (Proctor et al. 2012). Sin embargo, la tensión ejercida por el anillo está varios órdenes de magnitud por debajo de la requerida (Stachowiak et al. 2014; Thiyagarajan et al. 2015), lo que sugiere que no es la constricción del anillo sino la síntesis del septo la fuerza dominante que dirige la citoquinesis.

La pared celular está compuesta por polisacáridos formados por tres glúcidos: glucosa, manosa y galactosa. Los principales componentes son el $\beta(1,3)$-D-glucano con ramificaciones $\beta(1,6)$ y el $\alpha(1,3)$-D-glucano lineal. Además, tiene en menor proporción $\beta(1,6)$-D-glucano con alta frecuencia de ramificaciones $\beta(1,3), \beta(1,3)$-D-glucano lineal y galactomanano unido a 
proteínas para formar la capa glicoproteica (Humbel etal. 2001; Sugawara etal. 2004; Grün etal. 2005; Magnelli et al. 2005). A nivel estructural, estos polisacáridos se disponen formando una capa de $\beta(1,3)$-D-glucano ramificado $y$ $\alpha(1,3)$-D-glucano rodeada por dos capas de galactomanano; el $\beta(1,6)$-D-glucano se encuentra en la confluencia entre la capa central y la externa de galactomanano (Humbel et al. 2001; Sugawara etal. 2004) (Figura 8). A pesar de tener en su genoma dos genes de quitín sintasas $\left(\right.$ chs $1^{+}$y chs2 ${ }^{+}$) (Matsuo et al. 2004), la pared celular de las células vegetativas de $S$. pombe no contiene
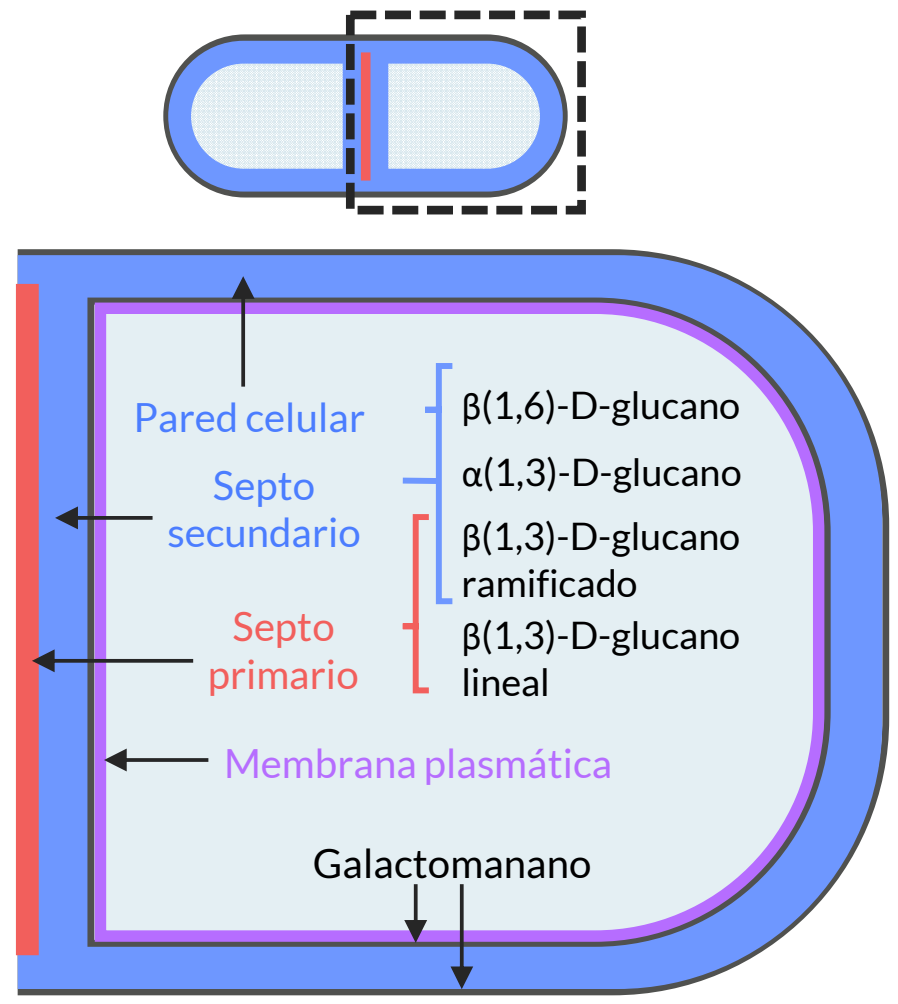

Figura 8 Esquema y localización de los componentes de la pared celular y septo. Adaptado de (Cortés et al. 2016a). quitina (Free 2013).

El septo está formado por dos tipos de estructuras que se sintetizan de forma simultánea durante la citoquinesis (Cortés et al. 2007): una banda central de septo primario rodeada por dos capas de septo secundario. Tanto el septo primario y como el septo secundario están formados por $\beta(1,3)$-D-glucano ramificado y $\alpha(1,3)$-D glucano; el septo primario tiene además $\beta(1,3)$-D-glucano lineal mientras que el septo secundario está compuesto adicionalmente por $\beta(1,6)$-D-glucano (Humbel et al. 2001; Cortés et al. 2012; Muñoz et al. 2013) (Figura 8). Una vez completado el cierre del septo éste incrementa su grosor a través de una ronda adicional de síntesis de septo secundario.

El septo primario queda flanqueado en su extremo en contacto con la pared por dos estructuras circulares conocidas como material triangular denso y de otra estructura que va desde el septo primario hasta la superficie de la pared conocida como anillo denso, ambas de composición y estructura desconocidas (Cortés et al. 2012; Muñoz et al. 2013).

El $\beta(1,3)$-D-glucano de la pared celular de las levaduras es sintetizado por la $\beta(1,3)$-D-glucán sintasa ( $\beta G S)$, un complejo enzimático formado por una subunidad catalítica y otra reguladora. En S. pombe la subunidad reguladora es la GTPasa Rho1 (Arellano et al. 1996), mientras que se han identificado hasta cuatro posibles componentes de la subunidad catalítica, Bgs1, Bgs2, Bgs3 y Bgs4 (Cortés et al. 2016b). Estas son proteínas de alto peso molecular con 
múltiples dominios transmembrana. Bgs1, Bgs3 y Bgs4 aparecen en los polos y el septo de división, siendo las tres esenciales para la supervivencia celular. La función de Bgs3 es todavía desconocida (Martín et al. 2003), mientras que Bgs2 es esencial para la formación de la pared de la espora durante el ciclo sexual (Martín et al. 2000b).

El análisis de los septos formados en esporas bgs1 $\Delta$ germinadas demostró que Bgs1 es responsable de la síntesis del $\beta(1,3)$-D-glucano lineal y de la formación del septo primario (Cortés et al. 2007). Sin embargo, existen dudas sobre si Bgs1 es el único responsable de la síntesis del $\beta(1,3)$-D-glucano lineal. Se ha visto que en células vegetativas la depleción de Bgs1 obtenida mediante la represión prolongada del gen todavía presenta una cantidad importante de $\beta(1,3)$-D-glucano lineal, además de un fenotipo de células multiseptadas y encadenadas (Cortés et al. 2007).

Bgs4 es responsable de la síntesis del $\beta(1,3)$-D-glucano ramificado, de la formación del septo secundario y de la compleción del septo primario (Cortés et al. 2005; Muñoz et al. 2013). Su ausencia produce lisis celular explosiva, principalmente durante la separación de las células hijas (Cortés et al. 2005; Muñoz et al. 2013); además presenta fallos en el anclaje del CAR a la membrana y una reducción de la velocidad de la constricción del anillo y, en mayor medida,

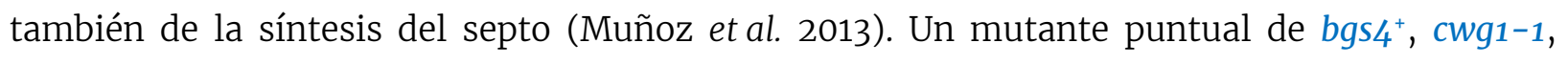
presenta una importante bajada del $\beta$-glucano y de la actividad $\beta$ GS, que normalmente van asociadas a la lisis celular (Ribas et al. 1991; Cortés et al. 2005), así como defectos en el posicionamiento del anillo similares a los de la pérdida del gen (Muñoz et al. 2013).

La septación comienza durante la anafase B. Bgs1 se localiza en la zona media antes de que comience la septación mientras que Bgs4 aparece en telofase cuando la velocidad de septación y de contracción del anillo se aceleran (Cortés et al. 2018). Su localización depende de la actividad SIN y del establecimiento del anillo de actomiosina (Liu et al. 2002; Cortés et al. 2018).

Aunque tanto el anillo como el septo son necesarios para producir la invaginación de la membrana y del surco citoquinético, una vez comenzada la síntesis del septo éste es capaz por sí solo de terminar el cierre en ausencia del anillo, aunque a velocidad reducida (Proctor et al. 2012). La tensión del anillo podría estar modulando la actividad de la glucán sintasa; asumiendo que la síntesis del septo sea mecanosensible y acoplada al anillo, la tensión del CAR regularía la velocidad de crecimiento del septo de acuerdo a la curvatura local de la membrana para mantener la circularidad del surco citoquinético (Thiyagarajan et al. 2015; Zhou et al. 2015) (Figura 9). 

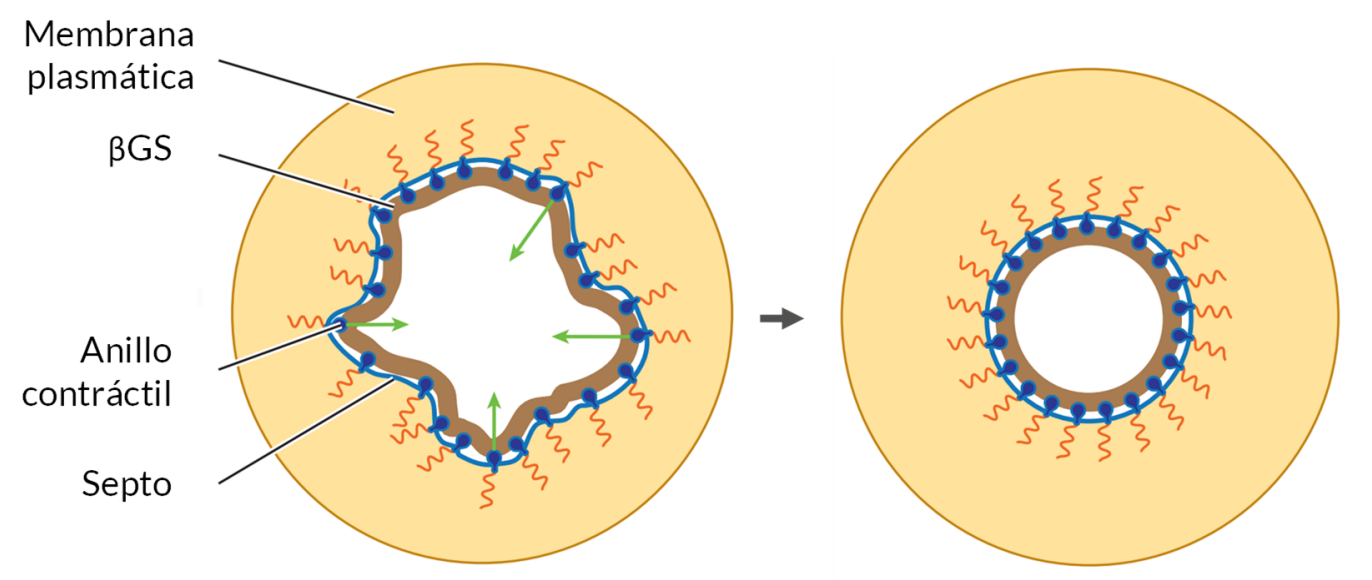

Figura 9 La actividad glucán sintasa podría ser mecanosensible, con una síntesis más rápida en aquellas zonas donde la curvatura y la fuerza por la tensión del anillo es mayor (flechas verdes). Traducida de (Pollard \& O'Shaughnessy 2019).

\section{Separación celular}

La última etapa en la citoquinesis de S. pombe es la disolución del septo que mantiene juntas físicamente a las dos células hijas. Este proceso también es muy específico y crítico para la integridad de la célula. La disolución comienza por la pared que rodea al septo seguido de la degradación del septo primario, mientras que el septo secundario permanece intacto, pues constituirá la pared de los polos nuevos de las células hijas tras la separación (Martín-García \& Santos 2016). En este proceso intervienen la endo- $\beta$-1,3-glucanasa Eng1 (Martín-Cuadrado et al. 2003) y la endo- $\alpha-1,3$-glucanasa Agn1 (Dekker et al. 2004; García et al. 2005). Ambas son localizadas de forma dependiente del exocisto en una estructura anular que rodea al septo y cuya formación depende de las septinas y de Mid2 (Martín-Cuadrado et al. 2005).

Las septinas también participan en la localización de Gef3 (Muñoz et al. 2014b), que activa a la GTPasa Rho4, la cual es necesaria para la secreción de las glucanasas (Perez et al. 2015; Wang et al. 2015). Finalmente, la ruta MOR (Morphogenesis Orb6 Network), que es inhibida por la ruta SIN hasta el final de citoquinesis, también participa en la separación celular. Fallos en la señalización de esta ruta producen lisis celular por el inicio prematuro de la degradación del septo, aunque su mecanismo de actuación es desconocido (Gupta et al. 2014).

\section{Ruta de inicio de septación, SIN}

El regulador por excelencia de la citoquinesis es la ruta de inicio de septación (SIN). En ausencia de los principales componentes activadores de la ruta las células se vuelven alargadas, multinucleadas y sin septos, mientras que su activación ectópica induce la formación de 
múltiples septos desligados de la mitosis (Simanis 2015). Esta ruta está compuesta en esencia por una GTPasa, tres proteínas kinasas, sus respectivos reguladores y proteínas de andamiaje.

La GTPasa de la familia Ras Spg1 es el centro regulador de la ruta SIN (Schmidt et al. 1997). Su estado de activación está mediado por un inhibidor GAP bipartito formado por la subunidad catalítica Cdc16 y la proteína de unión Byr4 (Furge et al. 1998; Krapp et al. 2008); hasta la fecha no ha sido identificado ningún activador GEF de Spg1. Durante interfase Spg1 y su GAP Cdc16-Byr4 colocalizan en el SPB, manteniendo la señal inactiva. Tras la entrada en mitosis, en metafase, Cdc16-Byr4 se disocia de los dos SPBs, lo que permite la activación de Spg1 y su unión a la kinasa Cdc7 (Schmidt et al. 1997) (Figura 10).

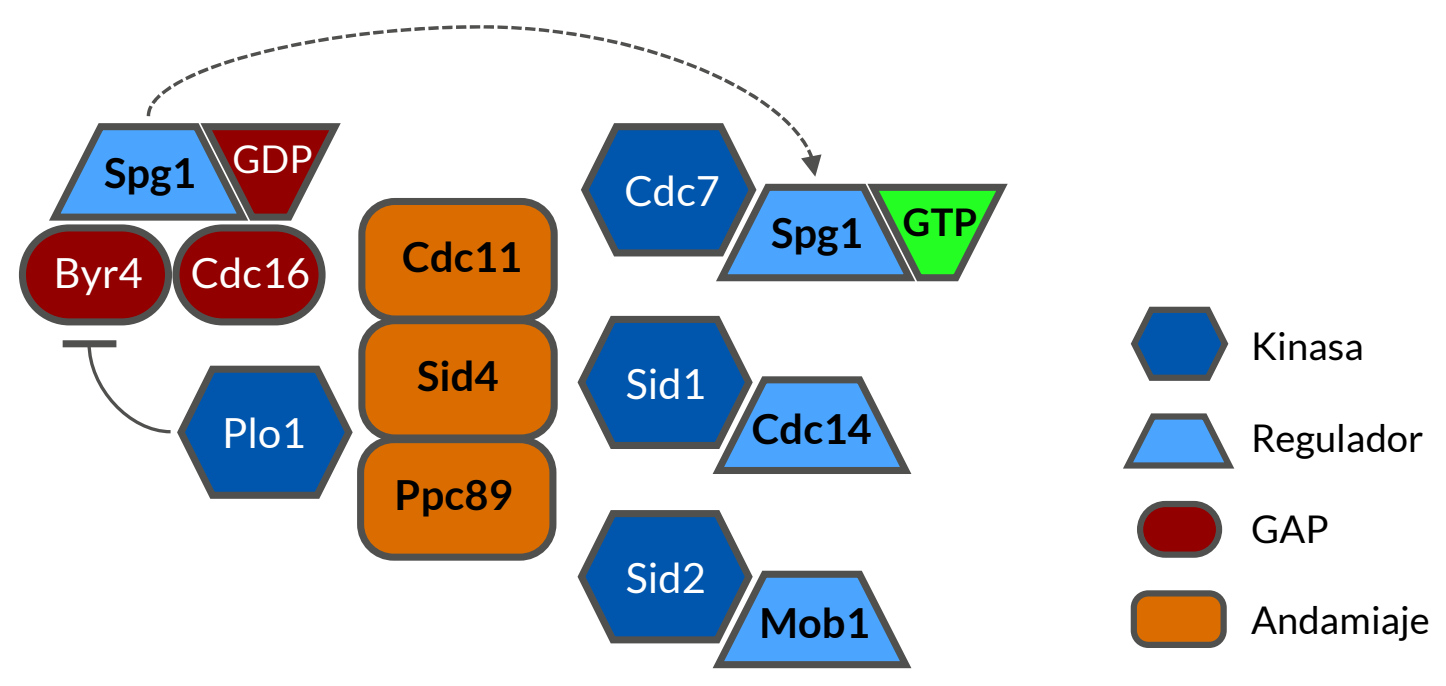

Figura 10 Componentes de la ruta SIN. En interfase Cdc16-Byr4 mantiene a la GTPasa Spg1 en su estado inactivo unido a GDP. Con la entrada en mitosis Plo1 inhibe al complejo GAP, lo que permite el intercambio del GDP de Spg1 por GTP y su activación. Adaptada de (Simanis 2015).

A continuación Cdc7 activaría al complejo kinasa-regulador Sid1-Cdc14 y este a su vez al equivalente Sid2-Mob1, siendo Sid2 la kinasa final en la transmisión de la señal (Guertin et al. 2000). Todos estos componentes se unen a los SPBs a través de tres proteínas de anclaje: Ppc89 ancla a Sid4 al SPB (Rosenberg et al. 2006) y este a su vez media la unión de Cdc11, quien finalmente sirve de plataforma para el reclutamiento de las proteínas mencionadas anteriormente (Krapp et al. 2001; Morrell-Falvey et al. 2004).

Entre los sustratos de Sid2 están la fosfatasa Clp1 (Mishra et al. 2005), la formina Cdc12 (Bohnert et al. 2013), la proteína de anclaje Cdc11 (Feoktistova et al. 2012), la kinesina Klp2 (Mana-Capelli et al. 2012), la kinasa Cdr2 (Rincon et al. 2017) y la anillina Mid1 (Willet et al. 2019) entre otras (Grallert et al. 2012; Gupta et al. 2013). La ruta SIN participa en la condensación de los nodos durante el ensamblaje del CAR cooperando con Mid1, y asegura la estabilidad del anillo en 
anafase (Wu et al. 2003; Hachet \& Simanis 2008; Huang et al. 2008; Willet et al. 2019). Aunque no se han identificado dianas directas se cree que la ruta SIN participa en la activación de la constricción del CAR y el inicio de la septación (Jin et al. 2006; Alcaide-Gavilán et al. 2014). Finalmente la ruta SIN participa junto con Clp1 en el checkpoint de citoquinesis, un mecanismo que estabiliza el CAR y bloquea la progresión del ciclo en presencia de ciertos tipos de estreses que dañan la integridad del anillo (Trautmann et al. 2001).

La señal del SIN se transmite de forma polarizada desde los SPBs hacia el CAR en anafase. Durante anafase B Cdc16-Byr4 vuelve al SPB, pero solo al antiguo, donde inactiva a Spg1 y la señal del SIN en el polo viejo. Por otro lado, aunque Cdc7 es reclutado a los dos SPBs de forma temprana, se acumula preferentemente en el nuevo SPB, donde Spg1 está activo. Con el establecimiento de esta asimetría en la señal del SIN, Sid1 y Cdc14 son reclutadas preferentemente al SPB nuevo (Cerutti \& Simanis 1999; Guertin et al. 2000; Li et al. 2000; Cortés \& McCollum 2009; Wachowicz et al. 2015) (Figura 11). Sid2 y Mob1 se localizan en ambos SPBs durante mitosis y aparecen también en el plano de división antes del inicio de la septación (Sparks et al. 1999; Hou et al. 2000; Wachowicz et al. 2015).
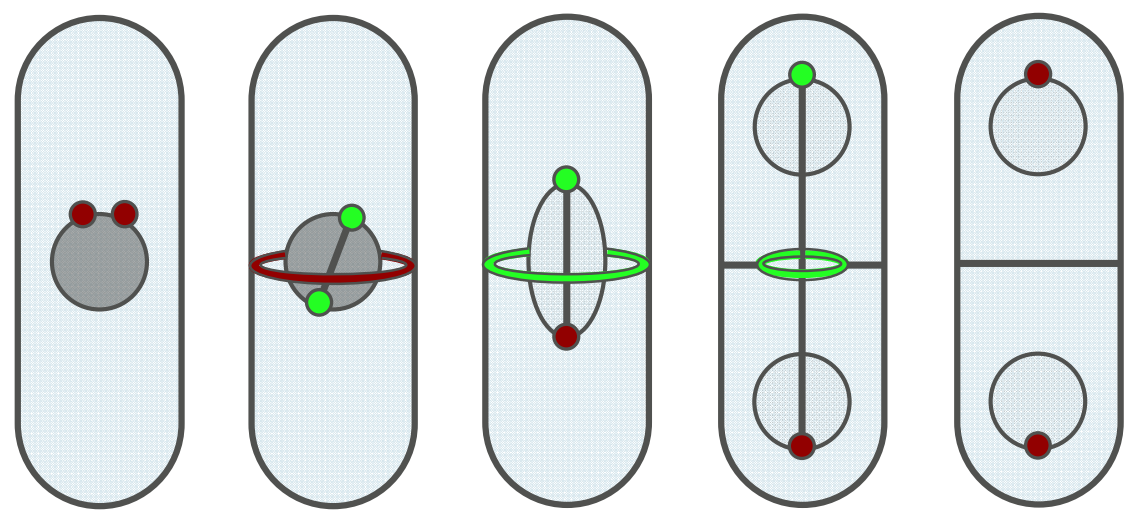

- SPB con SIN inactivo

O SPB con SIN activo

0 Sid2 fuera del CAR

(0) Sid2 en CAR

Alta actividad CDK

Baja actividad CDK

Figura 11 Patrón de la activación polarizada de la ruta SIN. Spg1 en su forma activa recluta a Cdc7 (SPB en verde). Con la elongación del huso en anafase Cdc16-Byr4 inactiva a Spg1 en el SPB viejo (SPB en rojo) y Sid2 aparece en el anillo. Tras la septación la señal del SIN desaparece. Adaptada de (Johnson et al. 2012).

La regulación del SIN es compleja siendo la kinasa Plo1 el activador más conocido. Plo1 se asocia con los SPBs mitóticos parcialmente a través de su interacción con la proteína estructural Sid4 (Chang \& Gould 2000; Tanaka et al. 2001; Mulvihill \& Hyams 2002), pero también se localiza en el huso mitótico y en el CAR (Bähler et al. 1998). En anafase Plo1 promueve la activación de la ruta a través de la eliminación de Byr4 de los SPBs. La kinasa dependiente de ciclina (CDK) Cdc2 también actúa como un activador de la ruta SIN foforilando a Byr4, y junto a Plo1 contribuye a la eliminación completa de Byr4 de los SPBs (Rachfall et al. 2014). 
La función activadora de Cdc2 es algo inusual puesto que durante interfase y al comienzo de mitosis Cdc2 actúa como inhibidor de la ruta SIN (Cerutti \& Simanis 1999; Dischinger et al. 2008). De hecho, la asociación del módulo Sid1-Cdc14 con el SPB requiere una disminución de la actividad CDK (Guertin et al. 2000), mientras que en general una actividad CDK alta se considera un inhibidor de la citoquinesis (revisado en (Bohnert \& Gould 2011)).

Etd1 es un activador de la ruta SIN necesario para la localización asimétrica de Cdc7 al final de anafase (Cortés \& McCollum 2009) y de Sid2 en el CAR (Daga et al. 2005). Etd1 promueve la actividad de la GTPasa Rho1 y se ha propuesto la participación de las dos proteínas en un bucle retroalimentativo que regula el SIN a través de la activación de Spg1 (Alcaide-Gavilán et al. 2014).

\section{Checkpoint de citoquinesis}

La existencia del checkpoint de citoquinesis que detecta fallos en la integridad de CAR se descubrió a través del estudio de mutantes en la $\beta(1,3)$-D-glucán sintasa Bgs1. Algunos alelos de bgsi ${ }^{+}$, en concreto el mutante cps1-191, completan la mitosis, pero no pueden formar un septo de división, y se paran con una matriz de microtúbulos interfásicos y con dos núcleos colocados en el medio de lo que deberían ser las células hijas. Los núcleos completan la fase S pero quedan bloqueados en G2 sin volver a entrar en mitosis (Liu et al. 1999). En esta situación de bloqueo el CAR se mantiene en el córtex sin contraerse, Cdc7 y Sid1 permanecen asociados con el SPB nuevo y no se produce la reactivación del crecimiento en los polos (Le Goff et al. 1999; Liu et al. 2000) (Figura 12).

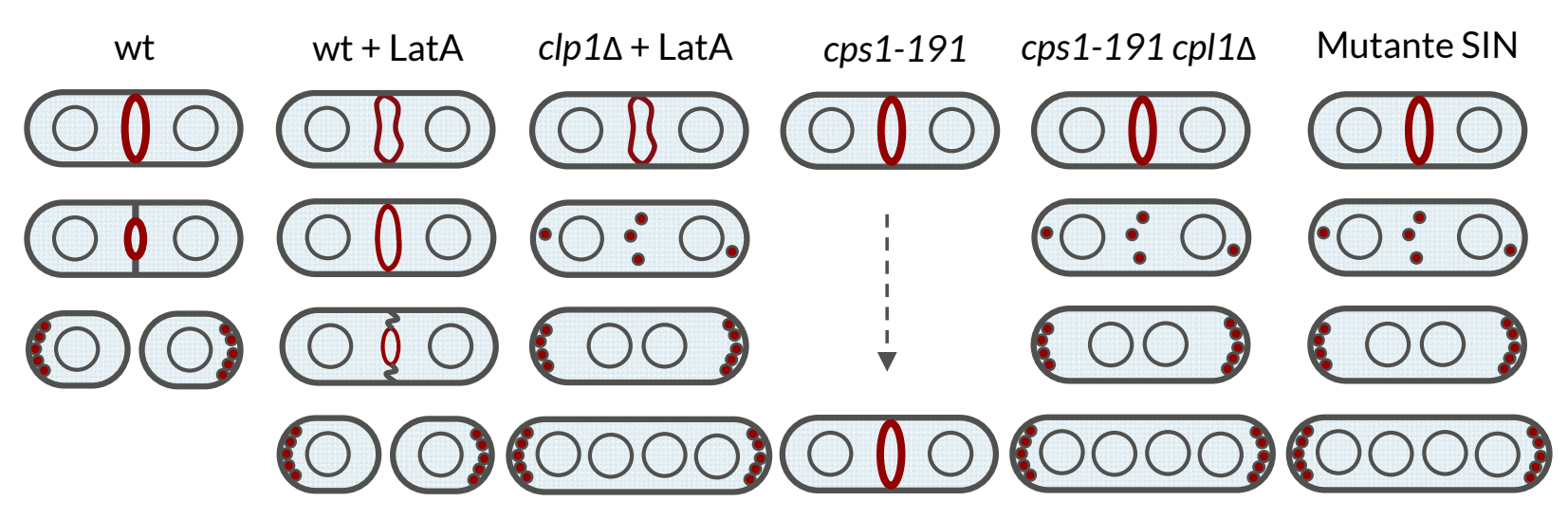

Figura 12 Comportamiento celular en distintos genotipos y condiciones de crecimiento relacionados con el checkpoint de citoquinesis. Adaptada de (Mishra et al. 2004). 
El checkpoint de citoquinesis depende de la ruta SIN y de la fosfatasa Clp1; en su ausencia los núcleos se saltan el bloqueo de G2 y el anillo termina por desensamblarse dando lugar a células multinucleadas (Trautmann et al. 2001). Este checkpoint responde además ante agresiones del CAR, ya sea con bajas dosis de latrunculina (Mishra et al. 2004), un agente despolimerizador de actina, o en mutantes con defectos en la formación del anillo (Trautmann et al. 2001), lo que induce la estabilización del CAR a la vez que se bloquea la progresión del ciclo (Figura 12).

Clp1 se localiza en el nucleolo en interfase. Al comienzo de mitosis es liberado al citoplasma y se puede ver en el SPB, en el huso y en el anillo, al que se une a través de la anillina Mid1 (Clifford et al. 2008). Tras finalizar la septación Clp1 vuelve a su localización nucleolar original (Trautmann et al. 2001; Chen et al. 2013). La liberación de Clp1 del nucleolo no depende del SIN; sin embargo, en respuesta a la activación del checkpoint la kinasa Sid2 fosforila a Clp1 y crea sitios de unión para la proteína 14-3-3 Rad24, lo que favorece su retención en el citoplasma (Chen et al. 2008).

Clp1 a su vez media la desfosforilación de Cdc11, induciendo así la activación del SIN en un feedback positivo con Sid2 (Chen et al. 2013). Sid2 también regula a Cdc11 (Feoktistova et al. 2012). De esta manera Clp1 mantendría al SIN activo para producir la parada en G2 y permitir el reensamblaje del anillo (Trautmann et al. 2001; Mishra et al. 2004; Trautmann \& McCollum 2005). A pesar de ello no está claro si la retención citoplásmica de Clp1 es necesaria para mantener el bloqueo de la progresión del ciclo puesto que el mutante Clp1-6A, el cual tiene todos sitios de fosforilación por Sid2 mutados a alanina, se comporta como la cepa silvestre en cuanto a la activación del checkpoint (Trautmann \& McCollum 2005; Chen et al. 2008).

\section{GTPASAS DE LA FAMILIA RHO}

Las GTPasas de la familia Rho forman parte de la superfamilia de GTPasas pequeñas (20-40 kDa) relacionadas con Ras (Ras homology). Son proteínas de unión e hidrólisis de GTP que se encuentran en todos los organismos eucariotas (Militello \& Colombo 2013). La unión del nucleótido determina su estado de activación, de manera que sólo están activas cuando están unidas a GTP, lo que les permite interaccionar con sus efectores, mientras que en su forma unida a GDP la transmisión de la señal queda interrumpida. Por ello son conocidas como interruptores moleculares (Vetter \& Wittinghofer 2001).

Están implicadas en la transducción y regulación de una amplia diversidad de procesos como el control de la proliferación y diferenciación celular, la regulación del citoesqueleto de actina, el tráfico endosomal, la polaridad celular y en la regulación transcripcional (Hall 2012; Ueyama 2019). En levaduras se conocen algunas de sus funciones en el crecimiento polarizado, 
en citoquinesis, mantenimiento de la integridad celular y regulación del citoesqueleto de actina (García et al. 2006b; Perez \& Rincón 2010).

\section{Regulación de las GTPasas de la familia Rho}

La activación de las GTPasas se produce por la unión de GTP mediada por las proteínas GEF (Guanine nucleotide Exchange Factor). Estas proteínas activadoras se unen a la GTPasa en su estado inactivo (unida a GDP) e inducen un cambio de conformación que promueve la disociación del GDP y la entrada del GTP, que es más abundante en la célula. Aunque la transición hacia el estado inactivo unido a GDP depende de la hidrólisis del GTP por parte de la GTPasa, la cinética de este proceso es muy lenta, por lo que también son necesarios los elementos inactivadores GAP (GTPase Acivating Protein) para aumentar su eficiencia (Figura 13). Las proteínas GAP se unen a la conformación activa de la GTPasa y

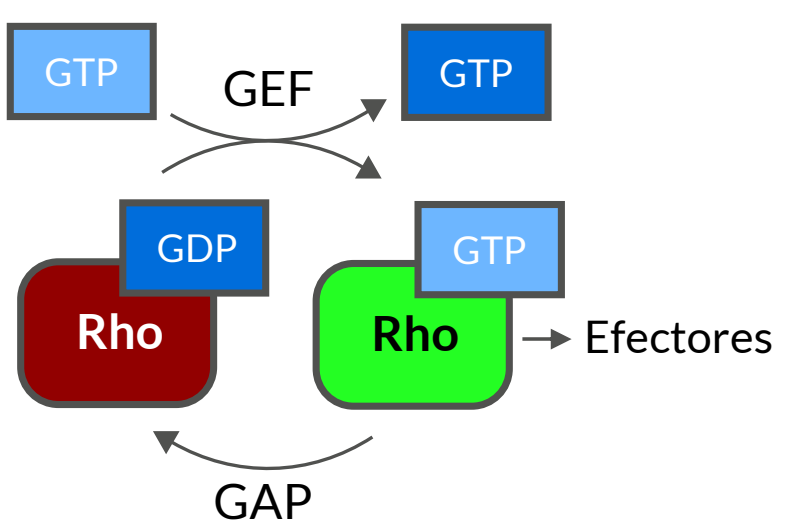

Figura 13 Regulación de las Rho-GTPasas por cambio de nucleótido.

estímulo (Lipshtat et al. 2010).

Tanto GEFs como GAPs son proteínas de mayor tamaño y complejidad que las GTPasas, están reguladas por señales extra- e intracelulares y contienen múltiples dominios capaces de interaccionar con otras proteínas y con los lípidos de la membrana. Su estructura les permite actuar no solo en el cambio del estado de activación de la GTPasa, sino también como adaptadores en complejos multiproteicos para acoplar las señales y sus efectores, además de contribuir en la localización espacial y temporal de las Rho-GTPasas. El número de reguladores GEFs y GAPs es mayor que el de GTPasas, pudiendo una misma GTPasa ser regulada por más de una de estas proteínas; además un mismo GEF o GAP puede regular a distintas GTPasas, incrementando la complejidad del sistema (Bos et al. 2007; Cherfils \& Zeghouf 2013). 
La localización subcelular de las GTPasas Rho es uno de los mecanismos más importantes en la regulación de estas proteínas. Muchas de estas proteínas ciclan entre el citosol y la membrana plasmática, guiadas por la incorporación de un grupo de naturaleza isoprenoide (farnesilo o geranilgeranilo) en una cisteína conservada en el motivo C' - terminal CAAX, lo que les permite anclarse a la membrana. (Wennerberg et al. 2005; Bustelo et al. 2007). Pueden ser desplazadas de las membranas y secuestradas en el citosol gracias a los GDIs (GDP Dissociation Inhibitors), proteínas reguladoras que enmascaran estos grupos lipídicos altamente insolubles separándolos del solvente (DerMardirossian \& Bokoch 2005; Cherfils \& Zeghouf 2013). Además de la prenilación, otras modificaciones postraduccionales como la palmitoilación pueden afectar a la localización subcelular de las Rho-GTPasas. Algunas tienen una región polibásica formada por una serie de lisinas o argininas que preceden al motivo C' - terminal CAAX y que actúan como secuencia de localización nuclear (NLS) (Liu et al. 2012).

Además de los mecanismos de control por GEFs y GAPs y de los cambios en la localización, existen otros mecanismos de regulación "no convencionales" como: I) regulación por microRNA (miRNA) del procesamiento postranscripcional de los RNA mensajeros que codifican las Rho-GTPasas; II) modificaciones covalentes como la ADP-ribosilación y la glucosilación que normalmente inactivan a las proteínas Rho; III) transglutaminación, fosforilación, y AMP-ilación que afectan a la señalización activando constitutivamente a la GTPasa, y IV) ubiquitinación, que controla por la vía del proteasoma la estabilidad y reciclaje de las proteínas Rho (Liu et al. 2012).

\section{La GTPasa Rho1}

La familia Rho GTPasas en S. pombe está compuesta por seis miembros: Cdc42, Rho1, Rho2, Rho3, Rho4 y Rho5; de estos sólo dos, Cdc42 y Rho1, son esenciales para la supervivencia celular (Arellano et al. 1999a; García et al. 2006b; Perez \& Rincón 2010).

Rho1 es el homólogo funcional de RhoA en humanos y de Rho1 en S. cerevisiae. En S. pombe Rho1 participa en la síntesis de la pared celular y la regulación del citoesqueleto de actina, ambos procesos relacionados con el crecimiento polarizado. La depleción de la actividad de Rho1 durante el crecimiento vegetativo provoca la pérdida de la integridad celular, acompañada de la disminución drástica de la actividad $\beta$-glucán sintasa ( $\beta G S$ ) y la desaparición de la actina polimerizada. Eventualmente las células se terminan lisando, la mayoría en el momento de la separación al final de citoquinesis (Arellano et al. 1996; Nakano et al. 1997; Arellano et al. 1999a). El incremento de la expresión de Rho1 induce la aparición de grandes cúmulos de actina distribuidos por toda la célula y un incremento del grosor de la pared celular, apareciendo en 
ocasiones células encadenadas, lo que sugiere, junto a la lisis del mutante, un papel en citoquinesis (Arellano et al. 1997, 1999a).

Los efectores de Rho1 mejor conocidos son las $\beta-(1,3)$-GSs, responsables de la biosíntesis del $\beta$-(1,3)-glucano, componente más abundante de la pared celular, y las proteínas Pck1 y Pck2, kinasas de la familia PKC (Arellano et al. 1996, 1999b) (Figura 14). Rho1, Pck1 y Pck2 funcionan como activadores de la cascada de MAPK de integridad celular, la cual se activa frente a condiciones adversas y regula la separación celular, morfogénesis, síntesis de pared y homeostasis iónica (Madrid et al. 2006; Perez \& Cansado 2010). Hasta la fecha no se han encontrado efectores de Rho1 en la regulación del citoesqueleto de actina.

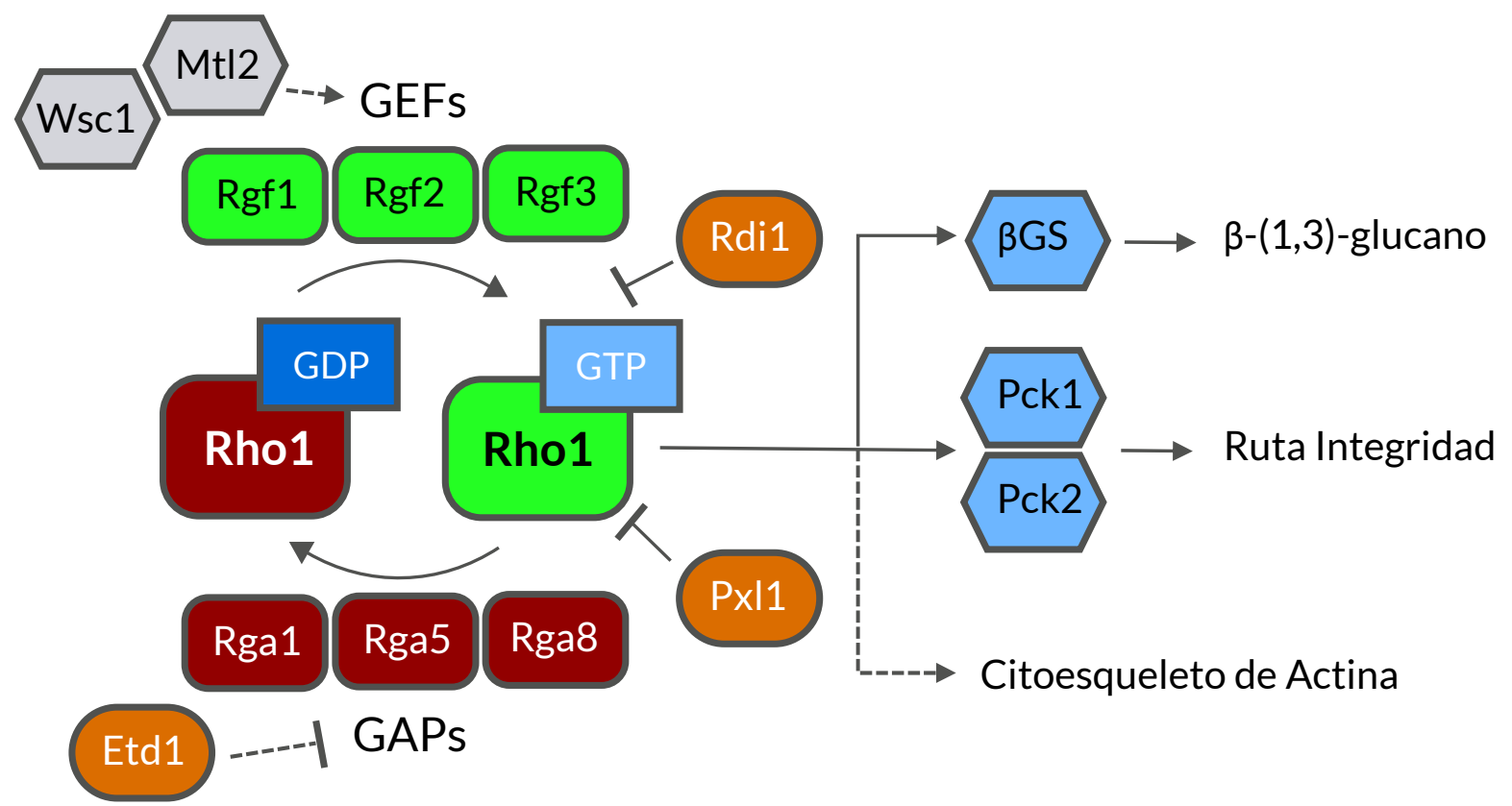

Figura 14 Reguladores y efectores de la GTPasa Rho1. Las líneas continuas son interacciones demostradas, las líneas discontinuas representan vías hipotéticas.

En lo que respecta a los componentes activadores de Rho1 en repuesta a daños en la pared celular, hay dos proteínas Mtl2 y Wsc1, con características similares a los sensores de estrés de S. cerevisiae, que actúan activando a la GTPasa. Ambas proteínas son necesarias para mantener los niveles fisiológicos de Rho1-GTP bajo el estrés crónico de la pared celular producido por agentes antifúngicos (Cruz et al. 2013). Recientemente se ha visto que mutaciones en uno de estos sensores aumentan la fragilidad de las células en respuesta a cambios en la presión (Minc 2019), y que la falta de Wsc1 afecta a la homeostasis de la pared durante el crecimiento (Davì et al. 2018). 


\section{Regulación de Rho1}

La actividad de Rho1 está regulada por tres GEFs: Rgf1, Rgf2 y Rgf3 (Mutoh et al. 2005). A grandes rasgos Rgf1 activa a Rho1 durante el crecimiento polarizado y participa en la reorganización de la actina, necesaria para iniciar la transición de crecimiento monopolar a crecimiento bipolar (García et al. 2006a). Rgf2 activa a Rho1 durante el proceso de esporulación (García et al. 2009a). Rgf3 activa a Rho1 durante citoquinesis y regula específicamente la síntesis del $\beta$ - $(1,3)$-glucano del septo de división (Tajadura et al. 2004; Morrell-Falvey 2005). Otro de los Rho-GEFs, Gef2, interacciona in vitro con Rho1, Rho4 y Rho5 (Zhu et al. 2013). Gef2 participa en la estabilización de los nodos durante la formación del anillo de actomiosina (Ye et al. 2012), pero se desconoce si lo hace activando a Rho1 o a otra GTPasa de la misma familia.

Además de los GEFs, Rho1 está regulada por tres proteínas GAP, Rga1, Rga5 y Rga8, y por una proteína GDI, Rdi1 (Figura 14). Rga1 tiene un papel importante en el crecimiento celular y la morfogénesis (Nakano et al., 2001); Rga5 participa en citoquinesis y regula de forma negativa la actividad $\beta-(1,3)$-GS (Calonge et al. 2003); Rga8 tiene actividad GAP in vivo sobre Rho1 en $S$. pombe, pero su función se desconoce (Yang et al. 2003). Rdi1 es el único GDI descrito en S. pombe, pero se desconoce el proceso celular en el que participa (Nakano et al. 2003).

Otras proteínas son también capaces de regular la actividad de Rho1. La paxilina Pxl1, que participa en la estabilidad, anclaje y constricción del CAR en combinación con Bgs1 (Cortés et al. 2015), actúa como regulador negativo de Rho1 (Pinar et al. 2008). También se ha visto que Etd1, regulador de la ruta SIN que controla el inicio de la septación (Daga et al. 2005; Cortés et al. 2018), se une directamente a Rho1 y actúa como activador de la GTPasa (Alcaide-Gavilán et al. 2014). Además, los mismos autores han descrito que Rho1 actúa como activador de la ruta SIN, a través de un mecanismo de retroalimentación positiva que incluye a Etd1, Rho1 y la GTPasa de la ruta SIN Spg1. Ya que Etd1 no muestra actividad GEF in vitro (Cortés \& McCollum 2009), se ha propuesto que podría activar a Rho1 compitiendo con sus GAPs o reguladores negativos (AlcaideGavilán et al. 2014).

\section{GEFs de Rho1}

Los GEFs de la GTPasa Rho1, como la mayoría de Rho-GEFs, son proteínas con múltiples dominios. Todas ellas presentan el dominio Dbl1-homology (DH) o Rho-GEF, que establece contacto con la GTPasa y cataliza la disociación del GDP, y en muchos casos este dominio va seguido de un dominio Pleckstrin homology (PH) de unión a fosfolípidos (Rossman et al. 2005).

En S. pombe existen 8 proteínas con dominio Rho-GEF. Rgf1, Rgf2 y Rgf3 son reguladores de Rho1 (Morrell-Falvey 2005; Mutoh et al. 2005; García et al. 2006b; a); Scd1 y Gef1 actúan como GEF específicos de Cdc42 (Coll et al. 2003; Hirota et al. 2003); Gef3 es un activador de Rho4 
(Muñoz et al. 2014b; Wang et al. 2015), mientras que los GEFs Gef2 (Ye et al. 2012) y Mug10 y no han sido asignados a ninguna GTPasa (Figura 15).

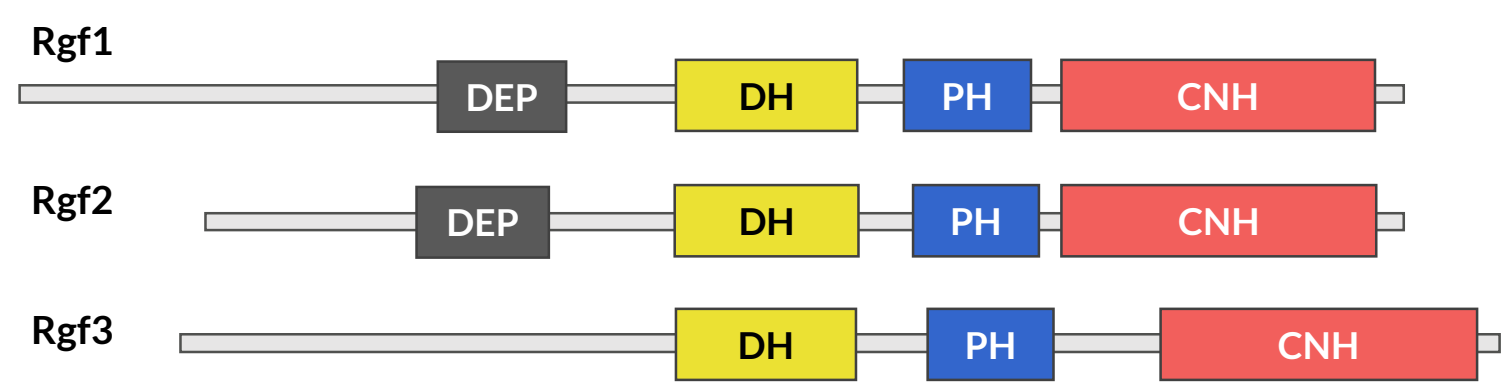

Figura 15 Esquema de los dominios de los GEF de Rho1.

Por estudios cristalográficos sabemos que la unión del dominio DH induce cambios conformacionales en las regiones switch y P-loop de la GTPasa, dejando el resto de la estructura sin grandes cambios (Dvorsky \& Ahmadian 2004; Bos et al. 2007; Cherfils \& Zeghouf 2013). El dominio DH estabiliza los intermediarios de Rho libres de nucleótido, lo que conduce a la carga del GTP debido a los altos niveles de GTP intracelular (Buchsbaum 2007). Los dominios DH contienen tres regiones conservadas (CR1, CR2 y CR3) que forman estructuras similares a $\alpha$-helices dispuestas hacia la superficie. Las sustituciones de aminoácidos dentro de estas regiones conservadas reducen la actividad intercambiadora de nucleótido. En S. pombe, una mutación puntual localizada en la hélice H8 (CR3) de Rgf3, o la eliminación de cuatro aminoácidos en la misma región del los dominios DH de Rgf1 y Rgf2 produce un fenotipo de pérdida de función (Tajadura et al. 2004; García et al. 2006a, 2009a).

Los dominios $\mathrm{PH}$ de los Rho-GEFs presentan una variedad de funciones reguladoras, pueden ser autoinhibidores, ayudar en la reacción de intercambio de nucleótido o dirigir a los Rho-GEFs hacia las membranas que contienen fosfoinosítidos (Rossman \& Sondek 2005). Una mutación en Rgf3 que se encuentra entre los dominios $\mathrm{PH}$ y CNH (citron and NIK1-like kinase homology), el mutante lad1-1, impide que Rgf3 se localice en el anillo de actomiosina durante la citoquinesis (Morrell-Falvey 2005). Del mismo modo, en el mutante Rgf1 $\triangle \mathrm{PH}-\mathrm{GFP}$ la localización normal de Rgf1 en los dos polos desaparece y la señal se vuelve monopolar (Muñoz et al. 2014a).

Aparte del módulo DH-PH, Rgf1, Rgf2 y Rgf3 contienen dominios de interacción proteína-proteína. Rgf1 y Rgf2 tienen un dominio DEP que fue descubierto en moscas (Disheveled), gusanos (EGL-10) y mamíferos (Pleckstrin). Se trata de un dominio globular de unos 100 aminoácidos presente en familias de proteínas con diversas funciones relacionadas con la 
transducción de señales. La función más conocida de los dominios DEP es el anclaje a la membrana plasmática, aunque también están involucrados en la terminación de la señal, la unión intra-dominios y la dimerización (Xu \& He 2010; Consonni et al. 2014; Gammons et al. 2016). Rgf1 y Rgf2, los dos GEFs que contienen un dominio DEP, se localizan en ambos polos y en el septo, mientras que Rgf3, que carece del dominio DEP, se localiza exclusivamente en el anillo (Tajadura et al. 2004; Morrell-Falvey 2005; Mutoh et al. 2005). Además en el mutante Rgf1 $\triangle \mathrm{DEP}$, que carece de 26 aminoácidos en este dominio, la proteína desaparece parcialmente de los polos y se acumula dentro del núcleo (Muñoz et al. 2014a).

Los tres GEFs tienen un dominio regulatorio C-terminal CNH (citron homology domain), el cual está presente también en el extremo C-terminal de varias kinasas implicadas en la regulación del citoesqueleto de actina. Su función en estos GEFs es desconocida, pero podría ser un dominio de interacción proteína-proteína (Taira et al. 2004; Bassi et al. 2013). El dominio CNH es esencial para la función Rgf1 en la integridad y polaridad celular (Muñoz et al. 2014a). Además, las células portadoras de deleciones en el dominio CNH de Rgf3 son inviables (Tajadura 2004) y el intercambio del dominio CNH de Rgf3 por el respectivo de Rgf1 no rescata la letalidad en el diploide $\operatorname{rgf} 3 \Delta / \mathrm{rgf}_{3}{ }^{+}$(datos no publicados).

\section{Rgf3}

Rgf3 se localiza exclusivamente en el anillo contráctil (Tajadura et al. 2004; Morrell-Falvey 2005; Mutoh et al. 2005); aparece en anafase y se cierra con el anillo hasta desaparecer al final de la constricción. El análisis de los componentes del anillo por microscopía de superresolución indica que Rgf3 se localiza en la capa intermedia del anillo que incluye a Pxl1, Fic1, Spa2, Pck1, Clp1, Pom1 y Cyk3 (McDonald et al. 2017). Esta localización depende de Cdc15, Imp2 (RobertsGalbraith et al. 2009, 2010; Davidson et al. 2015; Ren et al. 2015) y de la arrestina Art1. Art1 y Rgf3 interactúan físicamente y su localización es interdependiente; además, ambas proteínas están implicadas en el mantenimiento de los niveles de Rho1 activo en la zona de la división (Davidson et al. 2015).

Rgf3 es, igual que Rho1, una proteína esencial y los mutantes conocidos de Rgf3 presentan defectos relacionados con una activación deficiente de Rho1 (Tajadura et al. 2004; Mutoh et al. 2005). Por ejemplo, las células mutantes lad1-1 se lisan tras la división celular, específicamente cuando comienza la disolución del septo primario (Morrell-Falvey 2005), mientras que las células del alelo mutante ehs2-1 presentan hipersensibilidad a equinocandina. Esta sensibilidad es suprimida por la sobreexpresión de Bgs1, Bgs2 y Bgs3 en plásmidos multicopia bajo el control de su propio promotor (Tajadura et al. 2004). Estos datos inducen a pensar que Rgf3 activa a Rho1 y la actividad $\beta$ GS tras ser reclutado a la zona del anillo (Tajadura et al. 2004; Davidson et al. 2015; Ren et al. 2015). Además, la maduración y constricción del anillo son más prolongadas en los 
mutantes de rgf3+ (Mutoh et al. 2005; Davidson et al. 2015) aunque no se conoce la razón de este retraso o qué componentes del anillo pueden estar afectados. Es posible que Rgf3 actúe como un enlace físico entre los componentes del CAR y el crecimiento del septo mediado por las enzimas Bgs unidas a la membrana (McDonald et al. 2017).

\section{Rgf2}

Rgf2 es esencial durante la diferenciación sexual. Se localiza en la periferia de la espora de forma uniforme, probablemente asociada a la membrana interna. La fluorescencia de Rgf2-GFP aparece en la fracción de células que ya han sufrido meiosis I y II, cuando el contorno de la espora está perfectamente definido (García et al. 2009a). La señal de fluorescencia apenas se ve en las células vegetativas de tipo silvestre, sin embargo, cuando se expresa en un plásmido multicopia con su propio promotor, Rgf2 se localiza en los polos de crecimiento, el septo y a lo largo de toda la superficie celular (Morrell-Falvey 2005; Mutoh et al. 2005; García et al. 2009a).

Los datos de localización indican que Rgf2 también juega un papel durante el crecimiento vegetativo; de hecho, aunque las células $r g f 2 \Delta$ crecen como células de tipo silvestre (incluso en situaciones de estrés), la disrupción de $r g f 1^{+}$en un fondo genético $r g f 2 \Delta$ es letal, lo que sugiere que Rgf2 comparte con Rgf1 una función esencial durante el crecimiento vegetativo (Mutoh et al. 2005; García et al. 2009a). La sobreexpresión leve de rgf2+ (bajo su propio promotor o con el promotor de $r g f_{1}{ }^{+}$en un plásmido multicopia) rescata completamente el fenotipo de células lisadas del mutante $\operatorname{rgf}_{1} \Delta$ y parcialmente su defecto de crecimiento monopolar (García et al. 2009a). La sobreexpresión del alelo de falta de función rgf2-PTTR $\Delta$ (García et al. 2009a), bajo el control del promotor nmt1, aumenta el porcentaje de células lisadas y monopolares en la cepa silvestre (resultados no publicados). Por tanto, niveles altos de Rgf2 fenocopian la ausencia de Rgf1, sugiriendo que ambas proteínas compiten por los mismos sustratos. En ausencia de Rgf1, Rgf2 asumiría las funciones esenciales sobre Rho1 durante el crecimiento vegetativo.

\section{Rgf1, principal GEF de la GTPasa Rho1}

Rgf1 es una proteína de 1.334 aminoácidos, no esencial, y posiblemente responsable de la mayor parte del Rho1 activo disponible en la célula. La eliminación de Rgf1 disminuye enormemente la cantidad de Rho1 unido GTP (García et al. 2006a, 2009b), algo que no ocurre en los mutantes de los otros GEFs.

Rgf1 presenta una localización dinámica durante el ciclo celular; su distribución sigue a la de los parches de actina cortical, que se acumulan en los polos de crecimiento activo durante interfase y se reubican en un anillo central en mitosis (Mutoh et al. 2005; García et al. 2006a) (Figura 16A). Por consiguiente, la localización de Rgf1-GFP en los polos de la célula se ve 
fuertemente afectada por el desensamblaje de los filamentos de actina al añadir latrunculina A, pero no por la alteración severa de los microtúbulos después del tratamiento con MBC (resultados no publicados).

A

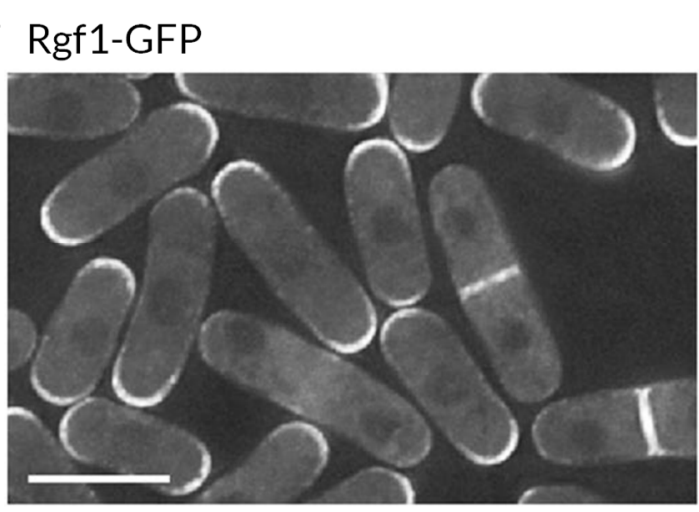

B

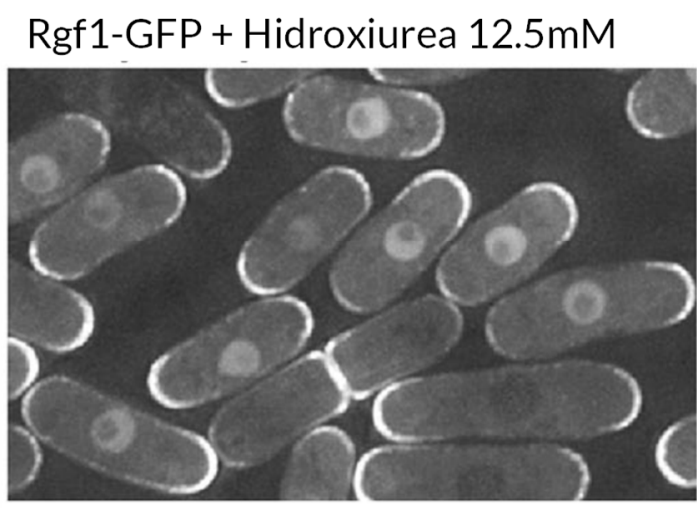

Figura 16 Localización de Rgf1-GFP. (A) En células en crecimiento Rgf1 se localiza en el septo y los polos. (B) Frente al bloqueo replicativo por HU Rgf1 se acumula también en el núcleo. Barra $10 \mu \mathrm{m}$. Tomada de (Muñoz et al. 2014a).

Rgf1 se acumula en el núcleo en respuesta al daño en la replicación del DNA causado por la presencia de hidroxiurea (HU, un inhibidor de la ribonucleótido reductasa que bloquea la replicación del DNA) (Figura 16B). En interfase, además de localizarse en los polos, Rgf1 entra y sale del núcleo, pero en ausencia de estrés su exporte está favorecido de manera que la fluorescencia de Rgf1-GFP es menos intensa en el núcleo que en el citoplasma (Muñoz et al. 2014a). En presencia de estrés replicativo ocurre lo contrario, se produce un bloqueo de su salida del núcleo. El proceso de importación al núcleo está mediado por una secuencia de localización nuclear (NLS) en el extremo N-terminal, mientras que la liberación en el citoplasma requiere dos secuencias de exportación nuclear ricas en leucina (NES1 y NES2) en la región C-terminal de la proteína (Muñoz et al. 2014a).

\section{Rgf1 es necesario en el mantenimiento de la integridad celular y crecimiento bipolar}

Aunque $r g f 1^{+}$no es un gen esencial, en un cultivo asincrónico el $\sim 10 \%$ de las células del mutante rgf1 $\Delta$ se lisan (García et al. 2006a) (Figura 17). El fenotipo de células lisadas es similar al que se observa en el apagado de $r h o 1^{+}$(Arellano et al. 1997), pero mientras que en el caso de rho1 ${ }^{+}$la mayoría de las células se lisan en parejas (durante la separación), en el mutante rgf1 $\Delta$ la lisis celular ocurre en células individuales y en parejas de células largas que ya han empezado a crecer 
por un polo. El mutante $r g f_{1} \Delta$ es además extremadamente sensible a caspofungina, un antibiótico que inhibe la síntesis del $\beta(1,3)$-glucano (García et al. 2006a).
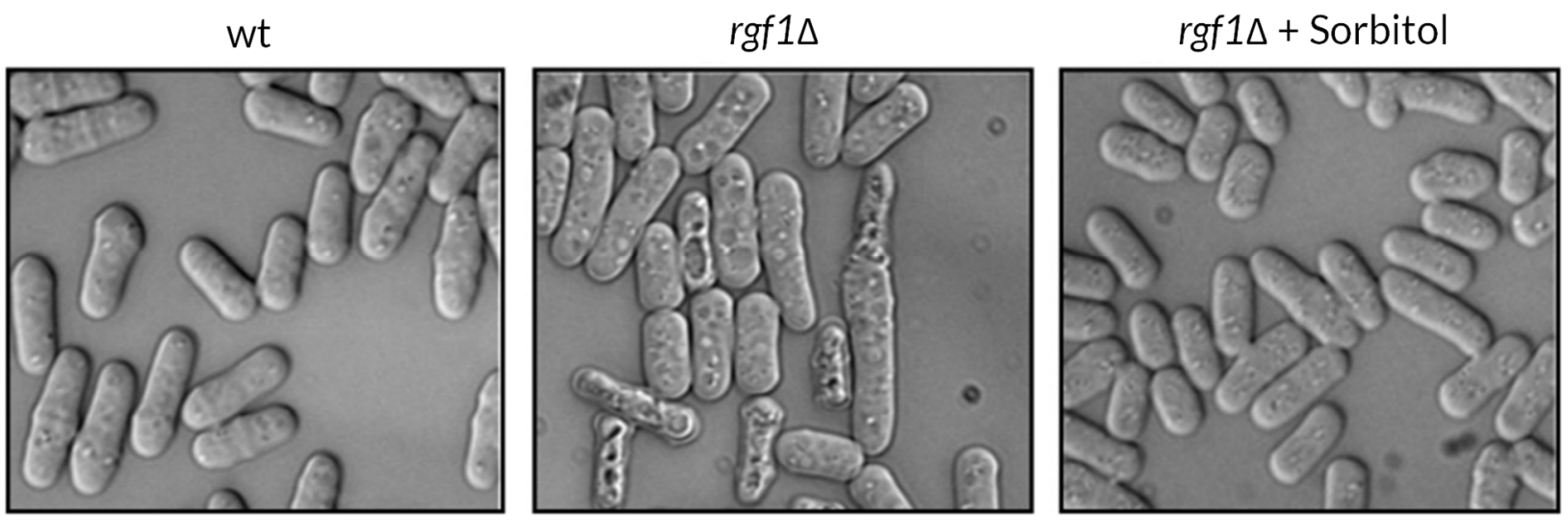

Figura 17 Fenotipo de lisis de las células $r g f_{1} \Delta$. Células silvestres y mutantes $r g f_{1} \Delta$ creciendo en medio YES y YES suplementado con sorbitol 1.2M. Tomada de (García et al. 2006a).

Otra característica de las células de $r g f_{1} \Delta$ es que son monopolares; en un cultivo asincrónico el 80\% de las células del mutante presentan crecimiento monopolar comparado con el 20\% observado en la cepa silvestre. En ausencia de Rgf1, Cdc42 y los parches de actina se localizan exclusivamente en el polo de crecimiento (García et al. 2006a). Estas observaciones apuntan hacia un papel de Rgf1 en el crecimiento polarizado promoviendo la reorganización de actina necesaria para iniciar el crecimiento en el polo nuevo.

\section{Rgf1 participa en la tolerancia al estrés replicativo}

Rgf1 se acumula en el núcleo durante el bloqueo replicativo causado por hidroxiurea (HU) y su presencia en el núcleo protege a las células del estrés replicativo (Muñoz et al. 2014a). La HU causa la depleción de los dNTPs al inactivar la ribonucleótido reductasa, con lo que se bloquea la progresión de las horquillas de replicación y se dispara la respuesta del checkpoint de replicación (Boddy \& Russell 2001). La kinasa sensora Rad3 fosforila a la kinasa del checkpoint Cds1 (también a Chk1 cuando el daño se produce en G2), que regula a través de sus efectores la parada de la progresión del ciclo celular y la activación de mecanismos de reparación del daño (Langerak \& Russell 2011; Lambert \& Carr 2013).

La acumulación nuclear de Rgf1 durante el estrés replicativo depende de Rad3 y Cds1, y de la chaperona Rad24. En el modelo propuesto la activación de Cds1, recluta a Rgf1 fosforilada y promueve su interacción con Rad24. Esta interacción ocultaría la secuencia NES de Rgf1, 
reduciendo su asociación con la exportina Crm1 y bloqueando así su salida del núcleo (Muñoz et al. 2014a) (Figura 18).

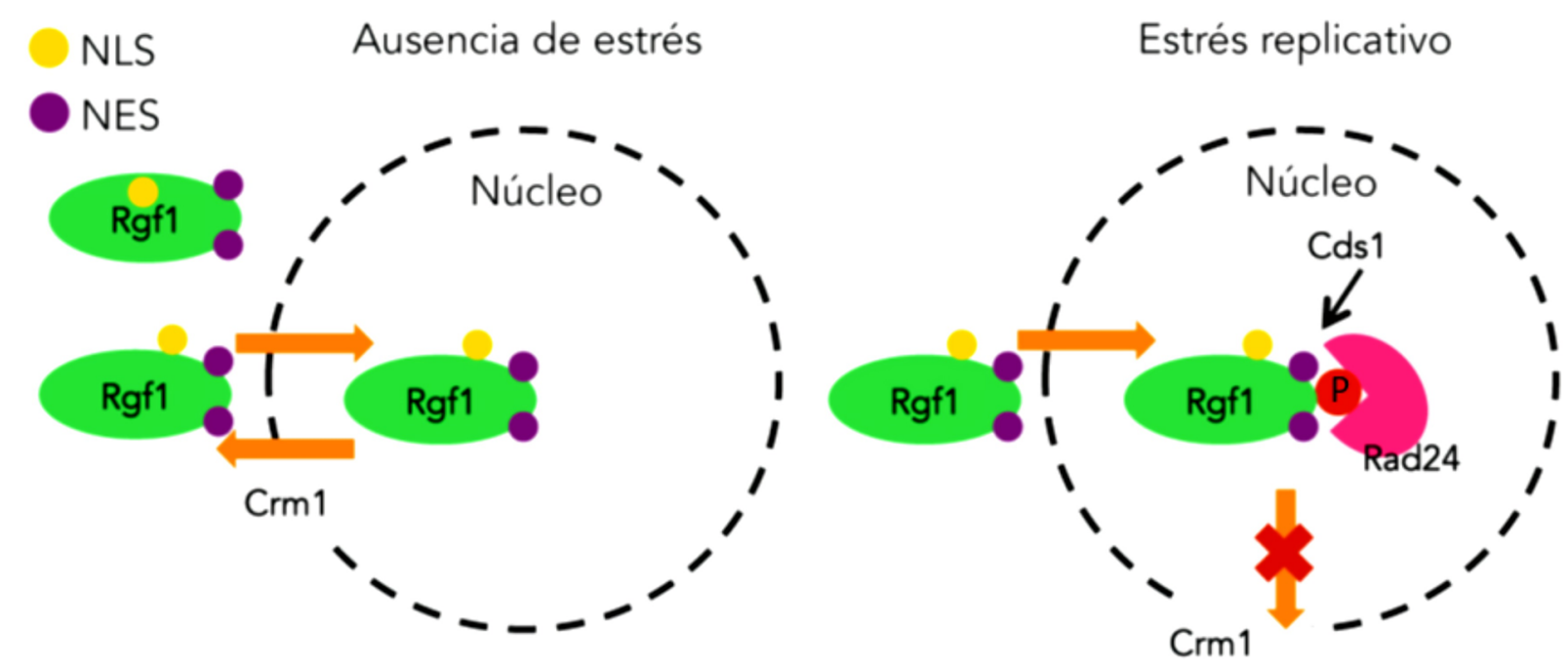

Figura 18 Modelo de la acumulación de Rgf1 en el núcleo en respuesta a estrés replicativo .Traducida de (Muñoz et al. 2014a).

Las células que carecen de Rgf1 son sensibles a HU. Curiosamente, la proteína mutada Rgf1-9A, en la que se han sustituido las serinas de los 9 posibles sitios de fosforilación por Cds1 por alaninas, no se acumula en el núcleo en respuesta a estrés replicativo y tampoco interactúa con Rad24. Las células del mutante Rgf1-9A son sensibles a HU (Muñoz et al. 2014), pero no muestran otros fenotipos característicos del mutante nulo como el crecimiento monopolar o la sensibilidad a caspofungina (Csp) (García et al. 2006a, 2009b). Estos datos sugieren que la interacción de Rgf1 con Cds1-Rad24 y su acumulación en el núcleo son necesarias específicamente para la tolerancia al estrés de replicación.

\section{Rgf1 está involucrado en la reparación de daño en el DNA}

Rgf1 también está implicado en la tolerancia a agentes genotóxicos distintos de HU (Manjón et al. 2017). Las células rgfi $\Delta$ son sensibles a camptotecina (CPT, un inhibidor de la topoisomerasa) y muy sensibles a la exposición a fleomicina (Phl, un derivado de la bleomicina); ambos agentes inducen roturas de doble cadena en el DNA (DSBs) (Levin \& Demple 1996; Pommier 2006).

Estas agresiones activan el checkpoint de daño en el DNA, que bloquea la progresión del ciclo celular y promueve la reparación de la rotura a través de dos vías, la recombinación 
homóloga (HR) cuando la cromátida hermana está disponible en fase G2 y fase S, y la unión de extremos no homólogos (NHEJ) en fase G1 (Langerak \& Russell 2011; Chapman et al. 2012).

Rgf1 participa en la reparación de las roturas de doble cadena producidas por el tratamiento con Phl (Manjón et al. 2017). La eliminación de Rgf1 no afecta al establecimiento de la parada de ciclo inducida por el checkpoint, pero sí impide la recuperación de las células tras producirse el daño en el DNA. Las células de $r g f 1 \Delta$ presentan focos de reparación que no se resuelven y son incapaces de reparar eficazmente los cromosomas fragmentados después del tratamiento con Phl (Figura 19). Estos efectos van ligados a la activación permanente de Chk1 y el bloqueo de las células en G2/M.

\section{wt Rad54-GFP 3h tras Phl}

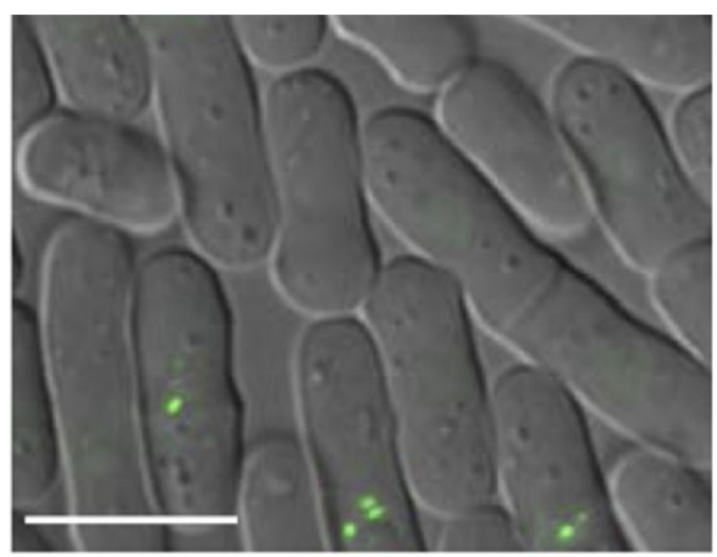

rgf1 $\triangle$ Rad54-GFP 3h tras Phl

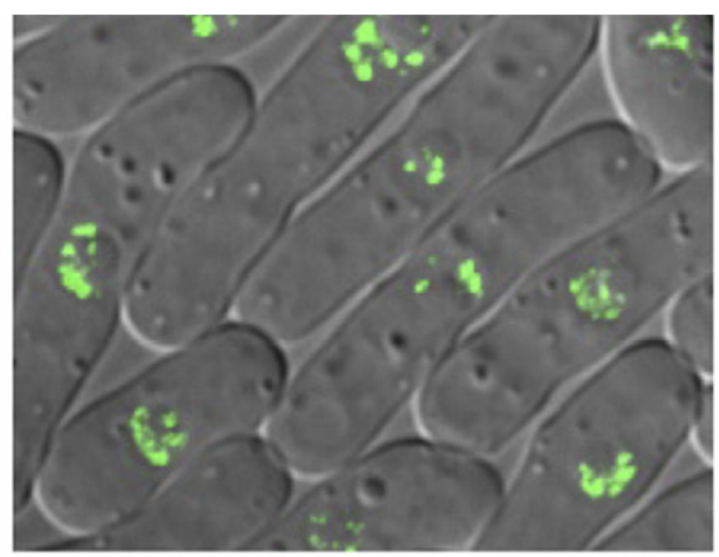

Figura 19 Focos de reparación de daño sin resolver en el mutante $\operatorname{rgf}_{1} \triangle$. Después de 3 horas en recuperación del tratamiento con fleomicina las células $\operatorname{rgf}_{1} \Delta$ todavía presentan un elevado número de focos de Rad54, a diferencia de la cepa silvestre que ya ha resuelto la mayoría. Barra $10 \mu \mathrm{m}$. Tomado de (Manjón et al. 2017).

De forma similar a las células rgf1 $\Delta$, el mutante rho1-596 (Viana et al. 2013) es sensible a CPT y Phl. La tasa de disolución de los focos Rad52 inducidos por Phl en las células rho1-596 y en el doble mutante $r g f_{1} \Delta$ rho1-596 es muy similar a la del mutante sencillo $r g f_{1} \Delta$, lo que sugiere que Rho1 participa en la reparación de DSBs (Manjón et al. 2017).

\section{Rgf1 es un activador de la ruta de integridad celular}

Al estudiar la relación de Rgf1 con alguno de los efectores conocidos de Rho1 se vio que la sobrexpresión moderada de $b g 4^{+}, p c k 1^{+}$y $p c k 2^{+}$suprimía la sensibilidad a Csp del mutante rgf $1 \Delta$ (García et al. 2006a). Además de ser efectores de Rho1, las kinasas Pck1 y Pck2, son activadores de la ruta de integridad celular (CIP) (Ma et al. 2006; Barba et al. 2008; Sánchez-Mir et al. 2014), 
lo que llevó a investigar la relación de Rgf1 con la ruta CIP. Los datos más relevantes se resumen a continuación:

I) Las células $r g f_{1} \Delta$ presentan el fenotipo vic (viable in the presence of immunosuppressant and chlorine ion), característico de los mutantes nulos de los genes implicados en la ruta de integridad. En S. pombe se sabe que la eliminación del gen de la calcineurina, $p p b 1^{+}$, o la inhibición de su actividad mediante inmunosupresores como FK506, produce hipersensibilidad al ion $\mathrm{Cl}^{-}$, mientras que una mutación adicional en los miembros de la ruta de MAPK suprime este fenotipo (Sugiura et al. 1999).

II) Tanto el mutante $r g f_{1} \Delta$ como los mutantes nulos de los componentes de la ruta son sensibles a estrés osmótico, a Csp y muestran un retraso en la reentrada al ciclo celular desde fase estacionaria (García et al. 2009b).

III) Rgf1 es necesario para la activación de Pmk1 en respuesta a estrés osmótico y a daños en la pared celular. Este fenotipo es característico de Rgf1, que es el único de los GEFs de Rho1 implicado en esta señalización (García et al. 2009b).

IV) La sobreexpresión de rho1 ${ }^{+}$y la de un alelo constitutivamente activo, rho1-G15V, aumentan los niveles de fosforilación de Pmk1 de forma dependiente de Pck2 y de Mkh1 (García et al. 2009b).

Todos estos datos sitúan a Rgf1 como un activador de la ruta de integridad celular que podría actuar a través de Rho1 y/o de Pck2.

\section{RESPUESTA CELULAR A ESTRÉS: RUTAS DE MAPK}

Las condiciones de crecimiento altamente controladas que se mantienen en los laboratorios tienen muy poco que ver con el ambiente cambiante en el que han evolucionado los seres vivos. Las células no son ciegas al medio externo, al contrario, todos los organismos poseen mecanismos para detectar y responder en consecuencia a los cambios en el ambiente que les rodea. Hablamos de variaciones ambientales, como pueden ser cambios en la temperatura, presión osmótica, $\mathrm{pH}$, disponibilidad de nutrientes, presencia de ciertos iones, otros agentes químicos o radiación. Para recabar la información del medio y transmitir las señales ambientales hacia el interior celular los organismos eucariotas poseen unas vías de señalización conservadas conocidas como cascadas de MAPK (Mitogen activated protein kinase) (Rispail et al. 2009).

Las rutas de MAPK están formadas por cuatro módulos compuestos por proteínas sensoras, proteínas que transmiten la señal, proteínas efectoras y reguladoras. Según la naturaleza del estímulo, los receptores de la señal pueden ser proteínas G acopladas a receptores transmembrana, sistemas de regulación de dos componentes, receptores de membrana tirosina 
kinasa o proteínas integrales de membrana. En levaduras, se han identificado receptores pertenecientes a todos los grupos con la excepción de los de tipo tirosina kinasa (Perez \& Cansado 2010).

El módulo de transmisión de la señal está integrado por una cascada de kinasas muy conservadas que actúan en orden secuencial (Figura 20), aquí listado en orden inverso de actuación: la MAP kinasa (MAPK), la MAPK kinasa (MAPKK) y la MAPKK kinasa (MAPKKK). Tras la transducción del estímulo la MAPKKK es activada por otras proteínas, ya sean otras kinasas o GTPasas de la familia Ras o Rho (Perez \& Cansado 2010). La MAPKKK activa a la MAPKK por fosforilación en residuos de serina o treonina (Ser/Thr). La MAPKK activada actúa como kinasa dual fosforilando a la MAPK en residuos de treonina y tirosina en el loop de activación (Thr-X-Tyr) que induce el cambio conformacional de la kinasa final y su activación (Cargnello \& Roux 2011).

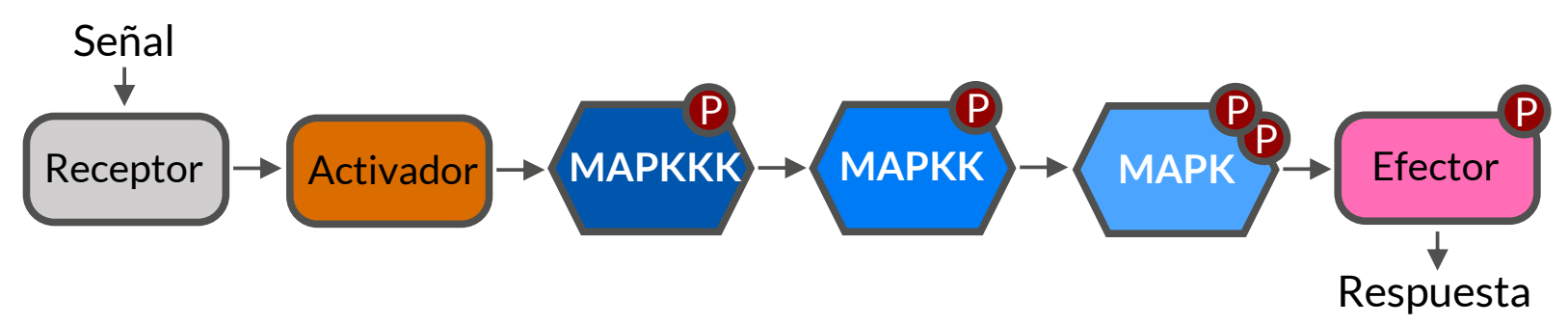

Figura 20 Orden de actuación de los cuatro módulos de las rutas de MAPK. El módulo de transmisión de la señal (en azul) lo forman MAP kinasas que dan nombre a la ruta.

La MAPK fosforila a sus efectores en residuos de serina o treonina seguidos de prolina (Ser/Thr-Pro). Estos efectores son generalmente factores de transcripción que al ser fosforilados cambian el patrón transcripcional de la célula para adaptarse al estímulo, aunque también se han identificado otro tipo de sustratos, como reguladores del ciclo celular, proteínas del citoesqueleto, canales iónicos, remodeladores de cromatina, proteínas de unión a RNA y moduladores de la traducción (Chen \& Thorner 2007; Cargnello \& Roux 2011).

Las rutas de MAPK no actúan de manera independiente o aislada, de hecho hay una variedad de mecanismos que contribuyen a la especificidad de la respuesta mediada por estas rutas (Chen \& Thorner 2007). Uno de los más importantes es el mediado por proteínas que actúan a modo de adaptadores, que mantienen a los componentes de la cascada próximos entre sí y a la membrana plasmática para maximizar la propagación de la señal a la vez que se evita la activación inapropiada de otras respuestas (Atay \& Skotheim 2017). Adicionalmente, el 
reclutamiento localizado y la compartimentalización subcelular es también parte importante de la regulación de la señal (Atay \& Skotheim 2017).

Otro mecanismo de regulación es el que concierne al apagado de la señal. De forma general, en ausencia de los estímulos apropiados, las MAPK se mantienen en niveles mínimos de activación, y tras activarse y desencadenar su señal son inactivadas rápidamente. Esta dinámica se debe a la activación secuencial del módulo de MAP kinasas (Piala et al. 2014) y a la acción de proteínas fosfatasas (González-Rubio et al. 2019). En conjunto, las propiedades de estos componentes dotan al sistema de un comportamiento del tipo interruptor molecular, capaz de ejercer una respuesta rápida y contundente (Huang \& Ferrell 1996; English et al. 2015).

Por último está la propia interacción entre las distintas rutas de MAPK, que incluye la participación de más de una ruta en la regulación de un mismo proceso, la interacción entre las distintas proteínas pertenecientes a diferentes rutas de MAPK, así como la interacción entre varías rutas de MAPK entre ellas o con otras vías de señalización (Chen \& Thorner 2007; Martínez-Soto \& Ruiz-Herrera 2017).

En S. pombe existen tres rutas de MAPK: la ruta de integridad celular (CIP), cuya MAP kinasa final es Pmk1, la ruta de respuesta a estrés (SAPK), con Sty1 como elemento final, y la ruta de respuesta a feromonas con la kinasa Spk1 (Figura 21).

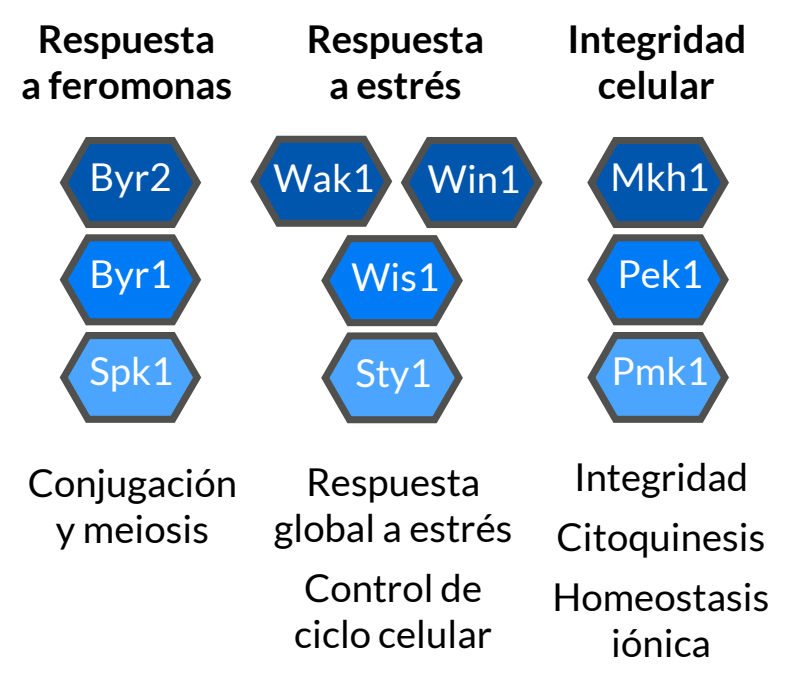

Figura 21 Módulos centrales de las tres rutas de MAPK de $S$. pombe y los procesos en los que intervienen. Adaptado de (Perez \& Cansado 2010).

\section{Ruta de integridad celular, CIP}

La ruta de MAPK de integridad celular (CIP) se activa frente a estrés osmótico, térmico, oxidativo, daño en la pared celular y ayuno de glucosa (Madrid et al. 2006). Gracias al uso de mutantes en sus componentes se sabe que esta ruta participa en la homeostasis de la pared celular, en la homeostasis iónica y en la fusión de vacuolas (Toda et al. 1996; Zaitsevskaya-Carter \& Cooper 1997; Sugiura et al. 1999; Loewith et al. 2000; Madrid et al. 2006). 


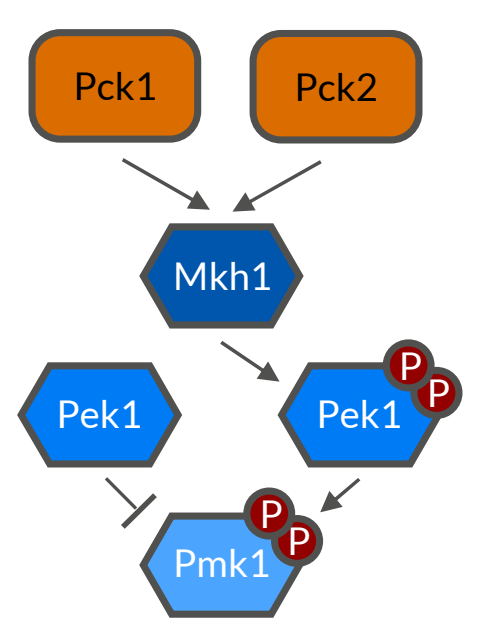

Figura 22 MAP kinasas de la ruta de integridad celular y sus activadores Pck1 y Pck2. Pek1 tiene actividad dual sobre Pmk1 dependiendo de su estado de fosforilación.
El módulo de MAP kinasas de la ruta CIP comienza con la MAPKKK Mkh1. Mkh1 es fosforilada por los reguladores Pck1 y principalmente Pck2, y transmite la señal fosforilando a la MAPKK Pek1, con quien se encuentra formando un complejo ternario junto a la MAPK Pmk1 (Loewith et al. 2000; SánchezMir et al. 2014) (Figura 22). En su forma activa Pek1 fosforila a Pmk1 de manera dual en un residuo de treonina y otro de tirosina (Sugiura et al. 1999; Loewith et al. 2000), mientras que en su forma no fosforilada actúa como regulador negativo de la MAPK Pmk1, inhibiendo la señalización (Sugiura et al. 1999). La activación de Pmk1 es totalmente dependiente de Mkh1 y Pek1, y los mutantes nulos en cualquiera de las tres kinasas presentan los mismos fenotipos, lo que

indica que en este tramo la señalización es lineal (Madrid et al. 2006).

Mkh1, Pek1 y Pmk1 se localizan en el citoplasma y el septo. Pmk1 aparece también en el núcleo, huso mitótico y SPB (Madrid et al. 2006). La localización de estas tres MAPK no se ve alterada por la inducción de distintos estreses. Tampoco se han observado cambios en la localización de Pmk1 en ausencia de Mkh1 o Pek1, lo que sugiere que su activación se puede dar tanto en el citoplasma como en el septo y que esto no condiciona su transporte al núcleo (Madrid etal. 2006; Sánchez-Mir etal. 2012). Curiosamente, un mutante en el que Pmk1 está mayoritariamente anclada a la membrana plasmática, y por lo tanto excluida del núcleo, se comporta prácticamente igual que la cepa silvestre.

\section{Sensores y reguladores positivos}

La identidad de los sensores que detectan el estrés y activan la ruta de integridad celular todavía no se conoce en S. pombe. En S. cerevisiae las proteínas transmembrana Wsc1, Mtl1 y Mid2 detectan los cambios mecánicos en la pared celular causados por distintos estreses. Transducen la señal a través de Rom2, el GEF de Rho1, que a su vez activa a Pkc1 y este a la ruta de MAPK de integridad celular (Levin 2005).

En S. pombe se han descrito las proteínas Wsc1 y Mtl2 con estructura similar a los sensores de S. cerevisiae. Ambas tienen una cola citoplásmica, un dominio transmembrana y una región rica en serinas y treoninas (altamente glicosilada), Wsc1 tiene además un dominio rico en cisteínas (Cruz et al. 2013). Mtl2 se localiza en la periferia celular y es necesario para la supervivencia frente a distintos estreses de pared, mientras que Wsc1 se concentra en las zonas 
de crecimiento y su sobreexpresión activa la síntesis de pared celular. Wsc1 y Mtl2 participan en la activación de Rho1, de hecho, la sobreexpresión de Rho1 o de sus GEFs rescata el fenotipo letal de la doble deleción wsc1 $\Delta$ mtl $2 \Delta$. Sin embargo, ninguno de los mutantes individuales presenta defectos en la activación de la ruta CIP en respuesta a estrés osmótico (Cruz et al. 2013).

Aun desconociendo el sensor, sí se conoce bastante acerca del módulo de reguladores positivos que activan a la cascada de MAPK. Este está compuesto por las GTPasas de la familia Rho, Rho1 y Rho2, los dos ortólogos de PKC, Pck1 y Pck2, y la kinasa dependiente de fosfolípidos (PDK) Ksg1 (Figura 23).

Pck1 y Pck2 son kinasas con un porcentaje alto de identidad en su secuencia. Ambas presentan un dominio regulador en la región $\mathrm{N}$-terminal mediante el cual se unen a la forma activa de las GTPasas Rho1 y Rho2 (Matsuyama et al. 2006). Esta interacción estabiliza a las kinasas, que de forma normal presentan una vida media reducida. Pck1 y Pck2 tienen papeles parcialmente complementarios sobre la viabilidad celular. La doble deleción de ambas kinasas resulta inviable, el mutante sencillo pck2 $\Delta$ tiene defectos en polaridad celular, presenta una pared celular delgada y es hipersensible a temperaturas altas, estrés salino y al tratamiento con enzimas líticas (Toda et al. 1993; Sengar et al. 1997); por su parte el mutante pck1 $\Delta$ presenta sensibilidad a agentes que dañan la pared como el calcoflúor, la cafeína y las equinocandinas (Arellano et al. 1999b; Calvo et al. 2009). La sobreexpresión de Pck1 no tiene efectos notables, pero la sobreexpresión de Pck2 origina un incremento en la síntesis de pared celular que acaba siendo letal (Toda et al. 1993; Arellano et al. 1999b). Ksg1 actúa como regulador positivo de la ruta de integridad celular en S. pombe (Gräub et al. 2003), y se asocia y fosforila in vivo a Pck1 y Pck2 (Madrid et al. 2015, 2017).

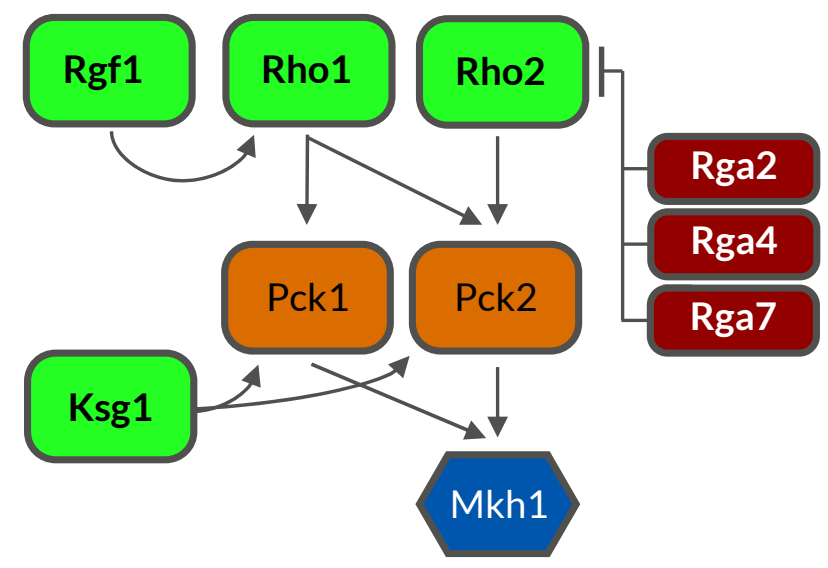

Figura 23 Reguladores positivos de la ruta CIP. Se muestran en granate los GAP de Rho2 relacionados con la inhibición de la señal.

La GTPasa Rho2, a diferencia de Rho1, no es esencial, pero comparte con Rho1 funciones en el control de la polaridad celular, la remodelación del citoesqueleto de actina y la síntesis de la pared celular; además, las dos GTPasas comparten localización en las zonas de crecimiento (Arellano et al. 1997; Hirata et al. 1998; Calonge et al. 2000). La deleción de Rho2 origina células ligeramente redondeadas que son sensibles a glucanasas, caspofungina y cafeína (Hirata et al. 1998; Villar-Tajadura et al. 2008; Calvo et al. 2009). No se conocen los GEFs de Rho2, pero sí se han descrito cuatro GAPs: Rga2, 
Rga4, Rga7 y Rga6. De estos, los tres primeros están relacionados con la inhibición de la señal de Pmk1 (Villar-Tajadura et al. 2008; Soto et al. 2010; Revilla-Guarinos et al. 2016).

Al margen de la activación de la ruta CIP, Rho1 regula la síntesis del $\beta$ - $(1,3)$-glucano de la pared a través de dos vías, una directa modulando la actividad de las enzimas Bgs y otra indirecta a través de la activación de Pck1 y Pck2, que a su vez regulan la síntesis del $\beta$ - $(1,3)$-glucano in vitro (Arellano et al. 1999b). Rho2 no regula a las enzimas Bgs pero sí controla la actividad de la a-glucán sintasa Mok1 en una vía únicamente dependiente de Pck2 (Calonge et al. 2000). También se ha propuesto que las GTPasas Rho4 y Rho5 actúan como reguladores positivos de la ruta CIP a través de Pck2, pues se asocian con esta proteína y con Pck1, su sobreexpresión y deleción afectan a la fosforilación de Pmk1 y presentan fenotipo vic (Doi et al. 2015).

\section{Vías de activación de Pmk1}

Pmk1 se activa ante múltiples situaciones de estrés que incluyen: temperatura alta, estrés salino $\left(\mathrm{NaCl}, \mathrm{KCl}, \mathrm{CaCl}_{2}\right)$, estrés oxidativo $\left(\mathrm{H}_{2} \mathrm{O}_{2}\right.$, diamida, $\mathrm{DEM}, \mathrm{t}-\mathrm{BOOH}$, Paraquat), estrés hipertónico (sorbitol) e hipotónico, estrés en la pared celular (cafeína, vanadato sódico, calcoflúor, caspofungina) y estrés por ayuno de glucosa, pero no de nitrógeno (Zaitsevskaya-Carter \& Cooper 1997; Madrid et al. 2006; García et al. 2009b). Sin embargo, la relación entre los distintos activadores y la cascada de MAPK no es para nada simple y está condicionada por la naturaleza de cada estrés en cuestión. Los detalles fenotípicos de estas relaciones se citan a continuación:

- La presencia de Rho2 y Pck2 es crítica para la activación de Pmk1 frente a KCl, sorbitol y estrés hipotónico, mientras que en los mutantes rho2 $\Delta$, pck2 $\Delta$ y en el doble rho2 $\Delta$ pck2 $\Delta$, Pmk1 responde (aunque con menor intensidad) a los tratamientos con calcoflúor, cafeína, vanadato sódico y ayuno de glucosa. Frente a los tratamientos con DEM y Paraquat la activación de Pmk1 cae sensiblemente en el mutante rho2 $\Delta$ y drásticamente en $p c k 2 \Delta$. Con la exposición a alta temperatura Pmk1 se activa de forma normal en rho2 $\Delta$ pero no responde en el mutante pck2 $\Delta$ (Barba et al. 2008).

- Rgf1 es necesaria para la activación de Pmk1 frente a $\mathrm{KCl}$, sorbitol, estrés hipotónico y caspofungina, pero no afecta a la activación de Pmkı cuando el estrés es la temperatura o el ayuno de glucosa. Además, la sobreexpresión de Rho1 aumenta los niveles de fosforilación de Pmk1 a través de una vía dependiente de Pck2 (García et al. 2009b).

- El mutante termosensible rho1-596 presenta un nivel de basal de fosforilación de Pmk1 más alto que la cepa silvestre, que se suprime al delecionar a $r h o 2^{+}$o $p c k 2^{+}$. No presenta cambios en la fosforilación de Pmk1 ante $\mathrm{KCl}, \mathrm{H}_{2} \mathrm{O}_{2}$ y estrés hipotónico. Es posible que en este mutante la activación constitutiva de Pmk1 sea causada por los defectos en la pared celular señalizados vía Rho2 y Pck2 (Viana et al. 2013). 
- La activación de Pmk1 frente $\mathrm{H}_{2} \mathrm{O}_{2}$ y caspofungina es parcialmente dependiente de Rho2. En el doble mutante rho2 $\Delta$ rho1-596 los niveles de fosforilación de Pmk1 son similares a los del mutante sencillo rho2 $\Delta$ en presencia de $\mathrm{H}_{2} \mathrm{O}_{2}$, pero más bajos en respuesta a caspofungina, poniendo de manifiesto el papel de Rho1 junto a Rho2 en la activación de la ruta CIP en respuesta a daño en la pared (Sánchez-Mir et al. 2014).

- El mutante pck1 $\Delta$ presenta niveles de fosforilación de Pmk1 basales más elevados que la cepa silvestre. Este aumento se reduce al delecionar rho2 $2^{+}$y todavía más con la mutación adicional de rho1 ${ }^{+}$. Además, la hiperactivación de Pmk1 por la sobreexpresión de Rho1 se atenúa en $p c k 1 \Delta$ aunque no tanto como en $p c k 2 \Delta$ (Sánchez-Mir et al. 2014).

- Frente a caspofungina la fosforilación de Pmk1 baja ligeramente en el mutante pck1 $\Delta$, aunque no tanto como en pck $2 \Delta$ o rho2 $\Delta$. Esta menor fosforilación debida a la ausencia de $p c k 1^{+}$disminuye todavía más en los mutantes pck1 $\Delta$ rho2 $\Delta$ y pck1 $\Delta$ rho1-596, y se suprime totalmente en el triple mutante pck1 $\Delta$ rho1-596 rho2 $\Delta$ (Sánchez-Mir et al. 2014). Estos datos indican que Pck1 también juega un papel, aunque más discreto que Pck2, en la respuesta a daños en la pared celular.

- La activación de la ruta CIP ante la limitación de glucosa depende de Pck2 pero opera a través de un mecanismo independiente de la actividad de Rho1 y Rho2 (Madrid et al. 2013). Tanto en este caso como en el daño en la pared celular existe un mecanismo en el que participan los complejos de la ruta TOR (Target of Rapamycin). Estos complejos actúan incrementando los niveles de Pck1 y Pck2, lo que favorecería la activación de la ruta CIP. Se ha visto que un activador del complejo TORC2, la GTPasa Rhy1 de la familia Rab, promueve la activación de Pmk1 a través del tráfico y estabilización de Ksg1 y Rgf1 (Madrid et al. 2015, 2016, 2017).

- Pmk1 presenta una fosforilación en condiciones normales que depende del ciclo celular, aumenta en fase M y llega al máximo en citoquinesis. La regulación precisa de esta fosforilación cíclica depende de la fosfatasa Pmp1 (Madrid et al. 2007) y es independiente de Rho2 y de Pck2 (Barba et al. 2008). Aunque no se conoce el papel de Pmk1 en ausencia de estrés, esto explicaría por qué las células pmk1 $\Delta$ y pmp1 $\Delta$ tienen fallos en separación celular, que a largo plazo se traducen en fenotipos de multiseptación (Madrid et al. 2007).

\section{Efectores y reguladores negativos}

Se conocen pocos efectores de la ruta CIP en S. pombe. En S. cerevisiae esta ruta responde regulando la síntesis de polisacáridos de pared así como su transporte polarizado, sin embargo en S. pombe no se ha encontrado un papel similar (Perez et al. 2018). En S. pombe, Pmk1 fosforila al factor de transcripción Atf1, uno de los principales efectores de la ruta de respuesta a estrés SAPK, en respuesta a estrés en la pared celular (Takada et al. 2007). Pmk1 también refuerza la 


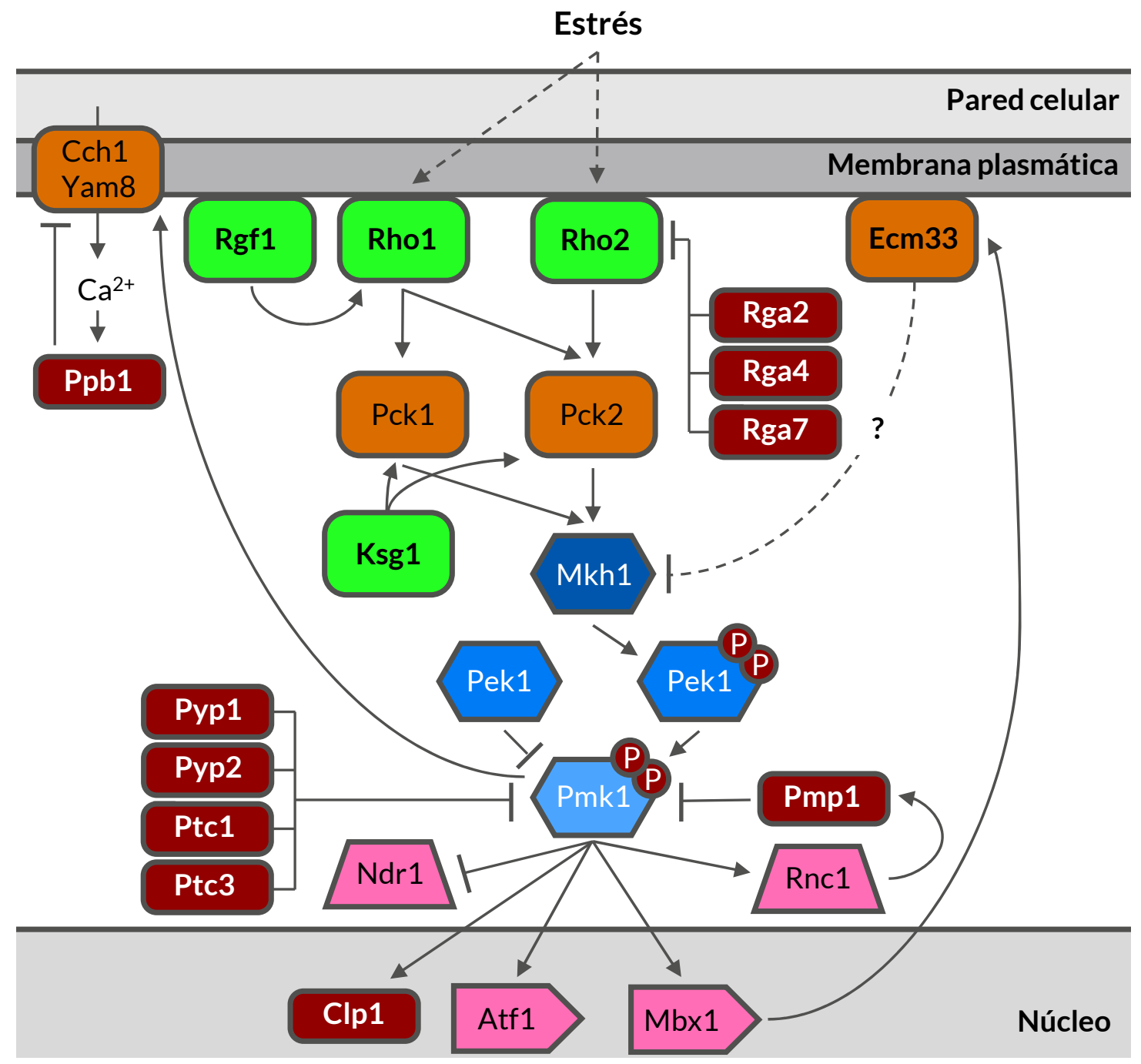

Figura 24 Modelo de la ruta de MAPK de integridad celular CIP, sus activadores, efectores y reguladores. Adaptado de (Perez et al. 2018).

respuesta de la ruta SAPK a través de Atf1 en condiciones de estrés producido por la privación de glucosa (Madrid et al. 2013) y frente a estrés oxidativo (Zhou et al. 2012). Otro factor de transcripción, Mbx1, también tiene un papel en el mantenimiento de la integridad celular de forma dependiente de Pmk1. En este caso es a través de la regulación de Ecm33, una proteína de la superficie celular anclada a glicosilfosfatidilinositol (GPI), que se localiza en los polos de crecimiento y en el septo (Fang et al. 2014) y que establece un feedback de regulación negativa sobre la ruta CIP (Takada et al. 2010) (Figura 24).

En su estado activo Pmk1 fosforila a dos proteínas de unión a RNA, Nrd1 y Rnc1. Nrd1 estabiliza el mRNA de $c d 4_{4}{ }^{+}$, la cadena ligera de la miosina II. Al fosforilar a Nrd1, Pmk1 bloquea su unión con este mRNA, promoviendo su desestabilización (Satoh et al. 2009). Rnc1 fosforilado por Pmk1 estabiliza el mRNA de pmp1 $^{+}$, la fosfatasa dual específica de Pmk1 y principal regulador 
negativo (Sugiura et al. 1998), estableciendo un mecanismo de retroalimentación negativa sobre la ruta CIP (Sugiura et al. 2003).

Además de Pmp1 otras fosfatasas también tienen capacidad de unirse y desfosforilar a Pmk1 in vivo, es el caso de Pyp1, Pyp2 y Ptc1. Estas tres fosfatasas, que son efectores de la ruta SAPK (su activación transcripcional depende de Sty1 y Atf1), desfosforilan a Pmk1 en respuesta a estrés osmótico, mientras que Pyp1, Ptc1 y Pmp1 controlan los niveles basales de fosforilación de Pmk1 durante el crecimiento vegetativo (Madrid et al. 2007). También se ha descrito que Ptc3 modula junto con Ptc1 la fosforilación de Pmk1 (Takada et al. 2007). Como hemos visto en el apartado anterior, Pmp1 juega un papel importante en el control de Pmk1 durante la separación celular, pues su ausencia produce un fenotipo de multiseptación similar al de la disrupción de Pmk1 (Sugiura et al. 1998; Madrid et al. 2007).

En presencia de estrés salino ( $\mathrm{NaCl}, \mathrm{KCl}$ o $\mathrm{MgCl}$ ) Pmk1 fosforila a Cch1. Cch1 es la subunidad catalítica de un canal de $\mathrm{Ca}^{2+}$ del que también forma parte la subunidad Yam8, clonada en nuestro laboratorio como el mutante ehs1-1 (echinocandin hypersensitive 1) (Carnero et al. 2000). La fosforilación de Cch1 induce la apertura del canal y la entrada de $\mathrm{Ca}^{2+}$ en la célula, lo que promueve la activación de la calcineurina Ppb1, una fosfatasa dependiente de calcio. Ppb1 desfosforila a Cch1 inhibiendo la entrada de más $\mathrm{Ca}^{2+}$. La ausencia de actividad Ppb1 por su deleción o mediante su inactivación con el inhibidor FK506 ocasiona hipersensibilidad a estrés salino en las células, que es suprimida por la deleción de los componentes de la ruta CIP, lo que se conoce como fenotipo vic (viable in the presence of immunosuppressant and chlorine ion) (Ma et al. 2011).

Por último, también se ha descrito que Pmk1 fosforila a la fosfatasa Clp1, induciendo junto a Cdk1 su liberación del nucleolo en presencia de estrés oxidativo mediado por $\mathrm{H}_{2} \mathrm{O}_{2}$ (Broadus \& Gould 2012).

\section{Ruta de respuesta a estrés, SAPK}

La ruta de MAPK de respuesta a estrés (SAPK) es crítica para la supervivencia de S. pombe cuando se enfrenta a una amplia variedad de situaciones que condicionan la homeostasis de la levadura. Por ello los mutantes de los componentes de esta ruta son sensibles o hipersensibles a la presencia de estrés hiperosmótico, metales pesados, temperaturas altas y bajas, radiación UV, aumento de la presión osmótica y estrés oxidativo (Warbrick \& Fantes 1991; Millar et al. 1995; Shiozaki \& Russell 1995; Soto et al. 2002; George et al. 2007). Estos mutantes también presentan defectos en la transición G2/M, que se traducen en morfología alargada, pérdida de viabilidad al entrar en fase estacionaria y fallos en la diferenciación sexual ante la limitación de nitrógeno (Shiozaki \& Russell 1995; Wilkinson et al. 1996). 
El módulo de MAP kinasas de la ruta SAPK comienza con dos MAPKKK, Wis4 (también conocida como Wak1 o Wik1) y Win1. El regulador de respuesta Mcs4 transmite la señal de estrés uniéndose y activando a Wis4 y a Win1, y es necesario para la activación de la ruta en respuesta todos los estreses (Buck et al. 2001; Soto et al. 2002). Por otra parte, las dos MAPKKK no se comportan de la misma forma ante todos los tipos de estrés; en algunos casos son redundantes pero en otros son necesarias ambas o domina una de ellas (Shiozaki et al. 1998; Quinn et al. 2002; Soto et al. 2002). Wis4 y Win1 fosforilan y activan a la MAPKK Wis1, con la excepción de la respuesta frente a estrés térmico o en presencia de arsenito (Nguyen \& Shiozaki 1999; Rodríguez-Gabriel \& Russell 2005). En el resto de estreses Wis1 activa a la MAPK Sty1 en el citoplasma e induce su translocación al núcleo (Gaits et al. 1998; Nguyen et al. 2002) (Figura 25).

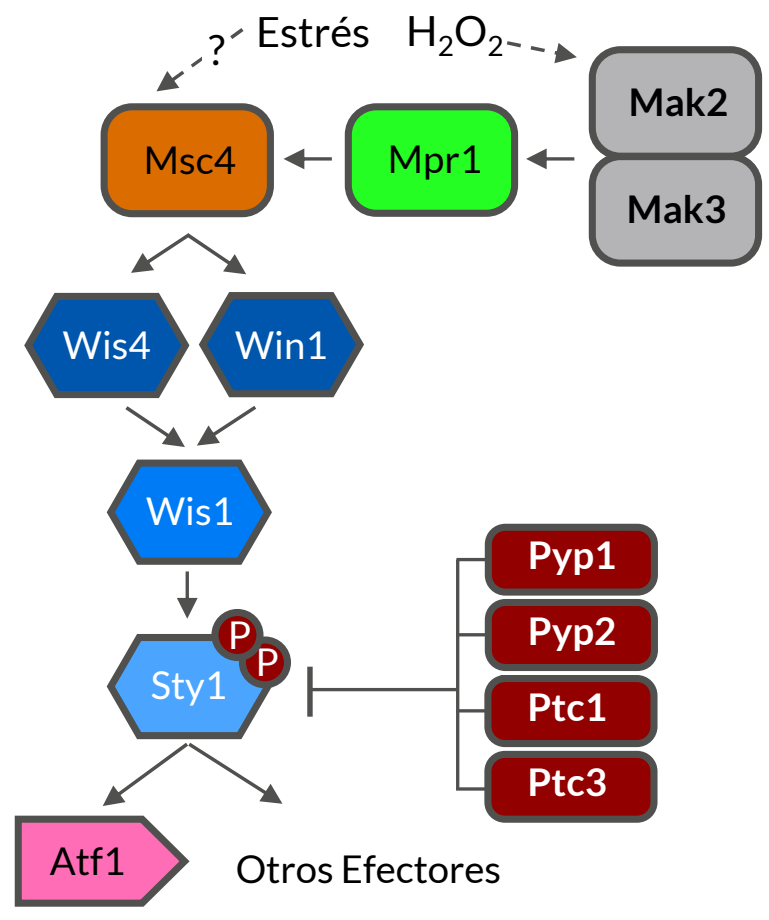

Figura 25 Modelo resumido de la ruta de MAPK de respuesta a estrés SAPK. Adaptado de (Perez et al. 2019).

Se sabe poco acerca de los sensores que detectan los daños que activan la ruta SAPK. El único mecanismo de activación conocido es el que concierne a la respuesta ante estrés oxidativo causado por el peróxido de hidrógeno. En este caso se activa un sistema fosfotransferasa compuesto por dos sensores histidín kinasa, Mak2 y Mak3, que se autofosforilan y que, por medio del transmisor Mpr1 (Spy1), transfieren el grupo fosfato al regulador de respuesta Mcs4, quien activa a la cascada de MAPK (Papadakis \& Workman 2015). Además, Mcs4 es necesario para activar a Sty1 en respuesta a cualquier tipo de estés, aunque los sensores de estos otros estreses son desconocidos (Perez et al. 2019).

De entre los efectores de Sty1, Atf1 es el factor de transcripción que mejor se conoce. La activación de la ruta de MAPK promueve la translocación de Sty1 al núcleo donde fosforila a Atf1 (Shiozaki \& Russell 1996), lo que permite su interacción con la maquinaria transcripcional (Salat-Canela et al. 2017). Atf1 induce la expresión de un grupo de genes que cooperarán en la respuesta celular al estrés, incluyendo los genes del grupo CESR (core environmental stress response) (Chen et al. 2003). Sty1 también controla la expresión génica a través de otros efectores como proteínas de unión a RNA (Csx1, Cip1, Cip2 y Upf1) y factores de regulación de la traducción 
(eEF2, eIF2 $\alpha$ y eIF3a) (Perez et al. 2019). Otros efectores de Sty1 actúan como reguladores de la entrada en mitosis (Srk1, Plo1 y Cdr1) (Opalko \& Moseley 2017; Perez et al. 2019).

Las tirosina fosfatasas Pyp1 y Pyp2 regulan negativamente a Sty1 desfosforilándola conjuntamente en situaciones de estrés, mientras que Pyp1 inhibe a Sty1 durante el crecimiento vegetativo en ausencia de estrés (Opalko \& Moseley 2017). Las serina/treonina fosfatasas Ptc1 y Ptc3 recuperan los niveles basales de fosforilación de Sty1 tras su activación por choque térmico (Nguyen \& Shiozaki 1999). Sty1 junto a Atf1 induce la expresión de estas fosfatasas, estableciendo así un mecanismo de retroalimentación negativa que se encarga de amortiguar la señalización como parte de la respuesta al estrés (Degols et al. 1996; Wilkinson et al. 1996). 



\section{2}

\section{OBJETIVOS}

Los GEFs de la familia Rho son proteínas clave en la citoquinesis desde mamíferos a levaduras. Sin embargo, en S. pombe su papel en la biosíntesis de la pared celular ha enmascarado su función en etapas más tempranas, como el ensamblaje y contracción del anillo de actomiosina y la invaginación de la membrana.

Entre los GEFs de Rho1, solo se conoce parcialmente la función de Rgf3 en citoquinesis. Rgf1 y Rgf2 también se localizan en la zona de división y entre los dos desempeñan una función esencial. Para determinar si esta función esencial era la citoquinesis obtuvimos un mutante termosensible $r g f_{1}-\Delta 45 \mathrm{rgf} 2 \Delta$ y vimos que el principal defecto del mutante se manifiesta durante el crecimiento polarizado y no durante la separación celular. Aun así, nos pareció interesante estudiar el papel de Rgf1 en la división celular.

A continuación, se describen los objetivos que nos propusimos al iniciar este trabajo:

- Analizar la localización de Rgf1 durante la citoquinesis.

- Estudiar la relación de Rgfi con componentes del anillo contráctil y la ruta de inicio de septación.

- Buscar fenotipos relacionados con defectos en citoquinesis en el mutante $\operatorname{rgf}_{1} \triangle$. 



\section{RESULTADOS}

\section{RGF1 SE LOCALIZA JUNTO AL ANILLO CONTRÁCTIL DE ACTOMIOSINA}

Rgf1 se localiza en interfase en los polos de crecimiento de S. pombe, pasando de un único polo tras la división celular a ambos después de que tenga lugar la transición a crecimiento bipolar (NETO). Durante la división celular cesa el crecimiento por los polos y la maquinaria de síntesis de la pared se relocaliza a la zona media de la célula para formar el septo. En este momento Rgf1 desaparece de los polos y aparece concentrado en la zona de septación, en forma de un disco transversal que colocaliza con la señal del septo teñido por blankophor (García et al. 2006b; a).

En ocasiones se puede observar esta estructura resuelta como dos discos paralelos separados por lo que sería el propio septo, presumiblemente localizados en la nueva membrana fruto de la citoquinesis (Figura 26).

Para conocer la dinámica concreta de los cambios de localización de Rgf1 durante la citoquinesis y establecer su cronología con respecto a la mitosis realizamos el seguimiento de la fluorescencia de Rgf1-GFP en el tiempo mediante microscopía en time-lapse. A la vez que visualizamos la fluorescencia de Rgf1 en el canal verde tomamos fotografías de marcadores fluorescentes en otros canales de emisión (rojo y cian) para seguir los eventos mitóticos y de citoquinesis. Utilizamos Sad1-DsRed,

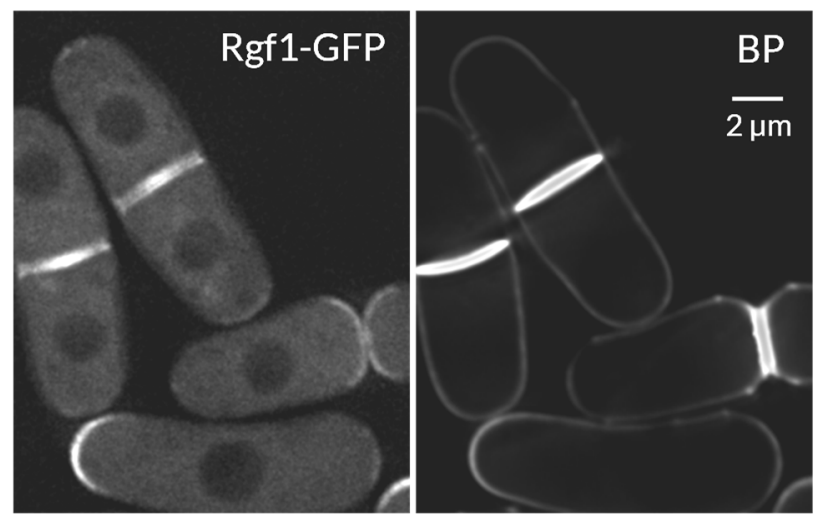

Figura 26 Rgf1 se localiza en la zona de división además de en los polos de la célula. Imagen de fluorescencia en DeltaVision de Rgf1-GFP teñidas con BP para marcar el septo. 
proteína asociada al SPB, como marcador de la progresión mitótica (Hagan \& Yanagida 1995). Este marcador nos permite diferenciar las distintas etapas de la mitosis en base a la distancia que separa a los dos SPBs, además de la propia segregación de los SBP al comienzo de la mitosis que utilizamos como tiempo o en las reconstrucciones fotográficas (Nabeshima et al. 1998).

El componente regulador de la cadena ligera de la miosina Rlc1-tdTomato nos sirve como marcador de las etapas del desarrollo del anillo de actomiosina (CAR), pues es uno de los componentes tempranos del anillo (aparece en los nodos) y permanece formando esta estructura hasta el final de la constricción (Wu et al. 2003). Por último, utilizamos el blankophor (BP, también llamado calcoflúor o fluorescent brighterner), colorante fluorescente que se une al $\beta$-glucano en S. pombe (Cortés et al. 2007), y nos sirve para identificar el inicio de la síntesis del septo y seguir su progresión (Ribas \& Cortés 2016).

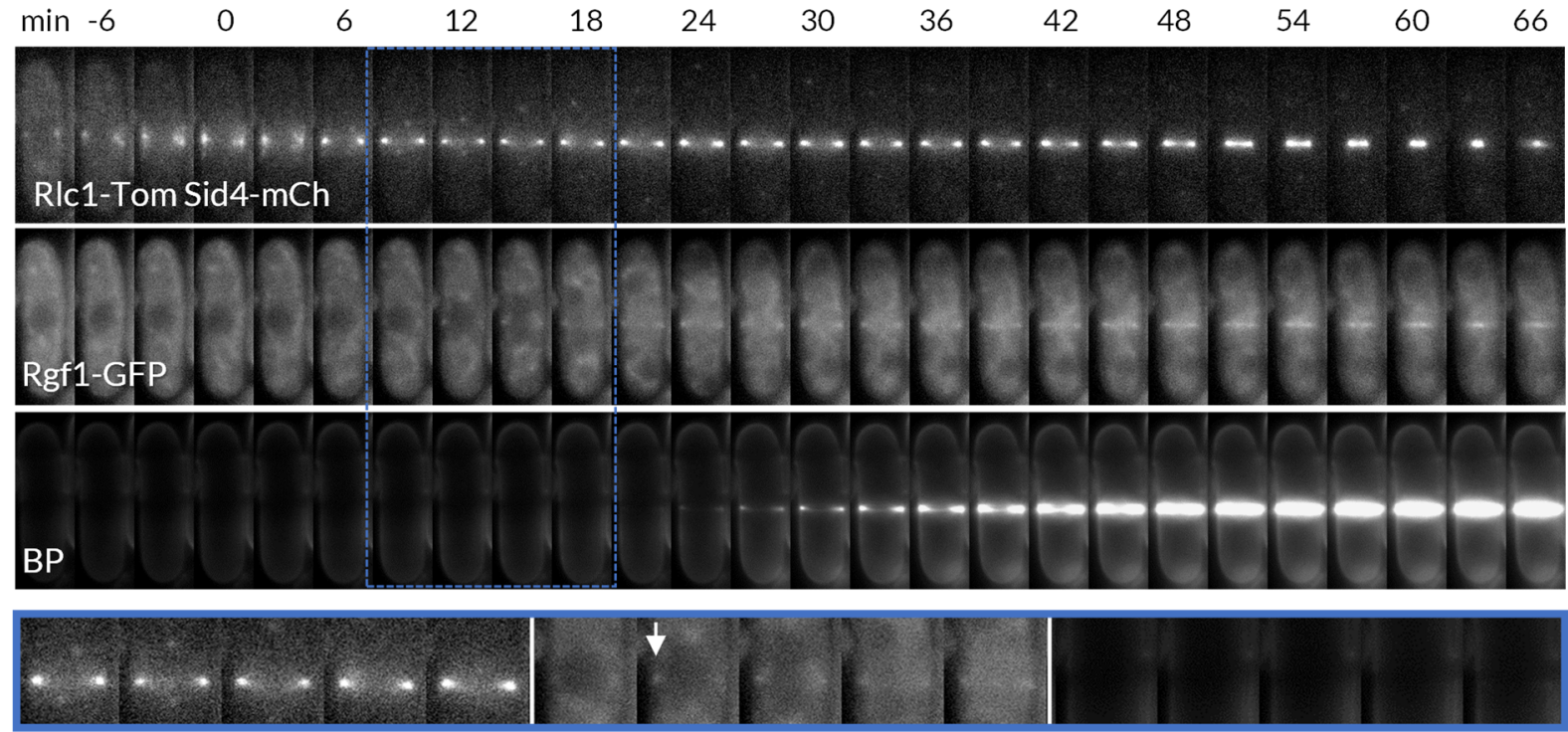

Figura 27 Rgf1 llega a la zona de división en la fase de maduración del anillo. Imágenes de time-lapse en DeltaVision de células marcadas con Rlc1-tdTomato, Sid4-mCherry, Rgf1-GFP y teñidas con BP. Fotografías tomadas cada 3 minutos. Debajo se muestra una ampliación del intervalo señalizado en azul (918 min). La flecha señala la aparición de Rgf1.

Rgf1-GFP aparece en la zona de división hacia el final de anafase A, cuando los SPBs se han separado, pero todavía se encuentran próximos a la zona media de la célula (Figura 27, recuadro azul). En este punto el anillo de actomiosina ya presenta una estructura anular definida con una señal de fluorescencia homogénea, lo que indica que ha concluido la coalescencia de los nodos y con ello la fase de formación. En el momento en el que se detecta, Rgf1 se localiza junto con Rlc1 en una estructura anular (Figura 27). Además, en este instante el anillo de actomiosina marcado por Rlc1-tdTomato se encuentra en su diámetro máximo y permanece así varios minutos antes 
de iniciar la constricción. Estos resultados indican que Rgf1 llega a la zona de división cuando el anillo se encuentra en la fase de maduración. En esta etapa desaparece Mid1 y aparecen las proteínas con motivo F-BAR (Imp2, Pxl1, Fic1) (Roberts-Galbraith et al. 2009), la tropomiosina (Skau \& Kovar 2010), la miosina no-convencional Myp2 (Laplante et al. 2015) y la $\beta$-glucán sintasa Bgs1 (Goss et al. 2014) entre otras.

La señal de blankophor en la zona del septo es indetectable hasta minutos después de la llegada de Rgf1 (Figura 27), por lo que pensamos que Rgf1 es reclutada a la zona de división antes de que se inicie la septación. Durante la constricción Rgf1 progresa con el anillo y se invagina hacia el interior celular. Sin embargo, en esta etapa en la que se aprecia cómo el anillo sufre una disminución progresiva de su diámetro, Rgf1 presenta un comportamiento diferente. Su señal de fluorescencia, originalmente como un anillo en la periferia celular, va extendiéndose hacia el centro de la célula en un avance que acompaña al de la constricción del anillo. La dinámica de localización de Rgf1 se asemeja pues más a la del septo o la membrana, la formación centrípeta de un disco (Figura 26), que a la del anillo contráctil, aunque estos tres procesos progresan a la vez.

Recientemente hemos podido fotografiar estas mismas células utilizando microscopía óptica de superresolución (Figura 28). Las imágenes muestran en detalle cómo Rgf1-GFP se localiza en forma de invaginaciones desde la periferia celular que no pueden ser otra cosa más que la membrana plasmática, ya que, como reflejan los line-scan, su señal no colocaliza con el anillo de Rlc1.
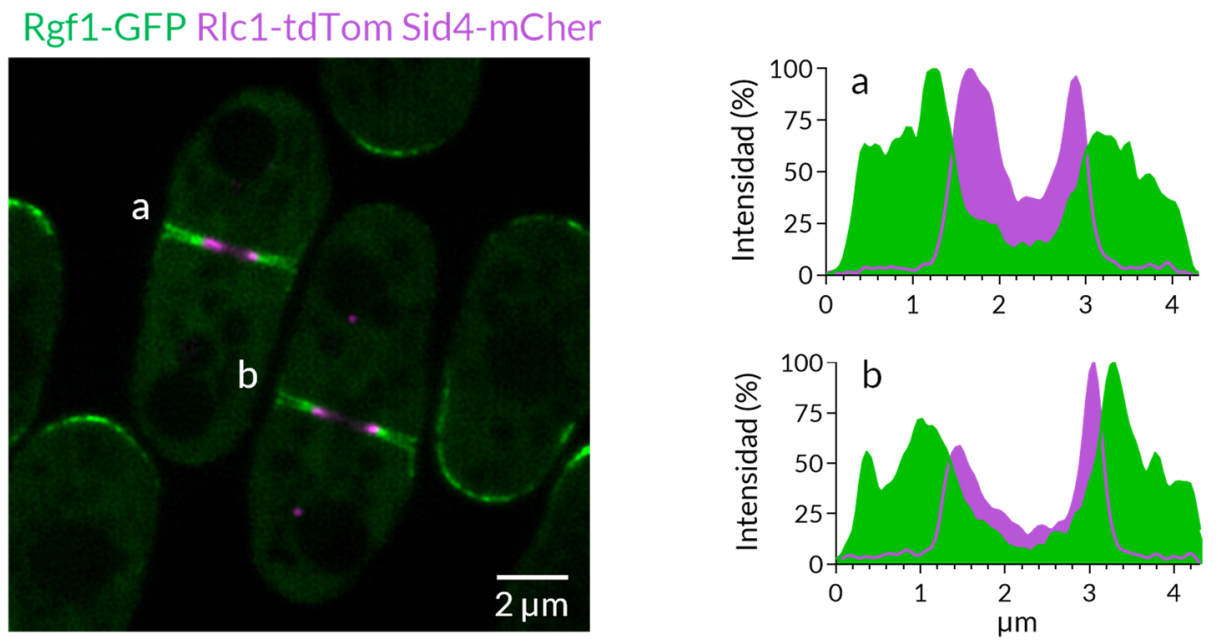

Figura 28 Localización en detalle de Rgf1. Imagen de superresolución en Olympus IX71 de células marcadas con Rgf1-GFP, Rlc1-tdTomato y Sid4-mCherry. Derecha, line-scan de la intensidad de fluorescencia de Rgf1-GFP y Rlc1-tdTomato a lo largo de los anillos de la imagen. 


\section{LA LOCALIZACIÓN DE RGF1 EN EL SEPTO DEPENDE DE SU INTERACCIÓN CON LOS COMPONENTES DEL CAR}

Puesto que la relocalización de Rgf1 en la proximidad del anillo se produce una vez que este se ha formado, nos preguntamos si su reclutamiento era dependiente del estado del anillo. Para ello examinamos la localización de Rgf1-GFP en distintos mutantes termosensibles con defectos en la formación o mantenimiento del anillo de actomiosina. Entre los mutantes utilizados están cdc15-140, cdc3-6, cdc11-119 y sid2-250 (Nurse et al. 1976; Balasubramanian et al. 1994, 1998; Fankhauser et al.1995). En estos experimentos, cultivos de células mutantes y de la cepa silvestre que expresan de manera endógena Rgf1-GFP, se incubaron a $25^{\circ} \mathrm{C}$ hasta alcanzar la fase exponencial y se pasaron a $36^{\circ} \mathrm{C}$ (temperatura restrictiva) $3 \mathrm{~h}$ antes de tomar las fotografías. También se realizó una tinción con BP en el momento para visualizar el septo.

$36^{\circ} \mathrm{C}$

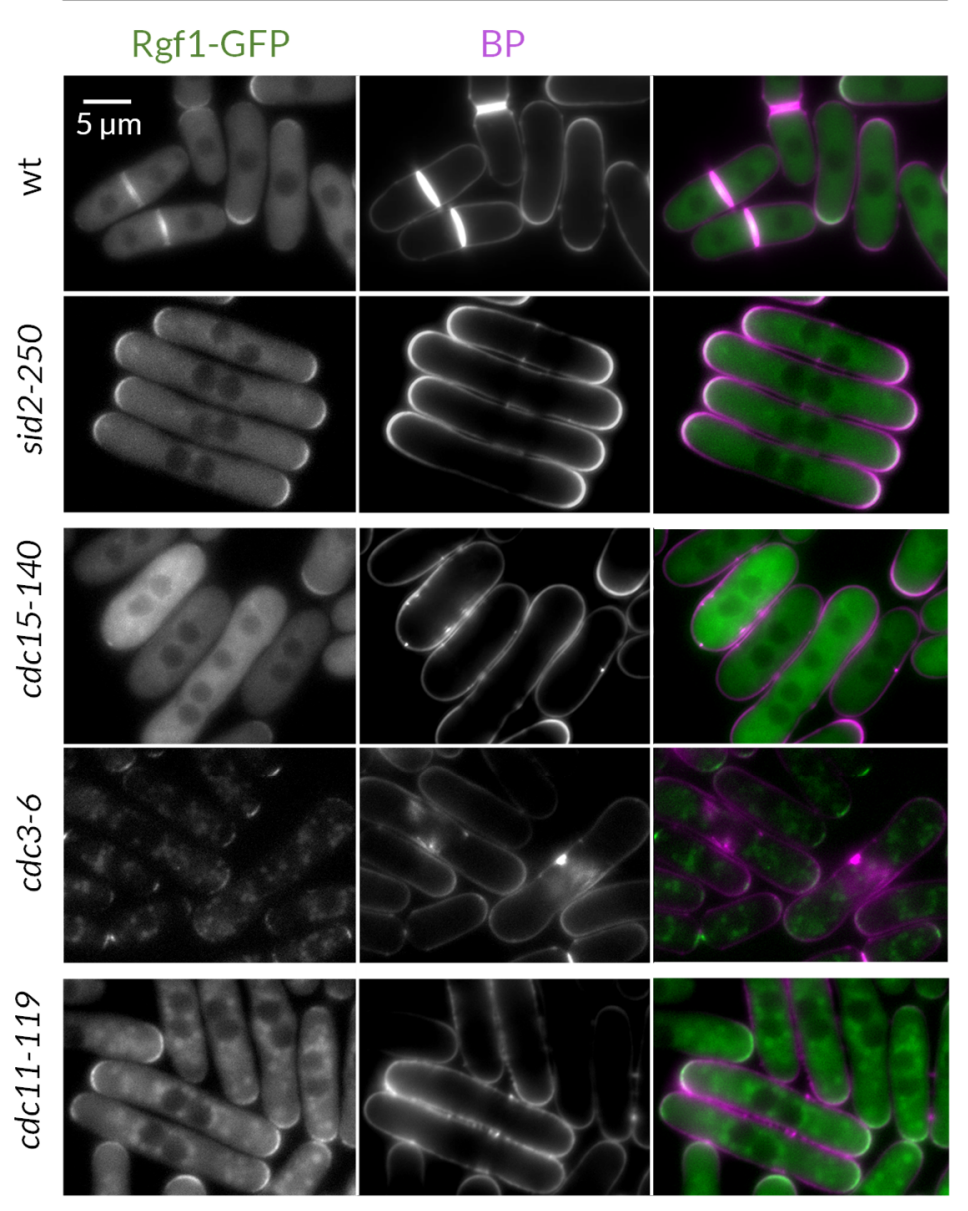

$25^{\circ} \mathrm{C}$
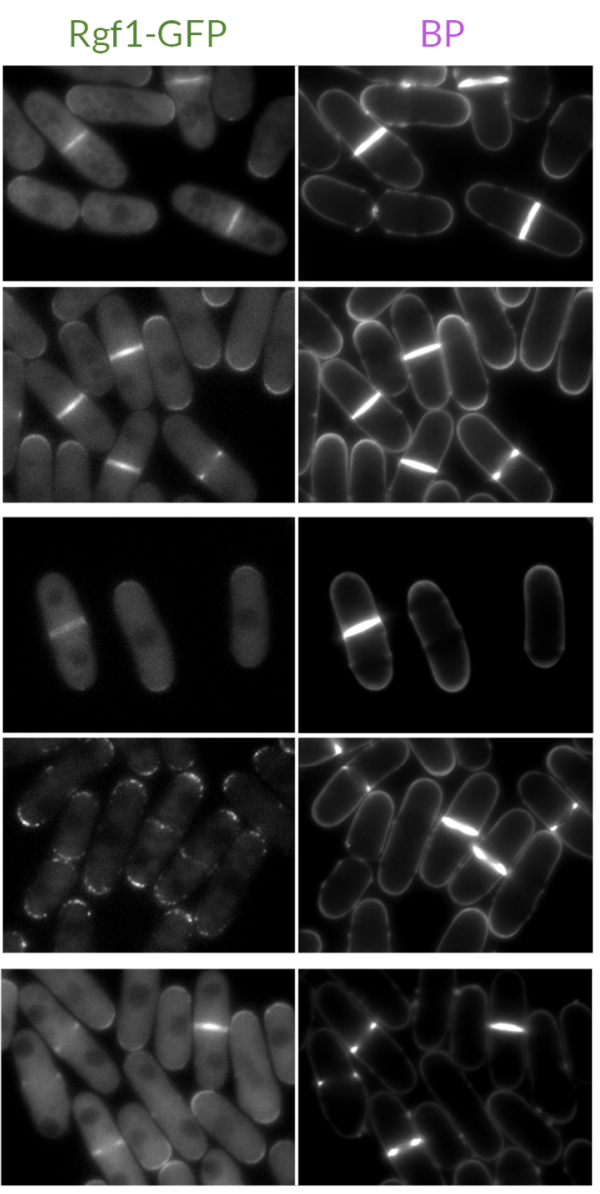

Figura 29 La localización de Rgf1 en la zona de división se ve afectada en mutantes defectivos en la formación del CAR. Imágenes de fluorescencia en DeltaVision de Rgf1-GFP y BP. Las células de las cepas indicadas fueron crecidas a $25^{\circ} \mathrm{C}$ (panel derecho) y después pasadas $3 \mathrm{~h}$ a $36^{\circ} \mathrm{C}$ (panel izquierdo). 
En la cepa silvestre a $36^{\circ} \mathrm{C}$, Rgf1-GFP se localiza en la zona del septo (marcada por la señal de $\mathrm{BP}$ ), sin embargo, en ninguno de los mutantes es posible detectar Rgf1 en la misma zona (Figura 29). En las condiciones del experimento $\left(36^{\circ} \mathrm{C}\right)$, estos mutantes son incapaces de formar o mantener el CAR, por lo que tampoco pueden generar septos más allá de alguna marca de BP en la periferia, señal de una septación abortiva (Gould \& Simanis 1997; Balasubramanian et al. 1998).

Curiosamente, en el mutante cdc3-6 la señal de Rgf1-GFP en los polos de la célula se ve como puntos discretos en lugar de una banda uniforme (Figura 29). Esta distribución aparece tanto a $25^{\circ} \mathrm{C}$ como a $36^{\circ} \mathrm{C}$, aunque en este caso se aprecia peor, y podría estar relacionada con el mecanismo de unión de Rgf1 a la actina en los polos.

Aunque en la mayoría de estas las células Rgf1 está ausente de la zona de división, hay un pequeño porcentaje en las que todavía observamos dicha señal (Figura 30, triángulos). Examinamos el origen de estas excepciones a través del marcador Rlc1-tdTomato, que nos permite observar el estado del CAR junto a Rgf1-GFP.

En condiciones restrictivas $\left(36^{\circ} \mathrm{C}\right)$ sobre los fondos mutantes cdc15-140 y cdc11-119 vemos ahora con el doble marcaje fluorescente cómo esa señal infrecuente de Rgf1-GFP en la zona media de la célula se corresponde con puntos en los que todavía se ve señal de Rlc1-tdTomato (Figura 30). Esta señal de Rlc1 es de uno o pocos puntos discretos de baja intensidad, probablemente partes de anillos no formados o restos de anillos disueltos fruto de la pérdida de actividad propia de estos mutantes. Por tanto, para que Rgf1 se localice en la zona de división de la célula es necesario que previamente exista un CAR estable.
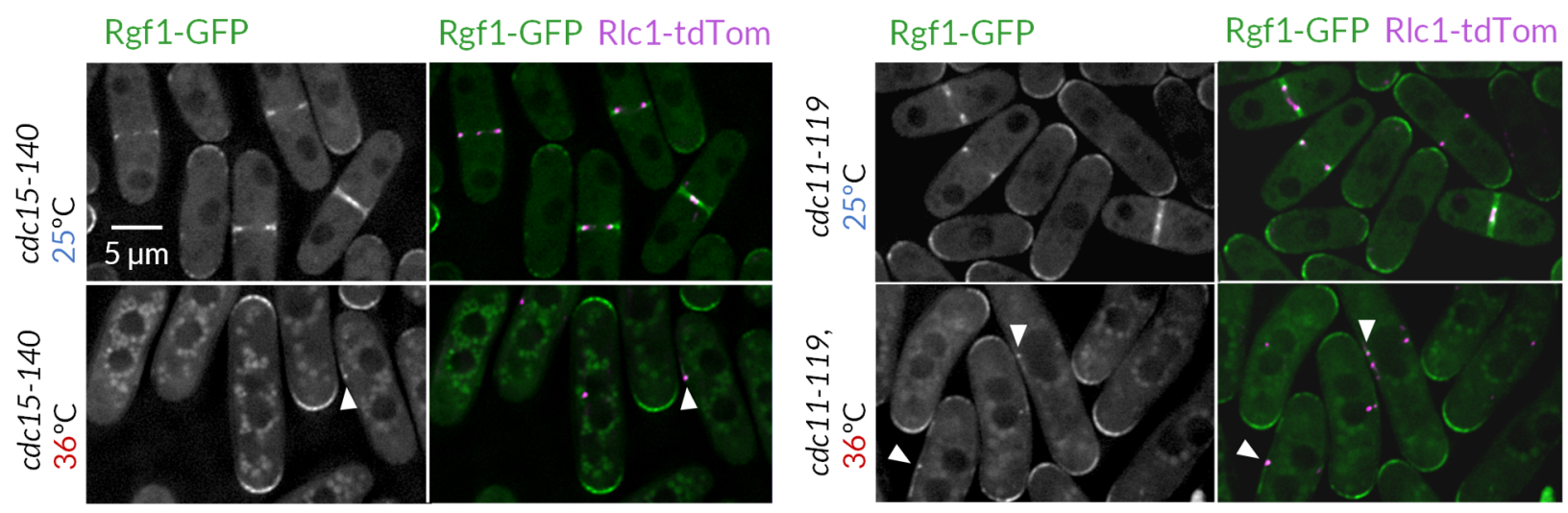

Figura 30 Rgf1 requiere la presencia del CAR para localizarse en la zona de división. Imágenes de fluorescencia de células $c d c 15-140$ y cdc11-119 que expresan Rgf1-GFP y Rlc1-tdTotamo a $25^{\circ} \mathrm{C}$ y $3 \mathrm{~h}$ a $36^{\circ} \mathrm{C}$, tomadas en DeltaVision. Los triángulos señalan puntos donde Rgf1-GFP permanece en la zona media y sus respectivas señales de Rlc1-tdTomato. 
A continuación, analizamos las interacciones genéticas entre Rgf1 y las proteínas que forman el CAR. En primer lugar, obtuvimos cepas que llevan la deleción de Rgf1 junto con mutaciones o deleciones en genes de los componentes del CAR y después examinamos su capacidad de crecimiento a distintas temperaturas en ensayos de gota. Los datos obtenidos se muestran en la Figura 31. Aunque crecen un poco peor, no hay una diferencia grande en el crecimiento de los mutantes $r_{f f} \Delta c_{1} c_{4}-8$ y rgf1 $\Delta$ rlc1 $\Delta$ comparados con los mutantes simples de las miosinas $c d c 4-8$ y rlc1 $\Delta$. Sin embargo, vimos una interacción fuerte entre el mutante $r g f 1 \Delta y$ los mutantes $c d c 15-140$ e imp2 $\Delta$ (mutantes en las proteínas BAR, Cdc15 e Imp2), que son componentes estructurales del CAR, también con el mutante cdc12-112 (mutante de la formina Cdc12). Así, mientras los mutantes sencillos son capaces de formar colonias (entre $30^{\circ} \mathrm{C} \mathrm{y} 32^{\circ} \mathrm{C}$ ), los dobles mutantes que carecen de Rgf1 son inviables. Estos resultados sugieren que Rgf1 podría colaborar con proteínas citoquinéticas para que la división celular se desarrolle correctamente.

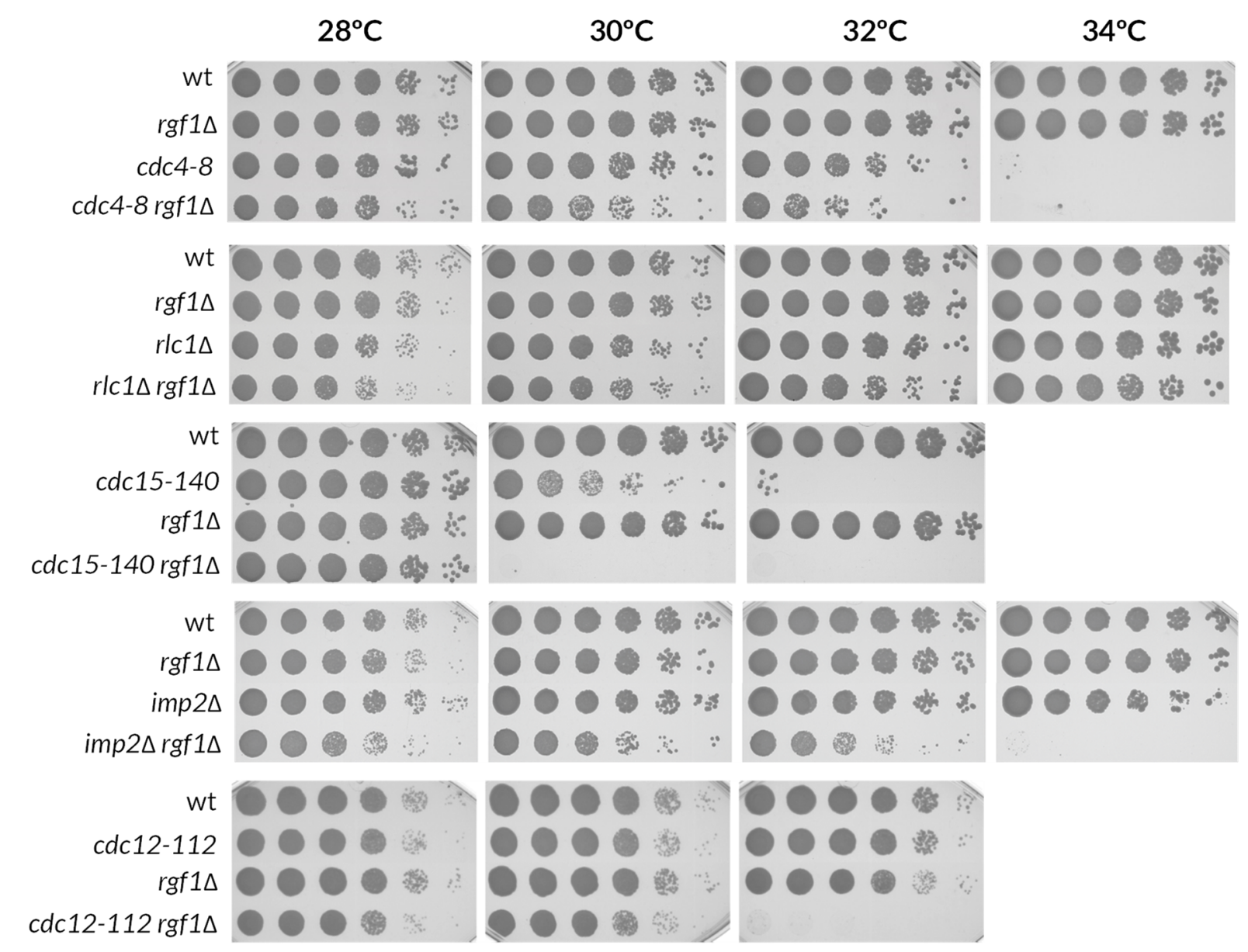

Figura 31 Rgf1 presenta interacciones genéticas con componentes del CAR. Ensayos de viabilidad con diluciones seriadas 1:5 de las cepas indicadas crecidas a $25^{\circ} \mathrm{C}$. En todos los casos la D.O inicial fue de 2.0. 
Tras ver que localización de Rgf1 depende del CAR, examinamos el carácter de esta asociación utilizando el mutante de la $\beta$-tubulina nda3-KM311. Este mutante es "sensible al frío" y presenta defectos en la formación del huso mitótico cuando se mantiene a $18^{\circ} \mathrm{C}$; las células se bloquean en prometafase por su incapacidad de continuar la mitosis en ausencia de esta estructura (Hiraoka et al. 1984).

Al analizar la localización de Rgf1-GFP en las células bloqueadas (Figura 32), vimos que se acumulaba en la región media en un $\sim 50 \%$ de las células del cultivo, formando una especie de corsé. Esta localización va acompañada de una leve o nula señal de invaginación del BP, indicando una parada en el mismo comienzo de la septación o previa a este, respectivamente. Este resultado confirma que Rgf1 se localiza en la zona del CAR antes del inicio de la septación.

En algunas células nda3-KM311 bloqueadas también se ve señal de Rgf1-GFP en uno de los polos a la vez que en la zona del CAR (Figura 32). Es posible que éstas sean células que intentan iniciar el crecimiento polarizado tras el prolongado bloqueo mitótico. Esto concuerda con la presencia de Rgf1 en los polos de los mutantes con defectos en la formación del CAR (Figura 30). A la temperatura restrictiva, estas células post-mitóticas que no septan, reanudan el crecimiento y relocalizan a Rgf1 en los polos.

También nos llamó la atención el patrón que presenta la señal de Rgf1-GFP durante el bloqueo mitótico. En este caso la señal no se mantiene como una estructura anular definida (Figura 32). Esto podría ser debido a la asociación de Rgf1 a la membrana más que al propio anillo, difundiendo sobre la misma cuando la citoquinesis está bloqueada. Esta localización de Rgf1 en forma de corsé recuerda a la localización
nda3-KM311 $18^{\circ} \mathrm{C}$

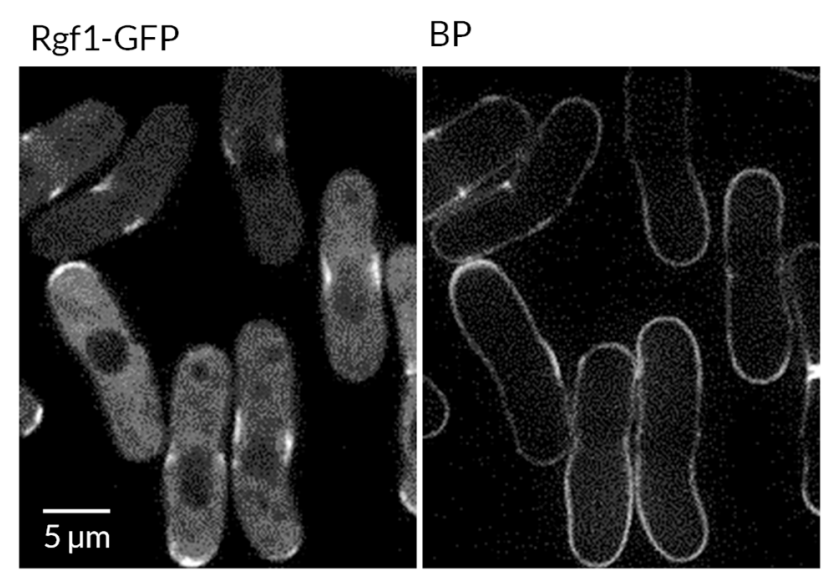

Figura 32 Rgf1 está presente en la región media durante un bloqueo mitótico en prometafase. Las células del mutante nda3-KM311 que expresan Rgf1GFP se crecieron a $32^{\circ} \mathrm{C}$ y después se incubaron $8 \mathrm{~h}$ a $18^{\circ} \mathrm{C}$ para inducir el bloqueo. Justo antes de tomar las imágenes de fluorescencia se añadió BP.

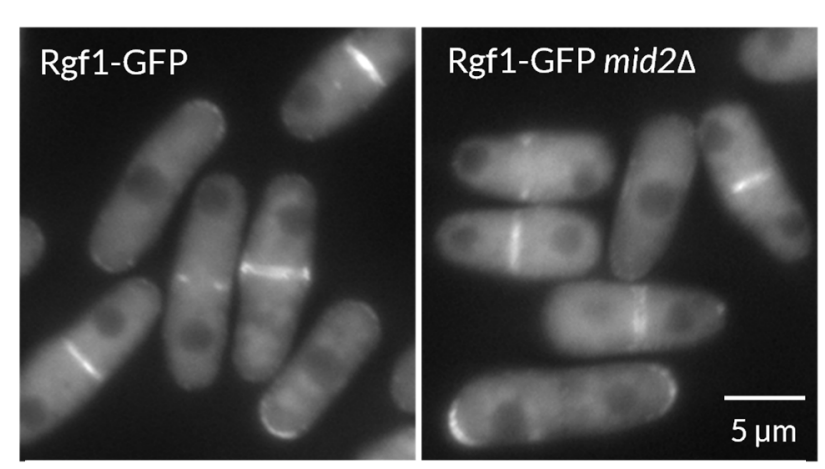

Figura 33 La ausencia de la anilina Mid2 no afecta a la localización de Rgf1. Imágenes de fluorescencia de Rgf1-GFP en cepas wt y mid2 $\Delta$ tomadas en el DeltaVision. 
de las septinas durante la formación del CAR (Zheng et al. 2018). Sin embargo, no hemos visto diferencias en la localización de Rgf1 en un mutante nulo de Mid2, la anillina que organiza el anillo de septinas y que presenta un fenotipo casi idéntico al de la eliminación de estas (Berlin et al. 2003; Tasto et al. 2003) (Figura 33).

\section{EL BLANKOPHOR PRODUCE UN RETRASO DE LA CITOQUINESIS AUSENTE EN PARTE EN EL MUTANTE RGF1A}

El siguiente paso en el estudio de la implicación de Rgf1 en citoquinesis pasó por observar cómo transcurría este proceso en el mutante nulo $\operatorname{rgf}_{1} \Delta$. Realizamos el seguimiento de todo el proceso citoquinético por microscopía de time-lapse en las cepas silvestre y rgfi $\Delta$. En este caso utilizamos cepas que expresan de manera endógena la tubulina Atb2 marcada en verde con GFP, lo que permite detectar fácilmente la formación del huso como un punto brillante tras la desaparición de los microtúbulos interfásicos (Wu et al. 2003). Empleamos de nuevo la cadena ligera de la miosina de tipo II, Rlc1-tdTomato, para seguir la dinámica del CAR y la tinción de BP como marcador del septo.

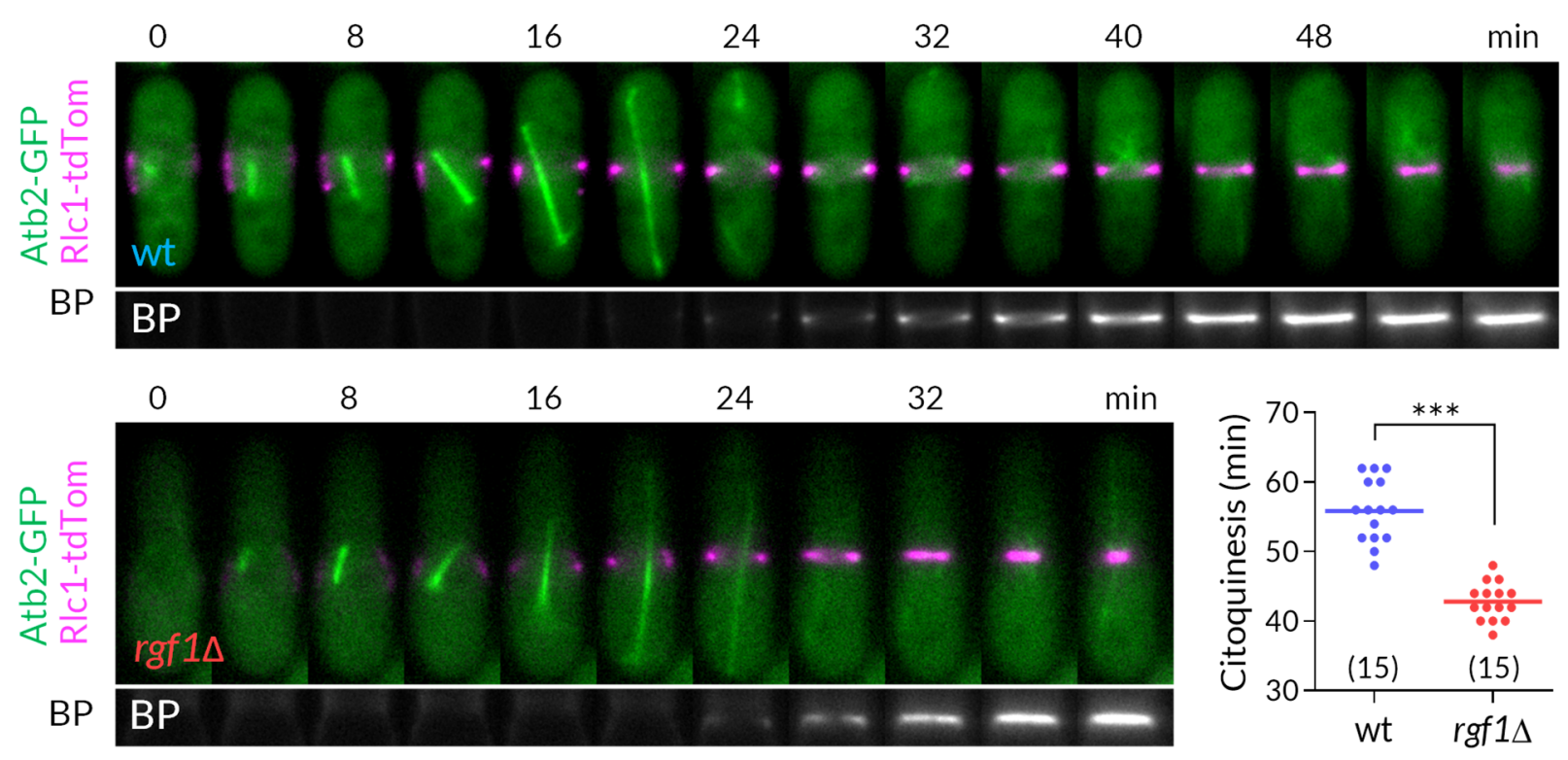

Figura 34 Las células $r g f 1 \Delta$ completan la citoquinesis más rápido que la cepa silvestre. Imágenes de timelapse en DeltaVision de células wt y rgfis marcadas con Rlc1-tdTomato, Atb2-GFP y teñidas con BP. Fotografías tomadas cada 2 minutos (se muestran cada 4). Derecha, tiempos de citoquinesis de ambas cepas medidos desde la aparición del spindle hasta el cierre del CAR, analizados con el test $\mathrm{t}$ de Student (*** $\mathrm{p}<0.0001,(\mathrm{n})$ ). 
Al alinear temporalmente los time-lapses de ambas cepas (con inicio de la formación del spindle como tiempo 0) vimos que las células del mutante rgf $1 \Delta$ completaban el cierre del anillo antes que la cepa silvestre (Figura 34). Este fue un resultado sorprendente pues parecía indicar que la ausencia de Rgf1 aceleraba la citoquinesis, algo inusual ya que generalmente las mutaciones que afectan a la velocidad de este proceso tienden a retrasarlo o impedirlo, no hacer que vaya más rápido (Wu et al. 2003). Nuestros datos parecían revelar una función de Rgf1 como freno de la citoquinesis.

Quisimos confirmar este resultado variando las proteínas empleadas como marcadores del CAR y del ciclo mitótico para ver si el fenotipo era robusto. Cambiamos el reportero de ciclo de Atb2 a Sid4-GFP, componente de reclutamiento de la ruta SIN (Chang \& Gould 2000) y el marcador del anillo a Imp2-GFP, proteína con dominio F-BAR de carácter estructural que es reclutada durante maduración (Roberts-Galbraith et al. 2009, 2010; Ren et al. 2015). Con las nuevas cepas volvimos a ver el mismo resultado en el que rgf1 $\Delta$ presentaba una citoquinesis más corta que la de la cepa silvestre (Figura 35A). Sin embargo, al repetir el experimento encontramos unas condiciones en las que el fenotipo desaparecía y los tiempos se igualaban.

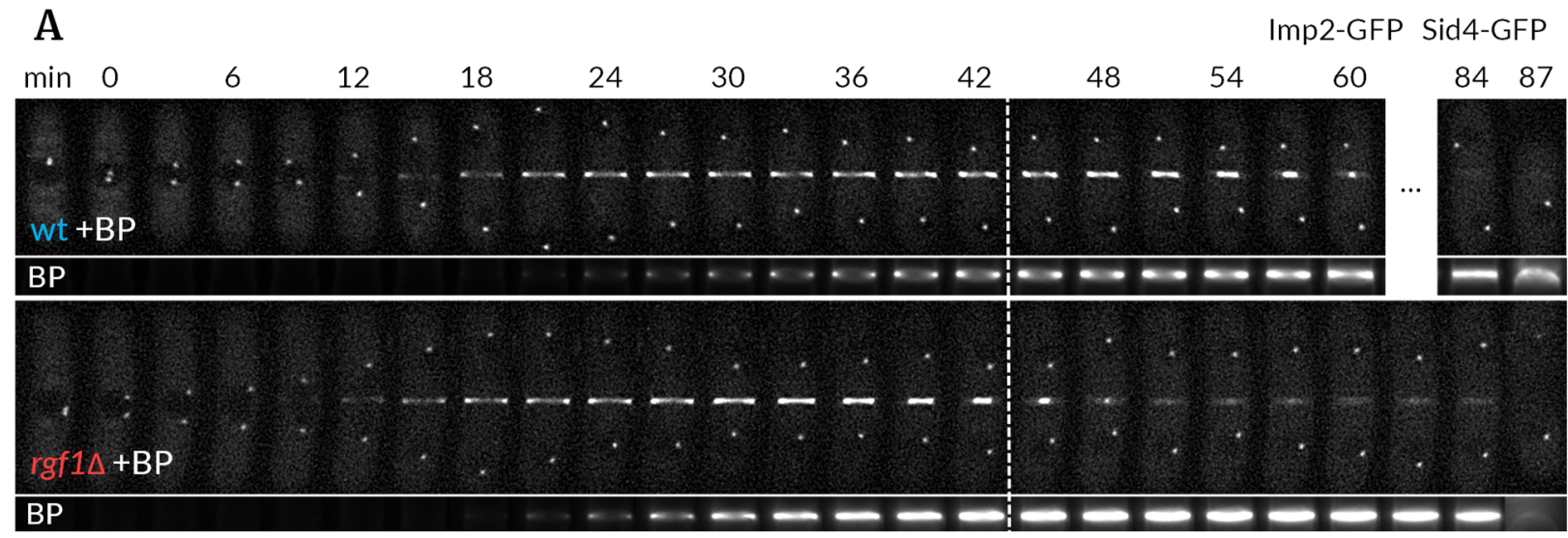

B

Imp2-GFP Sid4-GFP C
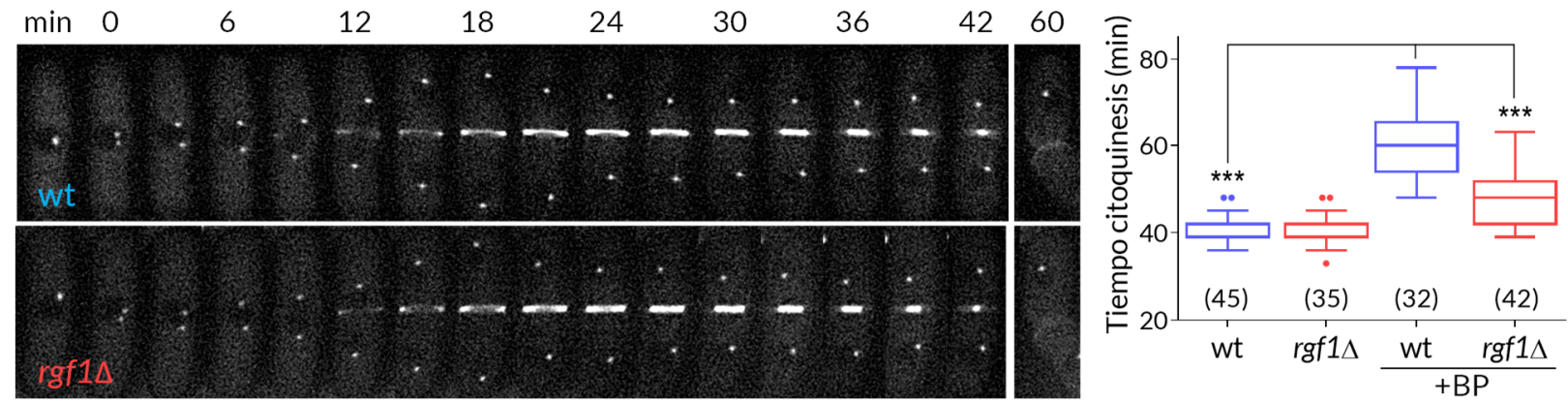

Figura 35 El blankophor produce un retraso de la citoquinesis, que es menor en la cepa $r g f 1 \Delta$. Imágenes de time-lapse en DeltaVision de células marcadas con Imp2-GFP y Sid4-GFP, en presencia (A) o ausencia (B) de BP $5 \mathrm{\mu g} / \mathrm{ml}$. Fotografías tomadas cada 3 minutos (en (A) se omiten las fotos tomadas del minuto 63 a 81 para mostrar la separación celular al final). (C) Tiempos de citoquinesis de las cepas wt y rgfi $\Delta$ en presencia y ausencia de BP, contados desde la separación de los SPBs hasta el cierre del anillo y analizados con test de Šidák $(* * * \mathrm{p}<0.0001,(\mathrm{n}))$. 
En los primeros experimentos, con el afán de recoger la mayor información posible, además de los marcadores de ciclo y anillo utilizamos el marcaje del septo con BP. Examinando las condiciones experimentales nos dimos cuenta de que en alguna de las réplicas habíamos prescindido de la tinción de $\mathrm{BP}$, y fue entonces cuando vimos que en ausencia de este compuesto los tiempos de la cepa silvestre y mutante se igualaban (Figura 35B).

Nuestra primera interpretación de una citoquinesis acelerada en el mutante $r g f_{1} \Delta$ resultó equivocada. En condiciones normales (ausencia de BP) no había diferencia en el tiempo de citoquinesis entre el mutante $r g f_{1} \Delta$ y la cepa silvestre, considerado éste desde el momento en el que se separan los SPBs hasta que el anillo se contrae completamente y se ve como un punto. Con la adición del BP el tiempo de citoquinesis de la cepa silvestre se extiende, y es entonces cuando vemos la diferencia con respecto al mutante rgf1 $\Delta$ (Figura 35A). Es la presencia de BP lo que produce un retraso en la cepa silvestre, que es mucho menor en el mutante $\operatorname{rgf}_{1} \Delta$.

Obtuvimos el mismo resultado de retraso por BP al repetir los experimentos con diferentes combinaciones de marcadores del anillo como las miosinas Myo2 y Myp2 (East \& Mulvihill 2011), o los ya mencionados Rlc1 e Imp2 y con marcadores de ciclo como Sfi1 (Rüthnick \& Schiebel 2016), Sid4, Sad1 y Atb2 (Figura 36).

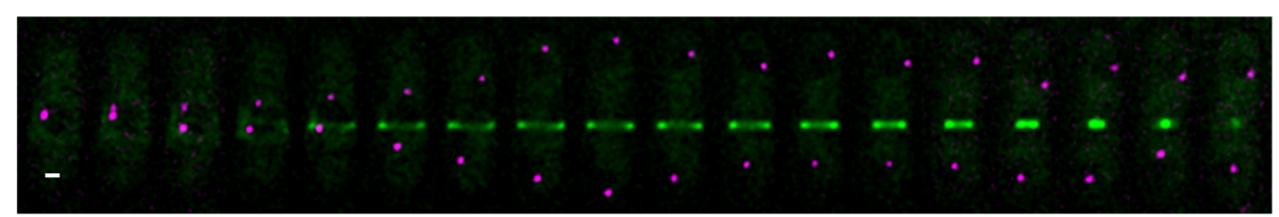

A Myo2-GFP Sid4-mCherry
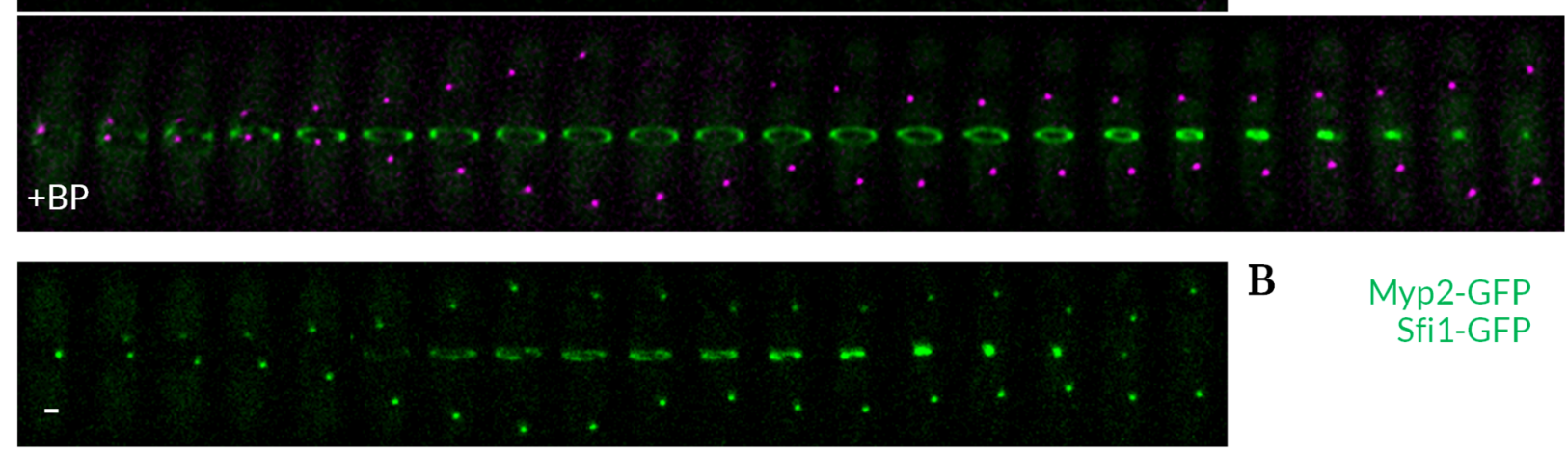

Sfi1-GFP

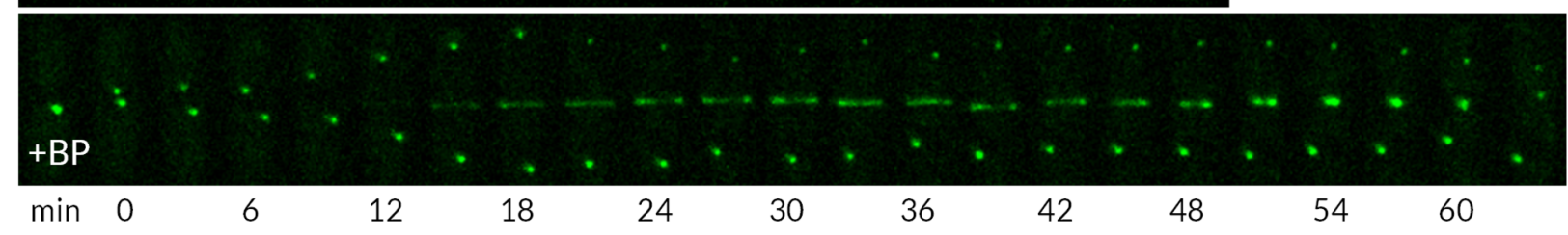

Figura $36 \mathrm{El}$ retraso en citoquinesis causado por el blankophor es robusto frente a la variación de marcadores fluorescentes. Imágenes de time-lapse de células de tipo silvestre en presencia o ausencia de BP $5 \mu \mathrm{g} / \mathrm{ml}$, (A) las células expresan Myo2-GFP, Sid4-mCherry y fueron capturadas en DeltaVision, o (B) las células expresan Myp2-GFP, Sfi1-GFP y fueron capturadas en Spinning Disk. 
En estas últimas réplicas (Figura 36) dejamos de capturar el canal de fluorescencia del BP, cuya excitación está en el rango de luz UV, con lo que descartamos que el efecto sea por la iluminación o excitación del compuesto.

Bajo esta nueva perspectiva en la que es el BP quien produce un retraso en citoquinesis decidimos evaluar el alcance de este efecto. Realizamos los mismos experimentos de time-lapse para medir el tiempo de citoquinesis en la cepa silvestre utilizando concentraciones crecientes de BP. Los resultados se muestran en la Figura 37A, donde se observa que cuanto mayor es la concentración de BP más se incrementa el tiempo total de citoquinesis. Por lo tanto, el efecto de este compuesto sobre la célula es directamente dependiente de la dosis.

A

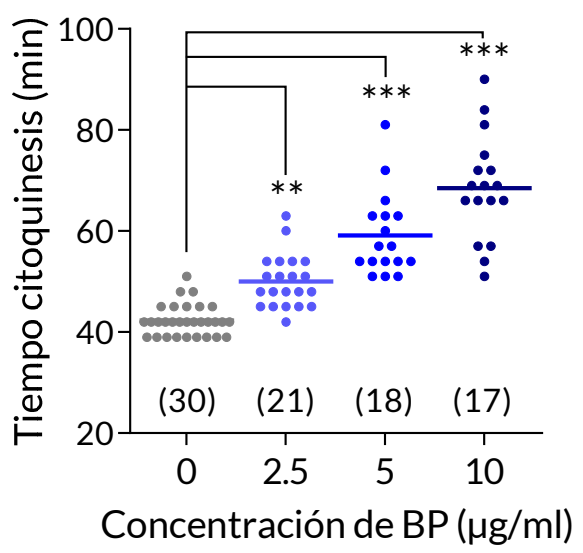

B

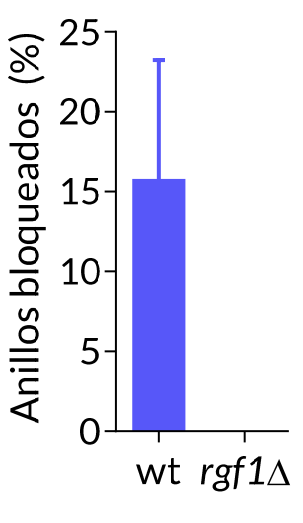

Figura $37 \mathrm{El} \mathrm{BP}$ alarga la citoquinesis de forma dependiente de la dosis y bloquea la constricción de algunos anillos. (A) Relación dosis-respuesta en el tiempo de citoquinesis de células wt frente a concentraciones crecientes de BP. Analizados con test de Šidák (** $\mathrm{p}<0.001$, $* * * \mathrm{p}<0.0001,(\mathrm{n}))$. (B) Fracción de células wt y rgfi $\Delta$ con anillos que no inician la constricción en presencia de BP $5 \mu \mathrm{g} / \mathrm{ml}$ (Media \pm SD, n: 3 réplicas con $>20$ células/réplica). Datos cuantificados a partir de time-lapses de Imp2-GFP, Sid4GFP en DeltaVision.

Además del alargamiento de la citoquinesis encontramos otro efecto que producía el BP y que definimos como bloqueo. Una fracción de las células, tanto mayor cuanto más incrementábamos la dosis de BP, formaban un anillo que permanecía con un diámetro constante, es decir sin constricción, en el tiempo que duraba el experimento. Definimos como anillos bloqueados aquellos en los que, dentro de las 2 horas que dura el experimento, no vemos su constricción y que permanecen sin cambios durante al menos 45 minutos, el tiempo que dura la citoquinesis completa en condiciones normales. La cuantificación de los anillos bloqueados en la cepa silvestre y en el mutante $r g f_{1} \Delta$ en presencia de BP $(5 \mu \mathrm{g} / \mathrm{ml})$ se muestran en la Figura 37B.

En el 15\% de las células de la cepa silvestre que tienen anillo éste se encuentra bloqueado. Sin embargo, este efecto de anillos bloqueados está ausente en la cepa rgf $1 \Delta$ tratada en las mismas condiciones. Este dato indica de nuevo que la presencia de Rgf1 es necesaria para prolongar la citoquinesis en condiciones de estrés sobre la pared celular. 


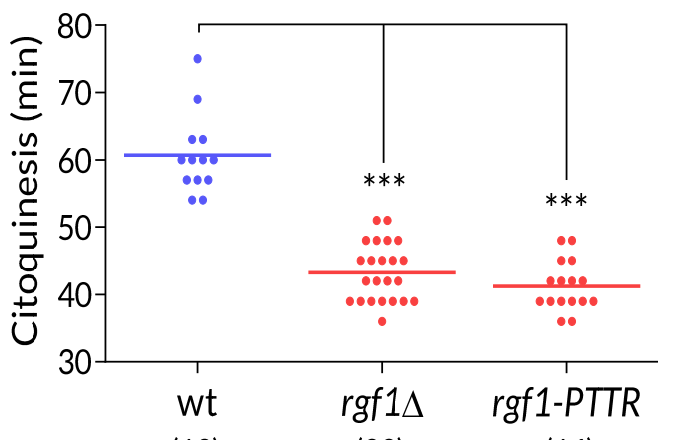

(13) (23)

Figura 38 La actividad GEF de Rgf1 condiciona el retraso citoquinético del BP. Tiempos de compleción de la citoquinesis de cepas wt, $r g f_{1} \triangle$ y rgfi-PTTR en presencia de BP $5 \mu \mathrm{g} / \mathrm{ml}$. Analizados con test de Šidák (** $\mathrm{p}<0.001, \quad * * * \quad \mathrm{p}<0.0001, \quad(\mathrm{n}))$. Datos cuantificados a partir de time-lapses de Imp2-GFP, Sid4-GFP en DeltaVision.

Nos preguntamos también si el retraso producido por el BP depende de la actividad catalítica o actividad GEF de Rgf1 hacia Rho1. Para ello utilizamos el mutante rgf1-PTTR, el cual lleva una deleción de cuatro aminoácidos en el dominio Rho-GEF (García et al. 2006a) que reduce su actividad intercambiadora de nucleótido o activadora de Rho1 (García et al. 2009b). En presencia de BP, la cepa rgf1-PTTR se comporta como el mutante nulo $\operatorname{rgf} 1 \Delta$, con tiempos de citoquinesis alejados del retraso que se ve en la cepa silvestre (Figura 38). En resumen, la actividad GEF de Rgf1 es crítica para que se produzca el retraso por BP.

Antes de continuar con los siguientes resultados es necesario señalar que los experimentos subsiguientes en los que utilizamos BP, este se añadió a una concentración final de $5 \mathrm{\mu g} / \mathrm{ml}$, salvo que se indique explícitamente otra concentración. Usamos esta concentración porque, examinados los resultados, vimos que era suficiente para producir un retraso apreciable y una diferencia entre las cepas silvestre y mutante. No utilizamos una concentración mayor para no incrementar el porcentaje de células con anillos bloqueados, en las que no podemos medir el tiempo de citoquinesis, ni extender el efecto del retraso, lo que nos obligaría a incrementar el tiempo de captura de los time-lapses para recoger los datos de un buen número de células en cada experimento.

De esta forma, un tiempo de captura total de 2 horas junto a la selección previa de los campos de la preparación más adecuados (aquellos con un buen número de células cercanas a entrar en mitosis, es decir, las que tienen una longitud cercana al máximo y solo un SPB) nos permite medir la citoquinesis de entre 15 y 30 células por experimento. Contamos solo aquellas células en las que vemos la duplicación del SPB y el cierre del anillo dentro del mismo experimento, y definimos el tiempo que tardan las células en completar la citoquinesis como la diferencia entre estos dos valores. 


\section{EL INICIO DE LA SEPTACIÓN Y DE LA CONSTRICCIÓN DEL CAR ESTÁN DESACOPLADOS EN PRESENCIA DE BLANKOPHOR}

Hasta ahora hemos visto un retraso en la citoquinesis en presencia de BP teniendo en cuenta el tiempo de contracción del anillo de actomiosina. En S. pombe la constricción del CAR lleva acoplada la invaginación de la membrana plasmática y la síntesis del septo (Roncero \& Sánchez 2010; Cortés et al. 2016b), por lo que decidimos estudiar el comportamiento de estos otros dos componentes durante el retraso por BP.

Visualizamos la membrana plasmática empleando el marcador de unión a fosfatidilserina LactC2-GFP (Yeung et al. 2008; Haupt \& Minc 2017). En la cepa silvestre en condiciones normales, la invaginación de la membrana plasmática se puede observar como un incremento en la fluorescencia de este marcador en la región media de la célula, desde la periferia hacia el interior, que se produce tras la ruptura del huso mitótico (spindle breakdown), esto es de acuerdo con nuestros marcadores, el momento en el que la distancia que separa a los SPBs se acorta tras haber llegado al máximo (Figura 39).
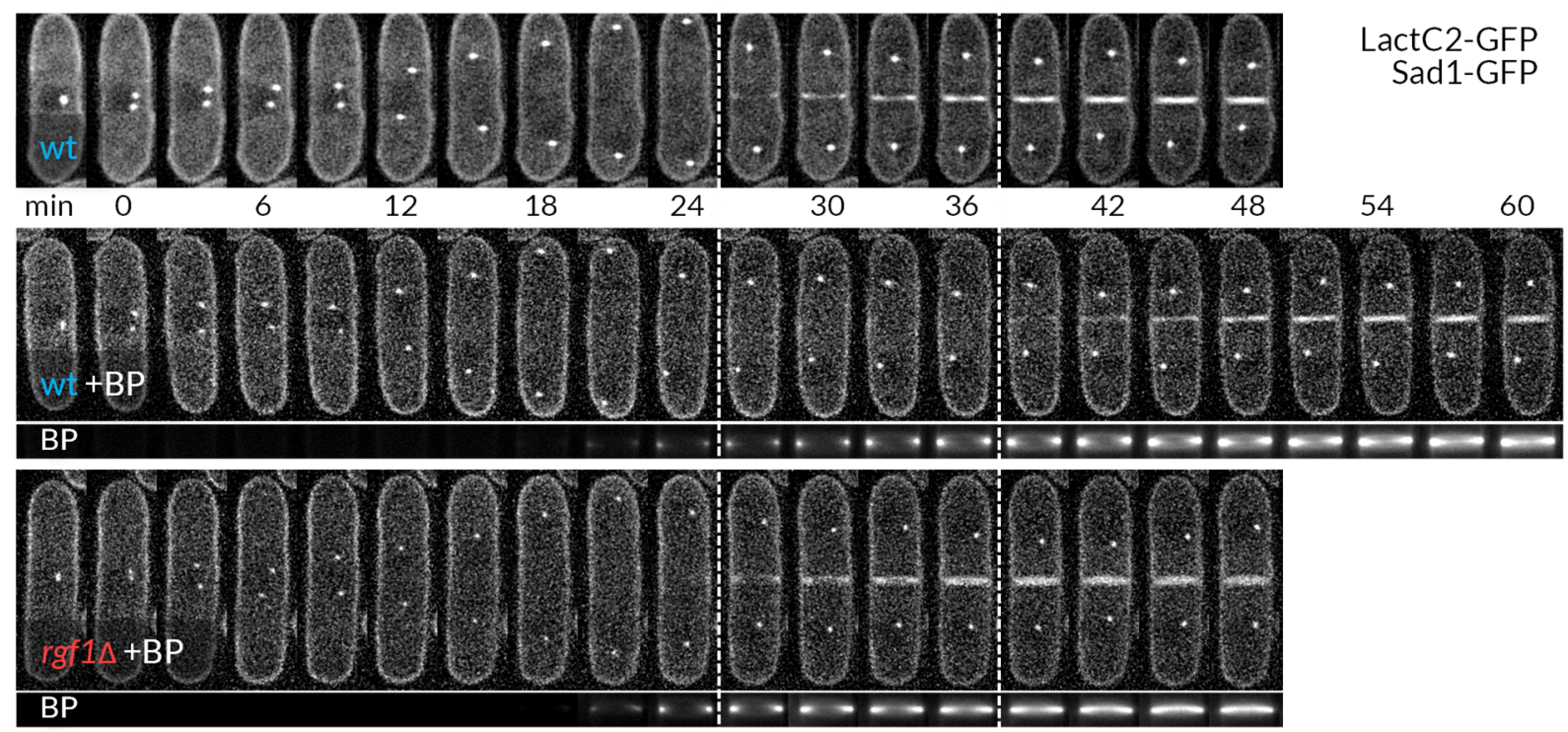

Figura 39 La invaginación de la membrana plasmática se ve retrasada por la presencia de blankophor. Imágenes de time-lapse en DeltaVision de células de tipo silvestre y rgf1 $\triangle$ que expresan LactC2-GFP y Sad1GFP, en presencia o ausencia de BP $5 \mu \mathrm{g} / \mathrm{ml}$. Las líneas discontinuas señalan el inicio de la invaginación de la membrana plasmática en condiciones normales (primera línea) y con la adición de BP (segunda). 
Estos tiempos concuerdan con el momento de inicio de la constricción publicado por otros autores (Laplante et al. 2015; Dey \& Pollard 2018; Zheng et al. 2018), sin embargo recientemente se ha descrito que la constricción del anillo ocurriría minutos antes del spindle breakdown (Cortés et al. 2018; Okada et al. 2019). Con la adición del BP la invaginación de la membrana se distancia temporalmente del spindle breakdown, comenzando hasta 15 minutos después (Figura 39). La ausencia de Rgf1 revierte este efecto, por lo que el retraso es mucho menor en el mutante rgf $1 \Delta$. Estos resultados sugieren que el retraso inducido por el BP, al que $\operatorname{rgf} 1 \Delta$ es menos sensible, se circunscribe a los procesos previos a la invaginación de la membrana.

Para visualizar la formación del septo se realizó una tinción con el marcador fluorescente blankophor (BP). De este modo, el BP ( $5 \mu \mathrm{g} / \mathrm{ml})$ nos sirve a la vez como agente causante del retraso y marcador de la formación del septo. Tanto en la cepa silvestre como en el mutante rgfi $\Delta$ el avance de la señal de BP, y por tanto de la síntesis del septo, va parejo a la constricción del anillo, y es el diámetro del anillo quien marca el límite interior del tamaño del septo en cada momento (Figura 40). Este proceso es más rápido (entre 10 y $15 \mathrm{~min}$ ) en el mutante $\operatorname{rgf} 1 \Delta$, que como hemos visto en resultados previos termina la citoquinesis antes que la cepa silvestre en presencia de BP. Al finalizar la contracción en ambas cepas aparece un septo de fluorescencia uniforme. Este septo se mantiene durante un tiempo similar en ambas cepas, que abarca desde el fin de la constricción del anillo hasta que las células se separan.

A
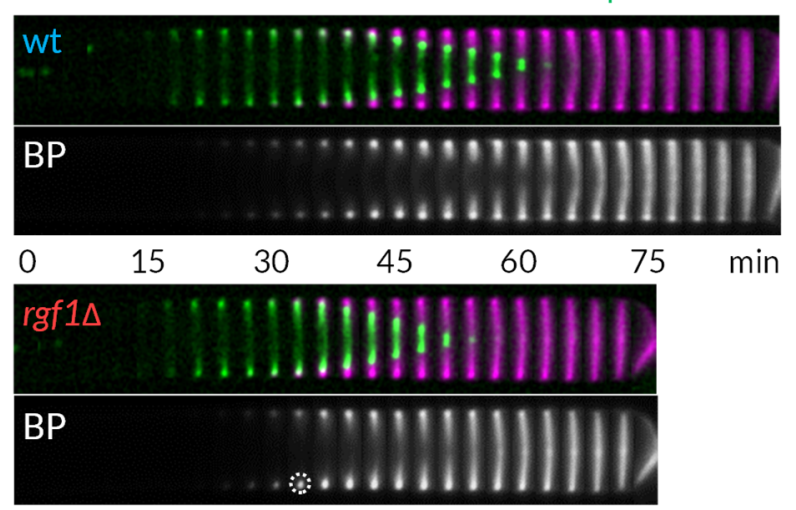

B

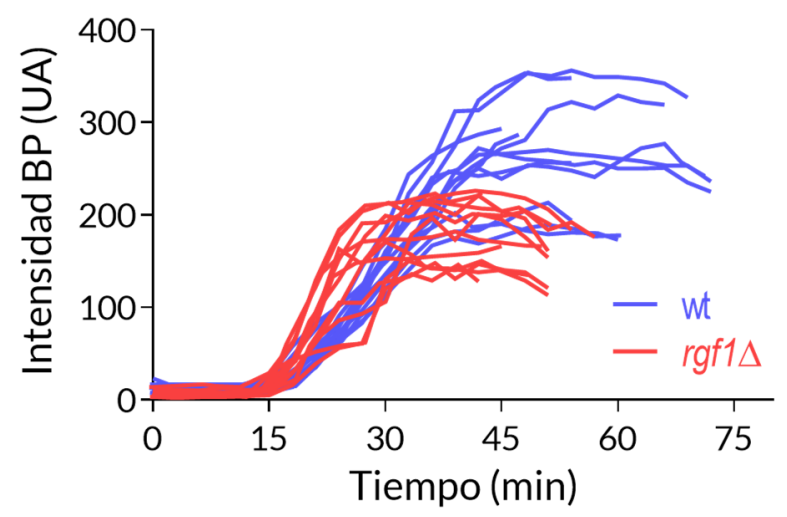

Figura 40 La síntesis del septo en presencia de BP comienza al mismo tiempo en las cepas wt y rgfi $1 \Delta$, y no se detiene durante el bloqueo citoquinético. (A) Representación quimográfica de la progresión del anillo y septo, obtenidos a partir de time-lapses en DeltaVision de células wt y rgf1 $\Delta$ que expresan Imp2-GFP, Sid4-GFP en presencia de BP 5 $\mu \mathrm{g} / \mathrm{ml}$. El tiempo o es la separación de los SPBs (no apreciable en la figura); el círculo discontinuo señala la región empleada para las medidas de intensidad (B) Cuantificación de la intensidad de fluorescencia del BP en la región periférica del septo de las células de (A) a lo largo del tiempo. Cada línea es la medida del septo de una célula (n: 12 células). 
También hemos cuantificado la progresión inicial del septo en las células de tipo silvestre retrasadas por BP y en las rgfi $\triangle$. Par ello medimos la intensidad de la señal de BP en la periferia celular (Figura 40A, círculo) a lo largo de la citoquinesis, tomando como tiempo o la separación de los SPBs.

En ambas cepas el incremento de la señal, es decir el inicio de la síntesis del septo, se da al mismo tiempo ( en 18 minutos) (Figura 40B). Esta intensidad crece de forma lineal hasta llegar a un máximo que se mantiene como una meseta (siempre contando sólo la intensidad en la periferia, donde comienza la síntesis; mientras tanto el septo continúa su progresión hacia el interior). La cepa $\operatorname{rgf}_{1} \Delta$, que apenas se para, alcanza este máximo antes que la cepa silvestre, y es además de una intensidad inferior. En la cepa silvestre esta señal continúa creciendo, aun con la constricción parada, lo que indica que durante el bloqueo la síntesis del septo no se detiene, sólo lo hace su ingresión (incursión hacia el interior), que va ligada a la invaginación del surco citoquinético. Finalmente, la existencia de una meseta de señal máxima de BP valida la metodología, pues indica que el colorante deja de incorporarse a la periferia aproximadamente tras comenzar la ingresión citoquinética (Figura 40).

En conjunto estos resultados indican que el BP es capaz de retrasar el inicio de la invaginación de la membrana, pero no el comienzo de la síntesis del septo. Se produce por tanto un desacoplamiento entre estos dos aspectos de la citoquinesis, que en condiciones normales se suceden sin retraso, y que la pérdida de Rgf1 revierte parcialmente. Los datos sugieren también que el origen del bloqueo por BP no es la parada de la síntesis del septo, lo que señala a la actividad del anillo como hipotético responsable. Adicionalmente, la incorporación continuada de BP durante el bloqueo resulta paradójica: el BP origina un bloqueo citoquinético, y cuanto más prolongado es este bloqueo más BP se incorpora al septo. Parecería que la parada es contraproducente; sin embargo, como veremos más adelante, la ausencia de bloqueo resulta en fenotipos de multiseptación.

\section{EL BLANKOPHOR RETRASA ESPECÍFICAMENTE EL INICIO DE LA CONSTRICCIÓN DEL CAR}

El retraso observado en el inicio de la invaginación de la membrana plasmática nos ayuda a situar el bloqueo producido por el BP en los eventos previos a este. No podemos estudiar los pasos previos a la invaginación mirando la membrana plasmática, ya que no detectamos ningún cambio por fluorescencia. Sin embargo, la invaginación de la membrana va asociada a la constricción del anillo en telofase, y este sí que lo podemos estudiar. En concreto analizamos el 
tiempo que dura cada una de las tres fases por las que pasa el anillo de actomiosina en citoquinesis.

La primera de estas tres etapas es la de formación. En esta etapa un conjunto de proteínas tempranas se distribuye como nodos dispersos en la membrana plasmática próxima a la posición del núcleo y determina la posición del anillo (Moseley et al. 2009; Akamatsu et al. 2014). Estos nodos se van aglutinando hasta formar una estructura anular discreta. La formación se define como el tiempo desde que aparecen los nodos hasta que se ensamblan formando un anillo de fluorescencia uniforme. En la etapa de maduración, el anillo sufre la remodelación de algunos de sus componentes, pero no cambia de tamaño (Pelham \& Chang 2002; Roberts-Galbraith et al. 2009). En los experimentos de time-lapse medimos indirectamente la etapa de maduración como el intervalo de tiempo desde que aparece el anillo uniforme hasta que se inicia la constricción. La constricción se mide por la disminución del diámetro del anillo fluorescente con el tiempo hasta que se cierra y aparece como un punto (Rincon \& Paoletti 2016).

A continuación, medimos las tres etapas en la cepa silvestre en ausencia y en presencia de BP. También medimos la formación, maduración y constricción en la cepa $r g f_{1} \Delta$ en las mismas condiciones para ver si la ausencia de retraso estaba asociaba a las mismas etapas. En esta ocasión utilizamos Myo2-EGFP para visualizar el anillo. Myo2-EGFP es una de las proteínas tempranas que aparece en nodos y se mantiene en el anillo hasta el final de citoquinesis, a diferencia de Imp2 que aparece en la etapa de maduración (Laplante et al. 2015; Ren et al. 2015) (Figura 41).

En la cepa silvestre la fase de formación no se ve alterada significativamente por la adición del BP, siendo el tiempo de formación en condiciones normales de $21.1 \pm 2.1$ min (media $\pm \mathrm{SD}$ ), y de $18.6 \pm 2.9$ min en presencia de BP. Los tiempos de formación en la cepa mutante rgf $1 \Delta$ tampoco difieren de los de la cepa silvestre en ninguna de las dos condiciones. Estos resultados indican que el tratamiento con BP no causa alteraciones en el tiempo de formación del anillo, y sugieren que Rgf1 no contribuye a la formación del anillo, lo que está de acuerdo con su aparición en la fase de maduración, cuando el anillo ya está ensamblado (ver Figura 27).

Sí observamos diferencias en fase de maduración en el tratamiento con BP. En la cepa silvestre el tiempo de maduración del anillo prácticamente se duplica al añadir la droga, pasando de $10 \pm 2.8 \mathrm{~min}$ en condiciones normales a $22.1 \pm 4.0$ min bajo la acción del BP. La cepa rgf $1 \Delta$ es mucho menos susceptible a este retraso; en este caso el tiempo de maduración pasa de $8.8 \pm 2.5$ min en condiciones normales ( $\sin$ BP) a $11.4 \pm 2.4$ min con BP. Tampoco hemos visto diferencias en la fase de constricción, lo que indica que el retraso en el tiempo de citoquinesis producido por el BP se manifiesta exclusivamente en la fase de maduración. 

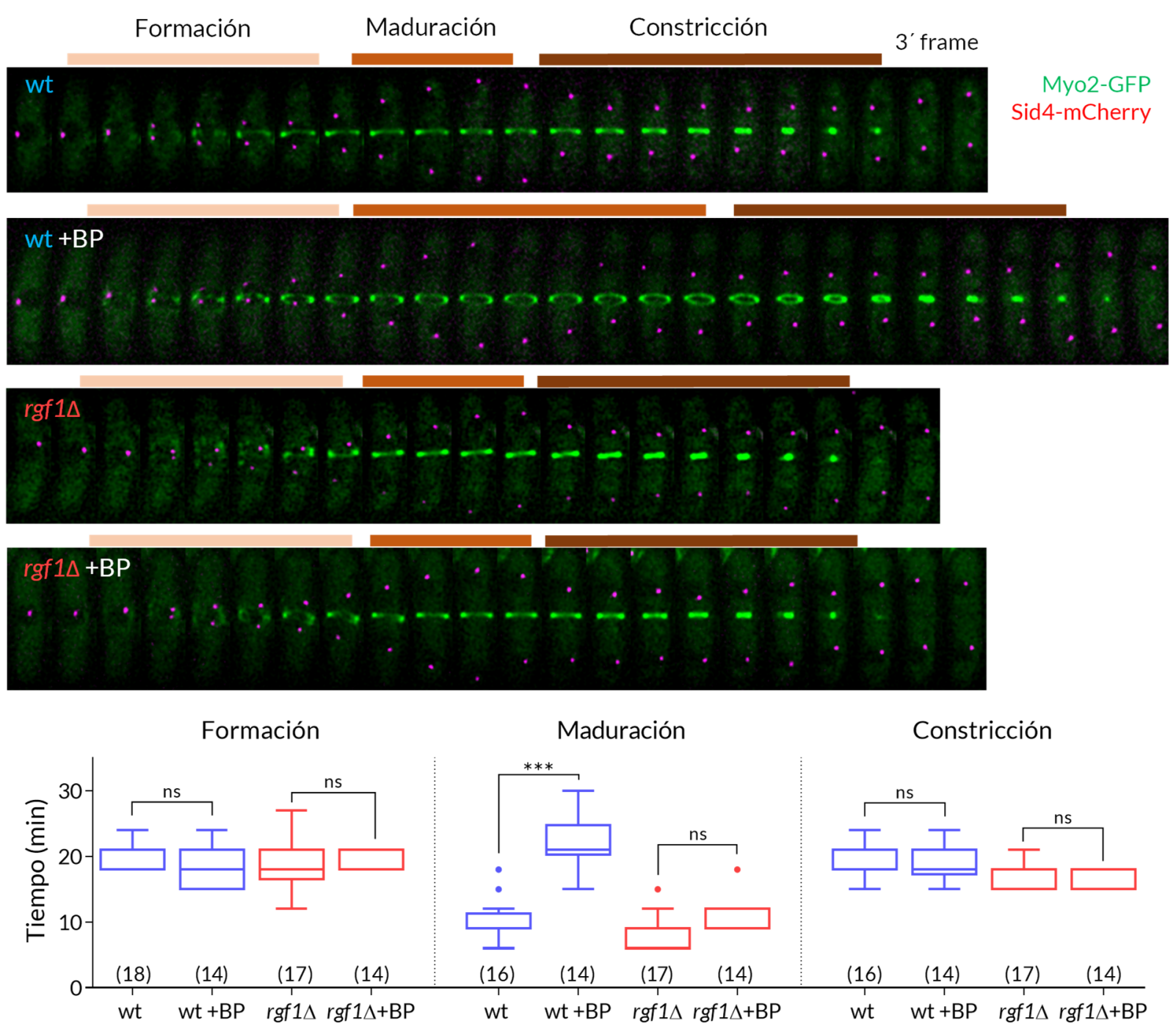

Figura $41 \mathrm{El}$ BP alarga la fase de maduración del CAR sin afectar a su formación y constricción. Imágenes de time-lapse de células de tipo silvestre y rgfi $\triangle$ que expresan Myo2-GFP y Sid4-mCherry, en presencia o ausencia de BP $5 \mu \mathrm{g} / \mathrm{ml}$. Las barras de color señalan las tres etapas por las que pasa el anillo: formación, maduración y constricción. Las cuantificaciones se muestran en los box-plots de los paneles inferiores. Datos analizados con test de Šidák (ns no significativo, $* * * \mathrm{p}<0.0001,(\mathrm{n})$ )

Otra forma de cuantificar las diferencias en la progresión del CAR entre cepas y condiciones consiste en medir la reducción del diámetro del anillo durante la citoquinesis. Estos datos nos permiten calcular la velocidad de la contracción y sirven para complementar y reforzar los resultados anteriores. Sabemos que el retraso no se da en la fase de formación, por lo que volvimos a utilizar las cepas con los marcadores Imp2-GFP y Sid4-GFP. Esta combinación resulta particularmente adecuada porque no hay solapamiento entre ambas señales, tal y como se explica a continuación.

Cuando los SPBs se están separando los componentes del anillo están en forma de nodos (ver Figura 41). Ambas estructuras se localizan en este momento en la zona media de la célula, 
los nodos en la MP y los SPBs en la envuelta nuclear, lo que hace que se confundan fácilmente sus señales de fluorescencia, especialmente bajo condiciones de microscopía pobres (pocos planos en $\mathrm{Z}$ o ausencia de confocalidad), o al visualizarlas como proyección en un único plano. Para evitar esta confusión se recurre a marcar estas estructuras con reporteros de fluorescencias distintas, separando así el solapamiento con el uso de dos canales. La adición de un segundo canal incrementa la presión por fotodaño al tener que iluminar las células con dos líneas de excitación en lugar de una (Magidson \& Khodjakov 2013). Al ser Imp2 una proteína tardía que no aparece en nodos, cuando los SPBs comienzan a separarse no hay señal de Imp2 y por tanto no hay solapamiento. Cuando Imp2 aparece en el anillo los SPBs ya están lo suficientemente alejados de esta región para que no interfieran. De este modo podemos visualizar ambas estructuras con la iluminación de un único canal de fluorescencia.

Medimos el diámetro del anillo de Imp2-GFP en cada tiempo del time-lapse usando la separación de los SPBs como referencia de tiempo o. Los primeros minutos no se pueden contabilizar debido a que Imp2 aparece en la fase madurativa. Tanto en ausencia como en presencia de BP, Imp2 llega al anillo alrededor del minuto 18 en la cepas silvestre y mutante rgf $1 \Delta$ (Figura 42). Esto indica que el BP no afecta el reclutamiento de Imp2 al anillo y que Rgf1 tampoco está involucrado en este proceso.

Con la aparición de Imp2 medimos el diámetro máximo o inicial del anillo. Utilizamos la media de los diámetros en los dos primeros tiempos para dar cuenta de la inexactitud de la medida, especialmente la del primer instante en que aparece Imp2 con baja intensidad de fluorescencia. Aunque el diámetro inicial es similar en ambas cepas, siempre observamos una ligera merma en el mutante $\mathrm{rgf}_{1} \Delta$ (wt: $3.56 \mu \mathrm{m}, \mathrm{rgf} 1 \Delta$ : $3.32 \mu \mathrm{m}$ ). Esto podría explicar la pequeña diferencia en los tiempos de constricción que veíamos al medir las fases con Myo2 (Figura 41).

En condiciones normales, tras la llegada de Imp2 el anillo permanece en su diámetro máximo durante unos minutos hasta que se inicia la constricción, marcada por un cambio brusco en la tendencia de las medidas de diámetros. La constricción comienza a un ritmo lento y en unos minutos alcanza la velocidad máxima; podemos ver la aceleración en el codo que forman las curvas, incluso con la resolución temporal de tres minutos. El anillo continúa su constricción a una velocidad constante hasta que se cierra como un punto discreto.

La adición de BP incrementa el tiempo en el que los anillos se mantienen con su diámetro máximo (Figura 42). Esto coincide con el aumento del tiempo de maduración (Figura 41), ya que no deja de ser un alargamiento del periodo en el que vemos anillos formados que todavía no han comenzado a contraer. 


\section{YES}

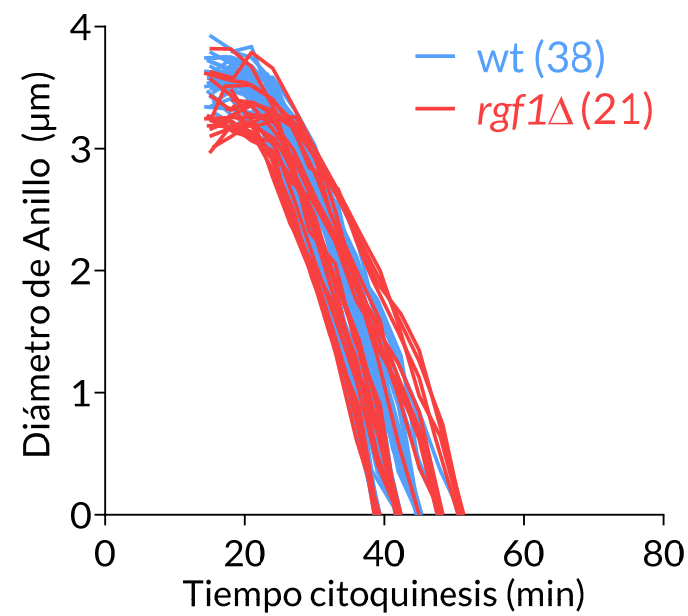

Blancophor $5 \mu \mathrm{g} / \mathrm{ml}$

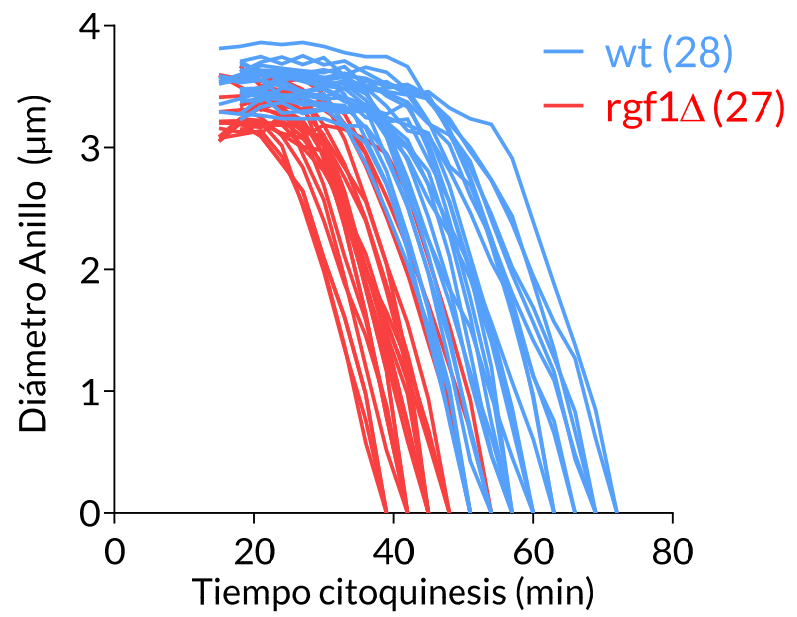

Figura 42 El BP retrasa el inicio de la constricción del CAR. Dinámicas de contracción de los anillos de cepas silvestre y rgf1 $\triangle$ que expresan Imp2-GFP y Sid4-GFP, en presencia y ausencia de BP $5 \mu \mathrm{g} / \mathrm{ml}$. Cada línea es un anillo al que medimos su diámetro en cada tiempo a partir de time-lapses capturados en DeltaVision.

En condiciones normales, en la cepa silvestre el anillo comienza a contraerse en el minuto $21 \pm 2$ tras la separación de los SBPs, la adición de BP retrasa este evento hasta el minuto $38 \pm 5$. Una vez iniciada, la constricción progresa a una velocidad similar en ambas condiciones, 150 $\mathrm{nm} / \mathrm{min}$, lo que indica que el BP no interfiere en el proceso de constricción del anillo. Este retraso en el inicio de la constricción en presencia de BP se suprime en gran medida en la cepa con la deleción de $r g f 1^{+}$; mientras que en la cepa silvestre veíamos una diferencia de 17 minutos, en el mutante $r g f_{1} \Delta$ este retraso se reduce a 6 minutos (Tabla 1). Como ocurría en la cepa silvestre la adición de BP no altera la velocidad de la constricción en el mutante rgf $1 \Delta$. Estos resultados sugieren que Rgf1 podría ser parte de un mecanismo que retrasa la constricción del anillo frente agresiones externas causadas por antifúngicos.

\begin{tabular}{lcccc}
\hline Constricción & wt - & wt +BP & rgfi $\Delta-$ & rgfi $\Delta+\mathrm{BP}$ \\
\hline Inicio (min) & $21 \pm 2$ & $38 \pm 5$ & $19 \pm 3$ & $25 \pm 4$ \\
Velocidad (nm/min) & $154 \pm 21$ & $158 \pm 31$ & $148 \pm 25$ & $175 \pm 30$ \\
\hline
\end{tabular}

Tabla 1 Momento de inicio y velocidad de constricción del CAR en cepas wt y $r g f_{1} \Delta$ en presencia y ausencia de blankophor $5 \mathrm{\mu g} / \mathrm{ml}$. El minuto de inicio de la constricción toma como referencia o la duplicación de los SPBs. La velocidad está medida como el cambio del diámetro del CAR en función del tiempo, en el tramo lineal de la curva. 


\section{LA RUTA DE INTEGRIDAD CELULAR ES NECESARIA PARA RETRASAR LA CONSTRICCIÓN DEL CAR EN RESPUESTA A BLANKOPHOR.}

Pensamos que Rgf1 podría actuar como parte de una vía de respuesta al estrés por BP produciendo un retraso en citoquinesis. Rgf1 es el principal activador de la GTPasa Rho1, y ya hemos visto que el bloqueo inducido por el BP depende de la actividad catalítica de Rgf1 sobre Rho1 (ver Figura 38). De acuerdo con esta interpretación el retraso en citoquinesis debería ser dependiente también de la propia GTPasa Rho1, por lo que en un mutante de Rho1 esperaríamos encontrar un fenotipo de "no retraso" frente al BP similar al que observamos en los mutantes rgfi $\triangle$ y rgfi-PTTR.

Rho1 es una proteína esencial, por lo que empleamos el mutante termosensible e hipomorfo rho1-596 (Viana et al. 2013). La inactivación parcial de Rho1 se realizó a la temperatura restrictiva de $36^{\circ} \mathrm{C}$. Partimos de células de la cepa silvestre y del mutante rho1-596 crecidas a $25^{\circ} \mathrm{C}$ hasta alcanzar la fase logarítmica. En el momento de realizar el experimento pasamos los cultivos a $36^{\circ} \mathrm{C}$ durante $1 \mathrm{~h}$, posteriormente añadimos el BP al medio y realizamos el time-lapse también a $36^{\circ} \mathrm{C}$.

Igual que sucedía con los mutantes de Rgf1, el retraso en citoquinesis en presencia de BP es menor en la cepa rho1-596 que en la cepa silvestre (Figura 43). En este caso hay que tener en cuenta que a $36^{\circ} \mathrm{C}$ el proceso citoquinético se acelera, dando por tanto tiempos menores en todas las situaciones con respecto a las medidas realizadas a $28^{\circ} \mathrm{C}$. Este resultado confirma que el retraso producido por el BP depende de la actividad GEF de Rgf1 sobre Rho1, y por

$36^{\circ} \mathrm{C}$

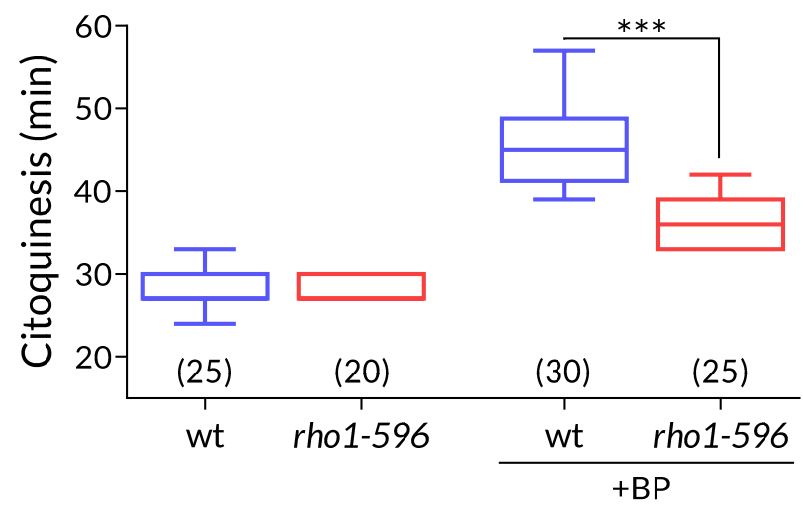

Figura $43 \mathrm{El}$ retraso citoquinético causado por BP depende de la actividad de Rho1. Tiempo que tarda en completarse la citoquinesis en cepas wt y rho1-596 que expresan Imp2-GFP y Sid4-GFP, en presencia y ausencia de BP $5 \mu \mathrm{g} / \mathrm{ml}$. Antes de realizar el timelapse en el DeltaVision las células se incubaron $1 \mathrm{~h}$ a $36^{\circ} \mathrm{C}$. Los datos se analizaron con el test $t$ de Student $(* * * \mathrm{p}<0.0001,(\mathrm{n}))$. tanto de la activación de Rho1.

¿Qué puede estar controlando Rho1 para producir el retraso en citoquinesis? Rho1 participa como regulador de diferentes procesos dentro de la célula: biosíntesis de la pared celular, organización del citoesqueleto de actina, crecimiento polarizado y el mantenimiento de la integridad celular entre otros (Arellano et al. 1996, 1997; García etal. 2009b). Su papel como activador de la síntesis de pared celular no parece ser el responsable, puesto que el inicio de la síntesis del septo ocurre por 
igual en presencia o ausencia de BP y no se detiene (ver Figura 40). Además, en presencia de BP, el septo tiene un aspecto normal y no encontramos fenotipo de lisis por la zona de división asociado al BP. Tampoco parece estar implicada su actividad relacionada con la actina, en tanto que la formación del anillo de actomiosina no se ve alterada por la presencia de BP y que la constricción, en la que intervienen la polimerización y despolimerización de actina, ocurre de forma normal (ver Figura 41).

De todos ellos, el papel de Rho1 y de Rgf1 como activadores de la ruta de integridad celular (CIP) parecía el más prometedor (García et al. 2009b; Sánchez-Mir et al. 2014). Esta vía de MAPK responde ante diversas condiciones de estrés para procurar la supervivencia celular y se activa, entre otros, ante la presencia de BP (Madrid et al. 2006; Barba et al. 2008). La ruta CIP, una de las tres rutas de MAPK en $S$. pombe, controla procesos como la formación y mantenimiento de la pared celular, morfogénesis, citoquinesis y homeostasis iónica (Perez \& Cansado 2010). Rho1 y Rho2 son los principales reguladores positivos de la ruta y Pmk1 su elemento central (Ma et al. 2006; Sánchez-Mir et al. 2014).

Otra de las rutas que también regula la separación celular en condiciones adversas es la ruta de respuesta a estrés (SAPK). La vía SAPK, cuyo componente central es la MAP kinasa Sty1, promueve la transcripción de cohortes de genes específicos y la inhibición de la entrada en mitosis en respuesta a distintos tipos de estrés (Shiozaki \& Russell 1995; Perez \& Cansado 2010; Salat-Canela et al. 2017). Si las ruta CIP o SAPK actuaran como sensores de BP esperaríamos ver el mismo fenotipo de ausencia de bloqueo al suprimir la actividad de estas cascadas de señalización. Para analizar la citoquinesis en estas condiciones construimos cepas mutantes de las MAP kinasas de las dos rutas, Pmk1 y Sty1 junto con los marcadores fluorescentes habituales (Imp2-GFP y Sid4-GFP).

Como se muestra en la Figura 44, el mutante pmk1 $\Delta$ no presenta retraso citoquinético frente al BP. De hecho, el fenotipo es incluso más pronunciado que el de los mutantes de Rgf1 y Rho1. Por el contrario, en el mutante sty $1 \Delta$ se observa un retraso en la citoquinesis similar al de

Figura 44 El retraso citoquinético causado por BP depende de la ruta CIP y no de la ruta SAPK. Tiempo que tarda en completarse la citoquinesis en cepas sty1 $\Delta$ y pmk1 $\triangle$ que expresan Imp2-GFP y Sid4GFP, en presencia y ausencia de BP $5 \mu \mathrm{g} / \mathrm{ml}$. Datos cuantificados a partir de time-lapses capturados en el DeltaVision y analizados con test de Šidák (ns no significativo, $* * *$ $\mathrm{p}<0.0001,(\mathrm{n}))$

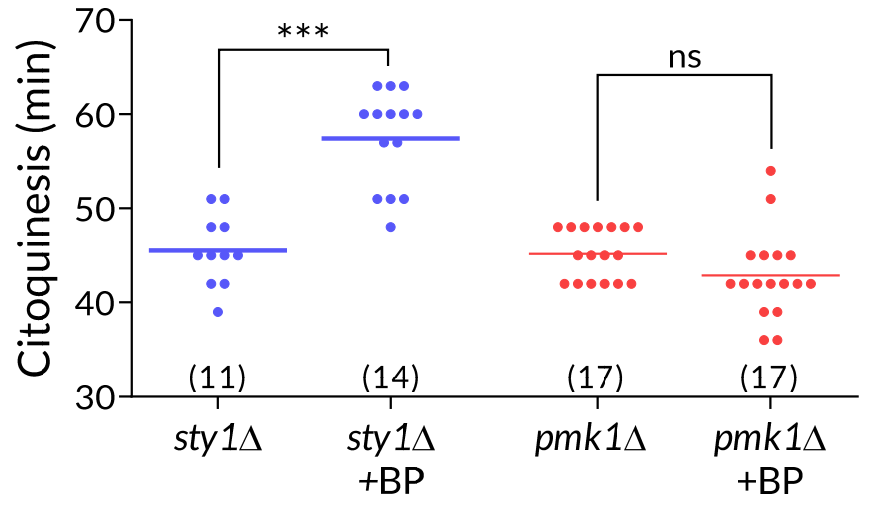


la cepa silvestre. En resumen, de las dos rutas analizadas, solo la ruta CIP está relacionada con el retraso en citoquinesis asociado al BP.

Para comprobar si el fenotipo observado en el mutante $p m k 1 \Delta$ se debía a la ausencia de respuesta de retraso, y no a un efecto compensatorio entre las distintas etapas de la citoquinesis, analizamos por separado el tiempo necesario para completar la formación, maduración y constricción. Como ocurría con $r_{f} f_{1} \Delta$, en pmk1 $\Delta$ las tres fases del CAR permanecen inalteradas en presencia de BP (Figura 45).
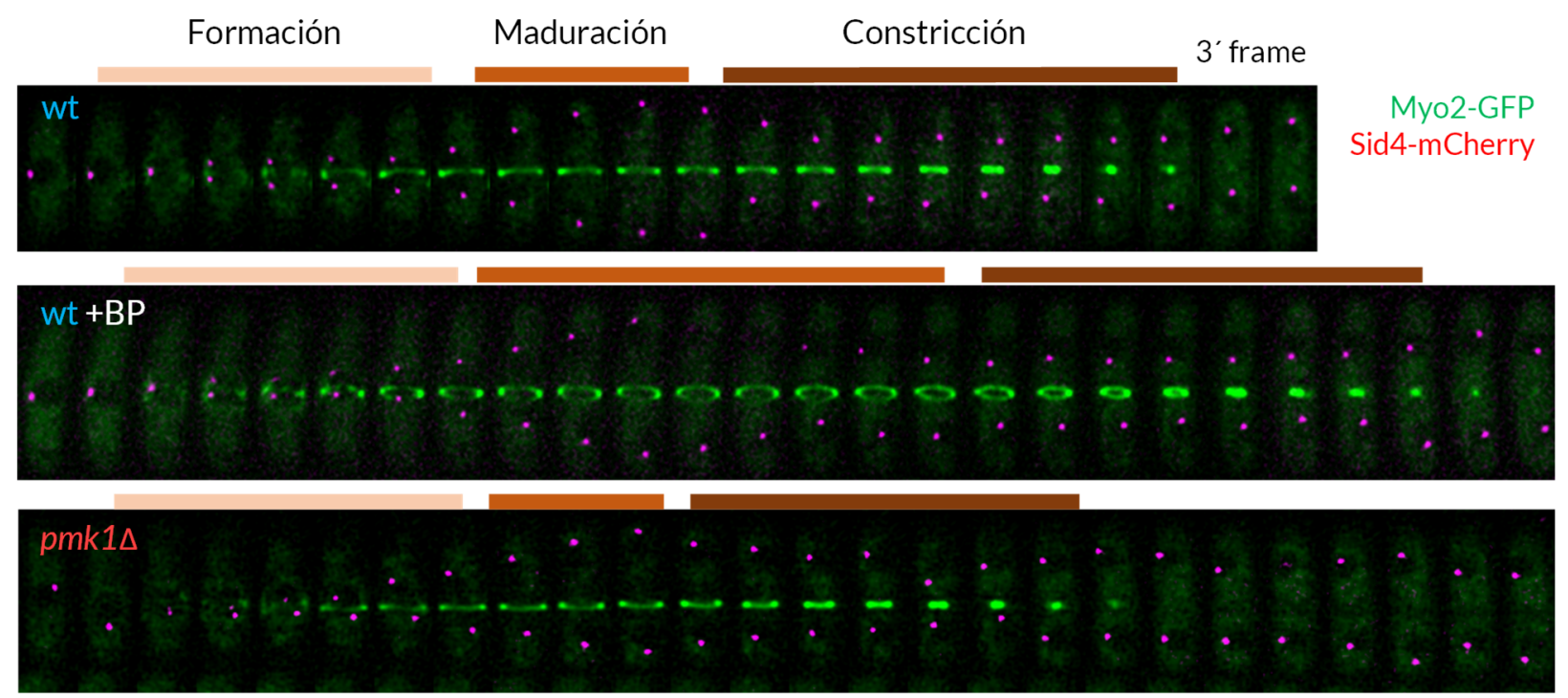

\section{pmk1 $1 \triangle+\mathrm{BP}$}

Formación

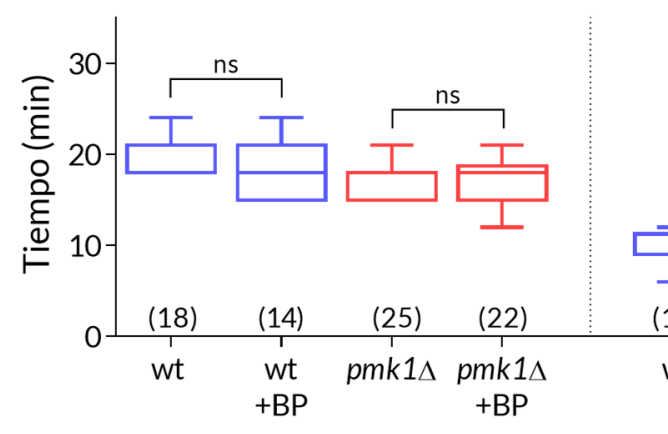

Maduración

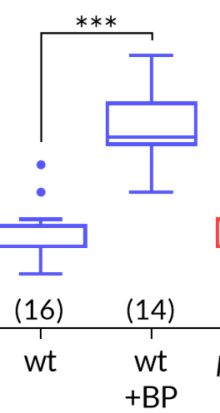

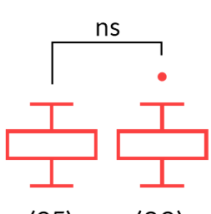

(25) (22)

pmk1 $\operatorname{pmk} 1 \Delta$

\section{Constricción}

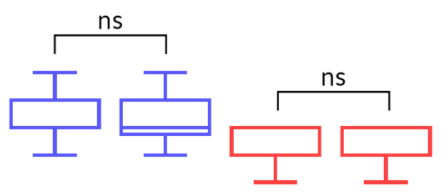

$\begin{array}{cccc}(16) & (14) & (25) & (22) \\ \text { wt } & \text { wt } & \text { pmk1 } 1 \Delta & p m k 1 \Delta \\ & +\mathrm{BP} & & +\mathrm{BP}\end{array}$

Figura 45 Pmk1 es necesaria para bloquear el inicio de la constricción en presencia de BP. Imágenes de time-lapse de células de tipo silvestre y pmk1 $\Delta$ que expresan Myo2-GFP y Sid4-mCherry, en presencia o ausencia de BP $5 \mu \mathrm{g} / \mathrm{ml}$. Las barras de color señalan las tres etapas por las que pasa el anillo, cuantificadas en los box-plots de los paneles inferiores como detalla en el texto que alude a la Figura 41. Datos analizados con test de Šidák (ns no significativo, $* * * \mathrm{p}<0.0001,(\mathrm{n})$ ). 
Si nos fijamos en la fase de maduración, aquella que se incrementa en la cepa silvestre, vemos que en el mutante pmk1 $\Delta$ apenas cambia por la presencia de BP. Cuando medimos la dinámica de constricción del anillo en el mutante pmk1 $\Delta$ vimos que el inicio de la constricción no se ve modificado por la presencia de BP, y tampoco su velocidad de cierre (Tabla 2). Estos datos indican que Pmk1 es parte fundamental de la maquinaria que induce un retraso en el inicio de la constricción del CAR en respuesta a daño en la pared celular provocado por BP.

\begin{tabular}{lcccccc}
\hline Constricción & wt - & wt $+\mathrm{BP}$ & rgfi $\Delta-$ & rgfi $\Delta+\mathrm{BP}$ & pmk1 $\Delta-$ & $\begin{array}{c}\text { pmk1 } \Delta \\
+\mathrm{BP}\end{array}$ \\
\hline Inicio (min) & $21 \pm 2$ & $38 \pm 5$ & $19 \pm 3$ & $25 \pm 4$ & $20 \pm 2$ & $20 \pm 4$ \\
Velocidad (nm/min) & $154 \pm 21$ & $158 \pm 31$ & $148 \pm 25$ & $175 \pm 30$ & $175 \pm 16$ & $187 \pm 15$ \\
\hline
\end{tabular}

Tabla 2 Momento de inicio y velocidad de constricción del CAR en cepas wt, $\operatorname{rgf}_{1} \Delta$ y pmk1 $\Delta$ que expresan Imp2-GFP y Sid4-GFP en presencia y ausencia de blankophor $5 \mathrm{\mu g} / \mathrm{ml}$. El minuto de inicio de la constricción toma como referencia o la duplicación de los SPBs. La velocidad se midió como el cambio del diámetro del CAR en función del tiempo, en el tramo lineal de la curva.

\section{COMPONENTES DE LA RUTA CIP QUE PARTICIPAN EN LA RESPUESTA A BLANKOPHOR}

La ruta de respuesta a estrés de Pmk1 no es lineal en su tramo superior, sino que presenta al menos dos activadores conocidos, Rho1 y Rho2. Estas GTPasas tienen papeles diferentes dependiendo del tipo estrés que origina la respuesta y actúan sobre la MAPKKK Mkh1 a través de dos proteínas PKC, Pck1 y Pck2 (ver Introducción) (Ma et al. 2006; Barba et al. 2008; SánchezMir et al. 2014).

Sabemos que Rho1, Rgf1 y Pmk1 participan en el retraso en citoquinesis, pero no sabemos por dónde se canaliza la señal ni qué componentes de la ruta participan en el proceso. Para ello construimos las cepas rho2 $\Delta$, pck2 $\Delta$ y pck1 $\Delta$ con los marcadores Imp2-GFP y Sid4-GFP y analizamos el tiempo de citoquinesis siguiendo el mismo procedimiento que en los experimentos anteriores. Hemos visto que el mutante $p c k 2 \Delta$ también es refractario al retraso citoquinético, mientras que los mutantes rho2 $\Delta$ y pck1 $\Delta$ responden de forma normal al BP (Figura 46). Estos datos indican que la vía Rgf1-Rho1-Pck2-Pmk1 de la ruta CIP es necesaria para el retraso del inicio de constricción del CAR inducido por BP. 


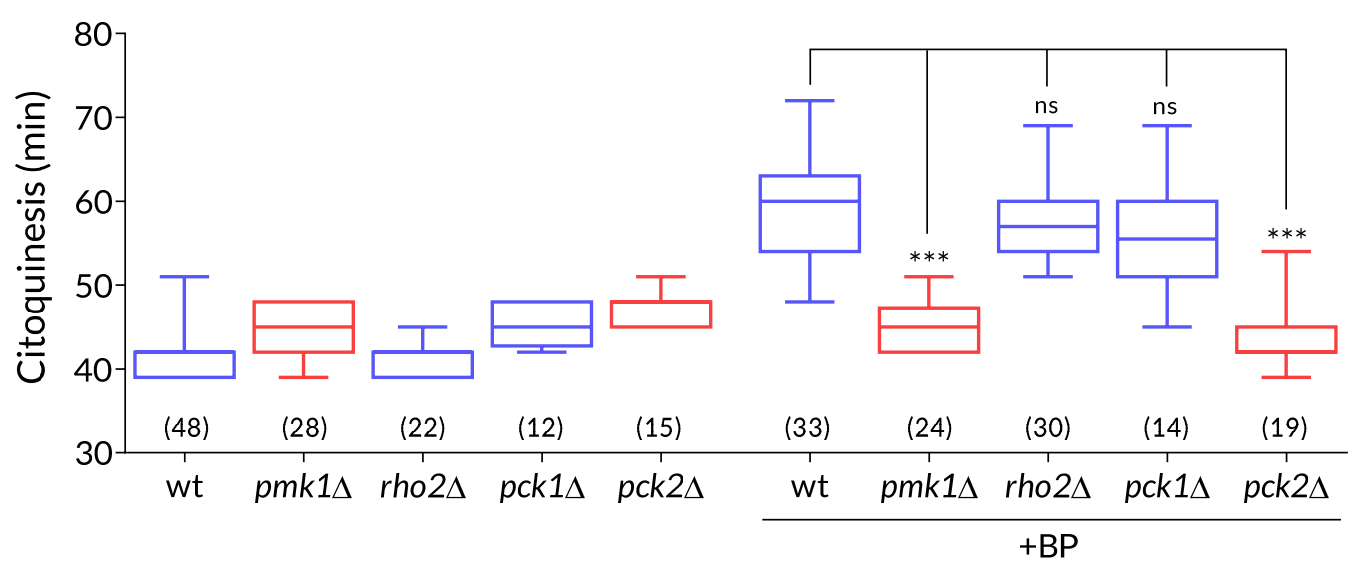

Figura 46 La vía Rgf1-Rho1-Pck2-Pmk1 de la ruta CIP es necesaria para retrasar la citoquinesis frente al BP. Tiempo que tarda en completarse la citoquinesis en cepas wt, pmk1 $\Delta$, rho2 $\Delta, p c k 1 \Delta$ y pck2 $\Delta$ que expresan Imp2-GFP y Sid4-GFP, en presencia y ausencia de BP $5 \mu \mathrm{g} / \mathrm{ml}$. Datos cuantificados a partir de time-lapses capturados en el DeltaVision y analizados con test de Šidák (ns no significativo, *** p<0.0001, $(\mathrm{n}))$.

\section{OTROS ESTRESES QUE ACTIVAN LA RUTA CIP TAMBIÉN RETRASAN LA CONSTRICCIÓN DEL CAR}

La ruta de integridad celular es activada por una amplia variedad de situaciones y sustancias exógenas (Madrid et al. 2006). Nos preguntamos si esta respuesta era exclusiva de la agresión producida por el BP o si otros agentes de estrés tendrían un efecto similar.

Seleccionamos otras sustancias que son, al igual que el BP, inductores de la ruta CIP: la caspofungina, un inhibidor de la $\beta$-1,3-glucán sintasa (Aguilar-Zapata et al. 2015), el KCl como agente de estrés salino hiperosmótico (Hohmann 2002), y la cafeína que, de manera potencialmente afín al BP, produciría cambios en la arquitectura de la pared celular (Martín et al. 2000a; Kuranda et al. 2006). Estos compuestos inducen la fosforilación de Pmk1 y la activación de la ruta CIP (Madrid et al. 2006; García et al. 2009b), pero más allá de la descripción de fenotipos de multiseptación no se había estudiado cómo progresaba la citoquinesis en células afectadas por estas drogas.

Medimos los tiempos de citoquinesis en células de tipo silvestre tratadas con estos tres compuestos. Como en el caso del BP ( $5 \mathrm{\mu g} / \mathrm{ml})$ empleamos también concentraciones bajas de los otros compuestos, cafeína (Caf) $2 \mathrm{mM}$, caspofungina (Csp) $0.2 \mu \mathrm{g} / \mathrm{ml} \mathrm{y} \mathrm{KCl} 0.2 \mathrm{M}$, que se añadieron en el momento inmediatamente previo al inicio del time-lapse. Los resultados mostraron que el BP no era un caso aislado (Figura 47).

Vimos que los tratamientos con cafeína, caspofungina y $\mathrm{KCl}$ también producen un aumento del tiempo que emplean las células en completar la citoquinesis, y que este retraso depende de la 
presencia de Pmk1. En el mutante rgf1 $\Delta$ la respuesta frente a Caf y Csp está a un nivel intermedio entre la del silvestre y el mutante $\operatorname{pmk}_{1} \Delta$, mientras que en el tratamiento con $\mathrm{KCl}$ responde de forma comparable al silvestre (Figura 47).

Estos datos sugieren que el punto final de la ruta, Pmk1, tiene mayor efecto que su tramo superior, Rgf1, en lo relativo a la parada frente a estrés. También podría ser indicativo de una amplificación de la señal a lo largo de la ruta o de una integración de señales que confluyen en Pmk1.

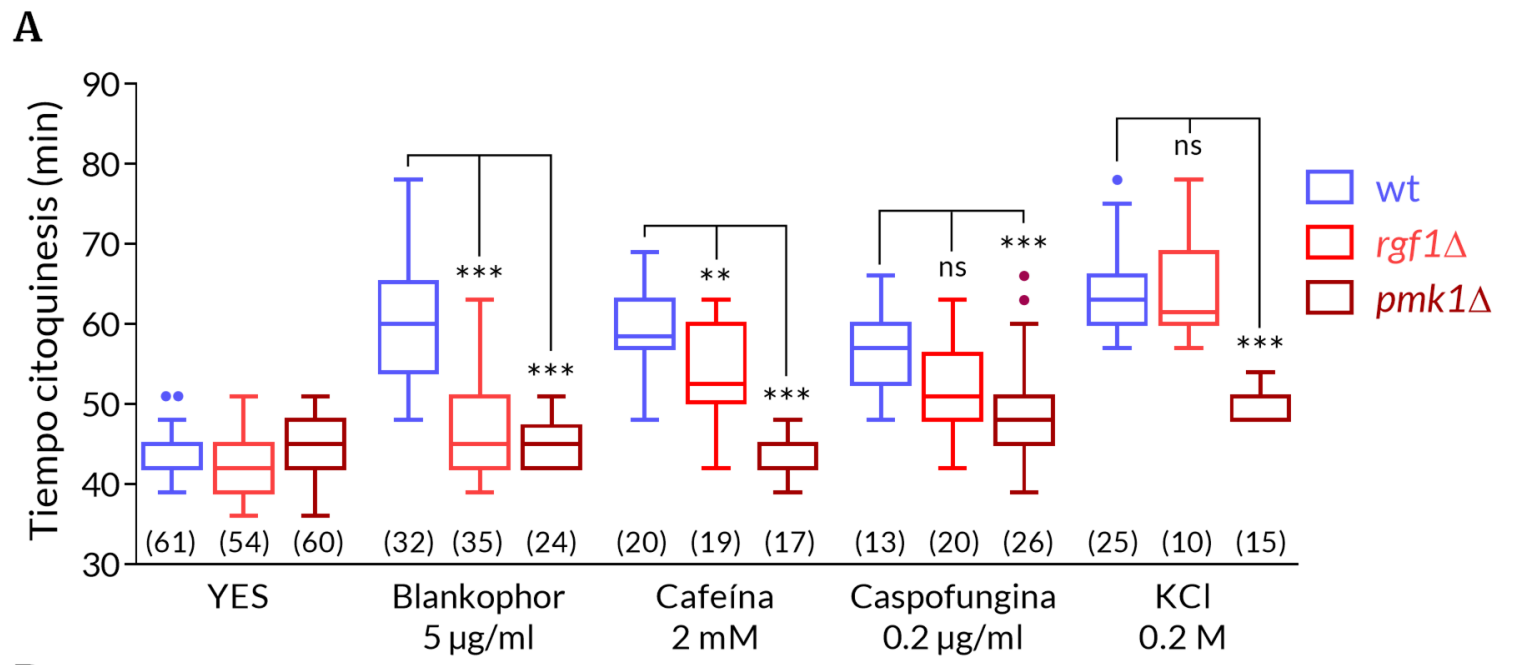

B
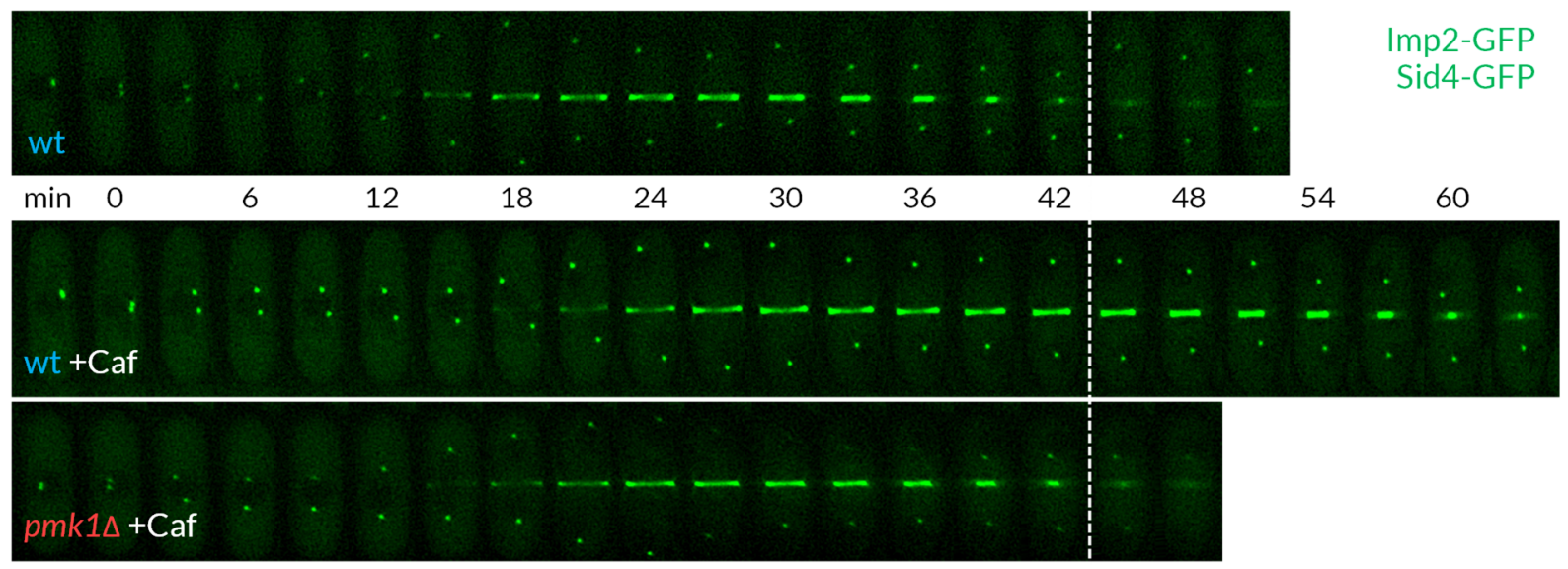

Figura 47 Además del BP, la cafeína, caspofungina y $\mathrm{KCl}$ también inducen un retraso en citoquinesis que depende de Pmk1. (A) Tiempo que tarda en completarse la citoquinesis en cepas wt, $r g f_{1} \Delta$ y pmk1 $\Delta$ que expresan Imp2-GFP y Sid4-GFP en condiciones normales (YES) y en presencia de BP $5 \mathrm{\mu g} / \mathrm{ml}$, Caf $2 \mathrm{mM}$, Csp $0.2 \mu \mathrm{g} / \mathrm{ml}$ y $\mathrm{KCl}$ 0.2M. Los distintos compuestos se añadieron al comienzo de los time-lapses. Datos cuantificados a partir de time-lapses capturados en DeltaVision y analizados con test de Šidák (ns no significativo, $* * \mathrm{p}<0.001 * * * \mathrm{p}<0.0001,(\mathrm{n})$ ). (B) Imágenes de películas representativas de los datos mostrados (A), en este caso células wt y pmk1 $\Delta$ tratadas con cafeína $2 \mathrm{mM}$. 
En el caso del estrés osmótico producido por el KCl no parece que la señal sea transducida a través de Rgf1, por lo que es probable que la agresión por estrés osmótico sea conducida por una vía independiente de Rgf1, quizá a través de Rho2. Esta posibilidad no ha sido estudiada.

También hemos visto diferencias en el retraso producido por el $\mathrm{KCl}$ con respecto los otros compuestos en el mutante pmk1 $\Delta$. Este mutante tiene también algo de retraso durante el tratamiento con $\mathrm{KCl}$ con respecto a sus condiciones basales (YES), aunque sin llegar a los tiempos de la cepa silvestre (Figura 47). Es posible que las nuevas condiciones osmóticas estuvieran originando un cambio en el ambiente celular que modificaría per se la citoquinesis al margen del retraso mediado por la ruta $\mathrm{CIP}$; de hecho, la adición de $\mathrm{KCl} 1 \mathrm{M}$ produce una disminución del volumen celular y hace que los anillos se encojan y desensamblen, para luego volverse a formar (Okada et al. 2019). Los tiempos de citoquinesis de las células pmk1 $\Delta$ tratadas con Csp presentan mayor dispersión que las de los otros casos (Figura 47); en este tratamiento encontramos algunas células lisadas en el cultivo, especialmente en el momento de la separación celular y también en la cepa silvestre, lo que nos estaría hablando de nuevo de efectos adicionales que se sumarían en global sobre el retraso que venimos definiendo.

Los cuatro compuestos analizados (BP, Caf, Csp y $\mathrm{KCl}$ ) producen un incremento del tiempo de citoquinesis, aunque su relación con los mutantes de la ruta CIP presenta particularidades en cada caso. Esto no resulta extraño puesto que, aun induciendo los cuatro la activación de Pmk1, el estrés que producen sobre la célula es de distinta naturaleza. Las discrepancias vendrán definidas pues por el conjunto de efectos de cada compuesto; simplificarlos en una agresión concreta probablemente dista de lo que ocurre en realidad, y sin embargo agruparlos en sus similitudes nos ayuda a conocer la clase de respuesta que producen, centrándonos en este caso en la mediada por Pmk1 durante citoquinesis.

En esta búsqueda de elementos comunes decidimos analizar la dinámica de los anillos de actomiosina. Hemos establecido que el efecto inducido por el BP es exclusivamente el retraso del inicio de la constricción. La Caf, Csp y el $\mathrm{KCl}$ aumentan también el tiempo de citoquinesis, pero no sabemos si su efecto es el mismo que el del BP. Medimos la progresión del diámetro del CAR a lo largo del tiempo en células tratadas con los tres nuevos compuestos y la comparamos con la condición sin tratamiento y con el efecto inducido por el BP (Figura 48).

La Caf, Csp y el KCl también producen un retraso del inicio de la constricción del CAR; las curvas que representan el diámetro del anillo inician su descenso más tarde en las células expuestas a las drogas. Este descenso coincide en los tres casos (a las concentraciones anteriormente referidas) de media en el minuto $27 \pm 3$, lejos del minuto $21 \pm 2$ de la condición sin tratamiento (Tabla 3). Esta diferencia de unos 6 minutos es inferior a los 17 minutos de retraso que causa el tratamiento con BP. La discrepancia podría deberse a efectos de la concentración; puesto que ya hemos visto anteriormente que el bloqueo producido por BP se incrementa con la 
dosis (ver Figura 37). También hemos visto que la Caf, Csp y el $\mathrm{KCl}$ provocan un descenso de la velocidad de constricción del CAR (Tabla 3).

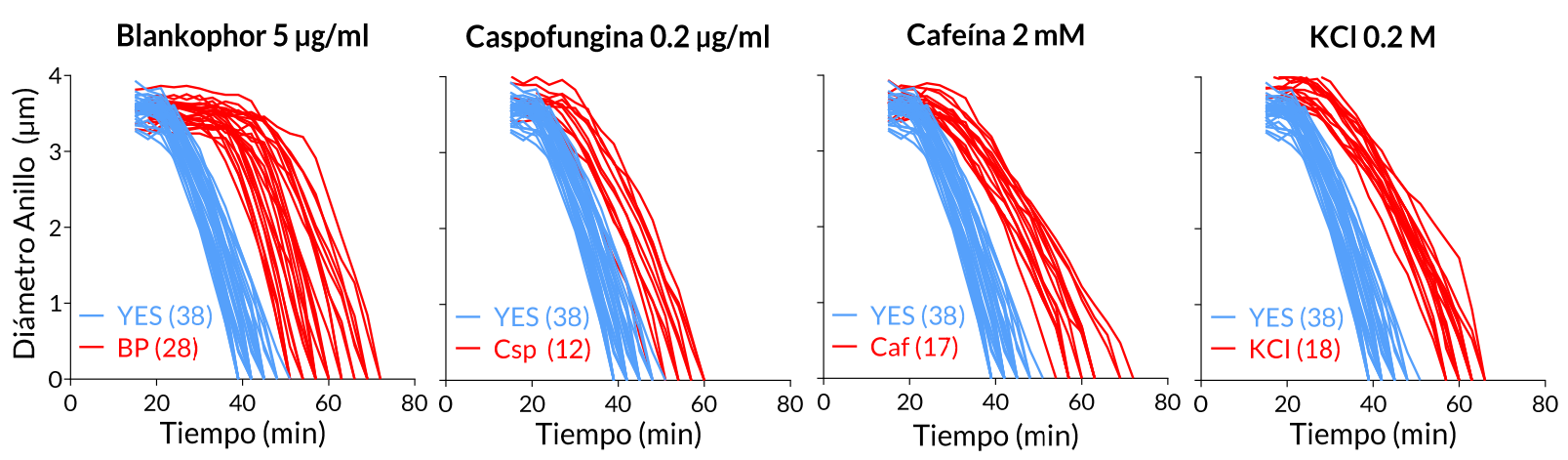

Figura 48 La cafeína, caspofungina y el $\mathrm{KCl}$ retrasan el inicio de la contracción del CAR y reducen su velocidad de cierre. Dinámicas de contracción de los anillos de la cepa silvestre wt que expresa Imp2-GFP y Sid4-GFP, en condiciones normales (YES) y en presencia de BP $5 \mu \mathrm{g} / \mathrm{ml}$, Caf $2 \mathrm{mM}$, Csp $0.2 \mu \mathrm{g} / \mathrm{ml}$ y KCl 0.2M. Cada línea es un anillo al que medimos su diámetro en cada tiempo a partir de time-lapses capturados en el DeltaVision.

\begin{tabular}{|c|c|c|c|c|c|}
\hline Constricción & YES & $\mathrm{BP} 5 \mu \mathrm{g} / \mathrm{ml}$ & Caf $2 \mathrm{mM}$ & Csp $0,2 \mu \mathrm{g} / \mathrm{ml}$ & $\mathrm{KCl} 0.2 \mathrm{M}$ \\
\hline Inicio (min) & $21 \pm 2$ & $38 \pm 5$ & $27 \pm 3$ & $27 \pm 3$ & $27 \pm 3$ \\
\hline Velocidad (nm/min) & $154 \pm 21$ & $158 \pm 31$ & $97 \pm 17$ & $114 \pm 13$ & $95 \pm 17$ \\
\hline
\end{tabular}

Tabla 3 Momento de inicio y velocidad de constricción del CAR en la cepa que expresa que expresa Imp2GFP y Sid4-GFP en ausencia de estrés (YES) y en presencia de blankophor $5 \mathrm{\mu g} / \mathrm{ml}$, cafeína $2 \mathrm{mM}$, Caspofungina $0.2 \mu \mathrm{g} / \mathrm{ml}$ y KCl 0.2M. El inicio de la constricción toma como referencia o min la duplicación de los SPBs. La velocidad está medida como el cambio del diámetro del CAR en función del tiempo, en el tramo lineal de la curva.

Que en estos compuestos veamos dos clases de respuestas sobre el anillo de actomiosina mientras que con BP únicamente se manifieste el del retraso del inicio de constricción no podemos sino achacarlo a la naturaleza de cada componente y a la diversidad de efectos que estos causen en la célula, aunque este es un terreno con más preguntas que respuestas.

Si la disminución de la velocidad de constricción del CAR es una respuesta activa de la célula o si es una consecuencia de cambios en la fisiología celular por los efectos del estrés y/o de la respuesta a dicho estrés, por ejemplo por cambios en la presión de turgencia (Proctor et al. 2012; Chang 2017), tampoco queda resuelto. Podemos de todas formas sugerir con los datos que tenemos que no se trata de un simple cambio en el entorno celular y que depende de la respuesta a la agresión. El hecho de que el mutante pmk1 $\Delta$ no incremente su tiempo de citoquinesis en 
respuesta a estos compuestos (ver Figura 47) querría decir que anula los dos efectos, el retraso del inicio y la disminución de la velocidad, o dicho de otra forma, que ambos efectos son dependientes de Pmk1. Como pone de manifiesto el BP los dos efectos no están ligados, en este caso sólo tenemos uno que depende enteramente de Pmk1, y sin embargo en las otras condiciones Pmk1 intervendría en una respuesta adicional, la bajada de la velocidad. Retrasar el inicio de la constricción y reducir su velocidad serían al final respuestas relacionadas con el control de la septación que media Pmk1 ante agresiones que afectan a la integridad de la pared celular o el septo.

\section{EL BLANKOPHOR, LA CASPOFUNGINA, LA CAFEÍNA Y EL KCL INDUCEN

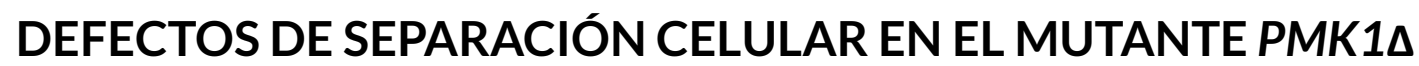

Las células pmk1 $\Delta$ presentan fenotipos ligados a la septación y al estrés. En el mutante pmk1 $\Delta$ el porcentaje de células con septo es más alto que en la cepa silvestre y también aparece un pequeño porcentaje de células multiseptadas; ambos fenotipos se agravan con el incremento de la temperatura o en situaciones de estrés (Toda et al. 1996; Zaitsevskaya-Carter \& Cooper 1997; Loewith et al. 2000). Para ver si el retraso que hemos descrito en citoquinesis tiene alguna consecuencia fisiológica examinamos el fenotipo de las células pmk1 $\Delta$ después del tratamiento con BP, Caf, Csp y KCl.

En las condiciones de cultivo utilizadas hasta ahora, medio YES a $28^{\circ} \mathrm{C}$, no habíamos detectado ningún fenotipo destacable, por lo que cambiamos las condiciones en favor de otras

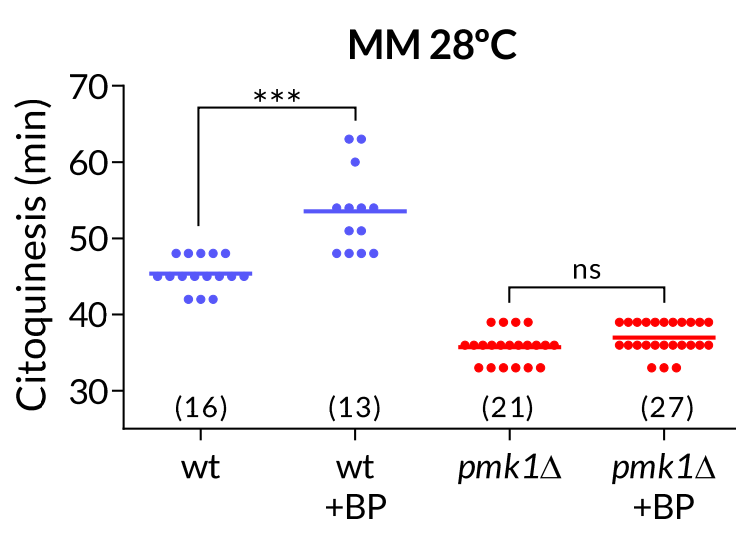

Figura 49 El blankophor produce un retraso de la citoquinesis tambien en medio mínimo. Tiempo que tarda en completarse la citoquinesis en cepas wt y pmk1 $\triangle$ que expresan Imp2-GFP y Sid4-GFP, en presencia y ausencia de BP $5 \mu \mathrm{g} / \mathrm{ml}$. Datos cuantificados a partir de time-lapses capturados en Spinning Disk y analizados con test de Fisher (ns no significativo, $* * * \mathrm{p}<0.0001,(\mathrm{n})$ ) en las que estos fenotipos se hacían más evidentes (Toda et al. 1996), esto es, medio mínimo $(\mathrm{MM})$ a $31^{\circ} \mathrm{C}$. Antes de comenzar con los experimentos en MM analizamos el tiempo que dura la citoquinesis en este medio en presencia de BP mediante time-lapse. Como se puede observar en la Figura 49, también hay un retraso de la citoquinesis en MM y que este retraso depende de la presencia de Pmk1.

A continuación, tomamos muestras de cultivos creciendo en fase exponencial en MM a $31^{\circ} \mathrm{C}$ durante $16 \mathrm{~h}$ (pasadas desde $25^{\circ} \mathrm{C}$ ), y las fotografiamos in vivo utilizando la tinción de BP en el momento para marcar 
los septos. En estas condiciones el mutante pmk1 $\Delta$ empieza a manifestar ciertos defectos en septación. El porcentaje de células con 1 septo aumentó del 17\% de la cepa silvestre a un 20\% en el mutante. Además, en el mutante hay un $2 \%$ de células con más de un septo, que no se ven en la cepa silvestre (Figura 50B).

A
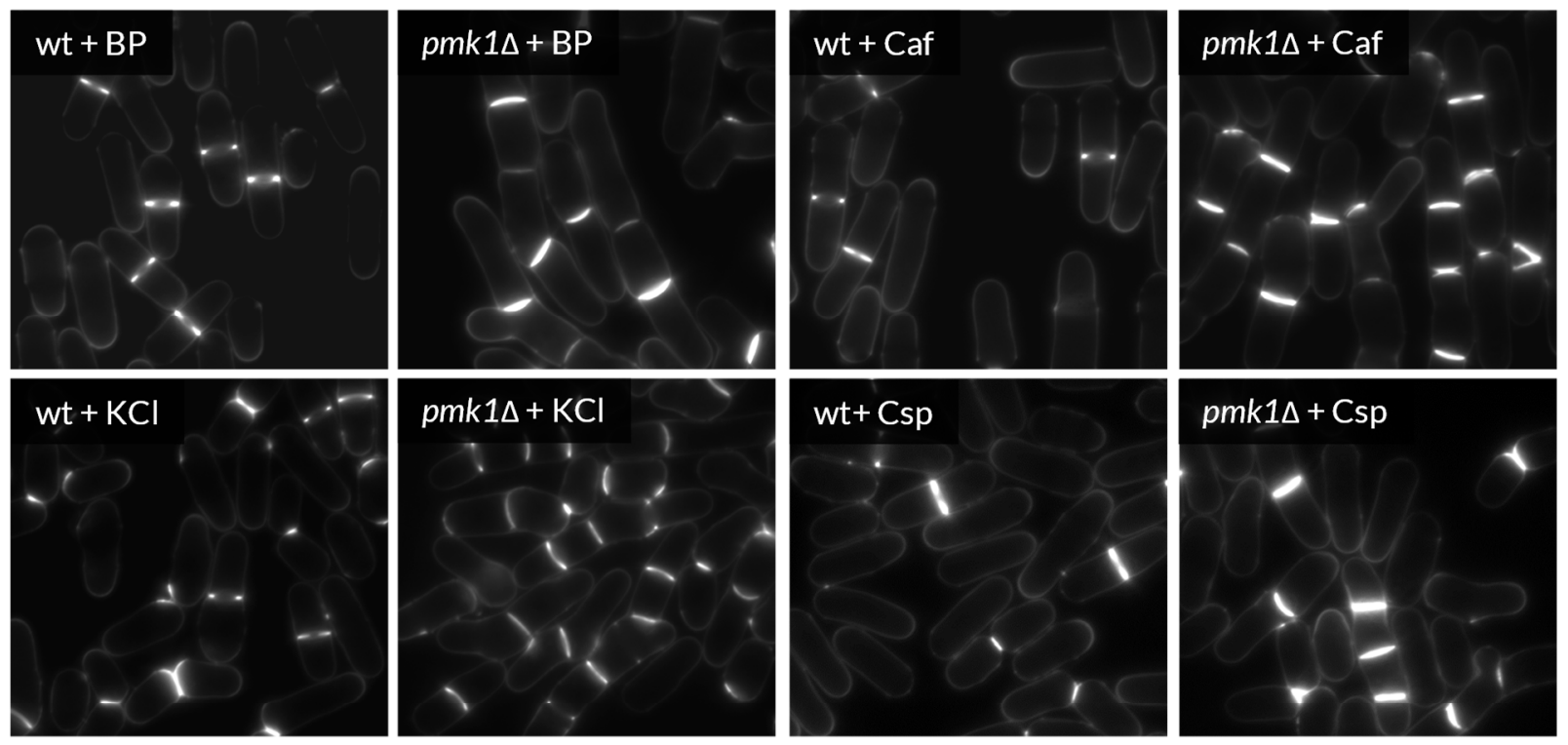

B

C

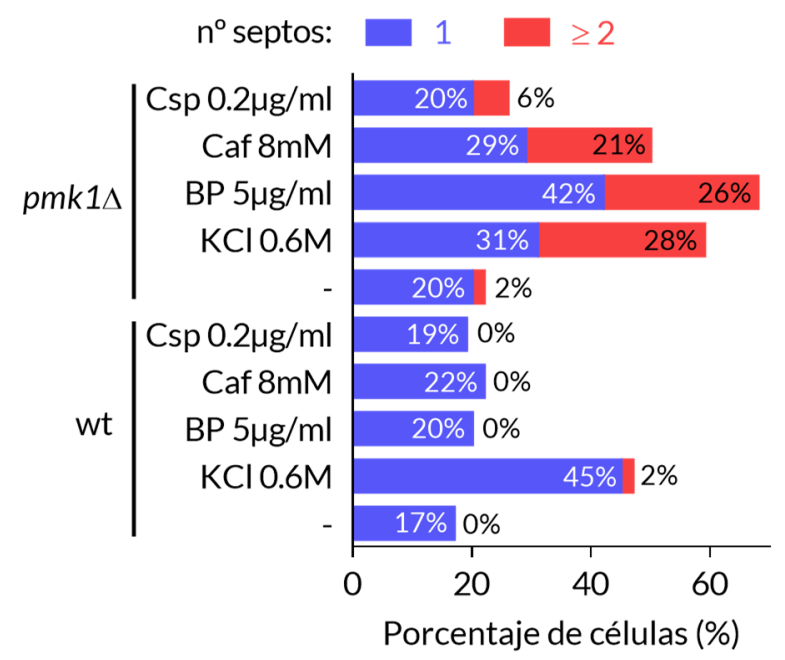

$p m k 1 \Delta$

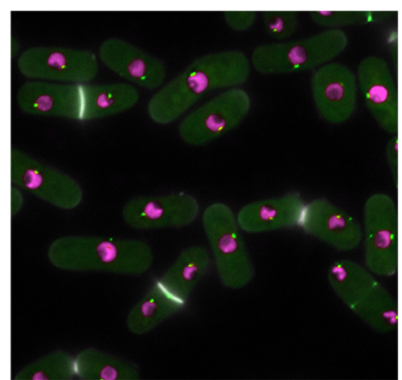

$p m k 1 \Delta+\mathrm{KCl}$

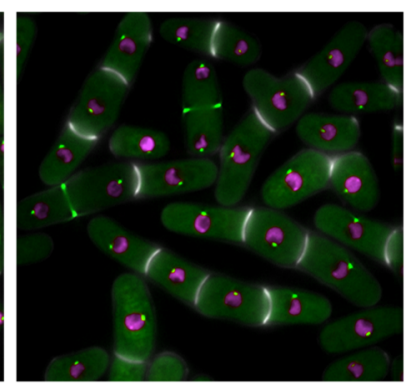

Hht1-RFP Imp2-GFP Sid4-GFP $\mathrm{BP}$

Figura 50 La presencia de blankophor, cafeína, caspofungina y $\mathrm{KCl}$ origina células encadenadas en el mutante pmk1 $\Delta$. (A) Imágenes de fluorescencia de células wt y pmk1 $\Delta$ crecidas a $31^{\circ} \mathrm{C}$ durante $16 \mathrm{~h}$ en $\mathrm{MM}$ en presencia de BP $5 \mathrm{\mu g} / \mathrm{ml}$, Caf $2 \mathrm{mM}$, Csp $0.2 \mathrm{\mu g} / \mathrm{ml} \mathrm{y} \mathrm{KCl} \mathrm{o.6M,} \mathrm{y} \mathrm{teñidas} \mathrm{con} \mathrm{BP} \mathrm{en} \mathrm{el} \mathrm{momento} \mathrm{de} \mathrm{capturar}$ las imágenes en DeltaVision. (B) Porcentaje de las células descritas en (A) que presenta uno (azul) o más septos (rojo) (>300 células/condición). (C) Imágenes de fluorescencia tomadas en DeltaVision de células pmk1 $\triangle$ que expresan la variante de histona Hht1-RFP, Imp2-GFP, Sid4-GFP. Las células fueron incubadas en presencia y ausencia de $\mathrm{KCl}$ y teñidas con $\mathrm{BP}$ como en (A). 
Cuando sobre estas condiciones de cultivo aplicamos el tratamiento con BP a 5 $\mu \mathrm{g} / \mathrm{ml}$, la misma concentración a la que se producía el fenotipo de retraso, y miramos las células a las 16h vemos que los fenotipos se agravan. El porcentaje de células pmk1 $\Delta$ con un septo se dispara al $42 \%$, y además otro $26 \%$ de las células son muy largas y tienen varios septos por célula, separados de forma aproximadamente equidistante, y en algunos casos con ramificaciones (Figura 50A); estos defectos están casi completamente ausentes en la cepa silvestre (20\% de células con un septo y ausencia de multiseptadas o ramificadas).

Los tratamientos con $\mathrm{KCl}$, cafeína y caspofungina producen resultados similares en las respectivas cepas, entre los que destacan dos situaciones (Figura 50B). El tratamiento con $\mathrm{KCl}$ en la cepa silvestre incrementa el porcentaje de células con un septo a un $45 \%$ y (2\%) de multiseptadas, mientras que en la cepa pmk1 $\Delta$ el número de células con un septo es similar pero las multiseptadas alcanzan el $28 \%$. Esto podría indicar que este estrés hipertónico origina una situación que complica la separación celular pero que puede llegar a término gracias la presencia de Pmk1. Por otro lado, el incremento de células multiseptadas producido por la caspofungina en pmk1 $\Delta$ es solo del (6\%). Curiosamente en MM y con una concentración de Caspofungina de 0.2 $\mu \mathrm{g} / \mathrm{ml}$, no vemos el fenotipo de lisis celular observado en los time-lapses en YES, lo que está de acuerdo con un efecto más suave.

Al margen de los detalles que diferencian los distintos tipos de estrés, la figura de Pmk1 establece la relación entre el fenotipo de multiseptación en presencia de estrés y el efecto del retraso de la citoquinesis. Dicho de otra manera, en el mutante $p m k 1 \Delta$ la ausencia de retraso ante estrés se correlaciona con la aparición a largo plazo de septos sin resolver.

Definimos así estos septos porque hemos mirado el estado de estas células multiseptadas marcando los núcleos celulares con la histona H3 con epítopo rojo, Hht1-RFP. Las células pmk1 $\Delta$ tratadas con $\mathrm{KCl}$ que describíamos como multiseptadas son en realidad células encadenadas (Figura 50C). Cada septo separa o bien un compartimento celular con un único núcleo, y por tanto una célula no separada, o con dos núcleos cuando esa célula está en mitosis, algo que podemos visualizar por la duplicación del SPB (Sid4-GFP) y la presencia del CAR (Imp2-GFP). Estos son por tanto septos mitóticos (no interfásicos) que se forman tras una mitosis exitosa, en tanto que la segregación nuclear no presenta defectos apreciables, lo que concuerda con el retraso en citoquinesis que hemos definido.

Pensamos que es la incapacidad del mutante para inducir el retraso en citoquinesis, y así garantizar la actuación de un hipotético mecanismo de control, lo que finalmente produce estos septos defectuosos. Esta idea favorece el modelo en el que estos defectos de separación celular tienen su origen en el comienzo de la septación. Por ello, más que defectos en la actuación de las glucanasas creemos que en este caso es la formación del septo la parte determinante para que el septo maduro se disuelva de forma adecuada (Martín-Cuadrado et al. 2003; García et al. 2005; 
Martín-García \& Santos 2016). Nuestros datos indican que la ruta CIP se activaría en respuesta a agresiones que afectan a la correcta formación del septo induciendo una parada antes de su invaginación a través del bloqueo del inicio de la constricción del CAR.

Nos preguntamos si esta respuesta de la ruta CIP se produce también en otras situaciones que afectan a la estabilidad del septo como es el caso de mutantes con defectos en la síntesis de la pared celular. Para ello analizamos el tiempo que dura la citoquinesis en la cepa cwg1-1, que tiene una mutación no letal en el gen $\mathrm{bgs}^{+}$, una de las cuatro subunidades catalíticas de la $\beta$-glucán sintasa. Esta mutación confiere a las células el carácter termosensible, así como una reducción del $\beta$-glucano de la pared celular y de la actividad glucán sintasa a la temperatura restrictiva (Cortés et al. 2005). Además de estos fenotipos, en el mutante cwg1-1 el tiempo que dura la citoquinesis es sensiblemente más largo que en la cepa silvestre (Muñoz et al. 2013). Nosotros hemos visto que este retraso se suprime parcialmente al delecionar Pmk1 (Figura 51), lo que sugiere que diversas situaciones de estrés en septación producirían también la activación de la ruta CIP para inducir el retraso en citoquinesis.

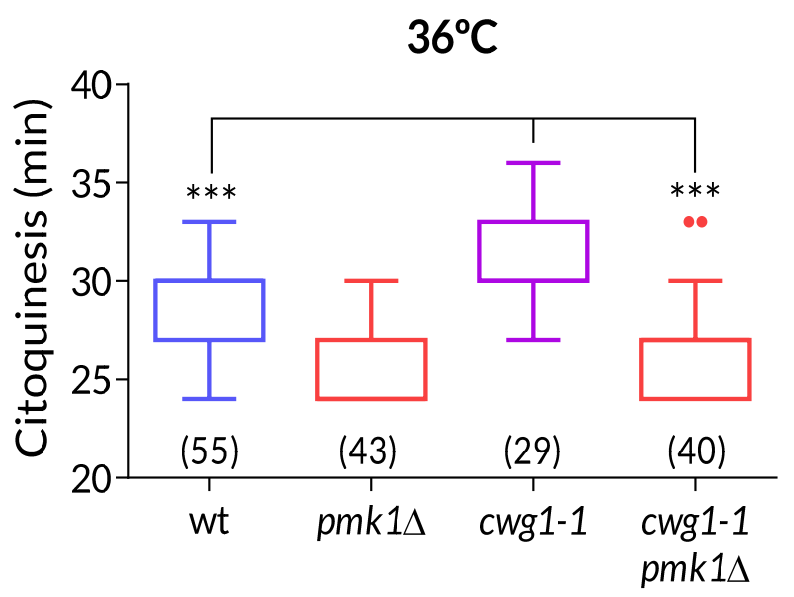

Figura 51 Pmk1 media en el retraso en citoquinesis del mutante $\mathbf{c w g} \mathbf{1 - 1}$. Tiempo que tarda en completarse la citoquinesis en cepas

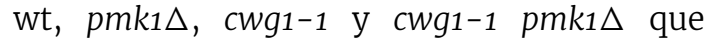
expresan Imp2-GFP y Sid4-GFP, crecidas previamente a $36^{\circ} \mathrm{C}$ durante $1.5 \mathrm{~h}$ (vienen de $25^{\circ} \mathrm{C}$ ). Datos cuantificados a partir de timelapses capturados en el Spinnig Disk a $36^{\circ} \mathrm{C}$ y analizados con test de Fisher $(* * * \mathrm{p}<0.0001$, (n)).

\section{RELACIÓN DE LA MIOSINA CON EL RETRASO CAUSADO POR EL ESTRÉS EN SEPTACIÓN}

El cierre del anillo de actomiosia es un proceso complejo que se produce gracias a la cooperación de dos actividades necesarias, la tensión generada por la interacción de las miosinas sobre los filamentos de actina y la síntesis acoplada del septo (Willet et al. 2015; Rincon \& Paoletti 2016; Pollard \& O'Shaughnessy 2019). Un bloqueo en la constricción del anillo como el que hemos descrito podría ser el resultado de una parada en uno de estos dos procesos, o en ambos. 
Hemos descartado ya que el bloqueo de la síntesis del septo sea la causa de la parada. Sabemos que la síntesis del septo se inicia a tiempos normales aun en condiciones de bloqueo y que la señal de BP va aumentando lentamente con el tiempo (ver Figura 40). La propia naturaleza del BP como colorante que se une preferentemente a las regiones de pared celular que crecen activamente invita a pensar que el estrés producido a esta concentración tan baja solo se origina una vez que ha comenzado la síntesis del septo. Decidimos mirar entonces si era la actividad motriz de la miosina o la polimerización de las fibras de actina lo que se veía bloqueado en presencia de BP y que paraliza transitoriamente la constricción del CAR.

S. pombe presenta dos isoformas de la miosina II, Myo2 es una miosina convencional y es esencial, mientras que Myp2 tiene una estructura diferente y no es esencial. Ambas cadenas pesadas se unen a las dos cadenas ligeras Cdc4 y Rlc1 (Bezanilla et al. 1997; Le Goff et al. 2000; Motegi et al. 2000). Myo2 es muy dinámica y se distribuye en nodos que capturan los filamentos de actina de nodos adyacentes. Myp2 es prácticamente inmóvil y se incorpora al anillo ya ensamblado. Las células del mutante myp2 $\Delta$ presentan retraso en constricción (Laplante et al. 2015), especialmente bajo condiciones de alto estrés salino (Okada et al. 2019).

Para saber si Myp2 era la diana que estaría siendo frenada para retrasar la constricción del CAR medimos los tiempos de citoquinesis del mutante myp2 $\Delta$ en ausencia y presencia de BP. Vimos que la presencia de BP produce un retraso adicional sobre el tiempo medio de constricción de myp $2 \Delta($ myp $\Delta: 48 \pm 5.5 \mathrm{~min}$, myp $2 \Delta+\mathrm{BP}: 60 \pm 5.9 \mathrm{~min}$ ) (Figura 52), lo que sugiere que el retraso de myp $2 \Delta$ y el del estrés de pared se dan por vías diferentes. Obtuvimos resultados similares al suprimir la cadena ligera Rlc1, componente regulador de Myo2 y de Myp2 (Figura 52). En conjunto estos datos indican que ni Myp2 ni Rlc1 son los responsables de la parada transitoria en la constricción del CAR producida por el BP.

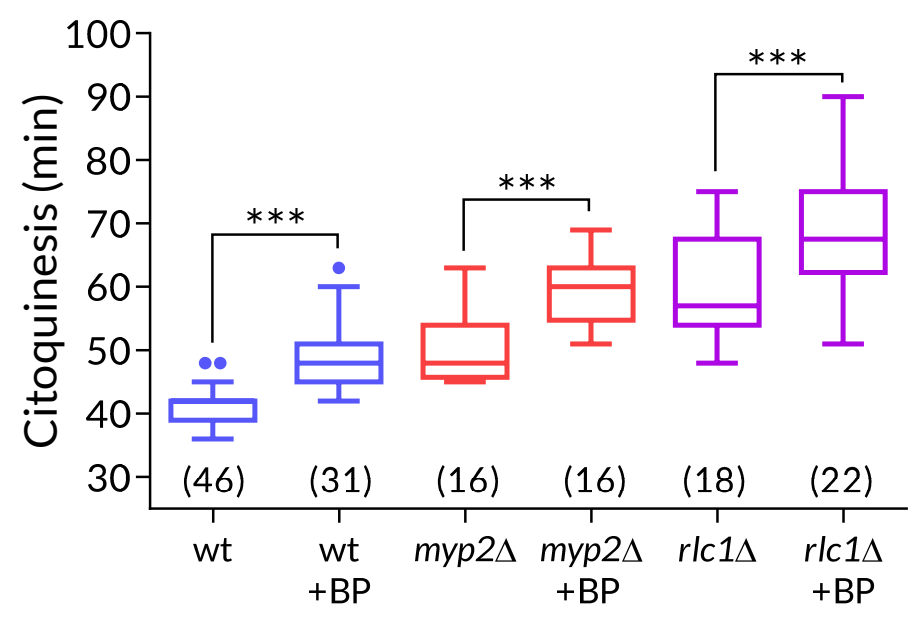

Figura 52 Los componentes de la miosina II Myp2 y Rlc1 no están involucrados en el retraso citoquinético frente a BP. Tiempo que tarda en completarse la citoquinesis en cepas wt, myp $2 \Delta$ y rlc1 $\Delta$ que expresan Imp2-GFP y Sid4-GFP en ausencia y en presencia de BP $5 \mu \mathrm{g} / \mathrm{ml}$. Datos cuantificados a partir de time-lapses capturados en Spinning Disk y analizados con el test de Fisher (*** $\mathrm{p}<0.0001,(\mathrm{n}))$. 


\section{RELACIÓN DE LA ACTINA CON EL RETRASO CAUSADO POR EL ESTRÉS EN SEPTACIÓN}

Dejando de lado la vía de la miosina estudiamos si el bloqueo del CAR podía venir dado por alteraciones en los procesos de remodelación de actina. Se sabe que tanto la polimerización como la despolimerización de los filamentos de actina son actividades necesarias para la integridad y constricción del CAR (Cheffings et al. 2016, 2019; Rincon \& Paoletti 2016). La formina Cdc12 nuclea y elonga los filamentos de actina (Chang et al. 1997; Kovar et al. 2003), mientras que la cofilina Adf1 participa en la remodelación seccionando estos (Nakano \& Mabuchi 2006).

Como las dos actividades son esenciales, utilizamos el mutante termosensible cdc12-112, el cual lleva una mutación puntual en el dominio FH2 (Formin Homology 2) que afecta a su actividad en el ensamblaje de actina (Coffman et al. 2013), y el mutante adf1-1, que está afectado en el desensamblaje y es también termosensible (Chen \& Pollard 2011). Empleamos la misma estrategia seguida con los mutantes de miosina, comparando los tiempos de citoquinesis de estos mutantes en presencia y ausencia de BP, pero en este caso, al tratarse de mutantes termosensibles, realizamos los experimentos a la temperatura semi-restrictiva de $32^{\circ} \mathrm{C}$.

En ambos mutantes la citoquinesis es más lenta que en la cepa silvestre a $32^{\circ} \mathrm{C}$, lo que nos indica que el proceso se encuentra afectado en estas condiciones (Figura 53A, B). Sin embargo, nuevamente en las dos cepas, $a d f_{1-1}$ y $c d c 12-112$, la presencia de BP produce un retraso aditivo sobre sus respectivas condiciones basales. Si bien los datos del mutante adf1-1 no dejaban lugar a dudas (Figura 53A), en el caso del mutante cdc12-112 el retraso inducido por el BP no era proporcional al visto en la cepa silvestre, es decir, el BP producía un retraso, pero más leve que en el control (Figura 53B).

Repetimos entonces el experimento incrementando la temperatura hasta los $34^{\circ} \mathrm{C}$ para condicionar todavía más la función de $c d c 12-112$, y medimos específicamente el tiempo desde la separación de los SPBs hasta el inicio de la constricción del CAR en lugar de la citoquinesis total. Esperábamos que si Cdc12 fuera el responsable del retraso se acortarían las diferencias entre la cepa mutante tratada con BP y el control sin tratar. El incremento de la temperatura condiciona más la citoquinesis en el mutante $c d c 12-112$ lo que sugiere que sus defectos se concentran antes del inicio de la constricción. Pero igual que a $32^{\circ} \mathrm{C}$, la adición de BP produce un retraso adicional (Figura 53C), lo que sugiere que no es Cdc12 ni tampoco Adf1 el efector involucrado en frenar la constricción ante la agresión por BP. 
A

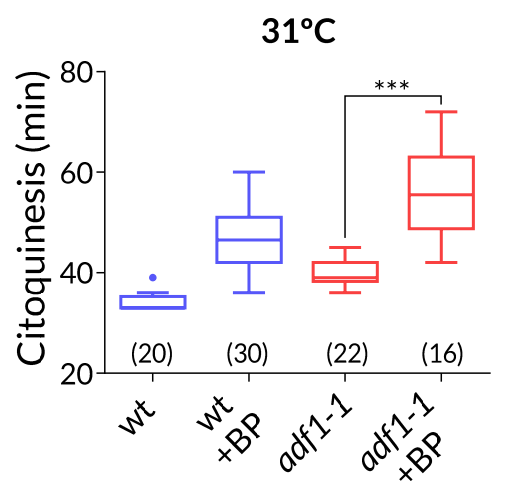

B

$32^{\circ} \mathrm{C}$

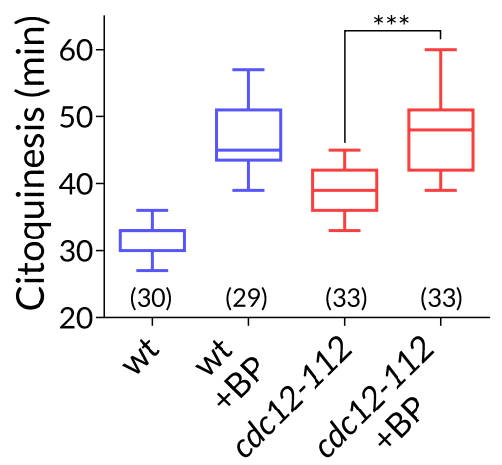

C

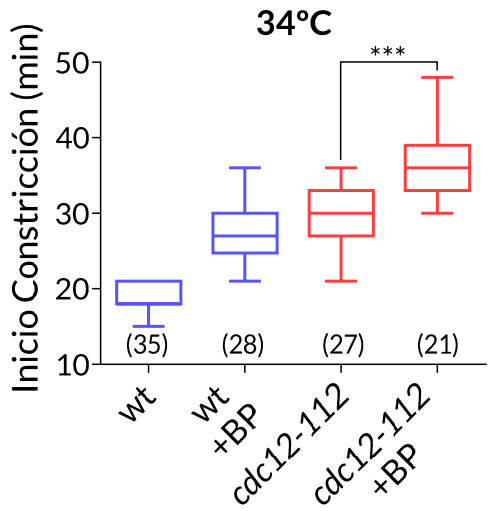

Figura 53 Ni la formina Cdc12 ni la cofilina Adf1 están involucradas en el retraso citoquinético frente a BP. (A, B) Tiempo que tarda en completarse la citoquinesis en cepas wt, adf1-1 y cdc12-112 que expresan Imp2-GFP y Sid4-GFP. Antes del time-lapse las células fueron incubadas durante $1 \mathrm{~h}$ a $31^{\circ} \mathrm{C}(\mathrm{A})$ y $32^{\circ} \mathrm{C}(\mathrm{B})$ y el time-lapse se realizó ausencia o en presencia de BP $5 \mathrm{\mu g} / \mathrm{ml}$. (C) Se analizó el tiempo desde la separación de los SPBs hasta el inicio de la constricción en cepas wt y cdc12-112 que expresan Imp2-GFP y Sid4-GFP en presencia y ausencia de BP $5 \mathrm{\mu g} / \mathrm{ml}$. Antes del time-lapse las células fueron incubadas durante $1 \mathrm{~h} \mathrm{a} 34^{\circ} \mathrm{C}$ y el time-lapse se realizó en ausencia o en presencia de BP $5 \mathrm{\mu g} / \mathrm{ml}$. Datos cuantificados a partir de timelapses capturados en el Spinning Disk a las respectivas temperaturas y analizados con test $t$ de Student (*** $\mathrm{p}<0.0001,(\mathrm{n}))$.

Hasta ahora nuestras aproximaciones para encontrar el origen del bloqueo dentro de los componentes del CAR han producido resultados negativos. Sin embargo, esto no nos permite descartar por completo que la naturaleza de la parada venga del freno en la actividad de la actina o miosina, puesto que usamos mutantes que todavía conservan cierta actividad. Hay múltiples proteínas involucradas en estos sistemas que podrían ser posibles candidatos, otras miosinas como Myo2 o Myo51 (Laplante et al. 2015), forminas como For3, u otras proteínas de unión a actina como Ain1 o Fim1 (Mishra et al. 2014; Willet et al. 2015).

Llegado a este punto, continuar con la búsqueda del elemento responsable nos parecía una tarea ineficiente con esta metodología, más si planteamos que pudiera tratarse de un sistema redundante o sinérgico entre varios componentes. Decidimos tomar distancia y abordar el estudio del bloqueo no desde el elemento final basado en la naturaleza física del cierre del anillo, sino como una regulación de la transición del CAR a la fase de constricción. Este cambio de enfoque nos llevó a fijarnos en un mecanismo de control cuya descripción encajaba con nuestros resultados, y así resolver la siguiente duda: ¿está el bloqueo por BP mediado por el checkpoint de citoquinesis? 


\section{CLP1 Y EL CHECKPOINT DE CITOQUINESIS FRENTE AL BLOQUEO POR BLAKOPHOR}

S. pombe tiene un mecanismo que controla la estabilidad de la maquinaria de división celular. Éste se conoce como checkpoint de citoquinesis y se activa frente a perturbaciones de los componentes del anillo, promoviendo su estabilización y el bloqueo de la progresión del ciclo celular (Le Goff et al. 1999; Liu et al. 2000). Esta respuesta depende de la fosfatasa Clp1 y de la actividad SIN. Clp1 mantendría el SIN activo para efectuar el bloqueo del ciclo celular en fase G2 mientras estabiliza el CAR (Mishra et al. 2004). De hecho, Clp1 es sustrato de Sid2, la kinasa final de la ruta SIN, y la fosforilación de Sid2 es necesaria para que Clp1 se mantenga en el citoplasma durante el bloqueo (Chen et al. 2008); por su parte Clp1 desfosforila a Cdc11, componente de reclutamiento del SIN, estableciendo un círculo de retroalimentación entre estos tres reguladores (Chen et al. 2013).

Existe cierta semejanza en la parada del CAR característica de este checkpoint con nuestros resultados con BP. Además, esta descrito que Pmk1 fosforila a Clp1 in vitro y regula su localización núcleo/citoplásmica en respuesta a estrés oxidativo (Broadus \& Gould 2012), por lo que nos preguntamos si Clp1 estaría mediando el bloqueo de constricción causado por el BP. Si esta hipótesis es correcta esperaríamos que el mutante $\operatorname{clp}_{1} \Delta$ se comportara de manera similar al mutante pmk1 $\Delta$ en lo referente al bloqueo causado por BP. Sin embargo, nuestros resultados indican justo lo contrario (Figura 54). En el mutante $c_{1 p 1} \Delta$, en presencia de BP, la citoquinesis es considerablemente más lenta que en el control clp1 $\Delta$ sin BP.

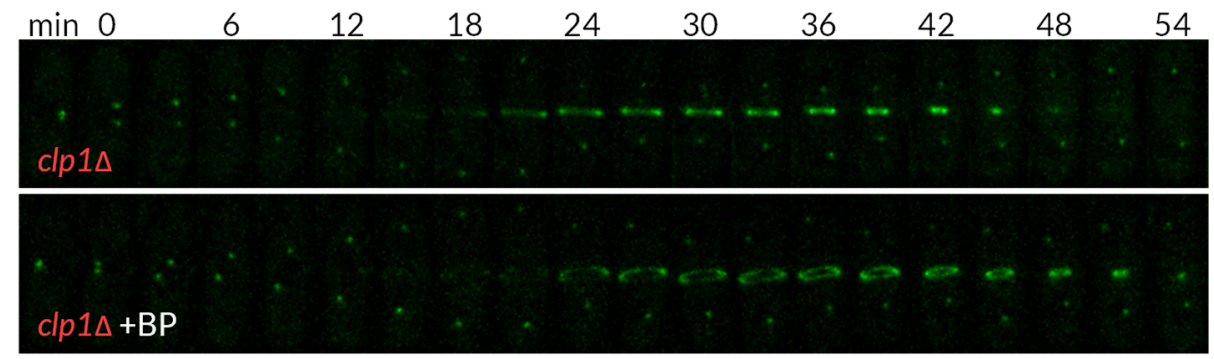

Imp2-GFP Sid4-GFP

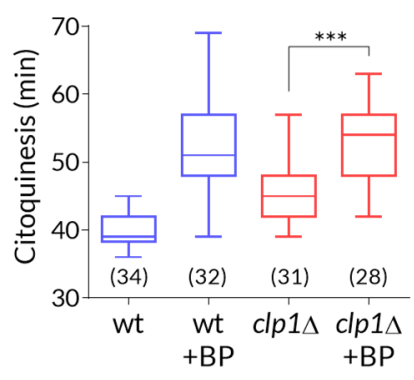

$+\mathrm{BP}$

Figura 54 El retraso citoquinético y la estabilización del CAR causados por BP no dependen de la fosfatasa Clp1. Imágenes de time-lapse capturadas en Spinning Disk de células clp1 $\triangle$ que expresan Imp2-GFP y Sid4GFP en presencia y ausencia de BP $5 \mu \mathrm{g} / \mathrm{ml}$. Fotografías tomadas cada 2 minutos (se muestran cada 4). Derecha, tiempo que tarda en completarse la citoquinesis en las cepas wt y $c^{l p} 1 \Delta$ en esas condiciones, analizados con el test $\mathrm{t}$ de Student $(* * * \mathrm{p}<0.0001,(\mathrm{n}))$. 
Por otra parte, nos resultó curioso ver que el anillo no se disolvía estando parado incluso en ausencia de Clp1 (Figura 54). Clp1 interviene en dos aspectos del checkpoint de citoquinesis: la parada del ciclo celular y la estabilización del CAR. Esta fosfatasa es necesaria para evitar la catástrofe del CAR en presencia de bajas dosis de latrunculina A (LatA) y en el mutante de la glucán sintasa cps1-191 defectivo en citoquinesis (Liu et al. 2000). En la cepa silvestre después del tratamiento con LatA, o en el mutante cps1-191 los anillos mantienen su estructura para que eventualmente puedan completar la septación. Sin embargo, en las mismas condiciones en el mutante $c l p 1 \Delta$ los anillos son inestables y terminan por disolverse (Mishra et al. 2004). En el caso del BP también vemos esta estabilización de los anillos, pues se mantienen parados sin contraerse, pero sin desensamblarse. Sin embargo, a diferencia de lo que ocurre en respuesta a LatA o en el mutante cps1-191, la estabilidad del anillo frente al BP no depende de Clp1.

También examinamos si Pmk1, de quien depende el bloqueo por BP, participaba en la estabilización del CAR conferida por el checkpoint de citoquinesis. Para ello utilizamos el mutante cps1-191, que a $36^{\circ} \mathrm{C}$ presenta un bloqueo en la septación y a la vez un aumento del número de anillos estables, gracias a la activación del checkpoint (Mishra et al. 2004). Al delecionar Pmk1 sobre esta cepa y pasarla a la temperatura restrictiva vimos que la fracción de células con anillo (Rlc1-tdTomato) se incrementaba en el doble mutante cps1-191 pmk1 $\Delta$ con respecto al sencillo cps1-191 (Figura 55A).

A

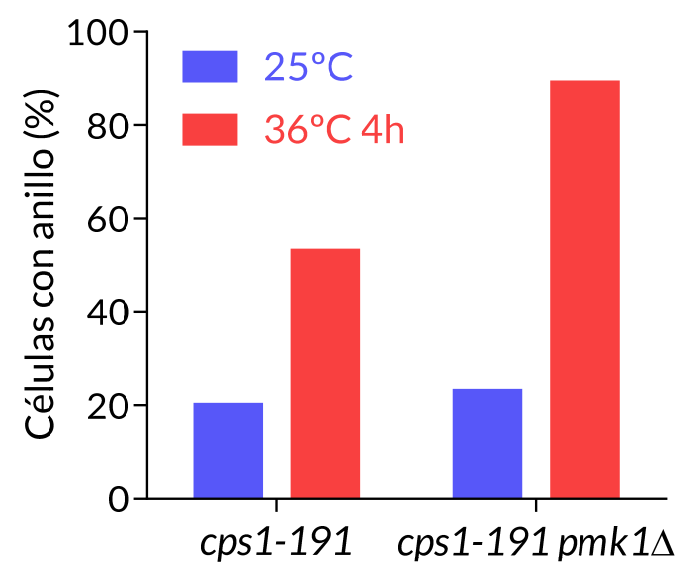

B

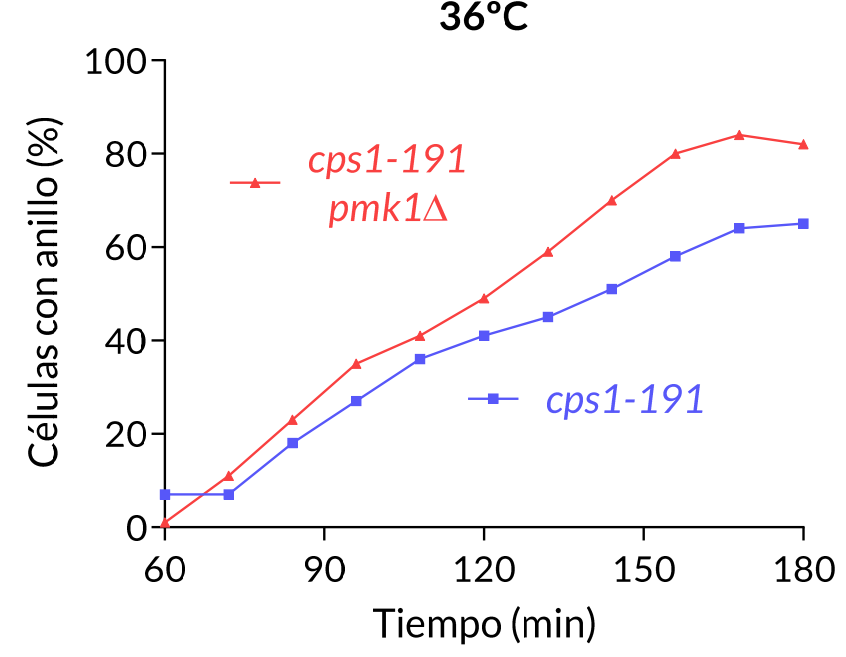

Figura 55 Pmk1 es innecesario para estabilizar el CAR en el mutante cps1-191. Se analizó la fracción de células con anillo en cepas cps1-191 y cps1-191 pmk1 $\Delta$ que expresan Imp2-GFP y Sid4-GFP. (A) En condiciones basales $\left(25^{\circ} \mathrm{C}\right)$ y después de $4 \mathrm{~h}$ a $36^{\circ} \mathrm{C}$ (>300 células/condición). (B) Tomando fotos cada 15 minutos a $36^{\circ} \mathrm{C}$ ( $>80$ células/condición). Datos cuantificados a partir de imágenes (A) y time-lapses (B) en DeltaVision. 
Lo inesperado de este incremento nos llevó a examinar el bloqueo de las dos cepas por time-lapse en condiciones restrictivas. No parecía que en el doble cps1-191 pmk1 $\Delta$ la citoquinesis fuera más lenta que en el sencillo cps1-191, o que menos células se saltaran dicho bloqueo, y sin embargo registramos cómo el porcentaje de células con presencia de anillo se incrementaba más rápido en la cepa que lleva la disrupción de Pmk1 (Figura 55B). Esta diferencia la achacamos a la apreciación cualitativa de que el mutante $p m k 1 \Delta$ crece más rápido, por lo que habría más células que llegan antes a formar anillos. Para comprobar este supuesto deberíamos caracterizar las velocidades de crecimiento de estas cepas o analizarlas a partir de cultivos sincrónicos. Estos resultados muestran que ni Pmk1 es necesario para estabilizar los anillos en el mutante cps1-191, ni Clp1 participa en el bloqueo por BP. También sugieren que se trata de mecanismos de control diferentes respondiendo a agresiones distintas, la integridad del anillo a través de Clp1 y la del septo mediante Pmk1.

Aun tratándose de respuestas diferentes, al ver en la parada por BP anillos bloqueados temporalmente ¿podemos decir que estos están estabilizados? Los mutantes que hemos identificado como mediadores de este proceso se saltan el bloqueo, pero en ningún caso hemos visto que en ausencia de Rgf1 o de Pmk1 se disuelva el anillo. Para analizar esta posibilidad examinamos la integridad/estabilidad de los anillos bloqueados por BP tratando las células con una concentración intermedia LatA ( $5 \mu \mathrm{M}$ ) (Mishra et al. 2004). La LatA secuestra monómeros de actina e inhibe la polimerización. Para visualizar la actina utilizamos el péptido LifeAct-GFP, que se une a la actina monomérica y polimérica (Riedl et al. 2008; Huang et al. 2012), y medimos la estabilidad como la fracción de células que presentan actina en estructura anular en función del tiempo de tratamiento con LatA (Figura 56).
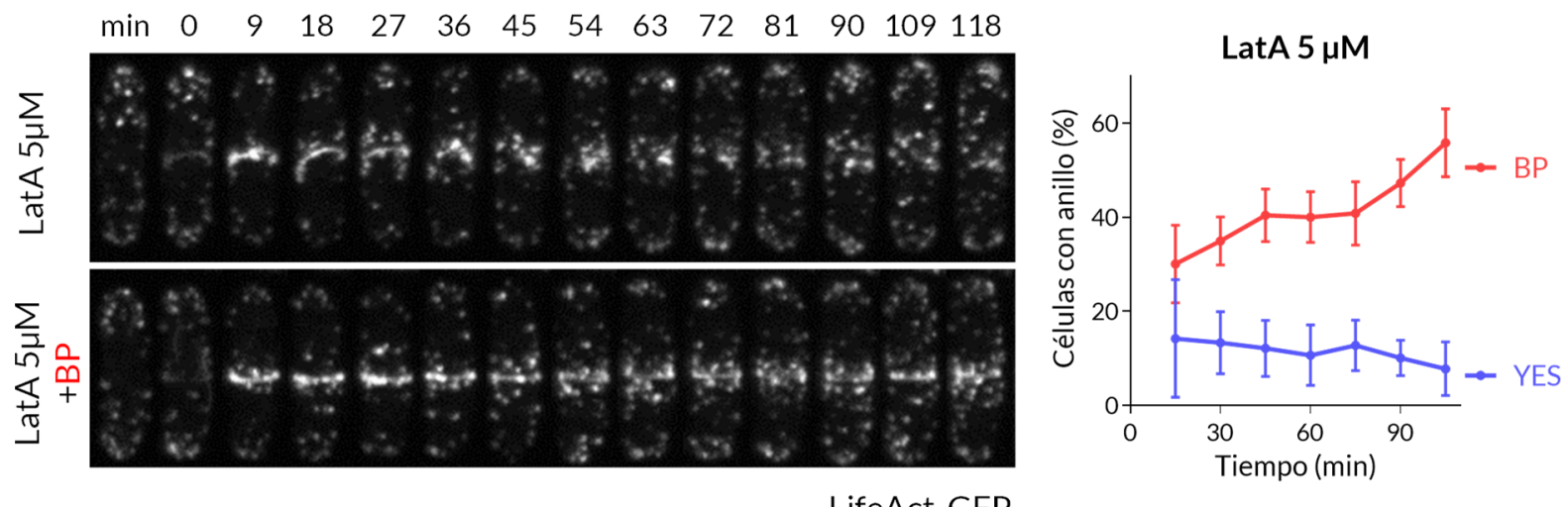

Figura $56 \mathrm{El}$ tratamiento con BP estabiliza el anillo de actomiosina. Imágenes de time-lapse capturadas en Spinning Disk de células de tipo silvestre que expresan LifeAct-GFP, en presencia de Latrunculina A 5 $\mu \mathrm{M}$ y con o sin BP $10 \mu \mathrm{g} / \mathrm{ml}$ (añadido 30 minutos antes que la LatA). Tiempo o es la aparición del anillo. Derecha, fracción de estas células con presencia de anillos de LifeAct-GFP a lo largo de los tratamientos (Media \pm SD, n: 4 réplicas con > 20 células/réplica). 
El tratamiento con LatA provoca una disminución del número de anillos. Sin embargo, cuando pretratamos las células con BP $10 \mu \mathrm{g} / \mathrm{ml}$ durante 30 minutos, antes de añadir la LatA, el porcentaje de células con anillo de actina no solo no disminuye, sino que aumenta con el tiempo (Figura 56). En este experimento incrementamos la dosis habitual de BP a $10 \mu \mathrm{g} / \mathrm{ml}$ para forzar más bloqueo. La exposición a BP hace que los anillos sean menos sensibles a LatA, lo que sugiere que el bloqueo de la constricción en respuesta al BP va acompañado de la estabilización del CAR.

Si la respuesta a BP implica una estabilización del CAR, pero el mutante clp1 $\Delta$ responde bloqueando los anillos de forma normal ¿Quién media entonces este efecto? ¿Qué puede estar regulando Pmk1 para estabilizar el anillo de actomiosina? Puesto que Sid2 es necesario para la estabilización del CAR en el checkpoint de citoquinesis, nos preguntamos si tendría una función similar en el caso del bloqueo por BP.

El mutante sid2-250 a temperatura restrictiva presenta células alargadas y multinucleadas junto con anillos inestables que se forman y desaparecen (Balasubramanian et al. 1998; Mishra et al. 2004). Nos preguntamos si la presencia de BP estabilizaría los anillos en el mutante sid2-250. Para ello medimos el porcentaje de anillos de Imp2-GFP en células sid2-250 incubadas a $36^{\circ} \mathrm{C}$ durante 2 y $3 \mathrm{~h}$, en ausencia o en presencia de BP $10 \mu \mathrm{g} / \mathrm{ml}$ añadido 30 minutos antes de tomar las muestras para inducir el bloqueo en las condiciones restrictivas. En la Figura 57 se muestran las fracciones de células con anillo en estos tratamientos y fotos de las células sid2-250 control y tratadas con BP después de $3 \mathrm{~h}$ a $36^{\circ} \mathrm{C}$.

Tanto las células sid2-250 tratadas con BP como el control expresaron el mismo fenotipo, y la fracción de anillos se redujo por igual. Por tanto, la estabilización del CAR ante la presencia de $\mathrm{BP}$ requiere la actividad de la ruta SIN.

\section{sid2-250 $36^{\circ} \mathrm{C}$}
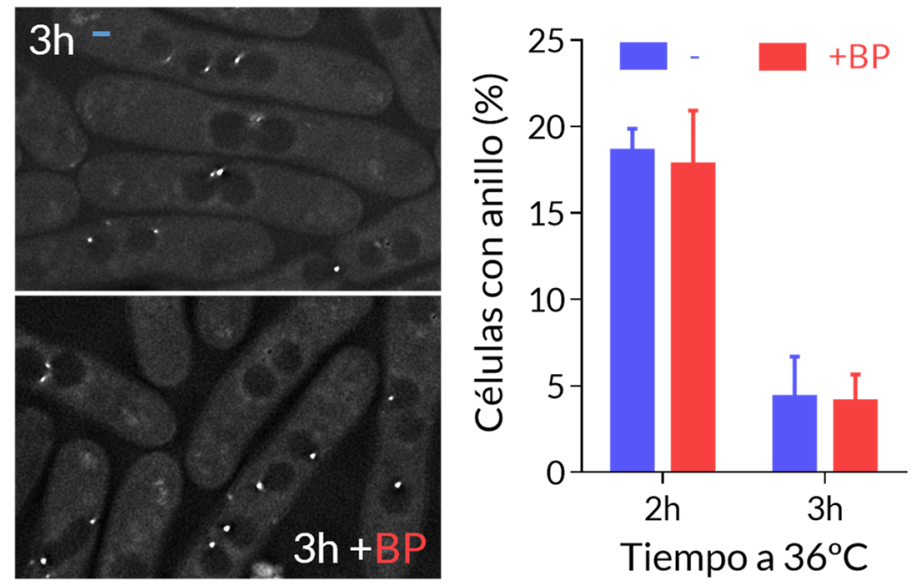

Figura 57 La kinasa de la ruta SIN Sid2 es necesaria para estabilizar el CAR en presencia de blankophor. Derecha, fracción de células sid2-250 que expresan Imp2-GFP y Sfi1-GFP con anillo después de 2 y 3 horas a $36^{\circ} \mathrm{C}$. Las células fueron tratadas o no con BP (10 $\mu \mathrm{g} / \mathrm{ml}) 30$ minutos antes de la captura de imágenes (Media $\pm \mathrm{SD}$, n: 2 réplicas con > 150 células/réplica). Izquierda, imágenes de fluorescencia capturadas en DeltaVision representativas de estas células a las $3 \mathrm{~h}$ a $36^{\circ} \mathrm{C}$. 


\section{LA RUTA SIN COMO MEDIADOR DEL BLOQUEO DEL CAR FRENTE AL ESTRÉS EN SEPTACIÓN}

Dado que la kinasa Sid2 es necesaria para mantener la integridad del anillo como respuesta al BP era de esperar que la ruta SIN estuviera activa durante el bloqueo. La actividad de la ruta SIN está ligada a la localización de sus componentes ya que integra señales desde el SPB hacia la zona de división (Simanis 2015). Esta característica nos permite monitorizar su estado de activación mediante el seguimiento de la localización de algunos de sus componentes.

La localización de Sid2 en la zona de división, así como la polarización de Cdc7 a uno de los dos SPBs en anafase se consideran eventos que reflejan la activación de la ruta SIN (Johnson et al. 2012). Para visualizar el estado del SIN en respuesta a daños en la pared, miramos la localización de estos dos componentes en células wt y rgf1 $\triangle$, con o sin BP (Figura 58).
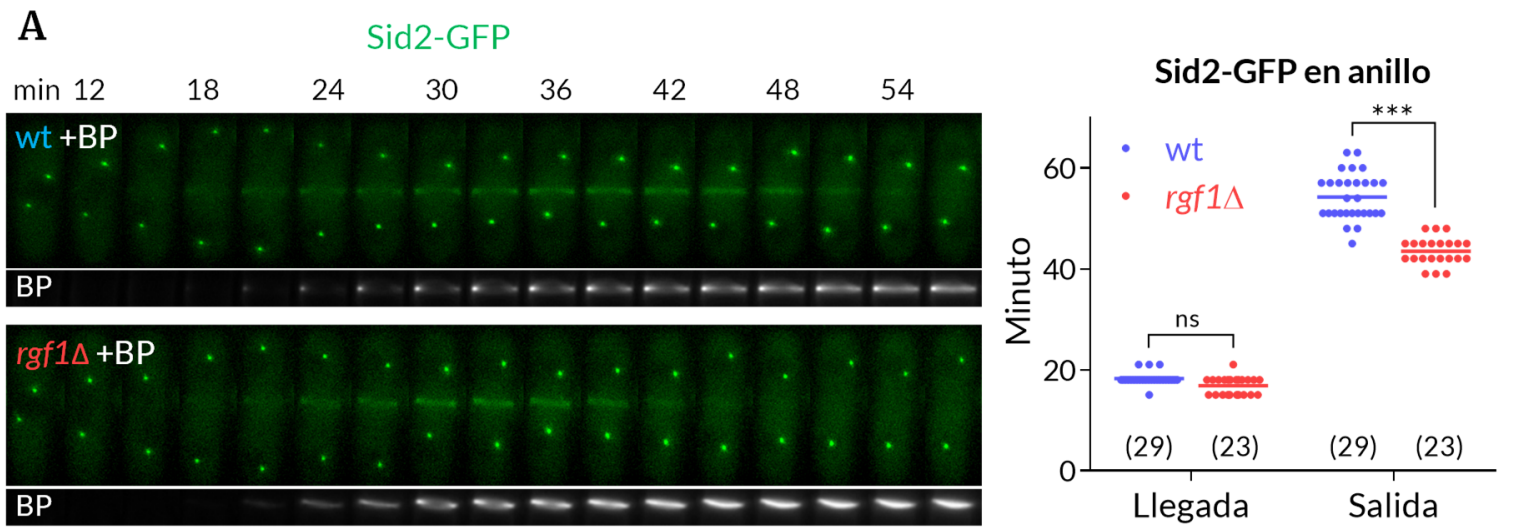

\section{B}

Cdc7-GFP Imp2-GFP BP
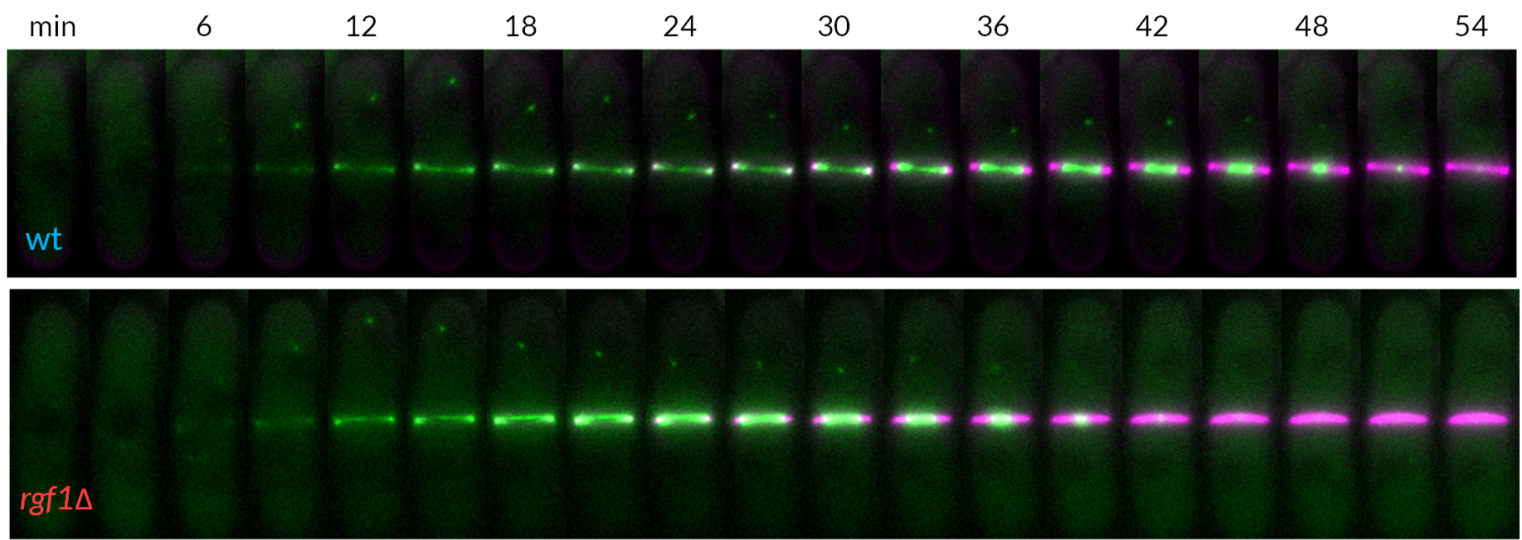

Figura 58 Localización de las kinasas Sid2 y Cdc7 durante el bloqueo por BP. Imágenes representativas de time-lapses de células wt y rgf1 $\triangle$ que expresan Sid2-GFP (A) y Cdc7-GFP, Imp2-GFP (B) en presencia de BP $5 \mathrm{\mu g} / \mathrm{ml}$ capturadas en DeltaVision. (A) Izquierda, se han omitido las imágenes de los primeros 9 minutos que comienzan con la separación de los SPBs. Derecha, tiempo de llegada y salida de Sid2-GFP a la zona del anillo, medido desde la separación de los SPBs. Datos analizados con el test t de Šidák (ns no significativo, $* * * \mathrm{p}<0.0001,(\mathrm{n}))$. 
En células tratadas con BP, Sid2-GFP llega a la zona de división en anafase al mismo tiempo en ambas cepas (Figura 58A), mientras Cdc7-GFP se polariza rápidamente, acumulándose en el SPB nuevo tanto en la cepa silvestre como en el mutante rgf1 $\Delta$ (Figura 58B). La localización de Sid2 en el septo y la de Cdc7 en el nSBP se mantienen hasta el final de la citoquinesis, que es cuando ambos desaparecen. Sin embargo, en presencia de BP Sid2 tarda más tiempo en desaparecer del septo en la cepa silvestre que en el mutante $\operatorname{rgf}_{1} \Delta$ y lo mismo ocurre con Cdc7 en el SPB (Figura 58). Esto es coherente con el mayor retraso que presentan los anillos de las células wt con respecto al mutante $\operatorname{rgf}_{1} \Delta$.

A continuación, caracterizamos el perfil de esta respuesta midiendo la intensidad de Cdc7-GFP en ambos SPBs a lo largo de la citoquinesis, en células tratadas con BP con respecto a condiciones normales. En este caso usamos además de Cdc7-GFP, el marcador de SPB Sad1-dsRed como referencia para delimitar esta estructura. Como ocurría anteriormente, la polarización de Cdc7 es rápida, cayendo su intensidad en uno de los SPB mientras se incrementa en el otro, y esto ocurre por igual en células con BP como sin él (Figura 59).

A
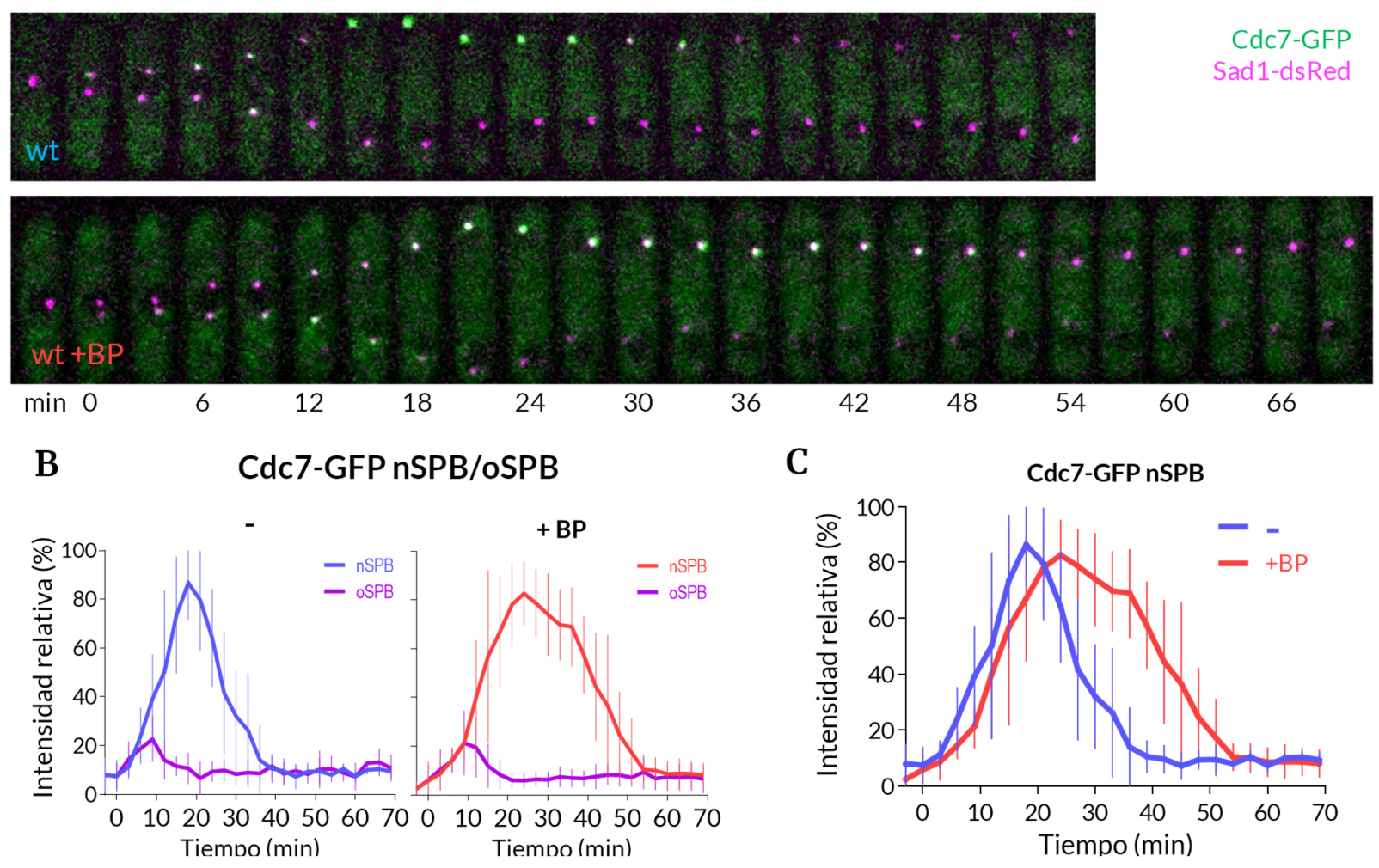

Figura 59 Cdc7 permanece asociada al nSPB durante el bloqueo por BP. (A) Imágenes de time-lapse representativas obtenidas a partir de células wt que expresan Cdc7-GFP y Sad1-dsRed en presencia y ausencia de BP 5 rg/ml, capturadas en el Spinning Disk. (B) Medidas de la intensidad de fluorescencia de Cdc7-GFP en ambos SPBs a lo largo del tiempo obtenidas a partir de las células de (A) (Media \pm SD, n: 12 células). (C) Superposición de las curvas de intensidad de Cdc7-GFP en los nSPBs de (B). 
En este caso usamos además de Cdc7-GFP, el marcador de SPB Sad1-dsRed como referencia para delimitar esta estructura. Como ocurría anteriormente, la polarización de Cdc7 es rápida, cayendo su intensidad en uno de los SPB mientras se incrementa en el otro, y esto ocurre por igual en células con BP como sin él (Figura 59).

La segunda mitad de la dinámica sí es diferente. En condiciones normales la intensidad de Cdc7 crece hasta un pico máximo para caer inmediatamente igual de rápido, mientras que en presencia de BP este pico se transforma en una meseta (Figura 59). Cdc7 se mantiene en su estado de máxima intensidad polarizada durante el bloqueo por BP para posteriormente caer hasta desaparecer.

Hemos visto que durante el tratamiento con BP la localización de Sid2 y Cdc7 presenta características de alta actividad SIN. Otra manera de seguir el estado de activación de Sid2 es a través de la localización de Clp1, uno de sus efectores. Clp1 es liberada del nucleolo al citoplasma en mitosis, donde es retenida de forma dependiente de la fosforilación por Sid2, y hacia el final de la citoquinesis vuelve a acumularse en el nucleolo (Chen et al. 2008).

Para monitorizar la liberación nuclear de Clp1 en respuesta al tratamiento con BP utilizamos la cepa Clp1-GFP que expresa de manera endógena los marcadores Imp2-GFP y Sid4-GFP. Con la entrada en mitosis la intensidad de Clp1 en el núcleo cae drásticamente y los niveles basales no se recuperan hasta que finaliza la constricción del CAR (Figura 60). El tratamiento con $5 \mu \mathrm{g} / \mathrm{ml}$ de BP no afecta a la dinámica de liberación nuclear de Clp1, sin embargo, la proteína permanece excluida del núcleo mientras dura el bloqueo del CAR (Figura 60). En resumen, el BP induce la retención citoplásmica de Clp1, a su vez relacionada con la actividad persistente de Sid2.

Clp1-GFP Imp2-GFP Sid4-GFP

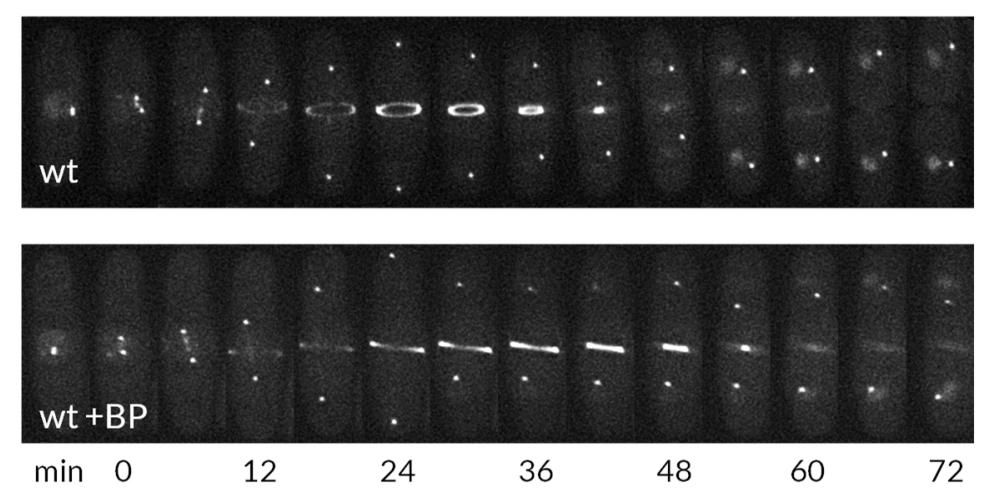

GFP nuclear

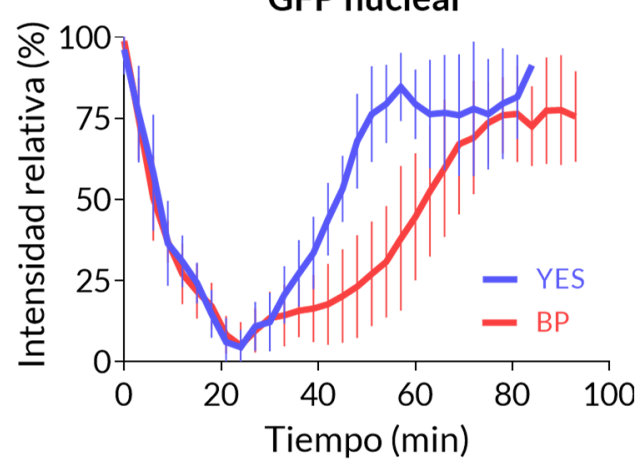

Figura 60 Clp1 permanece excluida del núcleo durante el bloqueo por BP. Imágenes de time-lapse en capturadas en DeltaVision de células wt que expresan Clp1-GFP, Imp2-GFP y Sid2-GFP en presencia y ausencia de BP $5 \mu \mathrm{g} / \mathrm{ml}$. Derecha, intensidad de fluorescencia de la señal de GFP en la región nuclear de dichas células, tomada como un círculo de tamaño constante, a lo largo de la citoquinesis (Media \pm SD, n: 12 células). 
Hemos visto que la actividad SIN se mantiene activa durante el bloqueo del CAR inducido por BP. Nos preguntamos si el SIN además de proporcionar estabilidad al anillo (ver Figura 57), también era responsable del propio retraso de citoquinesis. Examinamos si el BP modificaba la duración de la citoquinesis en el mutante $\operatorname{sid} 2-250$ a $32^{\circ} \mathrm{C}$, temperatura semi-restrictiva a la que sí es capaz de formar y contraer anillos. Los anillos de Imp2-GFP se formaron y contrajeron a tiempos normales en el mutante sid2-250 a esta temperatura, tanto en ausencia como en presencia de BP, es decir, no mostraron el retraso característico inducido por la presencia de BP (Figura 61). Este resultado demuestra que Sid2 es parte de la señalización que bloquea el CAR durante el estrés producido por BP.

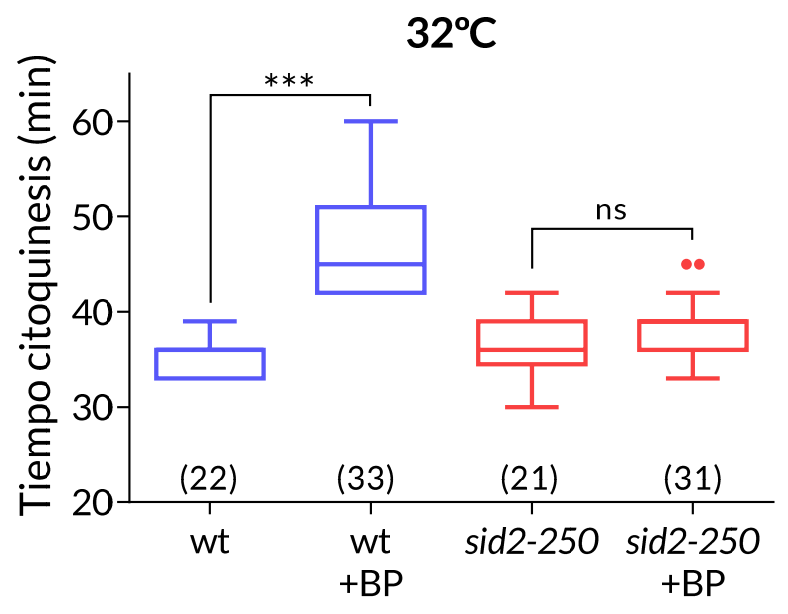

En conjunto estos resultados indican que:

- El retraso de la constricción del anillo causado por BP no es consecuencia de una baja actividad SIN, sino que, al contrario, está relacionado con el mantenimiento de la señal.

- Rgf1 y la ruta CIP participan el mantenimiento de la actividad SIN ante el daño inducido por BP.

- El fin del bloqueo y por tanto el inicio de la constricción del CAR coincide con la caída de la actividad SIN.

- Este mantenimiento de actividad SIN correlaciona con el aumento de la estabilidad del CAR y el bloqueo del inicio de su constricción, siendo Sid2, la kinasa final de la ruta, necesaria para ambas respuestas.

\begin{abstract}
Figura 61 La kinasa Sid2 es necesaria para bloquear la citoquinesis como respuesta al blankophor. Tiempo que tardan en completar la citoquinesis las células de genotipo wt y sid2-25o que expresan Imp2GFP y Sid2-GFP en presencia y ausencia de BP $5 \mu \mathrm{g} / \mathrm{ml}$ a $32^{\circ} \mathrm{C}$. Antes de iniciar el timelapse las células se incubaron $1 \mathrm{~h}$ a $32^{\circ} \mathrm{C}$. Datos cuantificados a partir de time-lapses capturados en el Spinning Disk a $32^{\circ} \mathrm{C}$ y analizados con test de Fisher (ns no significativo, $* * * \mathrm{p}<0.0001,(\mathrm{n}))$.
\end{abstract}


A continuación, examinamos si el bloqueo en citoquinesis era dependiente, en lo referente a la ruta SIN, exclusivamente de Sid2 o si otros integrantes de esta vía también eran necesarios para efectuar la parada. Utilizamos los mutantes termosensibles de las siguientes kinasas del SIN, Cdc7, la cual se une a la forma activa de la GTPasa Spg1 (Sohrmann et al.1998), y Sid1, que estaría por análisis de epistasia entre Cdc7 y Sid2 (Guertin et al. 2000).

A $32^{\circ} \mathrm{C}$ estos mutantes responden de manera diferente al BP, las células cdc7-24 (Fankhauser \& Simanis 1994) responden con un retraso de la citoquinesis proporcional al de la cepa control, mientras en el mutante sid1-239 (Guertin et al. 2000) dicho retraso es más contenido, lo que sugiere que el bloqueo depende fundamentalmente de Sid2 o del tramo "final" de la ruta SIN (Figura 62)

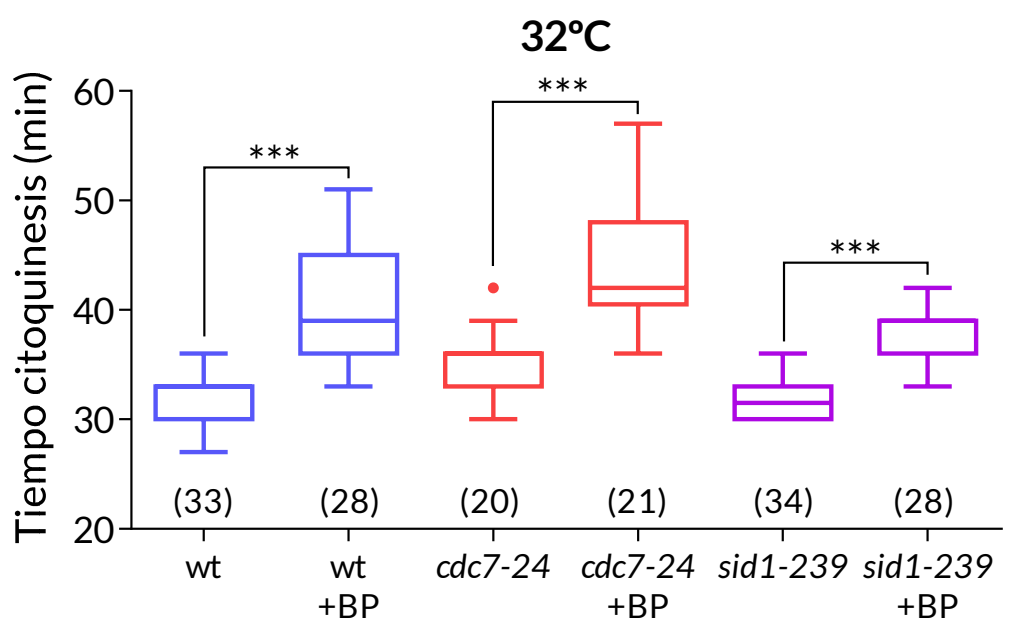

Figura 62 Efecto del bloqueo citoquinético por BP en mutantes de Cdc7 y Sid1. Tiempo que tardan en completar la citoquinesis las células de genotipo wt, cdc7-24 y sid1-239 que expresan Imp2-GFP y Sid2GFP en presencia y ausencia de BP $5 \mu \mathrm{g} / \mathrm{ml}$ a $32^{\circ} \mathrm{C}$. Antes de iniciar el time-lapse las células se incubaron $1 \mathrm{~h}$ a $32^{\circ} \mathrm{C}$. Datos cuantificados a partir de timelapses capturados en el Spinning Disk a $32^{\circ} \mathrm{C}$ y analizados con test de Šidák (ns no significativo, *** $\mathrm{p}<0.0001,(\mathrm{n})$ ).

Finalmente, para establecer una relación entre Pmk1 y Sid2 quisimos comprobar si, en tanto que Sid2 es necesaria para el bloqueo y que permanece activa durante este bloqueo, la activación ectópica de la ruta SIN era capaz de reestablecer la parada por BP en el mutante pmk1 $\Delta$. Empleamos para ello un mutante de Cdc16, quien actúa junto con Byr4 como GAP de Spg1, la inactiva y establece la asimetría del SIN (Johnson et al. 2012). El mutante cdc16-116 pierde la asimetría de Cdc7, forma septos en interfase y es capaz de mejorar los defectos de septación del mutante clp1 $\Delta$ con LatA (Mishra et al. 2004).

$\mathrm{Al}$ analizar el tiempo que dura la citoquinesis en presencia de BP, vimos que en el doble mutante $c d c 16-116$ pmk1 $\Delta$ no se revierte la ausencia de retraso observada en el mutante pmk1 $\Delta$ (Figura 63A). Este experimento se realizó a $32^{\circ} \mathrm{C}$ por lo que podría ser que Cdc16 no estuviera suficientemente inactivado y por consiguiente Spg1 no actuara como activador ectópico del SIN; 
sin embargo, al forzar las condiciones y repetir el experimento a $36^{\circ} \mathrm{C}$ obtuvimos un resultado muy parecido (Figura 63B).

Otro dato curioso, es que comparado con el retraso en citoquinesis que vemos en la cepa silvestre a $32^{\circ} \mathrm{C}$, la respuesta del mutante $c d c 16-116$ al BP es menor, es decir presenta menos retraso (Figura 63C).

A

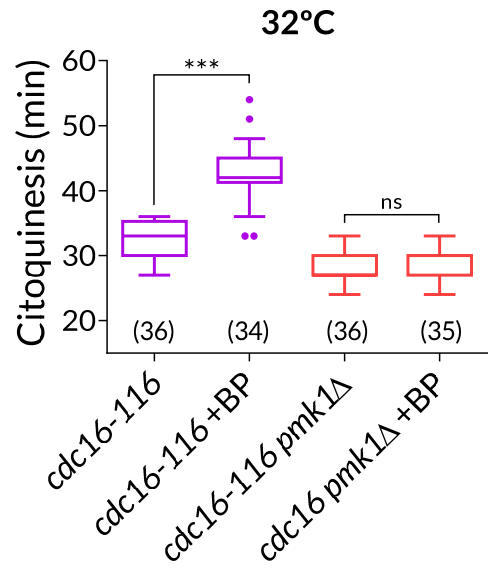

B

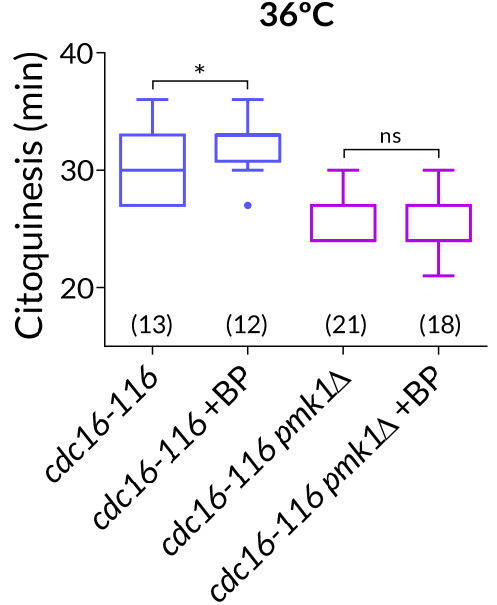

C

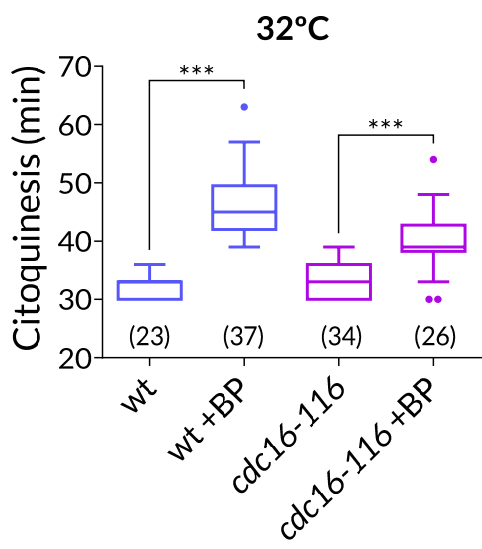

Figura 63 La mutación cdc16-116 no es suficiente para restaurar el bloqueo en citoquinesis por BP en pmk1 $\Delta$. Tiempo que tardan en completar la citoquinesis las células de genotipo wt, $c d c 16-116$ y cdc116 pmk1 $\Delta$ que expresan Imp2-GFP y Sid2-GFP en presencia y ausencia de BP $5 \mu \mathrm{g} / \mathrm{ml} \mathrm{a} 32^{\circ} \mathrm{C}$. Antes de iniciar el timelapse a $32^{\circ} \mathrm{C}$ o a $36^{\circ} \mathrm{C}$, las células se incubaron $1 \mathrm{~h}$ a $32^{\circ} \mathrm{C}$ o a $36^{\circ} \mathrm{C}$. Datos cuantificados a partir de time-lapses capturados en Spinning Disk a $32^{\circ} \mathrm{C}$ y $36^{\circ} \mathrm{C}$ y analizados con test de Fisher (ns no significativo, * $\mathrm{p}<0.05$, $* * * \mathrm{p}<0.0001,(\mathrm{n}))$.

Los tiempos mostrados están medidos a partir de los anillos contráctiles mitóticos, pero estos no son los únicos, puesto que en la cepa cdc16-116 también se forman septos en interfase. Al examinar los anillos interfásicos, descubrimos que estos sufren un bloqueo de la constricción muy fuerte al ser expuestos a BP $5 \mu \mathrm{g} / \mathrm{ml}$ (Figura 64), en clara contraposición con los de la cepa cdc16-116 sin tratar o los mitóticos de ambas condiciones que sí se contraen (Figura 63C). Además, estos anillos interfásicos bloqueados por BP sí son capaces de contraerse en el doble mutante $c d c 16-116$ pmk1 $\Delta$ (Figura 64). 


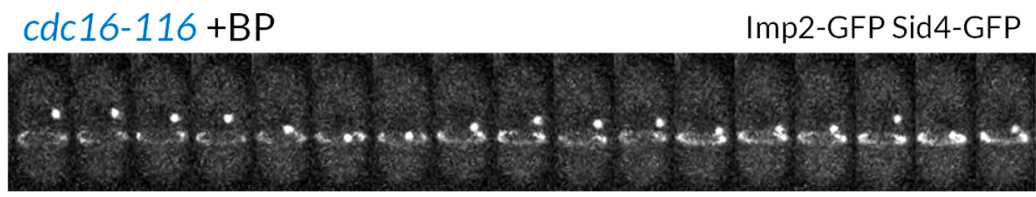

cdc16-116 pmk1 $1 \Delta+\mathrm{BP}$
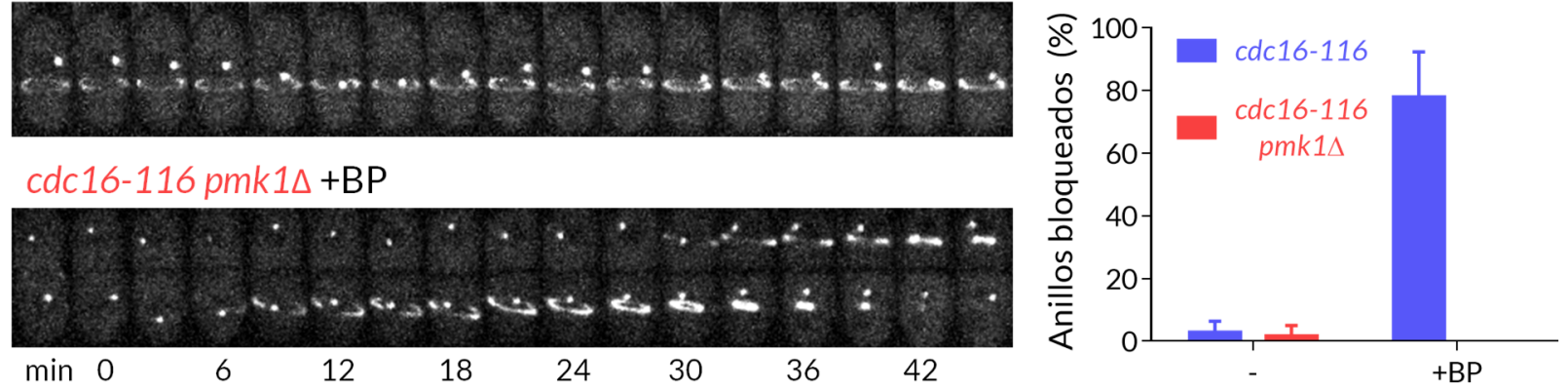

Figura 64 Los anillos interfásicos en el mutante cdc16-116 no se contraen en presencia de BP, de forma dependiente de Pmk1. Imágenes de time-lapse de anillos interfásicos (hay un solo núcleo y SPB por compartimento celular). Las imágenes fueron obtenidas a partir de células cdc16-116 y cdc16-116 pmk1 $\triangle$ que expresan Imp2-GFP y Sid4-GFP, en presencia de BP 5 mg/ml y capturadas en el Spinning Disk. Antes de iniciar el time-lapse a $36^{\circ} \mathrm{C}$, las células se incubaron $1 \mathrm{~h} \mathrm{a} 36^{\circ} \mathrm{C}$. Derecha, fracción de estas células con anillos que no se contraen en presencia y ausencia de BP 5 mg/ml (Media \pm SD, n: 4 réplicas con > 13 células/réplica). 



\section{4}

\section{DISCUSIÓN}

Las Rho-GTPasas y sus reguladores GEFs y GAPs controlan una gran variedad de procesos biológicos. Muchos, aunque no todos, implican la regulación del citoesqueleto de actina y la contractilidad de la miosina II. Dentro de estos, uno de los más importantes es la citoquinesis.

En células animales, la GTPasa RhoA, activada por el RhoGEF Ect-2 en la zona del ecuador celular, crea un dominio asociado a la membrana que favorece la polimerización de actina y la activación de miosina II. De hecho, la activación ectópica de Ect-2 es suficiente para reclutar y activar a RhoA, promoviendo la formación de un surco de división incluso en células interfásicas (Wagner \& Glotzer 2016). La activación local de Rho-GTPasas en el surco de escisión también activa a forminas en S. cerevisiae y Dictyostelium (Kühn \& Geyer 2014).

En S. pombe sabemos que la GTPasa Rho1 participa en la formación del septo como subunidad reguladora de la actividad $\beta$-glucán sintasa (Cortés et al. 2016b). Sin embargo, hasta la fecha no se ha descrito ninguna función relacionada con la polimerización de actina, ni se conoce si tiene un papel en la formación y contracción del anillo de actomiosina en las primeras etapas de la citoquinesis. Uno de los problemas que plantea trabajar con Rho1 es que resulta esencial para la viabilidad celular. Nosotros hemos marcado la proteína Rho1 con sfGFP en 3 regiones internas diferentes, que según la estructura tridimensional de RhoA no forman parte de los dominios importantes ( $\mathrm{P}$-loop, Switch 1 y 2), y hemos visto que, aunque las proteínas recombinantes expresaban la sfGFP correctamente, no podían sustituir a proteína silvestre. Esto indica que no es fácil disponer de herramientas para estudiar la función de Rho1. De hecho, gran parte de lo que sabemos sobre su función se debe al estudio de sus reguladores GEFs y GAPs, que modulan la localización y la actividad de Rho1 en momentos determinado del ciclo (Edreira et al. 2018). 
En esta memoria se describe una nueva función de Rgf1 y de Rho1 en la respuesta a estrés durante la citoquinesis. Hemos visto que el daño en la pared celular desencadena una respuesta "tipo checkpoint" durante la citoquinesis que promueve un retraso en el inicio de la constricción del CAR. Este retraso depende de Rgf1 y de Rho1, de la ruta de MAP quinasas que controla la integridad celular (CIP) y de la ruta que controla el inicio de la septación (SIN) (Figura 65).
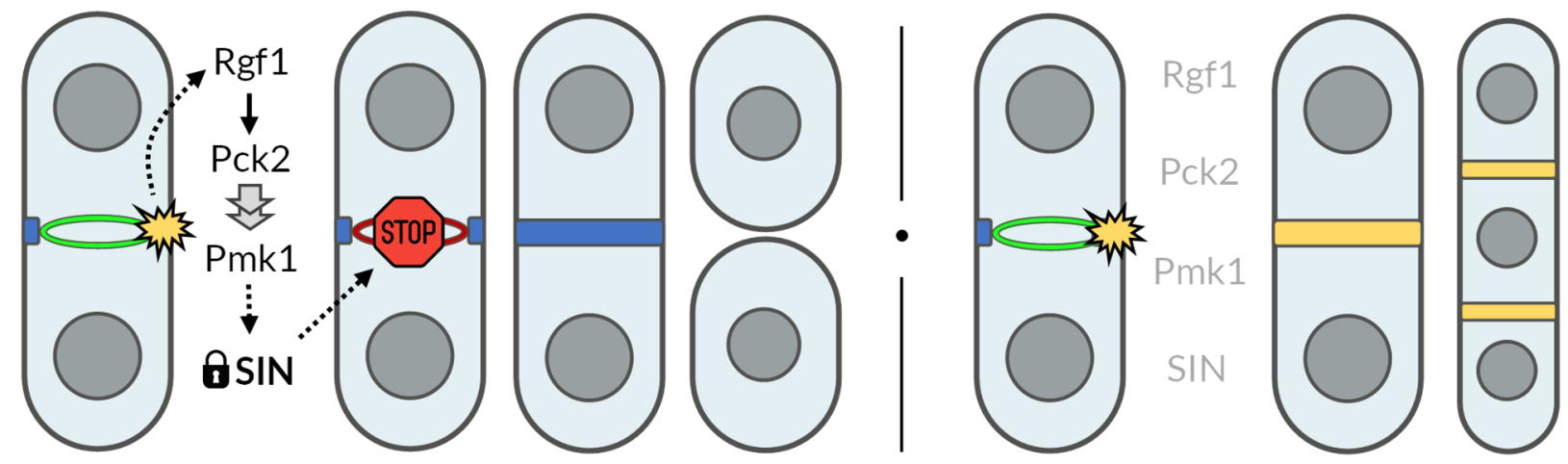

Figura 65 Modelo del retraso de la contracción del CAR frente al estrés en la pared celular. Frente al estés en la pared se transduce una señal a través de Rgf1 y Pmk1 que bloquea la constricción del CAR de forma dependiente del mantenimiento de la actividad SIN. En ausencia de esta señalización el anillo se cierra prematuramente y el estrés persistente conduce a la aparición de células encadenadas.

\section{Rgf1 se localiza cerca del CAR e interacciona con sus componentes}

Este trabajo comenzó con el objetivo de identificar el papel del Rho-GEF Rgf1 durante la citoquinesis. Los tres GEFs de Rho1, Rgf1, Rgf2 y Rgf3, se localizan en el septo, pero solo se conoce la participación de Rgf3 en este proceso (Tajadura et al. 2004; Morrell-Falvey 2005; Mutoh et al. 2005).

Nos preguntamos dónde, cómo y cuándo se detecta Rgf1 durante el proceso de citoquinesis. Mediante experimentos de time-lapse y microscopia de superresolución hemos visto que Rgf1 desaparece de los polos y se transloca a la región central, en la periferia del anillo, pero no en el propio anillo. Cuando empieza la contracción, Rgf1 avanza hacia el interior en el borde del septo y va dejando un rastro que se distribuye como una placa de fluorescencia a medida que se cierra el CAR (Figuras 27 y 28).

Rgf1 aparece en la fase de maduración del CAR. En esta etapa el anillo mantiene su diámetro máximo, pero no permanece estático puesto que el intercambio de proteínas con el citoplasma es constante; por ejemplo en este intervalo aparecen las proteínas con motivo F-BAR (Imp2, Pxl1, Fic1) (Roberts-Galbraith et al. 2009), la miosina Myp2 (Laplante et al. 2015) y la $\beta$-glucán sintasa Bgs1 (Goss et al. 2014), entre otras. 
Los experimentos de localización nos hicieron pensar que el mutante $\operatorname{rgf}_{1} \Delta$ podría presentar algún defecto en la etapa de invaginación de la membrana acoplada a la síntesis del septo. Sin embargo, en condiciones normales, la actividad de Rgf1 en citoquinesis es prescindible; el mutante $\operatorname{rgf}_{1} \Delta$ no presenta fenotipos asociados a defectos en la formación o en la contracción del CAR, salvo las interacciones genéticas con componentes del anillo.

\section{El blankophor bloquea temporalmente la citoquinesis y ese retraso depende de Rgf1, de Rho1 y de la ruta de integridad.}

Curiosamente empezamos a ver diferencias entre el mutante $\operatorname{rgf}_{1} \Delta$ y la cepa silvestre al teñir las células con calcoflúor/blankophor (BP). En presencia de BP el tiempo necesario para completar la citoquinesis era apreciablemente menor en el mutante $\operatorname{rgf}_{1} \Delta$ que en la cepa silvestre. Al intentar dilucidar la naturaleza de este fenotipo, observamos que la diferencia en la duración de la citoquinesis entre la cepa silvestre y el mutante $\operatorname{rgf}_{1} \Delta$ solo se veía en presencia de BP. Después de realizar múltiples experimentos y con diversos controles nos dimos cuenta de que es el BP el que induce un retraso en la cepa silvestre, y que el mutante $\operatorname{rgf}_{1} \Delta$ es refractario a dicho retraso.

La tinción con BP ha sido ampliamente utilizada para teñir la pared celular de levaduras tanto en S. cerevisiae (Roncero \& Durán 1985) como en S. pombe (Ribas \& Cortés 2016); siempre con la idea de que, aunque es un antifúngico, su utilización a baja concentración no interfiere con el crecimiento celular. Sin embargo, nosotros hemos visto que una concentración de BP igual o superior a $2.5 \mathrm{\mu g} / \mathrm{ml}$, interfiere con la citoquinesis, induciendo un bloqueo transitorio de la misma.

Este retraso depende de la concentración de BP en el medio y se observa al monitorizar la mitosis/citoquinesis con diferentes combinaciones de marcadores fluorescentes. El retraso también aparece de forma independiente de la temperatura, tanto a $28^{\circ} \mathrm{C}$ como a $36^{\circ} \mathrm{C}$, y en varios medios de cultivo, YES y MM. Estas evidencias aportan robustez a este efecto frente a las variaciones experimentales. Además, hemos comprobado que no depende de las propiedades fluorescentes del blankophor, pues sigue apareciendo aun sin excitación del compuesto.

Desde el principio sabíamos que el retraso inducido por BP depende de la presencia de Rgf1 (ya que no ocurre en mutante $\mathrm{rgf}_{1} \Delta$ ) pero poco a poco hemos ido caracterizando otras proteínas implicadas. Sabemos que el retraso depende de Rho1 puesto que en el mutante rho1-596 (Viana et al. 2013), este retraso es prácticamente inapreciable, y de la actividad GEF de Rgf1, puesto que el mutante rgf1-PTTR, mutado en el dominio catalítico, se comporta como el mutante nulo rgfi $\Delta$.

También hemos visto que está implicada la ruta de MAPK de Pmk1 o ruta de integridad, mientras que la ruta de MAPK de respuesta a estrés (SAPK) aparentemente no interviene en el retraso. La ruta CIP está ramificada en el tramo superior y hemos visto que la respuesta al BP se 
transmite a través de la vía Rgf1-Rho1-Pck2-Pmk1. Ni la GTPasa Rho2 ni la proteína Pck1, que son también activadores de esta ruta, median en esta respuesta. Nos sorprendió que el mutante rho $\Delta$ se comportara como la cepa silvestre en presencia BP, pues la activación de Pmk1 frente a $\mathrm{BP}$ en un mutante rho2 $\Delta$ se reduce a la mitad (Barba et al. 2008). Esto también ocurre en el mutante pck2 $\Delta$ (Barba et al. 2008), en el que sí vemos diferencias. También sabemos que Pck2 participa en la síntesis de $\beta$-glucano y de $\alpha$-glucano, mientras que Rho2 está relacionado exclusivamente con la síntesis de $\alpha$-glucano (Calonge et al. 2000). Es muy probable que el efecto del BP se produzca a través del $\beta$-glucano y no del $\alpha$-glucano (Cortés et al. 2007).

\section{El BP retrasa el inicio de la constricción del CAR en la cepa silvestre.}

Hemos visto que en la cepa silvestre el retraso producido por BP es específico de la fase de maduración. Esta es la etapa que se alarga, aproximadamente 15 minutos de media, mientras que tanto el tiempo que dura la formación como el de la constricción del CAR permanecen inalterados (Figura 41). El retraso en la fase de maduración prácticamente desaparece en los mutantes rgf1 $\Delta$ y pmk1 $\Delta$, lo que indica de nuevo que Rgf1 y Pmk1 están implicados en la propagación de este efecto. La fase de maduración viene definida a nivel experimental por el final de la formación (en la que no hemos observado cambios) y el inicio de la constricción del CAR. A continuación, se exponen algunas de las razones por las que creemos que el BP retrasa el comienzo de la constricción y no los procesos de remodelación del anillo de la fase madurativa:

- Hemos visto que cada uno de los marcadores analizados (Imp2, Myp2, Cdc7 y Sid2) aparece al mismo tiempo y en el mismo sitio en las células tratadas con o sin BP.

- Al mismo tiempo, el inicio de la septación tampoco está alterado, indicando que existe una actividad $\beta$ GS competente.

- La constricción del CAR se mantiene bloqueada y, una vez iniciada, progresa sin alteraciones de velocidad.

- Los mutantes rgfi $\Delta$ y pmk1 $\Delta$ no bloquean la constricción ni la ralentizan, lo que señala más hacia una respuesta activa de parada que a la ausencia de componentes esenciales para iniciar el cierre del CAR.

El bloqueo por BP retrasa la constricción del CAR, pero no el inicio de la septación, entendiendo por septación el comienzo y progresión de la síntesis del septo en la periferia celular, al margen de su invaginación. Hemos medido la incorporación de BP en el septo periférico durante el bloqueo y hemos visto que va aumentando con el tiempo hasta que comienza la constricción del CAR (Figura 40). Que la parada se produzca después del inicio de la síntesis del septo tiene sentido si entendemos que el BP estaría produciendo el daño 
(desorganización de la pared) al ser incorporado en el propio septo, por lo que no podría disparar la respuesta hasta que comience su síntesis. Lo que nos parece más extraño es que la síntesis del septo prosiga durante el bloqueo, provocando la "acumulación" de septo en la periferia, aunque no vaya acompañada de ingresión/invaginación.

Según estos datos la actividad de Bgs1 no estaría bloqueada en tanto que el BP se une de forma específica al $\beta(1,3)$-D-glucano lineal, de cuya síntesis es responsable Bgs1 (Cortés et al. 2007). Tampoco estaría bloqueada la actividad de Bgs4. El mutante cwg1-1 (bgs4) presenta un retraso en citoquinesis a la temperatura restrictiva, pero curiosamente en estas condiciones la síntesis del septo en la periferia no se para (Muñoz et al. 2013). Bgs4 llega con la constricción del CAR (Cortés et al. 2018) y nosotros hemos visto que el retraso citoquinético de este mutante es revertido en ausencia de Pmk1, lo que hace improbable que sea esta proteína la que se vea frenada por la parada. Sería interesante de todos modos comprobar si el mutante $c w g 1-1$, responde al tratamiento con BP y saber cómo se localiza Bgs4 durante el bloqueo en la cepa silvestre.

Estos hechos, junto a la estabilización del CAR (medido por la resistencia a la LatA que propicia la presencia de BP), favorecen la idea de que el origen del bloqueo está en la parada del CAR y no del septo. Tendríamos una actividad $\beta$ GS competente que se vería constreñida por el bloqueo del avance del anillo. Aunque el septo origine la fuerza para la invaginación del surco, nuestro modelo de bloqueo de constricción por el CAR está en concordancia con las propuestas de una síntesis del septo mecanosensible (Chang 2017; O'Shaughnessy \& Thiyagarajan 2018; Pollard \& O'Shaughnessy 2019).

\section{Pmk1 integra las señales de diferentes tipos de estrés que afectan a la pared celular y retrasan la citoquinesis}

Hemos visto que agentes como la caspofungina, la cafeína y el $\mathrm{KCl}$ producen un retraso en la citoquinesis similar al del BP, y que este retraso también depende de Pmk1. Estas sustancias provocan daños en la pared celular y/o cambios en el medio a los que la pared celular tiene que adaptarse. Por otra parte, el retraso en citoquinesis que presenta el mutante $c w g 1-1$, también es suprimido parcialmente al delecionar a Pmk1. En este caso el daño en la pared celular es consecuencia de una actividad $\beta$ GS defectuosa que termina con la "lisis explosiva" durante la separación celular (Muñoz et al. 2013). Estos datos apoyan la existencia de una respuesta tipo "checkpoint" que se activa en presencia de distintos tipos de estrés que afectan a la pared celular y que es capaz de retrasar la constricción del CAR.

Rgf1, Rho1 y Pck2 participan en la transducción de la señal inducida por BP en la pared celular hasta Pmk1. Sin embargo, en los otros compuestos como la caspofungina o la cafeína, la participación de Rgf1 no está tan clara. El mutante $r g f 1 \Delta$, presenta una respuesta intermedia que 
podría indicar que la transducción de la señal va a la vez a través de otros activadores. Resulta particularmente rara la situación con $\mathrm{KCl}$. La respuesta de bloqueo frente a este compuesto no depende de Rgf1 pero sí de Pmk1; sin embargo, la activación (fosforilación) de Pmk1 frente a KCl se ve totalmente abolida al delecionar a Rgf1 (García et al. 2009b), algo que también sucede en el mutante rho2 $\Delta$ (Barba et al. 2008). Tal vez se trate de respuestas no equivalentes, una rápida que se daría de forma generalizada en el cultivo frente a dosis altas de $\mathrm{KCl}$ (0.6 M) (Barba et al. 2008; García et al. 2009b), y otra, la que vemos nosotros, frente a cambios menores en la presión de turgencia $(0.2 \mathrm{M} \mathrm{KCl})$. De hecho, a esta concentración no detectamos cambios en el volumen celular o aberraciones en la integridad del anillo, algo que sí sucede a altas dosis de $\mathrm{KCl}$ (Okada et al. 2019).

El BP y los compuestos que producen estrés en la pared celular provocan la acumulación de gran cantidad de células multiseptadas o encadenadas en el mutante $p m k 1 \Delta$, pero no en la cepa silvestre (Figura 50). Este fenotipo es el resultado de un fallo en la etapa final de separación celular y sugiere que, si el estrés en la pared celular se produce durante la citoquinesis, la ruta CIP se encarga de retrasar el inicio de la constricción, lo que permitiría ganar tiempo para que se activen los programas de reparación. Al mismo tiempo, Pmk1 también induce la expresión de genes de respuesta a estrés, algunos de los cuales podrían servir para corregir la pared dañada y reiniciar la citoquinesis incluso en condiciones de estrés (Chen et al. 2003; Takada et al. 2007).

¿Qué está sucediendo durante la parada de constricción? No existe una explicación satisfactoria para el fenotipo de células encadenadas y septos engrosados observado en el mutante pmk1 $\Delta$ (Toda et al. 1996; Zaitsevskaya-Carter \& Cooper 1997). Se ha propuesto que Pmk1 podría participar en la regulación negativa de la formación del septo, a través de la interacción con componentes de la ruta SIN y las glucán sintasas, o que pudiera regular a las glucanasas (Madrid etal. 2006). Además, la deleción de Pmk1 suprime el fenotipo de multiseptación del mutante cdc4-8 (cadena ligera de la miosina II), de forma dependiente de Nrd1, aunque no suprime el mismo fenotipo en los mutantes myo2-E1 y myp2 $\Delta$, ni la actividad de Pmk1 correlaciona con la abundancia del mRNA de Cdc4 (Satoh et al. 2009).

A continuación, planteamos algunas ideas sobre lo que podría o no podría estar ocurriendo durante el bloqueo de la constricción en relación con nuestros datos:

- Eliminar la droga del septo para que no interfiera con la estructura. Esta idea parece improbable pues la síntesis del septo no se ve detiene durante el bloqueo, y en lo que dura el bloqueo más compuesto está siendo incorporado; por tanto, el bloqueo resultaría contraproducente, cuando no es el caso.

- Reforzar el septo. Este supuesto se basa en los datos de fluorescencia de BP, y con ello de septo, en la periferia, que son más elevados en las células paradas que en aquellas sin parar. Resultaría coherente tal vez si habláramos de defectos que terminan en la lisis 
celular por la región del septo, pero nos encontramos ante el caso contrario, septos que no se disuelven.

- Remodelar el septo periférico. Si estos compuestos interfieren con la conformación del glucano del septo, esto podría hacer que este fuera menos accesible a la actividad hidrolítica de las glucanasas (Martín-Cuadrado et al. 2008). Este periodo de bloqueo podría permitir una remodelación o síntesis de novo de cadenas de glucano correctas, o destrucción de las que son anómalas. Además, se ha visto que Pmk1, junto a Rgf1 y Wsc1, participan en la homeostasis del grosor de la pared (Davì et al. 2018). Esto podría contribuir al control de la estructura del septo para asegurar una posterior separación efectiva.

- Adaptar las condiciones internas. Las células podrían modificar, por ejemplo, su presión de turgencia para adaptarse al estrés antes de iniciar la constricción, algo que se ha visto influye en la velocidad de este proceso (Proctor et al. 2012), que sería necesario para la separación celular (Atilgan etal. 2015) y que podría relacionarse con fenotipos de multiseptación (Morris et al. 2019). Este podría ser el caso para los compuestos probados que reducen la velocidad de constricción, pero parece poco probable en el caso del BP, pues la constricción progresa a la misma velocidad.

- Incrementar la expresión de las glucanasas o regular su transporte.

\section{El estrés de la pared celular controla la contracción de CAR a través de la señalización del SIN}

Hasta ahora hemos visto que Pmk1 bloquea la contracción del CAR en respuesta al estrés en la pared celular. Pero otra cuestión es ¿cómo se lleva a cabo este bloqueo? En el proceso podrían participar proteínas que son componentes físicos del anillo o bien proteínas reguladoras que pueden conectar distintas vías entre sí (Cheffings et al. 2016; Pollard 2017).

Nuestra idea ha sido mirar si el bloqueo producido por BP se dejaba de dar en los mutantes de actina $a d f 1-1$ y $c d c 12-112$, además de en los de miosinas rlc1 $\Delta$ y myp2 $\Delta$. En todos los mutantes analizados se producía el retraso siempre mayor que el del propio mutante en ausencia de BP. Sin embargo, sí obtuvimos un resultado positivo al analizar el efecto del BP en un mutante de Sid2. Este mutante no presenta el retraso típico producido por el BP, lo cual sugiere que la vía CIP podría actuar promoviendo el mantenimiento de la actividad de SIN.

Otro dato que apoya esta idea es que el bloqueo de la constricción producido por el estrés de la pared se correlaciona con una señal SIN prolongada, donde Cdc7 permanece en el nuevo SPB durante más tiempo y el tiempo de retención citoplásmico para Clp1 es más largo. Es cierto 
que tanto la activación inicial del SIN cómo su desactivación una vez comenzada la constricción se dan por igual al margen del bloqueo, lo que no aclara si el mantenimiento de la señal del SIN es el origen o solo una consecuencia de la parada. Sin embargo, también hemos visto que Sid2 es el componente crucial en dicha respuesta, pues en un mutante sid2-250 desaparecen tanto el bloqueo de la constricción (Figura 61), como la estabilización del CAR (Figura 57). Creemos pues que el mantenimiento de la alta actividad SIN es la causa y no la consecuencia del bloqueo de la septación y del retraso en la constricción del anillo.

Las implicaciones de la ruta SIN durante la septación no han sido del todo esclarecidas, debido en parte a la falta de conocimiento sobre los sustratos de esta vía que participan en la formación del septo. La sobreactivación de la ruta por el mutante cdc16-116 puede inducir la septación incluso en interfase (Cerutti \& Simanis 1999; Hachet \& Simanis 2008). Sin embargo la ruta SIN no parece ser necesaria para iniciar la formación del anillo (Wu et al. 2003); hasta en las condiciones más restrictivas los mutantes sid2-250 y spg1-B8 comienzan a ensamblar un anillo, aunque este se disuelve antes de contraer (Hachet \& Simanis 2008). Se había descrito que el pico de actividad SIN coincide con el inicio de la constricción del anillo, pero sin establecer una relación de causalidad (Dey \& Pollard 2018). Los trabajos sobre el checkpoint de citoquinesis ya habían señalado que la actividad SIN es necesaria para estabilizar el CAR frente a sus agresiones (Trautmann et al. 2001; Mishra et al. 2004), pero no hacían mención a la progresión del anillo. Nosotros describimos aquí una nueva función de la ruta SIN cómo inhibidor del inicio de la constricción del CAR en presencia de estrés en la pared celular.

De acuerdo a nuestros resultados con el bloqueo, el pico de actividad del SIN no se da con la constricción del CAR; sube como en condiciones normales, pero se mantiene en su estado máximo hasta que empieza a caer justo en el momento en que se inicia la constricción (Figuras 59 y 60). Proponemos que la alta actividad SIN está realmente inhibiendo la constricción del CAR, probablemente a través de la estabilización de este, y que sería el descenso de esta actividad lo que liberaría al anillo del bloqueo y señalaría el inicio de la constricción.

En el trabajo de (Dey \& Pollard 2018) no encuentran que la sobreactivación del SIN con el mutante cdc16-116 modifique los tiempos de las tres etapas del CAR, sin embargo, en esas condiciones se pierde la polaridad de Cdc7 en los SPBs. Como indican estos autores, el número total de moléculas de esta kinasa se reparte por igual en albos SPBs, lo que equivale a decir que habría la mitad de Cdc7 activo en el nSPB. Esta puede ser la razón de que este mutante cdc16-116 se comporte de forma similar a uno de pérdida de función con respecto al bloqueo por BP cuando hay anillos mitóticos (2 SPBs), mientras que responde con un bloqueo excesivo de los anillos interfásicos (1 SPB) (Figura 64).

Si el bloqueo por BP es dependiente del SIN, no lo es de la fosfatasa Clp1, y por tanto descartamos que se trate del mismo checkpoint que el de citoquinesis. A pesar de que Clp1 es 
retenida en el citoplasma durante el bloqueo de la constricción, éste puede darse por igual aun en la deleción de la fosfatasa. Por esto y porque no vemos relación de Pmk1 con el mutante cps1191, creemos que el checkpoint de septación que hemos descrito respondería a agresiones del septo y no del anillo como lo hace el de Clp1. La retención citoplásmica de Clp1 se debería a la alta actividad SIN que origina la parada. Igual que ocurre con el checkpoint de citoquinesis, en el bloqueo por BP se da una estabilización del CAR, que podría ser lo que frene su constricción; sería interesante repetir el experimento en el que vemos que el BP confiere resistencia de los anillos a LatA en fondos mutantes clp1 $\Delta$ para ver únicamente los efectos de la vía que estudiamos.

Otra cuestión que arroja el mantenimiento del SIN y la similitud con el checkpoint de citoquinesis es si el bloqueo, además de en el CAR, se da también a nivel del ciclo celular. El checkpoint de Clp1 detiene el ciclo en G2; es de suponer que frente a las agresiones que describimos también se dé una parada similar en tanto que igualmente interviene Sid2. A falta de un examen de este posible bloqueo, otros datos que apoyan esta hipótesis son: que las células bloqueadas detienen completamente su crecimiento, que no hayamos visto en ningún caso situaciones de múltiples núcleos, ni en bloqueos prolongados ni en las células encadenadas del mutante pmk1 $\Delta$, y que de darse dicha parada de ciclo esta dependería de Sid2, pues las células sid2-250 a temperatura restrictiva se vuelven multinucleadas aun en presencia de BP.

Desconocemos el mecanismo por el que la ruta SIN estaría bloqueando la constricción del CAR. Los resultados de estabilización del anillo y la resistencia frente a LatA sugieren un papel relacionado con la dinámica de la actina (Mendes Pinto et al. 2012; O'Shaughnessy \& Thiyagarajan 2018; Cheffings et al. 2019). Como ya se ha comentado antes, hemos visto que en los mutantes de actina $a d f 1-1$ y $c d c 12-112$ y de miosinas $r l c 1 \Delta$ y myp2 $\Delta$ se produce el bloqueo en presencia de BP. Podríamos continuar la búsqueda de las proteínas responsables de la parada a partir de otros genes en los que se ha descrito un fenotipo de retraso en el inicio de la constricción del CAR (Pombase, FYPO:0004653): acp2 $2^{+}$, arp3 $^{+}$, art1 $1^{+}$, blt1 $^{+}, \mathrm{cyk}^{+}, \mathrm{myo1}^{+}, \mathrm{myo2}^{+}$, sbg $^{+}$, wsp $1^{+}$; además de los reguladores $g e \mathrm{f}^{+} \mathrm{y} \mathrm{rga}^{+}$.

Finalmente es interesante destacar que además del papel de RhoA (ortólogo de Rho1) como activador de las forminas, RhoA es un regulador negativo de la ruta HIPPO (ortóloga en mamíferos a la ruta SIN de S.pombe y a la ruta MEN de S. cerevisiae) (Plouffe et al. 2016). Se ha visto por primera vez que cuando se elimina RhoA, la quinasa final de la ruta LATS1/2 (ortóloga de Sid2) y el factor de transcripción por debajo de esta, YAP/TAZ, permanecen altamente fosforilados. En ausencia de suero la ruta Hippo se activa y YAP/TAZ es fosforilado y secuestrado en el citoplasma. Esto último también ocurre al eliminar RhoA, que el factor de transcripción se queda en el citoplasma y es inactivo transcripcionalmente incluso en presencia de suero (Plouffe et al. 2016). 
100 | DISCUSIÓN

Nuestro trabajo en S. pombe presenta ciertas similitudes con el papel de RhoA en la ruta Hippo. Rho1 y la ruta CIP controlan el SIN en presencia de estrés, lo que retrasa la constricción del anillo y da tiempo a que se induzcan los programas de adaptación. Comprender la relación entre Rho1 y la ruta SIN en levaduras es un paso importante y sería muy útil para comprender la interacción entre RhoA y la ruta Hippo en mamíferos. 


\section{CONCLUSIONES}

1. El estrés en la pared celular desencadena una respuesta de "tipo checkpoint" que retrasa el inicio de la constricción del CAR.

2. Este retraso depende de la GTPasa Rho1, su GEF Rgf1, la cascada de integridad celular CIP y la ruta de inicio de septación SIN.

3. Rgf1 se localiza en la membrana muy cerca del CAR en citoquinesis y llega cuando el CAR está ya formado, durante la etapa madurativa antes de la septación.

4. En condiciones de estrés en la pared celular las células que carecen de la MAPK Pmk1 no responden con el bloqueo del CAR y septan de forma prematura, mostrando un fenotipo de células encadenadas.

5. Sid2 participa en la estabilización y el bloqueo de la constricción del CAR independientemente de Clp1. 



\section{MATERIALES Y MÉTODOS}

\section{CEPAS DE Schizosaccharomyces pombe}

Este trabajo se ha realizado enteramente con la levadura de fisión Schizosaccharomyces pombe. Las cepas empleadas están recogidas en la siguiente tabla, donde se detalla su genotipo y procedencia.

\begin{tabular}{|c|c|c|}
\hline NOMBRE & GENOTIPO & ORIGEN \\
\hline PG40 & $\begin{array}{l}\text { leu1-32::rgf1-GFP:leu1+, rgf1::his3+, his3D1, ura4D18, ade6M210, } \\
\text { h- }\end{array}$ & Colección YSM \\
\hline YS5261 & $\begin{array}{l}\text { rgf1-EnvyGFP:leu1+, sid4-mcherry:hph, rlc1-tdTomato:nat, } \\
\text { rgf1::kanMX6, leu1-32, ura4D18 }\end{array}$ & Este trabajo \\
\hline TE149 & sid2-250, leu1-32::rgf1-GFP:leu1+, rgf1::nat, $h-$ & Este trabajo \\
\hline NG241 & cdc15-140, rgf1::his3+, leu1-32::rgf1-GFP:leu1+, h- & Colección YSM \\
\hline NG319 & cdc3-6, rgf1::his3+, leu1-32::rgf1-GFP:leu1+, h+ & Colección YSM \\
\hline TE301 & cdc11-119, rgf1::nat, leu1-32::rgf1-GFP:leu1+, h- & Este trabajo \\
\hline TE519 & $\begin{array}{l}\text { cdc15-140, rlc1-tdTomato:nat, leu1-32::rgf1-GFP:leu1+, } \\
\text { rgf1::his3+, leu1-32, his3D1 }\end{array}$ & Este trabajo \\
\hline TE348 & $\begin{array}{l}\text { cdc11-119, rgf1::kanMX6, rlc1-tdTomato:nat, } \\
\text { leu1-32::rgf1-GFP:leu1 }{ }^{+}\end{array}$ & Este trabajo \\
\hline SM213 & leu1-32, ura4D18, h+ & Colección YSM \\
\hline SM341 & rgf1::nat, leu1-32, ura4D18, h+ & Colección YSM \\
\hline
\end{tabular}




\begin{tabular}{|c|c|c|}
\hline NOMBRE & GENOTIPO & ORIGEN \\
\hline YS864 & $c d c 4-8$, leu1-32, $h+$ & Nurse P. \\
\hline TE377 & $c d c_{4}-8$, rgf1::kanMX6, leu1-32, $h+$ & Este trabajo \\
\hline YS862 & rlc1::kanMX6, ura4D18, leu1-32, ade6M210, h- & Simanis V. \\
\hline TE389 & rgf1::nat, rlc1::kanMX6, ura4D18, leu1-32, ade6M210, $h+$ & Este trabajo \\
\hline YS586 & cdc15-140, leu1-32, h- & Valdivieso M.H. \\
\hline NG203 & cdc15-140, rgf1::kanMX6 & Colección YSM \\
\hline TE264 & imp2::ura4+, leu1-32, ura4D18, ade6M210, h+ & Sazer S. \\
\hline TE454 & rgf1::nat, imp2::ura $4^{+}$, leu1-32 & Este trabajo \\
\hline YS865 & cdc12-112, ura $4 D 18, h+$ & Nurse P. \\
\hline TE251 & cdc12-112, rgf1::nat, $h-$ & Este trabajo \\
\hline SM440 & nda3-KM311, leu1-32::rgf1-GFP:leu1+, rgf1::nat, leu1-32, h+ & Colección YSM \\
\hline TE558 & mid2::ura4+, rgf1::nat, leu1-32::rgf1-GFP:leu1+, ura4D18, & Este trabajo \\
\hline TE249 & $\begin{array}{l}\text { leu1::GFP-atb2:ura4+, rlc1-tdTomato:nat, leu1-32, ura4D18, } \\
\text { his3D1, h+ }\end{array}$ & Cortés J.C.G. \\
\hline TE257 & $\begin{array}{l}\text { rgf1::kanMX6, leu1::GFP-atb2:ura4+, rlc1-tdTomato:natMX6, } \\
\text { leu1-32, ura4D18 }\end{array}$ & Este trabajo \\
\hline TE478 & imp2-GFP:kanMX6, leu1:sid4-GFP, ura4D18, leu1-32, h- & Este trabajo \\
\hline TE495 & $\begin{array}{l}\text { rgf1::nat, imp2-GFP:kanMX6, leu1:sid4-GFP, ura4D18, leu1-32, } \\
\text { h- }\end{array}$ & Este trabajo \\
\hline TE399 & mEGFP-myo2:kanMX6, sid4-mCherry:hph, leu1-32, ura4D18, $h+$ & Este trabajo \\
\hline TE566 & myp2-GFP:kanMX6, sfi1-GFP:kanMX6 & Este trabajo \\
\hline $\mathrm{RC} 34$ & $\begin{array}{l}\text { leu1-32::rgf1-PTTR-GFP:leu1+, rlc1-tdTomato:nat, } \\
\text { sid4-mCherry:hph, rgf1::kanMX6, leu1-32 }\end{array}$ & Este trabajo \\
\hline TE470 & LactC2-GFP:nat, sad1-GFP:kanMX6, leu1-32, ura4D18, ade6M210 & Este trabajo \\
\hline TE472 & $\begin{array}{l}\text { rgf1::nat, LactC2-GFP:nat, sad1-GFP:kanMX6, leu1-32, ura4D18, } \\
\text { ade6M210 }\end{array}$ & Este trabajo \\
\hline TE402 & $\begin{array}{l}\text { rgf1::nat, mEGFP-myo2:kanMX6, sid4-mCherry:hph, leu1-32, } \\
\text { ura4D18 }\end{array}$ & Este trabajo \\
\hline TE580 & $\begin{array}{l}\text { rho1-596:nat, imp2-GFP:kanMX6, leu1:sid4-GFP, ura4D18, } \\
\text { leu1-32 }\end{array}$ & Este trabajo \\
\hline
\end{tabular}




\begin{tabular}{|c|c|c|}
\hline NOMBRE & GENOTIPO & ORIGEN \\
\hline TE549 & sty1::ura4+, imp2-GFP:kanMX6, leu1:sid4-GFP, ura4D18, leu1-32 & Este trabajo \\
\hline TE491 & pmk1::ura4+, imp2-GFP:kanMX6, leu1:sid4-GFP, ura4D18, h- & Este trabajo \\
\hline TE585 & pmk1::ura4+, mEGFP-myo2:kanMX6, sid4-mcherry:hph, ura4D18 & Este trabajo \\
\hline TE418 & $\begin{array}{l}\text { rho2::natMX6, imp2-GFP:kanMX6, leu1:sid4-GFP, ura4D18, } \\
\text { leu1-32 }\end{array}$ & Este trabajo \\
\hline TE493 & $\begin{array}{l}\text { pck1::kanMX6, imp2-GFP:kanMX6, leu1:sid4-GFP, ura4D18, } \\
\text { leu1-32 }\end{array}$ & Este trabajo \\
\hline TE500 & $\begin{array}{l}\text { pck2::kanMX6, imp2-GFP:kanMX6, leu1:sid4-GFP, ura4D18, } \\
\text { leu1-32 }\end{array}$ & Este trabajo \\
\hline TE551 & pmk1::kanMX6, leu1-32, ura4D18, ade6M210, h- & Perez P. \\
\hline TE541 & $\begin{array}{l}\text { pmk1::ura4+, hht1-RFP:kanMX6, imp2-GFP:kanMX6, } \\
\text { leu1:sid4-GFP, ura4D18 }\end{array}$ & Este trabajo \\
\hline TE562 & cwg1-1, imp2-GFP:kanMX6, leu1:sid4-GFP, ura4D18, leu1-32 & Este trabajo \\
\hline TE564 & $\begin{array}{l}\text { cwg1-1, pmk1::ura4+, imp2-GFP:kanMX6, leu1:sid4-GFP, } \\
\text { ura4D18, leu1-32 }\end{array}$ & Este trabajo \\
\hline TE552 & $\begin{array}{l}\text { myp2::ura4+, imp2-GFP:kanMX6, leu1:sid4-GFP, ura4D18, } \\
\text { leu1-32 }\end{array}$ & Este trabajo \\
\hline TE615 & $\begin{array}{l}\text { rlc1::kanMX6, imp2-GFP:kanMX6, leu1:sid4-GFP, ura4D18, } \\
\text { leu1-32 }\end{array}$ & Este trabajo \\
\hline YS5154 & adf1-1, imp2-GFP:kanMX6, leu1:sid4-GFP, ura4D18, leu1-32 & Este trabajo \\
\hline TE592 & cdc12-112, imp2-GFP:kanMX6, leu1:sid4-GFP, ura4D18, leu1-32 & Este trabajo \\
\hline TE507 & clp1::kanMX6, imp2-GFP:kanMX6, leu1:sid4-GFP, leu1-32, h- & Este trabajo \\
\hline TE505 & $\begin{array}{l}\text { cps1-191, imp2-GFP:kanMX6, leu1:sid4-GFP, ura4D18, leu1-32, } \\
h+\end{array}$ & Este trabajo \\
\hline TE525 & $\begin{array}{l}\text { cps1-191, pmk1::ura4+, imp2-GFP:kanMX6, leu1:sid4-GFP, } \\
\text { ura4D18, leu1-32 }\end{array}$ & Este trabajo \\
\hline EM352 & pact1-LifeAct-GFP:leu1, ura4D18, leu1-32, h- & $\begin{array}{l}\text { Balasubramanian } \\
\text { M. K. }\end{array}$ \\
\hline RC8 & sid2-25o, imp2-GFP:kanMX6, sfi1-GFP:kanMX6 & Este trabajo \\
\hline YS826 & sid2-GFP:ura4+, leu1-32, ade6M210, ura4D18, h+ & Simanis V. \\
\hline TE427 & rgf1::nat, sid2-GFP:ura4+, leu1-32, ade6M210, ura4D18, h+ & Este trabajo \\
\hline TE413 & cdc7-GFP:ura4+, imp2-GFP:kanMX6, h+ & Este trabajo \\
\hline
\end{tabular}




\begin{tabular}{cll}
\hline NOMBRE & \multicolumn{1}{c}{ GENOTIPO } & ORIGEN \\
\hline TE414 & rgf1::nat, cdc7-GFP:ura4+, imp2-GFP:kanMX6 & \\
TE513 & cdc7-GFP:ura4+, sad1-dsRed:nat, ura4D18, $h+$ & Este trabajo \\
TE527 & clp1-GFP:kanMX6, imp2-GFP:kanMX6, leu1:sid4-GFP, h+ & Este trabajo \\
TE484 & imp2-GFP:kanMX6, sfi1-GFP:kanMX6, ura4D18, leu1-32, h- & Este trabajo \\
TE613 & cdc7-24, imp2-GFP:kanMX6, leu1:sid4-GFP, leu1-32 & Este trabajo \\
TE611 & sid1-239, imp2-GFP:kanMX6, leu1:sid4-GFP, leu1-32 & Este trabajo \\
TE597 & cdc16-116, imp2-GFP:kanMX6, leu1:sid4-GFP, ura4D18, leu1-32 & Este trabajo \\
TE598 & cdc16-116, pmk1::ura4+, imp2-GFP:kanMX6, leu1:sid4-GFP, & Este trabajo \\
& ura4D18, leu1-32 & \\
\hline
\end{tabular}

Tabla 4 Estirpes utilizadas en este trabajo

\section{MÉTODOS GENÉTICOS}

Para la construcción de dobles mutantes, o la introducción en determinadas cepas de proteínas integradas en el genoma marcadas con algún epítopo o proteína fluorescente, se realizaron cruces genéticos entre las cepas parentales correspondientes. Se analizaron las colonias resultantes y se seleccionaron los clones que portaban las mutaciones de interés, los marcadores, epítopos, así como las auxotrofías y el tipo sexual adecuado.

\section{Conjugación}

Los experimentos de conjugación se realizaron utilizando estirpes heterotálicas de distinto sexo $(\mathrm{h}+\mathrm{y} \mathrm{h}-)$. Para inducir los cruces las cepas se sembraron en placas de YES hasta alcanzar la fase estacionaria (48 horas). A continuación, se recogieron aproximadamente el mismo número de células de la estirpe $\mathrm{h}+\mathrm{y} \mathrm{h}-\mathrm{y}$ se mezclaron en un pequeño volumen de agua estéril (20 $\mu \mathrm{l}$ ). La mezcla se extendió en una placa de medio MEA. Los zigotos se forman al cabo de entre 12 y 20 horas e inmediatamente sufren meiosis y esporulación, formando ascas con 4 ascosporas al cabo de 2 días de incubación a $28^{\circ} \mathrm{C}$. 


\section{Aislamiento de ascosporas al azar}

Para liberar las esporas se hicieron suspensiones en agua estéril de las mezclas de conjugación incubadas durante 2 días a $28^{\circ} \mathrm{C}$ en placas de MEA, y se trataron con $1 \mu l$ de $\beta$-glucuronidasa arilsulfatasa (Roche) durante toda la noche en agitación a temperatura ambiente. Este tratamiento destruye la pared celular de las células vegetativas y las ascas, sin afectar a las ascosporas, que poseen una pared más resistente.

Se realizaron las diluciones apropiadas para obtener entre 100 y 1000 esporas por placa y se extendieron en placas de YES. Se incubaron las placas durante 4 días a $25^{\circ} \mathrm{C}$ o $28^{\circ} \mathrm{C}$. Mediante réplica en diferentes medios selectivos o a distintas temperaturas se seleccionaron las estirpes con el genotipo deseado, que posteriormente se comprobaron por PCR.

\section{Reacción en cadena de la polimerasa (PCR)}

La amplificación de fragmentos de DNA mediante PCR se llevó a cabo en un termociclador GeneCycler (Bio-Rad). Dependiendo de la temperatura de fusión de los oligonucleótidos empleados y del tamaño del producto esperado se realizaron modificaciones sobre el siguiente protocolo estándar de reacción:

- Desnaturalización inicial:

3 minutos a $98^{\circ} \mathrm{C}$

- 30 ciclos de:
- Desnaturalización:
30 segundos a $95^{\circ} \mathrm{C}$
○ Anillamiento:
45 segundos a $55^{\circ} \mathrm{C}$
- Extensión:
1-3 minutos a $72^{\circ} \mathrm{C}$

- Extensión final:

5 minutos a $72^{\circ} \mathrm{C}$

Las mezclas de reacción están compuestas por una mezcla de dNTPs (dATP, dTTP, dGTP, dCTP, cada uno a una concentración final de $200 \mu \mathrm{M}$ ), los dos oligonucleótidos (1 $\mu \mathrm{M}$ cada uno), $\mathrm{MgCl} 23 \mathrm{mM}$, Taq-polimerasa (BIOTAQ Ecogen) $0.2 \mathrm{u} / \mu \mathrm{l}$ y el tampón de reacción suministrado con la enzima. Sobre esta mezcla se resuspendieron fracciones pequeñas de colonias de las cepas a analizar, para emplear a modo de DNA molde. Los oligonucleótidos empleados (suministrados por SIGMA o Life Technologies) se recogen en la tabla mostrada a continuación. 


\begin{tabular}{|c|c|c|}
\hline GEN & SECUENCIA & NOMBRE \\
\hline$r g f 1^{+}$ & CAAGGGTATGTGGTCTGG & Rom2-3'ext \\
\hline$p m k 1^{+}$ & TTCTGTCGAACGAGAGCCAC & Pmk1 5'ext F \\
\hline$p c k 2^{+}$ & CGTACCCGCGATTATTGACG & Pck2 5'ext F \\
\hline $\operatorname{rho}^{+}$ & CTGCATACGACGCTCAGCTA & Rho2 5'ext F2 \\
\hline$r l c 1^{+}$ & GACTGTACGGAACTGTGTAGGA & Rlc1 5'ext F \\
\hline$c l p 1^{+}$ & GTATTCAGAGGCGGCGTGTT & Clp1 5'ext F \\
\hline myp2 $2^{+}$ & AAAGCCAGCACGGTACTTCG & Myp2 5'ext F \\
\hline NatMX6 & TGAAGGACCCATCCAGTGCCT & Nat2 \\
\hline NatMX6 & GCGCTCTACATGAGCATGCCCT & Nat3 \\
\hline KanMX6 & CGGATTCAGTCGTCACTCATGGTG & Kan3 \\
\hline KanMX6 & AGAAACAACTCTGGCGCATCGG & Kan2b \\
\hline $\mathrm{ura}_{4}^{+}$ & GCAAGAGACCACGTCCC & M10 \\
\hline $\mathrm{ura}_{4}^{+}$ & CTGGTGGCCTTAGGT & M13 \\
\hline his $^{+}$ & GTGTTCGCTAATTGCGC & M22 \\
\hline
\end{tabular}

Tabla 5 Oligonucleótidos de comprobación empleados en este trabajo.

\section{CONDICIONES DE CULTIVO}

Empleamos los métodos genéticos y medios de cultivos estándar para Schizosaccharomyces pombe (Moreno et al. 1991). Crecimos las células en medio rico YES o medio selectivo MM suplementado con los requerimientos apropiados, ya sea a $25^{\circ} \mathrm{C}, 28^{\circ} \mathrm{C}$ o $32^{\circ} \mathrm{C}$ de acuerdo a la naturaleza de cada cepa.

Los experimentos se realizaron siempre con cultivos en fase exponencial de S. pombe. Estos se obtienen inoculando colonias aisladas, cuyas características genéticas se habían comprobado anteriormente, en $5 \mathrm{ml}$ del medio correspondiente. El cultivo se incuba en agitación orbital a la temperatura apropiada hasta que las células entran en fase estacionaria temprana. A continuación, se inocula con este cultivo otro mayor, teniendo en cuenta el tiempo de generación de la levadura en cada condición.

El crecimiento de la levadura en medio líquido se controló midiendo la turbidez del cultivo por absorbancia a $600 \mathrm{~nm}$ en un espectrofotómetro Hitachi U-2001, y recurriendo a tablas de 
calibración obtenidas previamente. Según estas tablas, una densidad óptica ( $\mathrm{DO}_{600}$ ) de 1.0 se corresponde aproximadamente con $10^{7}$ células $/ \mathrm{ml}$.

\section{Inducción de estrés}

Empleamos los compuestos listados en la siguiente tabla para inducir situaciones de estrés en la célula.

\begin{tabular}{ccccc}
\hline Nombre Común & ACRÓnimo & Solución Stock & Proveedor & Nombre Comercial \\
\hline Blankophor & BP & 10 mg/ml en agua & Bayer & Blankophor BA 267\% \\
Cloruro potásico & $\mathrm{KCl}$ & Añadido en forma de sal & Merck & Potassium chloride \\
Cafeína & Caf & 0.5 M en agua & Sigma-Aldrich & Caffeine, SigmaUltra \\
Caspofungina & Csp & $2.5 \mathrm{mg} / \mathrm{ml}$ en agua & Sigma-Aldrich & Caspofungin diacetate \\
Latrunculina A & LatA & $10 \mathrm{mM}$ en DMSO & Sigma-Aldrich & Latrunculin A \\
\hline
\end{tabular}

Tabla 6 Soluciones stock de los compuestos añadidos a los medios de cultivo.

Para el seguimiento in vivo de la respuesta al estrés preparamos una dilución a la concentración descrita en cada caso, en $2 \mathrm{ml}$ de YES, a partir de la solución stock. Usamos esta dilución para la resuspensión y lavado y mantenimiento de las células en su preparación inmediatamente antes de la captura de imágenes (ver apartado time-lapse).

El efecto de la exposición continuada a estrés se determinó empleando cultivos crecidos hasta fase logarítmica en $\mathrm{MM}+$ suplementos a $25^{\circ} \mathrm{C}$. Realizamos las diluciones de los cultivos en el mismo medio, añadiendo en cada caso el compuesto especificado. Usamos un tiempo de duplicación de entre 4 y 5 horas para los cálculos del pase, y dejamos crecer las células a $31^{\circ} \mathrm{C}$ durante 16h hasta alcanzar una DO de 0.4 - 0.6. Pasado este tiempo, fotografiamos las células con tinción de calcoflúor directamente en el microscopio DeltaVision.

\section{Ensayo de crecimiento en gota}

Los ensayos de crecimiento de cepas termosensibles se realizaron en placas de YES incubadas a las temperaturas indicadas en cada caso. Las cepas de estudio se sembraron en placas de YES a $25^{\circ} \mathrm{C}$ hasta alcanzar la fase estacionaria ( 48 horas). Posteriormente, las células se resuspendieron en $200 \mu \mathrm{l}$ de agua estéril a DO 2.0 y se realizaron seis diluciones seriadas 1:5. Se 
utilizó un replicador (SIGMA) para colocar una gota de cada concentración (aproximadamente 3 $\mu \mathrm{l})$ sobre las placas. De esta forma, se sembraron aproximadamente $6 \times 10^{4}$ células en la gota inicial, $1.2 \times 10^{4}$ células en la primera dilución, $2.4 \times 10^{3}$ en la segunda, $4.8 \times 10^{2}$ en la tercera, 100 en la cuarta y 20 en la última. Las placas fueron incubadas de 2 a 5 días dependiendo de la temperatura.

\section{MICROSCOPÍA DE FLUORESCENCIA}

Las imágenes de fluorescencia se obtuvieron por lo general con el sistema Personal DeltaVision (Applied Precision), equipado con un microscopio invertido Olympus IX71 (Olympus), objetivo Plan Apo 100x/1.40 de inmersión en aceite y cámara CoolSnap HQ2 (Photometrics). El sistema está controlado por el software SoftWoRx Resolve 3D (Applied Precision).

Las imágenes de superresolución se obtuvieron con el microscopio confocal Spinning disk Olympus IXplore SpinSR SoRa (Olympus), compuesto por el microscopio Olympus IX83 (Olympus), objetivo U Plan Super Apocromático 100x/1.45 de inmersión en aceite y cámara sCMOS ORCA Flash 4.0 V3 (Hamamatsu).

Empleamos cultivos celulares en fase logarítmica temprana cultivados a $25^{\circ} \mathrm{C}, 28^{\circ} \mathrm{C}$ o $32^{\circ} \mathrm{C}$ de acuerdo a los requerimientos de cada cepa. En el caso de cepas termosensibles, las cultivamos a la temperatura permisiva para luego cambiarlas durante el tiempo especificado (entre 1 y 3 horas) a la temperatura restrictiva. Concentramos las células centrifugando $1 \mathrm{ml}$ de cultivo a $3.500 \mathrm{~g}$ durante $1 \mathrm{~min}$ y las resuspendemos en 2-10 $\mu \mathrm{l}$ del mismo medio. Tomamos fotos de 10 secciones en $\mathrm{Z}$ espaciadas cada $0.4 \mu \mathrm{m}$.

\section{Tinción de blankophor}

Utilizamos el blankophor (Blankophor BA 267\%, Bayer) como marcador del septo. Centrifugamos $1 \mathrm{ml}$ de cultivo a $3.500 \mathrm{rpm}$ durante $1 \mathrm{~min}$, y resuspendemos las células en el

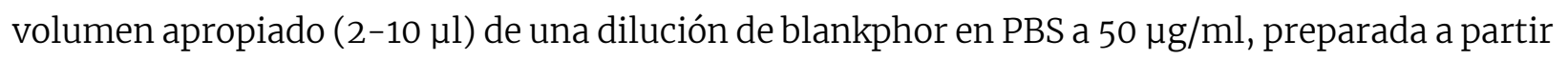
de una solución stock a $10 \mathrm{mg} / \mathrm{ml}$.

Preparamos la solución stock disolviendo el blankophor, que viene en forma de polvo, en agua a una concentración de $10 \mathrm{mg} / \mathrm{ml}$. Utilizamos unas gotas de $\mathrm{KOH} 10 \mathrm{M}$ para facilitar su total disolución. Esterilizamos la solución por filtración y la guardamos protegida de la luz a temperatura ambiente hasta 1 mes. En ocasiones, al día siguiente de la preparación se observa blankophor precipitado, situación que corregimos con la adición de otras gotas de KOH 10M. 


\section{Time-Lapse}

Para la obtención de imágenes en tiempo real empleamos los dos microscopios siguientes, el sistema DeltaVision descrito anteriormente y un microscopio confocal Spinning disk. Este consta del sistema Spinning disk (Roper Scientific) con microscopio Olympus IX81 (Olympus), cabezal confocal CSU-X1 (Yokogawa), platina motorizada con piezo en Z (ASI), objetivo Plan Apo 100x/1.40 de inmersión en aceite y una cámara Evolve (Photometrics) controlado por el software MetaMorph Premier (Molecular Devices).

La decisión entre emplear un equipo u otro responde a los datos que deseamos obtener en cada experimento concreto. La configuración del Spinning disk hace de este un sistema rápido y de alta sensibilidad. Dichas propiedades nos permiten capturar un gran número de fotografías durante el intervalo temporal de 3 minutos que establecemos entre tomas, con reducida excitación. Así, podemos capturar en una misma sesión, imágenes en stack de varias condiciones experimentales que corren simultáneamente, minimizando la variabilidad experimental. Por su parte, el equipo DeltaVision tiene menor sensibilidad y rapidez, pero en contrapartida captura imágenes de mayor resolución, lo que nos permite mejorar el detalle de las estructuras a analizar, a costa de realizar los experimentos de forma no simultánea. De acuerdo a las características descritas, empleamos el sistema Spinning disk para experimentos en los que nos interesa contar los tiempos en varias condiciones o cepas a la vez, mientras que reservamos el sistema DeltaVision para analizar en detalle procesos o estructuras, como puede ser la dinámica de constricción de los anillos.

Creemos además que la diferencia en resolución de los dos equipos puede estar dando cuenta de las diferencias en los tiempos de citoquinesis que vemos al usar un sistema u otro. En el equipo DeltaVision, la separación de los SPBs es un evento que se puede resolver antes que en el Spinning disk (requiere que estén menos separados para identificarlos como tal), mientras que en el cierre del anillo ocurre de manera opuesta, vemos un punto único "más tarde" en el equipo de mayor resolución. Ambos efectos se estarían sumando para hacer que los tiempos medidos en el sistema DeltaVision fueran mayores, y más exactos, que los del Spinning disk.

A nivel operativo, recogemos $1 \mathrm{ml}$ de cultivos celulares en fase exponencial (DO 0.3-0.6) por centrifugación (3500 g, $1 \mathrm{~min}$ ), y resuspendemos las células en $300 \mu \mathrm{l}$ de medio YES. Cuando el experimento se hace en condiciones de estrés, añadimos previamente a este medio de resuspensión los compuestos correspondientes. Pasamos esta suspensión celular a uno de los ocho pocillos de una cámara $\mu$-Slide (IBIDI), que previamente ha sido recubierta con $5 \mu$ de lectina de soja a $1 \mathrm{mg} / \mathrm{ml}$ (Sigma-Aldrich). Dejamos que las células se adhieran a la lectina del fondo del pocillo durante 2 minutos antes de retirar el medio. Inmediatamente lavamos este pocillo 3 veces con $300 \mu \mathrm{l}$ de medio y finalizamos añadiendo $300 \mu \mathrm{l}$ del mismo medio (que 
contiene el compuesto de estrés si procede). Llevamos a cabo la captura de imágenes en atmósfera controlada a $28^{\circ} \mathrm{C}$. En el caso de emplear cepas termosensibles, las cultivamos a $25^{\circ} \mathrm{C}$, y las cambiamos a la temperatura descrita 1 hora antes de pasarlas a la cámara y obtener las imágenes, manteniendo el sistema de captura también a la temperatura apropiada durante todo el experimento. En el equipo DeltaVision capturamos 7 secciones de $0.6 \mu \mathrm{m}$ de intervalo en $\mathrm{Z}$ en hasta 3 regiones diferentes cada 3 minutos. En el equipo Spinning disk tomamos 10 secciones de $0.4 \mu \mathrm{m}$ de intervalo en $\mathrm{Z}$ en hasta 16 regiones (usualmente 4 regiones por 4 pocillos) cada 3 min. El tiempo total de captura es por lo general de 2 horas, aunque puede ser extendido o acortado según la velocidad de los eventos a estudiar.

\section{ANÁLISIS Y PRESENTACIÓN DE DATOS}

\section{Análisis de imágenes}

Las imágenes capturadas en el sistema DelvaVision están corregidas por deconvolución 3D con el software softWoRx (GE Healthcare) bajo los siguientes parámetros: coeficiente conservador, 10 iteraciones y filtro de ruido medio. Los montajes para mostrar las fotografías, así como los análisis de las mismas se realizaron con la distribución Fiji de ImageJ (Schindelin et al. 2012)

Las fotografías se presentan como la proyección máxima de las secciones en Z con fines de facilitar la visualización; cuando las empleamos para fines de cuantificación utilizamos en su lugar la suma de las proyecciones. En todas las series de time-lapse utilizamos la separación de los SPBs como tiempo cero de referencia. Definimos el tiempo de compleción de la citoquinesis como el tiempo entre la separación de los SPBs y el cierre completo del CAR. El tiempo de las tres etapas del CAR se define en base a los siguientes criterios:

- Formación: desde la aparición de los nodos hasta que la señal del anillo presenta una morfología discreta y fluorescencia uniforme.

- Maduración: desde la señal de anillo uniforme hasta el primer cambio en su diámetro.

- Constricción: desde el cambio de diámetro hasta su cierre completo como punto único.

Medimos el diámetro del anillo trazando una línea sobre el mismo en las proyecciones máximas de las imágenes obtenidas por time-lapse en el sistema DeltaVision. La velocidad de constricción del CAR se obtuvo mediante regresión lineal en el tramo donde esta es constante, es decir, excluyendo los primeros valores de la curva, en los que se inicia y acelera la contracción.

La fluorescencia total de Cdc7-GFP en los SPBs a lo largo de la citoquinesis se midió a través de la suma de proyecciones de las secciones tomadas en el sistema Spinning disk. Empleamos 
una región vacía de células para determinar el promedio de fluorescencia de fondo, que restamos a las imágenes. Usamos la señal de Sad1-DsRed como guía para identificar ambos SPBs, los seleccionamos con un círculo de 5 píxeles de diámetro $\left(0.37 \mu^{2}\right)$ y medimos la intensidad total de fluorescencia en el canal de la GFP. Una vez obtenidos todos los datos, los normalizamos como porcentajes en base a sus valores máximos y mínimos.

La fluorescencia total de la señal de BP en el septo se midió a través de la suma de proyecciones de las secciones tomadas en el sistema DeltaVision. Empleamos una región vacía de células para determinar el promedio de fluorescencia de fondo, que restamos a las imágenes. Seleccionamos la región periférica donde aparece la primera señal de BP con un círculo de 5 píxeles de diámetro $\left(86 \mathrm{~nm}^{2}\right.$ ) y medimos la intensidad total de fluorescencia en el canal del DAPI. Usamos la misma región para determinar la fluorescencia en los frames previos, desde antes de la aparición de la señal hasta la separación de los SPBs, y de los siguientes, hasta la separación celular.

La intensidad nuclear de Clp1-GFP a lo largo del tiempo se midió utilizando la proyección de la suma de las secciones tomadas en el sistema DeltaVision. Empleamos una región vacía de células para determinar el promedio de fluorescencia de fondo, que restamos a las imágenes. Utilizamos la señal de Sid4-GFP como marcador de los SPBs para localizar el núcleo. Seleccionamos el núcleo dentro de un círculo de 42 píxeles de diámetro $\left(6.14 \mu \mathrm{m}^{2}\right)$ que contiene a Sid4 en su periferia, y medimos la intensidad total del canal verde en estas regiones. Una vez obtenidos todos los datos, los normalizamos como porcentajes en base a sus valores máximos y mínimos.

\section{Representación gráfica y análisis de datos}

La representación gráfica de los datos y los test estadísticos se realizaron con Prism 6.0 (GraphPad Software). Empleamos el box-plot de Tukey (Frigge et al. 1989) como representación gráfica de la tendencia central y desviación de los datos de tiempos. Con los datos de porcentajes utilizamos la representación de la media y desviación estándar en gráficos de barras. La notación "n" se refiere al número de células medidas en cada ocasión, salvo que se indique otra cosa. Definimos significancia estadística por un p-valor igual o menor a 0.05. En las parejas de datos que muestran una distribución normal empleamos el test t para muestras no apareadas, o el test de Mann-Whitney para distribuciones no normales. En los casos con más de dos conjuntos de datos utilizamos el test ANOVA seguido de los correspondientes test de Fisher, en el caso de datos tomados a la vez, o de los test de Šidák corregidos para comparaciones múltiples, para los experimentos no simultáneos (Glantz 2005) 



\section{BIBLIOGRAFÍA}

Aguilar-Zapata, D., Petraitiene, R. \& Petraitis, V. (2015). Echinocandins: The Expanding Antifungal Armamentarium. Clinical Infectious Diseases: An Official Publication of the Infectious Diseases Society of America, vol. 61 Suppl 6, pp. S604-611

Akamatsu, M., Berro, J., Pu, K.-M., Tebbs, I.R. \& Pollard, T.D. (2014). Cytokinetic nodes in fission yeast arise from two distinct types of nodes that merge during interphase. The Journal of Cell Biology, vol. 204 (6), pp. 977-988

Alcaide-Gavilán, M., Lahoz, A., Daga, R.R. \& Jimenez, J. (2014). Feedback regulation of SIN by Etd1 and Rho1 in fission yeast. Genetics, vol. 196 (2), pp. 455-470

Almonacid, M., Celton-Morizur, S., Jakubowski, J.L., Dingli, F., Loew, D., Mayeux, A., Chen, J.-S., Gould, K.L., Clifford, D.M. \& Paoletti, A. (2011). Temporal control of contractile ring assembly by Plo1 regulation of myosin II recruitment by Mid1/anillin. Current biology: CB, vol. 21 (6), pp. 473-479

Almonacid, M., Moseley, J.B., Janvore, J., Mayeux, A., Fraisier, V., Nurse, P. \& Paoletti, A. (2009). Spatial control of cytokinesis by Cdr2 kinase and Mid1/anillin nuclear export. Current biology: $C B$, vol. 19 (11), pp. 961-966

Arasada, R. \& Pollard, T.D. (2014). Contractile ring stability in S. pombe depends on F-BAR protein Cdc15p and Bgsip transport from the Golgi complex. Cell Reports, vol. 8 (5), pp. $1533-1544$

Arellano, M., Coll, P.M. \& Pérez, P. (1999a). RHO GTPases in the control of cell morphology, cell polarity, and actin localization in fission yeast. Microscopy Research and Technique, vol. 47 (1), pp. 51-60

Arellano, M., Durán, A. \& Pérez, P. (1996). Rho 1 GTPase activates the (1-3)beta-D-glucan synthase and is involved in Schizosaccharomyces pombe morphogenesis. The EMBO journal, vol. 15 (17), pp. 4584-4591

Arellano, M., Duran, A. \& Perez, P. (1997). Localisation of the Schizosaccharomyces pombe rho1p GTPase and its involvement in the organisation of the actin cytoskeleton. Journal of Cell Science, vol. 110 ( Pt 20), pp. 2547-2555

Arellano, M., Valdivieso, M.H., Calonge, T.M., Coll, P.M., Duran, A. \& Perez, P. (1999b). Schizosaccharomyces pombe protein kinase $\mathrm{C}$ homologues, pck1p and pck2p, are targets of rho1p and rho2p and differentially regulate cell integrity. Journal of Cell Science, vol. 112 ( Pt 20), pp. 3569-3578

Atay, O. \& Skotheim, J.M. (2017). Spatial and temporal signal processing and decision making by MAPK pathways. The Journal of Cell Biology, vol. 216 (2), pp. 317-330

Atilgan, E., Magidson, V., Khodjakov, A. \& Chang, F. (2015). Morphogenesis of the Fission Yeast Cell through Cell Wall Expansion. Current biology: CB, vol. 25 (16), pp. 2150-2157

Bähler, J., Steever, A.B., Wheatley, S., Wang, Y. l, Pringle, J.R., Gould, K.L. \& McCollum, D. (1998). Role of polo kinase and Midip in determining the site of cell division in fission yeast. The Journal of Cell Biology, vol. 143 (6), pp. 1603-1616

Balasubramanian, M.K., Bi, E. \& Glotzer, M. (2004). Comparative analysis of cytokinesis in budding yeast, fission yeast and animal cells. Current biology: CB, vol. 14 (18), pp. R806818

Balasubramanian, M.K., Hirani, B.R., Burke, J.D. \& Gould, K.L. (1994). The Schizosaccharomyces pombe cdc3+ gene encodes a profilin essential for cytokinesis. The Journal of Cell Biology, vol. 125 (6), pp. 1289-1301

Balasubramanian, M.K., McCollum, D., Chang, L., Wong, K.C.Y., Naqvi, N.I., He, X., Sazer, S. \& Gould, K.L. (1998). Isolation and Characterization of New Fission Yeast Cytokinesis Mutants. Genetics, vol. 149 (3), pp. 1265-1275 
Barba, G., Soto, T., Madrid, M., Núñez, A., Vicente, J., Gacto, M., Cansado, J. \& Yeast Physiology Group (2008). Activation of the cell integrity pathway is channelled through diverse signalling elements in fission yeast. Cellular Signalling, vol. 20 (4), pp. 748-757

Bassi, Z.I., Audusseau, M., Riparbelli, M.G., Callaini, G. \& D'Avino, P.P. (2013). Citron kinase controls a molecular network required for midbody formation in cytokinesis. Proceedings of the National Academy of Sciences of the United States of America, vol. 110 (24), pp. 97829787

Berlin, A., Paoletti, A. \& Chang, F. (2003). Mid2p stabilizes septin rings during cytokinesis in fission yeast. The Journal of Cell Biology, vol. 160 (7), pp. 1083-1092

Bezanilla, M., Forsburg, S.L. \& Pollard, T.D. (1997). Identification of a second myosin-II in Schizosaccharomyces pombe: Myp2p is conditionally required for cytokinesis. Molecular Biology of the Cell, vol. 8 (12), pp. 2693-2705

Boddy, M.N. \& Russell, P. (2001). DNA replication checkpoint. Current biology: CB, vol. 11 (23), pp. R953-956

Bohnert, K.A. \& Gould, K.L. (2011). On the cutting edge: post-translational modifications in cytokinesis. Trends in Cell Biology, vol. 21 (5), pp. 283-292

Bohnert, K.A. \& Gould, K.L. (2012). Cytokinesis-Based Constraints on Polarized Cell Growth in Fission Yeast. (Toczyski, D. P., ed.) PLoS Genetics, vol. 8 (10), p. e1003004

Bohnert, K.A., Grzegorzewska, A.P., Willet, A.H., Vander Kooi, C.W., Kovar, D.R. \& Gould, K.L. (2013). SIN-dependent phosphoinhibition of formin multimerization controls fission yeast cytokinesis. Genes \& Development, vol. 27 (19), pp. 2164-2177

Bos, J.L., Rehmann, H. \& Wittinghofer, A. (2007). GEFs and GAPs: critical elements in the control of small G proteins. Cell, vol. 129 (5), pp. 865-877

Broadus, M.R. \& Gould, K.L. (2012). Multiple protein kinases influence the redistribution of fission yeast Clp1/Cdc14 phosphatase upon genotoxic stress. Molecular Biology of the Cell, vol. 23 (20), pp. 4118-4128

Buchsbaum, R.J. (2007). Rho activation at a glance. Journal of Cell Science, vol. 120 (Pt 7), pp. 11491152

Buck, V., Quinn, J., Soto Pino, T., Martin, H., Saldanha, J., Makino, K., Morgan, B.A. \& Millar, J.B. (2001). Peroxide sensors for the fission yeast stress-activated mitogen-activated protein kinase pathway. Molecular Biology of the Cell, vol. 12 (2), pp. 407-419

Bustelo, X.R., Sauzeau, V. \& Berenjeno, I.M. (2007). GTP-binding proteins of the Rho/Rac family: regulation, effectors and functions in vivo. BioEssays: News and Reviews in Molecular, Cellular and Developmental Biology, vol. 29 (4), pp. 356-370

Calonge, T.M., Arellano, M., Coll, P.M. \& Perez, P. (2003). Rga5p is a specific Rho1p GTPaseactivating protein that regulates cell integrity in Schizosaccharomyces pombe. Molecular Microbiology, vol. 47 (2), pp. 507-518

Calonge, T.M., Nakano, K., Arellano, M., Arai, R., Katayama, S., Toda, T., Mabuchi, I. \& Perez, P. (2000). Schizosaccharomyces pombe Rho2p GTPase Regulates Cell Wall $\alpha$-Glucan Biosynthesis through the Protein Kinase Pck2p. Molecular Biology of the Cell, vol. 11 (12), pp. 4393-4401

Calvo, I.A., Gabrielli, N., Iglesias-Baena, I., García-Santamarina, S., Hoe, K.-L., Kim, D.U., Sansó, M., Zuin, A., Pérez, P., Ayté, J. \& Hidalgo, E. (2009). Genome-wide screen of genes required for caffeine tolerance in fission yeast. PloS One, vol. 4 (8), p. e6619

Cargnello, M. \& Roux, P.P. (2011). Activation and function of the MAPKs and their substrates, the MAPK-activated protein kinases. Microbiology and molecular biology reviews: MMBR, vol. 75 (1), pp. 50-83

Carnero, E., Ribas, J.C., García, B., Durán, A. \& Sánchez, Y. (2000). Schizosaccharomyces pombe ehs1p is involved in maintaining cell wall integrity and in calcium uptake. Molecular \& general genetics: $M G G$, vol. 264 (1-2), pp. 173-183

Celton-Morizur, S., Racine, V., Sibarita, J.-B. \& Paoletti, A. (2006). Pom1 kinase links division plane position to cell polarity by regulating Mid1p cortical distribution. Journal of Cell Science, vol. 119 (Pt 22), pp. 4710-4718 
Cerutti, L. \& Simanis, V. (1999). Asymmetry of the spindle pole bodies and spg1p GAP segregation during mitosis in fission yeast. Journal of Cell Science, vol. 112 ( Pt 14), pp. 2313-2321

Chang, F. (2017). Forces that shape fission yeast cells. Molecular Biology of the Cell, vol. 28 (14), pp. 1819-1824

Chang, F., Drubin, D. \& Nurse, P. (1997). cdc12p, a protein required for cytokinesis in fission yeast, is a component of the cell division ring and interacts with profilin. The Journal of Cell Biology, vol. 137 (1), pp. 169-182

Chang, F. \& Martin, S.G. (2009). Shaping fission yeast with microtubules. Cold Spring Harbor Perspectives in Biology, vol. 1 (1), p. a001347

Chang, L. \& Gould, K.L. (2000). Sid4p is required to localize components of the septation initiation pathway to the spindle pole body in fission yeast. Proceedings of the National Academy of Sciences of the United States of America, vol. 97 (10), pp. 5249-5254

Chapman, J.R., Taylor, M.R.G. \& Boulton, S.J. (2012). Playing the end game: DNA double-strand break repair pathway choice. Molecular Cell, vol. 47 (4), pp. 497-510

Cheffings, T.H., Burroughs, N.J. \& Balasubramanian, M.K. (2016). Actomyosin Ring Formation and Tension Generation in Eukaryotic Cytokinesis. Current biology: CB, vol. 26 (15), pp. R719-R737

Cheffings, T.H., Burroughs, N.J. \& Balasubramanian, M.K. (2019). Actin turnover ensures uniform tension distribution during cytokinetic actomyosin ring contraction. Molecular Biology of the Cell, vol. 30 (8), pp. 933-941

Chen, C.-T., Feoktistova, A., Chen, J.-S., Shim, Y.-S., Clifford, D.M., Gould, K.L. \& McCollum, D. (2008). The SIN Kinase Sid2 Regulates Cytoplasmic Retention of the S. pombe Cdc14-like Phosphatase Clp1. Current Biology, vol. 18 (20), pp. 1594-1599

Chen, D., Toone, W.M., Mata, J., Lyne, R., Burns, G., Kivinen, K., Brazma, A., Jones, N. \& Bähler, J. (2003). Global transcriptional responses of fission yeast to environmental stress. Molecular Biology of the Cell, vol. 14 (1), pp. 214-229

Chen, J.S., Broadus, M.R., McLean, J.R., Feoktistova, A., Ren, L. \& Gould, K.L. (2013). Comprehensive proteomics analysis reveals new substrates and regulators of the fission yeast clp1/cdc14 phosphatase. Molecular \& cellular proteomics: MCP, vol. 12 (5), pp. 10741086

Chen, Q. \& Pollard, T.D. (2011). Actin filament severing by cofilin is more important for assembly than constriction of the cytokinetic contractile ring. The Journal of Cell Biology, vol. 195 (3), pp. 485-498

Chen, R.E. \& Thorner, J. (2007). Function and regulation in MAPK signaling pathways: lessons learned from the yeast Saccharomyces cerevisiae. Biochimica Et Biophysica Acta, vol. 1773 (8), pp. 1311-1340

Cherfils, J. \& Zeghouf, M. (2013). Regulation of small GTPases by GEFs, GAPs, and GDIs. Physiological Reviews, vol. 93 (1), pp. 269-309

Chew, T.G., Huang, J., Palani, S., Sommese, R., Kamnev, A., Hatano, T., Gu, Y., Oliferenko, S., Sivaramakrishnan, S. \& Balasubramanian, M.K. (2017). Actin turnover maintains actin filament homeostasis during cytokinetic ring contraction. The Journal of Cell Biology, p. jcb.201701104

Clifford, D.M., Wolfe, B.A., Roberts-Galbraith, R.H., McDonald, W.H., Yates, J.R. \& Gould, K.L. (2008). The Clp1/Cdc14 phosphatase contributes to the robustness of cytokinesis by association with anillin-related Mid1. The Journal of Cell Biology, vol. 181 (1), pp. 79-88

Coffman, V.C., Nile, A.H., Lee, I.-J., Liu, H. \& Wu, J.-Q. (2009). Roles of Formin Nodes and Myosin Motor Activity in Midip-dependent Contractile-Ring Assembly during Fission Yeast Cytokinesis. Molecular Biology of the Cell, vol. 20 (24), pp. 5195-5210

Coll, P.M., Trillo, Y., Ametzazurra, A. \& Perez, P. (2003). Gef1p, a new guanine nucleotide exchange factor for Cdc42p, regulates polarity in Schizosaccharomyces pombe. Molecular Biology of the Cell, vol. 14 (1), pp. 313-323

Consonni, S.V., Maurice, M.M. \& Bos, J.L. (2014). DEP domains: structurally similar but functionally different. Nature Reviews. Molecular Cell Biology, vol. 15 (5), pp. 357-362 
Cortés, J.C.G., Carnero, E., Ishiguro, J., Sánchez, Y., Durán, A. \& Ribas, J.C. (2005). The novel fission yeast $(1,3) \beta-D$-glucan synthase catalytic subunit Bgs $4 \mathrm{p}$ is essential during both cytokinesis and polarized growth. J Cell Sci, vol. 118 (1), pp. 157-174

Cortés, J.C.G., Konomi, M., Martins, I.M., Muñoz, J., Moreno, M.B., Osumi, M., Durán, A. \& Ribas, J.C. (2007). The $(1,3) \beta-d$-glucan synthase subunit Bgs1p is responsible for the fission yeast primary septum formation. Molecular Microbiology, vol. 65 (1), pp. 201-217

Cortés, J.C.G. \& McCollum, D. (2009). Proper timing of cytokinesis is regulated by Schizosaccharomyces pombe Etd1. The Journal of Cell Biology, vol. 186 (5), pp. 739-753

Cortés, J.C.G., Pujol, N., Sato, M., Pinar, M., Ramos, M., Moreno, B., Osumi, M., Ribas, J.C. \& Pérez, P. (2015). Cooperation between Paxillin-like Protein Pxl1 and Glucan Synthase Bgs1 Is Essential for Actomyosin Ring Stability and Septum Formation in Fission Yeast. (Gould, K. L., ed.) PLOS Genetics, vol. 11 (7), p. e1005358

Cortés, J.C.G., Ramos, M., Konomi, M., Barragán, I., Moreno, M.B., Alcaide-Gavilán, M., Moreno, S., Osumi, M., Pérez, P. \& Ribas, J.C. (2018). Specific detection of fission yeast primary septum reveals septum and cleavage furrow ingression during early anaphase independent of mitosis completion. (McCollum, D., ed.) PLOS Genetics, vol. 14 (5), p. e1007388

Cortés, J.C.G., Ramos, M., Osumi, M., Pérez, P. \& Ribas, J.C. (2016a). Fission yeast septation. Communicative \& Integrative Biology, vol. 9 (4), p. e1189045

Cortés, J.C.G., Ramos, M., Osumi, M., Pérez, P. \& Ribas, J.C. (2016b). The Cell Biology of Fission Yeast Septation. Microbiology and molecular biology reviews: MMBR, vol. 80 (3), pp. 779791

Cortés, J.C.G., Sato, M., Muñoz, J., Moreno, M.B., Clemente-Ramos, J.A., Ramos, M., Okada, H., Osumi, M., Durán, A. \& Ribas, J.C. (2012). Fission yeast Ags1 confers the essential septum strength needed for safe gradual cell abscission. The Journal of Cell Biology, vol. 198 (4), pp. 637-656

Courtemanche, N., Pollard, T.D. \& Chen, Q. (2016). Avoiding artefacts when counting polymerized actin in live cells with LifeAct fused to fluorescent proteins. Nature Cell Biology, vol. 18 (6), pp. 676-683

Cruz, S., Muñoz, S., Manjón, E., García, P. \& Sanchez, Y. (2013). The fission yeast cell wall stress sensor-like proteins Mtl2 and Wsc1 act by turning on the GTPase Rho1p but act independently of the cell wall integrity pathway. MicrobiologyOpen, p. n/a-n/a

Daga, R.R. \& Chang, F. (2005). Dynamic positioning of the fission yeast cell division plane. Proceedings of the National Academy of Sciences, vol. 102 (23), pp. 8228-8232

Daga, R.R., Lahoz, A., Muñoz, M.J., Moreno, S. \& Jimenez, J. (2005). Etd1p is a novel protein that links the SIN cascade with cytokinesis. The EMBO journal, vol. 24 (13), pp. 2436-2446

Davì, V., Tanimoto, H., Ershov, D., Haupt, A., De Belly, H., Le Borgne, R., Couturier, E., Boudaoud, A. \& Minc, N. (2018). Mechanosensation Dynamically Coordinates Polar Growth and Cell Wall Assembly to Promote Cell Survival. Developmental Cell, vol. 45 (2), pp. 170-182.e7

Davidson, R., Laporte, D. \& Wu, J.-Q. (2015). Regulation of Rho-GEF Rgf3 by the arrestin Art1 in fission yeast cytokinesis. Molecular Biology of the Cell, vol. 26 (3), pp. 453-466

Davidson, R., Pontasch, J.A. \& Wu, J.-Q. (2016). Sbg1 Is a Novel Regulator for the Localization of the $\beta$-Glucan Synthase Bgs1 in Fission Yeast. PloS One, vol. 11 (11), p. e0167043

Degols, G., Shiozaki, K. \& Russell, P. (1996). Activation and regulation of the Spc1 stressactivated protein kinase in Schizosaccharomyces pombe. Molecular and Cellular Biology, vol. 16 (6), pp. 2870-2877

Dekker, N., Speijer, D., Grün, C.H., van den Berg, M., de Haan, A. \& Hochstenbach, F. (2004). Role of the $\alpha$-Glucanase Agn1p in Fission-Yeast Cell Separation. Molecular Biology of the Cell, vol. 15 (8), pp. 3903-3914

DerMardirossian, C. \& Bokoch, G.M. (2005). GDIs: central regulatory molecules in Rho GTPase activation. Trends in Cell Biology, vol. 15 (7), pp. 356-363

Dey, S.K. \& Pollard, T.D. (2018). Involvement of the septation initiation network in events during cytokinesis in fission yeast. Journal of Cell Science, vol. 131 (16) 
Dischinger, S., Krapp, A., Xie, L., Paulson, J.R. \& Simanis, V. (2008). Chemical genetic analysis of the regulatory role of Cdc2p in the S. pombe septation initiation network. Journal of Cell Science, vol. 121 (6), pp. 843-853

Doi, A., Kita, A., Kanda, Y., Uno, T., Asami, K., Satoh, R., Nakano, K. \& Sugiura, R. (2015). Geranylgeranyltransferase Cwg2-Rho4/Rho5 module is implicated in the Pmk1 MAP kinase-mediated cell wall integrity pathway in fission yeast. Genes to Cells: Devoted to Molecular \& Cellular Mechanisms, vol. 20 (4), pp. 310-323

Dvorsky, R. \& Ahmadian, M.R. (2004). Always look on the bright site of Rho: structural implications for a conserved intermolecular interface. EMBO reports, vol. 5 (12), pp. 11301136

East, D.A. \& Mulvihill, D.P. (2011). Regulation and function of the fission yeast myosins. Journal of Cell Science, vol. 124 (Pt 9), pp.1383-1390

Edreira, T., Manjón, E. \& Sánchez, Y. (2018). The Function of Fission Yeast Rho1-GEFs in the Control of Cell Growth and Division. En: Tanabe, S. (ed.) Peripheral Membrane Proteins. InTech,

Egel, R. (2013). The Molecular Biology of Schizosaccharomyces pombe: Genetics, Genomics and Beyond. Springer Science \& Business Media.

English, J.G., Shellhammer, J.P., Malahe, M., McCarter, P.C., Elston, T.C. \& Dohlman, H.G. (2015). MAPK feedback encodes a switch and timer for tunable stress adaptation in yeast. Science Signaling, vol. 8 (359), p. ra5

Fang, Y., Jaiseng, W., Ma, Y., Hu, L., Yamazaki, S., Zhang, X., Hayafuji, T., Shi, L. \& Kuno, T. (2014). E3 Ubiquitin Ligase Pub1 Is implicated in Endocytosis of a GPI-Anchored Protein Ecm33 in Fission Yeast. PLOS ONE, vol. 9 (1). DOI: https://doi.org/10.1371/journal.pone.0085238

Fankhauser, C., Reymond, A., Cerutti, L., Utzig, S., Hofmann, K. \& Simanis, V. (1995). The S. pombe cdc15 gene is a key element in the reorganization of $\mathrm{F}$-actin at mitosis. Cell, vol. 82 (3), pp. 435-444

Fankhauser, C. \& Simanis, V. (1994). The cdc7 protein kinase is a dosage dependent regulator of septum formation in fission yeast. The EMBO journal, vol. 13 (13), pp. 3011-3019

Fantes, P.A. \& Hoffman, C.S. (2016). A Brief History of Schizosaccharomyces pombe Research: A Perspective Over the Past 70 Years. Genetics, vol. 203 (2), pp. 621-629

Feoktistova, A., Morrell-Falvey, J., Chen, J.-S., Singh, N.S., Balasubramanian, M.K. \& Gould, K.L. (2012). The fission yeast septation initiation network (SIN) kinase, Sid2, is required for SIN asymmetry and regulates the SIN scaffold, Cdc11. (Li, R., ed.) Molecular Biology of the Cell, vol. 23 (9), pp. 1636-1645

Free, S.J. (2013). Fungal cell wall organization and biosynthesis. Advances in Genetics, vol. 81, pp. 33-82

Frigge, M., Hoaglin, D.C. \& Iglewicz, B. (1989). Some Implementations of the Boxplot. The American Statistician, vol. 43 (1), pp. 50-54

Furge, K.A., Wong, K., Armstrong, J., Balasubramanian, M. \& Albright, C.F. (1998). Byr4 and Cdc16 form a two-component GTPase-activating protein for the Spg1 GTPase that controls septation in fission yeast. Current biology: CB, vol. 8 (17), pp. 947-954

Gaits, F., Degols, G., Shiozaki, K. \& Russell, P. (1998). Phosphorylation and association with the transcription factor Atf1 regulate localization of Spc1/Sty1 stress-activated kinase in fission yeast. Genes \& Development, vol. 12 (10), pp. 1464-1473

Gammons, M.V., Renko, M., Johnson, C.M., Rutherford, T.J. \& Bienz, M. (2016). Wnt Signalosome Assembly by DEP Domain Swapping of Dishevelled. Molecular Cell, vol. 64 (1), pp. 92-104

García, I., Jiménez, D., Martín, V., Durán, A. \& Sánchez, Y. (2005). The alpha-glucanase Agn1p is required for cell separation in Schizosaccharomyces pombe. Biology of the Cell, vol. 97 (7), pp. 569-576

García, P., García, I., Marcos, F., de Garibay, G.R. \& Sánchez, Y. (2009a). Fission yeast rgf2p is a rho1p guanine nucleotide exchange factor required for spore wall maturation and for the maintenance of cell integrity in the absence of rgf1p. Genetics, vol. 181 (4), pp. 1321-1334 
García, P., Tajadura, V., García, I. \& Sánchez, Y. (2006a). Rgf1p is a specific Rho1-GEF that coordinates cell polarization with cell wall biogenesis in fission yeast. Molecular Biology of the Cell, vol. 17 (4), pp. 1620-1631

García, P., Tajadura, V., García, I. \& Sánchez, Y. (2006b). Role of Rho GTPases and Rho-GEFs in the regulation of cell shape and integrity in fission yeast. Yeast (Chichester, England), vol. 23 (13), pp. 1031-1043

García, P., Tajadura, V. \& Sanchez, Y. (2009b). The Rho1p Exchange Factor Rgf1p Signals Upstream from the Pmk1 Mitogen-activated Protein Kinase Pathway in Fission Yeast. (Boone, C., ed.) Molecular Biology of the Cell, vol. 20 (2), pp. 721-731

George, V.T., Brooks, G. \& Humphrey, T.C. (2007). Regulation of Cell Cycle and Stress Responses to Hydrostatic Pressure in Fission Yeast. Molecular Biology of the Cell, vol. 18 (10), pp. 4168-4179

Glantz, S. (2005). Primer of Biostatistics: Sixth Edition. 6 edition. New York: McGraw-Hill Medical.

Glotzer, M. (2017). Cytokinesis in Metazoa and Fungi. Cold Spring Harbor Perspectives in Biology, vol. 9 (10), p. a022343

González-Rubio, G., Fernández-Acero, T., Martín, H. \& Molina, M. (2019). Mitogen-Activated Protein Kinase Phosphatases (MKPs) in Fungal Signaling: Conservation, Function, and Regulation. International Journal of Molecular Sciences, vol. 20 (7)

Goss, J.W., Kim, S., Bledsoe, H. \& Pollard, T.D. (2014). Characterization of the roles of Blt1p in fission yeast cytokinesis. Molecular Biology of the Cell, vol. 25 (13), pp. 1946-1957

Gould, K.L. \& Simanis, V. (1997). The control of septum formation in fission yeast. Genes \& Development, vol. 11 (22), pp. 2939-2951

Grallert, A., Connolly, Y., Smith, D.L., Simanis, V. \& Hagan, I.M. (2012). The S. pombe cytokinesis NDR kinase Sid2 activates Fin1 NIMA kinase to control mitotic commitment through Pom1/Wee1. Nature Cell Biology, vol. 14 (7), pp. 738-745

Gräub, R., Hilti, N., Niederberger, C. \& Schweingruber, M.E. (2003). Ksg1, a homologue of the phosphoinositide-dependent protein kinase 1 , controls cell wall integrity in Schizosaccharomyces pombe. Journal of Basic Microbiology, vol. 43 (6), pp. 473-482

Grün, C.H., Hochstenbach, F., Humbel, B.M., Verkleij, A.J., Sietsma, J.H., Klis, F.M., Kamerling, J.P. \& Vliegenthart, J.F.G. (2005). The structure of cell wall alpha-glucan from fission yeast. Glycobiology, vol. 15 (3), pp. 245-257

$\mathrm{Gu}$, Y. \& Oliferenko, S. (2015). Comparative biology of cell division in the fission yeast clade. Current Opinion in Microbiology, vol. 28, pp. 18-25

Guertin, D.A., Chang, L., Irshad, F., Gould, K.L. \& McCollum, D. (2000). The role of the sid1p kinase and cdc14p in regulating the onset of cytokinesis in fission yeast. The EMBO journal, vol. 19 (8), pp. 1803-1815

Gupta, S., Govindaraghavan, M. \& McCollum, D. (2014). Cross talk between NDR kinase pathways coordinates cytokinesis with cell separation in Schizosaccharomyces pombe. Eukaryotic Cell, vol. 13 (8), pp. 1104-1112

Gupta, S., Mana-Capelli, S., McLean, J.R., Chen, C.-T., Ray, S., Gould, K.L. \& McCollum, D. (2013). Identification of SIN pathway targets reveals mechanisms of crosstalk between NDR kinase pathways. Current biology: CB, vol. 23 (4), pp. 333-338

Guzman-Vendrell, M., Baldissard, S., Almonacid, M., Mayeux, A., Paoletti, A. \& Moseley, J.B. (2013). Blt1 and Mid1 provide overlapping membrane anchors to position the division plane in fission yeast. Molecular and Cellular Biology, vol. 33 (2), pp. 418-428

Hachet, O., Berthelot-Grosjean, M., Kokkoris, K., Vincenzetti, V., Moosbrugger, J. \& Martin, S.G. (2011). A phosphorylation cycle shapes gradients of the DYRK family kinase Pom1 at the plasma membrane. Cell, vol. 145 (7), pp. 1116-1128

Hachet, O. \& Simanis, V. (2008). Mid1p/anillin and the septation initiation network orchestrate contractile ring assembly for cytokinesis. Genes \& Development, vol. 22 (22), pp. 32053216

Hagan, I. \& Yanagida, M. (1995). The product of the spindle formation gene sad1+ associates with the fission yeast spindle pole body and is essential for viability. The Journal of Cell Biology, vol. 129 (4), pp. 1033-1047 
Hall, A. (2012). Rho family GTPases. Biochemical Society Transactions, vol. 40 (6), pp. 1378-1382

Harigaya, Y. \& Yamamoto, M. (2007). Molecular mechanisms underlying the mitosis-meiosis decision. Chromosome Research: An International Journal on the Molecular, Supramolecular and Evolutionary Aspects of Chromosome Biology, vol. 15 (5), pp. 523-537

Haupt, A. \& Minc, N. (2017). Gradients of phosphatidylserine contribute to plasma membrane charge localization and cell polarity in fission yeast. Molecular Biology of the Cell, vol. 28 (1), pp. 210-220

Hercyk, B.S., Onwubiko, U.N. \& Das, M.E. (2019). Coordinating Septum Formation and the Actomyosin Ring during Cytokinesis in Schizosaccharomyces pombe. Molecular Microbiology,

Hersch, M., Hachet, O., Dalessi, S., Ullal, P., Bhatia, P., Bergmann, S. \& Martin, S.G. (2015). Pom1 gradient buffering through intermolecular auto-phosphorylation. Molecular Systems Biology, vol. 11 (7), p. 818

Hiraoka, Y., Toda, T. \& Yanagida, M. (1984). The NDA3 gene of fission yeast encodes betatubulin: a cold-sensitive nda3 mutation reversibly blocks spindle formation and chromosome movement in mitosis. Cell, vol. 39 (2 Pt 1), pp. 349-358

Hirata, D., Nakano, K., Fukui, M., Takenaka, H., Miyakawa, T. \& Mabuchi, I. (1998). Genes that cause aberrant cell morphology by overexpression in fission yeast: a role of a small GTPbinding protein Rho2 in cell morphogenesis. Journal of Cell Science, vol. 111 ( Pt 2), pp.149159

Hirota, K., Tanaka, K., Ohta, K. \& Yamamoto, M. (2003). Gef1p and Scd1p, the Two GDP-GTP exchange factors for Cdc42p, form a ring structure that shrinks during cytokinesis in Schizosaccharomyces pombe. Molecular Biology of the Cell, vol. 14 (9), pp. 3617-3627

Hoffman, C.S., Wood, V. \& Fantes, P.A. (2015). An Ancient Yeast for Young Geneticists: A Primer on the Schizosaccharomyces pombe Model System. Genetics, vol. 201 (2), pp. 403-423

Hohmann, S. (2002). Osmotic Stress Signaling and Osmoadaptation in Yeasts. Microbiology and Molecular Biology Reviews, vol. 66 (2), pp. 300-372

Hou, M.C., Salek, J. \& McCollum, D. (2000). Mob1p interacts with the Sid2p kinase and is required for cytokinesis in fission yeast. Current biology: CB, vol. 10 (10), pp. 619-622

Huang, C.Y. \& Ferrell, J.E. (1996). Ultrasensitivity in the mitogen-activated protein kinase cascade. Proceedings of the National Academy of Sciences of the United States of America, vol. 93 (19), pp. 10078-10083

Huang, J., Huang, Y., Yu, H., Subramanian, D., Padmanabhan, A., Thadani, R., Tao, Y., Tang, X., Wedlich-Soldner, R. \& Balasubramanian, M.K. (2012). Nonmedially assembled F-actin cables incorporate into the actomyosin ring in fission yeast. The Journal of Cell Biology, vol. 199 (5), pp. 831-847

Huang, Y., Yan, H. \& Balasubramanian, M.K. (2008). Assembly of normal actomyosin rings in the absence of Midip and cortical nodes in fission yeast. The Journal of Cell Biology, vol. 183 (6), pp. 979-988

Humbel, B.M., Konomi, M., Takagi, T., Kamasawa, N., Ishijima, S.A. \& Osumi, M. (2001). In situ localization of beta-glucans in the cell wall of Schizosaccharomyces pombe. Yeast (Chichester, England), vol. 18 (5), pp. 433-444

Jin, Q.-W., Zhou, M., Bimbo, A., Balasubramanian, M.K. \& McCollum, D. (2006). A Role for the Septation Initiation Network in Septum Assembly Revealed by Genetic Analysis of sid2250 Suppressors. Genetics, vol. 172 (4), pp. 2101-2112

Johnson, A.E., McCollum, D. \& Gould, K.L. (2012). Polar opposites: Fine-tuning cytokinesis through SIN asymmetry. Cytoskeleton, vol. 69 (10), pp. 686-699

Jourdain, I., Brzezińska, E.A. \& Toda, T. (2013). Fission Yeast Nod1 Is a Component of Cortical Nodes Involved in Cell Size Control and Division Site Placement. PLOS ONE, vol. 8 (1), p. e54142

Kashiwazaki, J., Yoneda, Y., Mutoh, T., Arai, R., Yoshida, M. \& Mabuchi, I. (2019). A unique kinesin-like protein, Klp8, is involved in mitosis and cell morphology through microtubule stabilization. Cytoskeleton (Hoboken, N.J.), 
Kovar, D.R., Kuhn, J.R., Tichy, A.L. \& Pollard, T.D. (2003). The fission yeast cytokinesis formin Cdc12p is a barbed end actin filament capping protein gated by profilin. The Journal of Cell Biology, vol. 161 (5), pp. 875-887

Krapp, A., Collin, P., Cano Del Rosario, E. \& Simanis, V. (2008). Homoeostasis between the GTPase Spg1p and its GAP in the regulation of cytokinesis in S. pombe. Journal of Cell Science, vol. 121 (Pt 5), pp. 601-608

Krapp, A., Schmidt, S., Cano, E. \& Simanis, V. (2001). S. pombe cdc11p, together with sid4p, provides an anchor for septation initiation network proteins on the spindle pole body. Current biology: $C B$, vol. 11 (20), pp. 1559-1568

Kühn, S. \& Geyer, M. (2014). Formins as effector proteins of Rho GTPases. Small GTPases, vol. 5 (3), p. e983876

Kuranda, K., Leberre, V., Sokol, S., Palamarczyk, G. \& Francois, J. (2006). Investigating the caffeine effects in the yeast Saccharomyces cerevisiae brings new insights into the connection between TOR, PKC and Ras/CAMP signalling pathways. Molecular Microbiology, vol. 61 (5), pp. 1147-1166

Lambert, S. \& Carr, A.M. (2013). Replication stress and genome rearrangements: lessons from yeast models. Current Opinion in Genetics \& Development, vol. 23 (2), pp. 132-139

Langerak, P. \& Russell, P. (2011). Regulatory networks integrating cell cycle control with DNA damage checkpoints and double-strand break repair. Philosophical Transactions of the Royal Society of London. Series B, Biological Sciences, vol. 366 (1584), pp. 3562-3571

Laplante, C., Berro, J., Karatekin, E., Hernandez-Leyva, A., Lee, R. \& Pollard, T.D. (2015). Three myosins contribute uniquely to the assembly and constriction of the fission yeast cytokinetic contractile ring. Current biology: CB, vol. 25 (15), pp. 1955-1965

Laporte, D., Coffman, V.C., Lee, I.-J. \& Wu, J.-Q. (2011). Assembly and architecture of precursor nodes during fission yeast cytokinesis. The Journal of Cell Biology, vol. 192 (6), pp. 10051021

Laporte, D., Ojkic, N., Vavylonis, D. \& Wu, J.-Q. (2012). $\alpha$-Actinin and fimbrin cooperate with myosin II to organize actomyosin bundles during contractile-ring assembly. Molecular Biology of the Cell, vol. 23 (16), pp. 3094-3110

Le Goff, X., Motegi, F., Salimova, E., Mabuchi, I. \& Simanis, V. (2000). The S. pombe rlc1 gene encodes a putative myosin regulatory light chain that binds the type II myosins myo3p and myo2p. Journal of Cell Science, vol. 113 (23), pp. 4157-4163

Le Goff, X., Woollard, A. \& Simanis, V. (1999). Analysis of the cps1 gene provides evidence for a septation checkpoint in Schizosaccharomyces pombe. Molecular and General Genetics MGG, vol. 262 (1), pp. 163-172

Leupold, U. (1949). Die Vererbung von Homothallie und Heterothallie bei Schizosaccharomyces Pombe. Luno.

Levin, D.E. (2005). Cell Wall Integrity Signaling in Saccharomyces cerevisiae. Microbiology and Molecular Biology Reviews, vol. 69 (2), pp. 262-291

Levin, J.D. \& Demple, B. (1996). In vitro detection of endonuclease IV-specific DNA damage formed by bleomycin in vivo. Nucleic Acids Research, vol. 24 (5), pp. 885-889

Li, C., Furge, K.A., Cheng, Q. \& Albright, C.F. (2000). Byr4 Localizes to Spindle-Pole Bodies in a Cell Cycle-regulated Manner to Control Cdc7 Localization and Septation in Fission Yeast. Journal of Biological Chemistry, vol. 275 (19), pp. 14381-14387

Lipshtat, A., Jayaraman, G., He, J.C. \& Iyengar, R. (2010). Design of versatile biochemical switches that respond to amplitude, duration, and spatial cues. Proceedings of the National Academy of Sciences of the United States of America, vol. 107 (3), pp. 1247-1252

Liu, J., Tang, X., Wang, H., Oliferenko, S. \& Balasubramanian, M.K. (2002). The localization of the integral membrane protein Cpsip to the cell division site is dependent on the actomyosin ring and the septation-inducing network in Schizosaccharomyces pombe. Molecular Biology of the Cell, vol. 13 (3), pp. 989-1000

Liu, J., Wang, H. \& Balasubramanian, M.K. (2000). A checkpoint that monitors cytokinesis in Schizosaccharomyces pombe. Journal of Cell Science, vol.113 ( Pt 7), pp. 1223-1230 
Liu, J., Wang, H., McCollum, D. \& Balasubramanian, M.K. (1999). Drc1p/Cps1p, a 1,3-beta-glucan synthase subunit, is essential for division septum assembly in Schizosaccharomyces pombe. Genetics, vol. 153 (3), pp. 1193-1203

Liu, M., Bi, F., Zhou, X. \& Zheng, Y. (2012). Rho GTPase regulation by miRNAs and covalent modifications. Trends in Cell Biology, vol. 22 (7), pp. 365-373

Liu, Y., Lee, I.-J., Sun, M., Lower, C.A., Runge, K.W., Ma, J. \& Wu, J.-Q. (2016). Roles of the novel coiled-coil protein Rng10 in septum formation during fission yeast cytokinesis. Molecular Biology of the Cell, vol. 27 (16), pp. 2528-2541

Liu, Y., McDonald, N.A., Naegele, S.M., Gould, K.L. \& Wu, J.-Q. (2019). The F-BAR Domain of Rga7 Relies on a Cooperative Mechanism of Membrane Binding with a Partner Protein during Fission Yeast Cytokinesis. Cell Reports, vol. 26 (10), pp. 2540-2548.e4

Lock, A., Rutherford, K., Harris, M.A., Hayles, J., Oliver, S.G., Bähler, J. \& Wood, V. (2019). PomBase 2018: user-driven reimplementation of the fission yeast database provides rapid and intuitive access to diverse, interconnected information. Nucleic Acids Research, vol. 47 (D1), pp. D821-D827

Loewith, R., Hubberstey, A. \& Young, D. (2000). Skh1, the MEK component of the mkh1 signaling pathway in Schizosaccharomyces pombe. Journal of Cell Science, vol. 113 ( Pt 1), pp. 153160

Ma, Y., Kuno, T., Kita, A., Asayama, Y. \& Sugiura, R. (2006). Rho2 is a target of the farnesyltransferase Cpp1 and acts upstream of Pmk1 mitogen-activated protein kinase signaling in fission yeast. Molecular Biology of the Cell, vol. 17 (12), pp. 5028-5037

Ma, Y., Sugiura, R., Koike, A., Ebina, H., Sio, S.O. \& Kuno, T. (2011). Transient Receptor Potential (TRP) and Cch1-Yam8 Channels Play Key Roles in the Regulation of Cytoplasmic Ca2+ in Fission Yeast. PLOS ONE, vol. 6 (7). DOI: https://doi.org/10.1371/journal.pone.0022421

Madrid, M., Fernández-Zapata, J., Sánchez-Mir, L., Soto, T., Franco, A., Vicente-Soler, J., Gacto, M. \& Cansado, J. (2013). Role of the fission yeast cell integrity MAPK pathway in response to glucose limitation. BMC microbiology, vol. 13, p. 34

Madrid, M., Jimenez, R., Sanchez-Mir, L., Soto, T., Franco, A., Vicente-Soler, J., Gacto, M., Perez, P. \& Cansado, J. (2015). Multiple layers of regulation influence cell integrity control by the PKC ortholog Pck2 in fission yeast. Journal of Cell Science, vol. 128 (2), pp. 266-280

Madrid, M., Núñez, A., Soto, T., Vicente-Soler, J., Gacto, M. \& Cansado, J. (2007). Stress-activated Protein Kinase-mediated Down-Regulation of the Cell Integrity Pathway Mitogenactivated Protein Kinase Pmk1p by Protein Phosphatases. (Chang, F., ed.) Molecular Biology of the Cell, vol. 18 (11), pp. 4405-4419

Madrid, M., Soto, T., Khong, H.K., Franco, A., Vicente, J., Pérez, P., Gacto, M. \& Cansado, J. (2006). Stress-induced response, localization, and regulation of the Pmk1 cell integrity pathway in Schizosaccharomyces pombe. The Journal of Biological Chemistry, vol. 281 (4), pp. 20332043

Madrid, M., Vázquez-Marín, B., Franco, A., Soto, T., Vicente-Soler, J., Gacto, M. \& Cansado, J. (2016). Multiple crosstalk between TOR and the cell integrity MAPK signaling pathway in fission yeast. Scientific Reports, vol. 6, p. 37515

Madrid, M., Vázquez-Marín, B., Soto, T., Franco, A., Gómez-Gil, E., Vicente-Soler, J., Gacto, M., Pérez, P. \& Cansado, J. (2017). Differential functional regulation of protein kinase C (PKC) orthologs in fission yeast. The Journal of Biological Chemistry, vol. 292 (27), pp. 1137411387

Magidson, V. \& Khodjakov, A. (2013). Circumventing photodamage in live-cell microscopy. Methods in cell biology, vol. 114. DOI: https://doi.org/10.1016/B978-0-12-4077614.00023-3

Magnelli, P.E., Cipollo, J.F. \& Robbins, P.W. (2005). A glucanase-driven fractionation allows redefinition of Schizosaccharomyces pombe cell wall composition and structure: assignment of diglucan. Analytical Biochemistry, vol. 336 (2), pp. 202-212

Mana-Capelli, S., McLean, J.R., Chen, C.-T., Gould, K.L. \& McCollum, D. (2012). The kinesin-14 Klp2 is negatively regulated by the SIN for proper spindle elongation and telophase nuclear positioning. Molecular Biology of the Cell, vol. 23 (23), pp. 4592-4600 
Mangione, M.C. \& Gould, K.L. (2019). Molecular form and function of the cytokinetic ring. Journal of Cell Science, vol. 132 (12), p. jcs226928

Manjón, E., Edreira, T., Muñoz, S. \& Sánchez, Y. (2017). Rgf1p (Rho1p GEF) is required for doublestrand break repair in fission yeast. Nucleic Acids Research, vol. 45 (9), pp. 5269-5284

Martín, H., Rodríguez-Pachón, J.M., Ruiz, C., Nombela, C. \& Molina, M. (2000a). Regulatory mechanisms for modulation of signaling through the cell integrity Slt2-mediated pathway in Saccharomyces cerevisiae. The Journal of Biological Chemistry, vol. 275 (2), pp. 1511-1519

Martín, V., García, B., Carnero, E., Durán, A. \& Sánchez, Y. (2003). Bgs3p, a putative 1,3-betaglucan synthase subunit, is required for cell wall assembly in Schizosaccharomyces pombe. Eukaryotic Cell, vol. 2 (1), pp. 159-169

Martín, V., Ribas, J.C., Carnero, E., Durán, A. \& Sánchez, Y. (200ob). bgs2+, a sporulation-specific glucan synthase homologue is required for proper ascospore wall maturation in fission yeast. Molecular Microbiology, vol. 38 (2), pp. 308-321

Martín-Cuadrado, A.B., Dedo, J.E.D., Medina-Redondo, M.D., Fontaine, T., Rey, F.D., Latgé, J.P. \& Aldana, C.R.V.D. (2008). The Schizosaccharomyces pombe endo-1,3- $\beta$-glucanase Eng1 contains a novel carbohydrate binding module required for septum localization. Molecular Microbiology, vol. 69 (1), pp. 188-200

Martín-Cuadrado, A.B., Dueñas, E., Sipiczki, M., Aldana, C.R.V. de \& Rey, F. del (2003). The endo$\beta-1,3$-glucanase eng1p is required for dissolution of the primary septum during cell separation in Schizosaccharomyces pombe. Journal of Cell Science, vol. 116 (9), pp. 16891698

Martín-Cuadrado, A.B., Morrell, J.L., Konomi, M., An, H., Petit, C., Osumi, M., Balasubramanian, M., Gould, K.L., del Rey, F. \& de Aldana, C.R.V. (2005). Role of Septins and the Exocyst Complex in the Function of Hydrolytic Enzymes Responsible for Fission Yeast Cell Separation. Molecular Biology of the Cell, vol. 16 (10), pp. 4867-4881

Martínez-Soto, D. \& Ruiz-Herrera, J. (2017). Functional analysis of the MAPK pathways in fungi. Revista Iberoamericana De Micologia, vol. 34 (4), pp. 192-202

Martín-García, R., Arribas, V., Coll, P.M., Pinar, M., Viana, R.A., Rincón, S.A., Correa-Bordes, J., Ribas, J.C. \& Pérez, P. (2018). Paxillin-Mediated Recruitment of Calcineurin to the Contractile Ring Is Required for the Correct Progression of Cytokinesis in Fission Yeast. Cell Reports, vol. 25 (3), pp. 772-783.e4

Martín-García, R., Coll, P.M. \& Pérez, P. (2014). F-BAR domain protein Rga7 collaborates with Cdc15 and Imp2 to ensure proper cytokinesis in fission yeast. Journal of Cell Science, vol. 127 (Pt 19), pp. 4146-4158

Martín-García, R. \& Santos, B. (2016). The price of independence: cell separation in fission yeast. World Journal of Microbiology \& Biotechnology, vol. 32 (4), p. 65

Matsuo, Y., Tanaka, K., Nakagawa, T., Matsuda, H. \& Kawamukai, M. (2004). Genetic analysis of chs1+ and chs2+ encoding chitin synthases from Schizosaccharomyces pombe. Bioscience, Biotechnology, and Biochemistry, vol. 68 (7), pp. 1489-1499

Matsuyama, A., Arai, R., Yashiroda, Y., Shirai, A., Kamata, A., Sekido, S., Kobayashi, Y., Hashimoto, A., Hamamoto, M., Hiraoka, Y., Horinouchi, S. \& Yoshida, M. (2006). ORFeome cloning and global analysis of protein localization in the fission yeast Schizosaccharomyces pombe. Nature Biotechnology, vol. 24 (7), pp. 841-847

McDonald, N.A., Lind, A.L., Smith, S.E., Li, R. \& Gould, K.L. (2017). Nanoscale architecture of the Schizosaccharomyces pombe contractile ring. eLife, vol. 6

Mendes Pinto, I., Rubinstein, B., Kucharavy, A., Unruh, J.R. \& Li, R. (2012). Actin Depolymerization Drives Actomyosin Ring Contraction during Budding Yeast Cytokinesis. Developmental Cell, vol. 22 (6), pp. 1247-1260

Merlini, L., Dudin, O. \& Martin, S.G. (2013). Mate and fuse: how yeast cells do it. Open Biology, vol. 3(3), p. 130008

Militello, R. \& Colombo, M.I. (2013). Small GTPases as regulators of cell division. Communicative \& Integrative Biology, vol. 6 (5), p. e25460 
Millar, J.B., Buck, V. \& Wilkinson, M.G. (1995). Pyp1 and Pyp2 PTPases dephosphorylate an osmosensing MAP kinase controlling cell size at division in fission yeast. Genes \& Development, vol. 9 (17), pp. 2117-2130

Minc, N. (2019). Cell wall dynamics in the control of fission yeast growth and morphogenesis. Proceedings of 1oth Fission Yeast meeting, Barcelona, julio 14 2019. Barcelona

Mishra, M., Huang, J. \& Balasubramanian, M.K. (2014). The yeast actin cytoskeleton. FEMS microbiology reviews, vol. 38 (2), pp. 213-227

Mishra, M., Karagiannis, J., Sevugan, M., Singh, P. \& Balasubramanian, M.K. (2005). The 14-3-3 protein rad24p modulates function of the cdc14p family phosphatase clp1p/flp1p in fission yeast. Current biology: CB, vol. 15 (15), pp. 1376-1383

Mishra, M., Karagiannis, J., Trautmann, S., Wang, H., McCollum, D. \& Balasubramanian, M.K. (2004). The Clp1p/Flp1p phosphatase ensures completion of cytokinesis in response to minor perturbation of the cell division machinery in Schizosaccharomyces pombe. Journal of Cell Science, vol. 117 (Pt 17), pp. 3897-3910

Mitchison, J.M. \& Nurse, P. (1985). Growth in cell length in the fission yeast Schizosaccharomyces pombe. Journal of Cell Science, vol. 75, pp. 357-376

Moreno, S., Klar, A. \& Nurse, P. (1991). Molecular genetic analysis of fission yeast Schizosaccharomyces pombe. Methods in Enzymology, vol. 194, pp. 795-823

Morrell-Falvey, J.L. (2005). Cell wall remodeling at the fission yeast cell division site requires the Rho-GEF Rgf3p. Journal of Cell Science, vol. 118 (23), pp. 5563-5573

Morrell-Falvey, J.L., Tomlin, G.C., Rajagopalan, S., Venkatram, S., Feoktistova, A.S., Tasto, J.J., Mehta, S., Jennings, J.L., Link, A., Balasubramanian, M.K. \& Gould, K.L. (2004). Sid4pCdc11p assembles the septation initiation network and its regulators at the S. pombe SPB. Current biology: CB, vol. 14 (7), pp. 579-584

Morris, Z., Sinha, D., Poddar, A., Morris, B. \& Chen, Q. (2019). Fission yeast TRP channel Pkd2p localizes to the cleavage furrow and regulates cell separation during cytokinesis. Molecular Biology of the Cell, vol. 30 (15), pp. 1791-1804

Moseley, J.B., Mayeux, A., Paoletti, A. \& Nurse, P. (2009). A spatial gradient coordinates cell size and mitotic entry in fission yeast. Nature, vol. 459 (7248), pp. 857-860

Motegi, F., Nakano, K. \& Mabuchi, I. (2000). Molecular mechanism of myosin-II assembly at the division site in Schizosaccharomyces pombe. Journal of Cell Science, vol. 113 ( Pt 10), pp. $1813-1825$

Mulvihill, D.P. \& Hyams, J.S. (2002). Cytokinetic actomyosin ring formation and septation in fission yeast are dependent on the full recruitment of the polo-like kinase Plo1 to the spindle pole body and a functional spindle assembly checkpoint. Journal of Cell Science, vol. 115 (Pt 18), pp. 3575-3586

Muñoz, J., Cortés, J.C.G., Sipiczki, M., Ramos, M., Clemente-Ramos, J.A., Moreno, M.B., Martins, I.M., Pérez, P. \& Ribas, J.C. (2013). Extracellular cell wall $\beta(1,3)$ glucan is required to couple septation to actomyosin ring contraction. J Cell Biol, vol. 203 (2), pp. 265-282

Muñoz, S., Manjón, E., García, P., Sunnerhagen, P. \& Sánchez, Y. (2014a). The checkpointdependent nuclear accumulation of Rho1p exchange factor Rgf1p is important for tolerance to chronic replication stress. Molecular Biology of the Cell, vol. 25 (7), pp. 11371150

Muñoz, S., Manjón, E. \& Sánchez, Y. (2014b). The putative exchange factor Gef3p interacts with Rho3p GTPase and the septin ring during cytokinesis in fission yeast. The Journal of Biological Chemistry, vol. 289 (32), pp. 21995-22007

Mutoh, T., Nakano, K. \& Mabuchi, I. (2005). Rho1-GEFs Rgf1 and Rgf2 are involved in formation of cell wall and septum, while Rgf3 is involved in cytokinesis in fission yeast. Genes to Cells: Devoted to Molecular \& Cellular Mechanisms, vol. 10 (12), pp. 1189-1202

Nabeshima, K., Nakagawa, T., Straight, A.F., Murray, A., Chikashige, Y., Yamashita, Y.M., Hiraoka, Y. \& Yanagida, M. (1998). Dynamics of Centromeres during MetaphaseAnaphase Transition in Fission Yeast: Dis1 Is Implicated in Force Balance in Metaphase Bipolar Spindle. Molecular Biology of the Cell, vol. 9 (11), pp. 3211-3225 
Nakano, K., Arai, R. \& Mabuchi, I. (1997). The small GTP-binding protein Rho1 is a multifunctional protein that regulates actin localization, cell polarity, and septum formation in the fission yeast Schizosaccharomyces pombe. Genes to Cells: Devoted to Molecular \& Cellular Mechanisms, vol. 2 (11), pp. 679-694

Nakano, K. \& Mabuchi, I. (2006). Actin-depolymerizing Protein Adf1 Is Required for Formation and Maintenance of the Contractile Ring during Cytokinesis in Fission Yeast. Molecular Biology of the Cell, vol. 17 (4), pp. 1933-1945

Nakano, K., Mutoh, T., Arai, R. \& Mabuchi, I. (2003). The small GTPase Rho4 is involved in controlling cell morphology and septation in fission yeast. Genes to Cells: Devoted to Molecular \& Cellular Mechanisms, vol. 8 (4), pp. 357-370

Nguyen, A.N., Ikner, A.D., Shiozaki, M., Warren, S.M. \& Shiozaki, K. (2002). Cytoplasmic localization of Wis1 MAPKK by nuclear export signal is important for nuclear targeting of Spc1/Sty1 MAPK in fission yeast. Molecular Biology of the Cell, vol. 13 (8), pp. 2651-2663

Nguyen, A.N. \& Shiozaki, K. (1999). Heat-shock-induced activation of stress MAP kinase is regulated by threonine- and tyrosine-specific phosphatases. Genes \& Development, vol. 13 (13), pp. 1653-1663

Nurse, P. (1990). Universal control mechanism regulating onset of M-phase. Nature, vol. 344 (6266), pp. 503-508

Nurse, P., Thuriaux, P. \& Nasmyth, K. (1976). Genetic control of the cell division cycle in the fission yeast Schizosaccharomyces pombe. Molecular \& general genetics: MGG, vol.146 (2), pp. 167-178

Okada, H., Wloka, C., Wu, J.Q. \& Bi, E. (2019). Distinct Roles of Myosin-II Isoforms in Cytokinesis under Normal and Stressed Conditions. iScience, vol. 14, pp. 69-87

Opalko, H.E. \& Moseley, J.B. (2017). Dynamic regulation of Cdr1 kinase localization and phosphorylation during osmotic stress. The Journal of Biological Chemistry, vol. 292 (45), pp. 18457-18468

O'Shaughnessy, B. \& Thiyagarajan, S. (2018). Mechanisms of contractile ring tension production and constriction. Biophysical Reviews, vol. 10 (6), pp. 1667-1681

Padte, N.N., Martin, S.G., Howard, M. \& Chang, F. (2006). The cell-end factor pom1p inhibits midip in specification of the cell division plane in fission yeast. Current biology: $C B$, vol. 16 (24), pp. 2480-2487

Palani, S., Chew, T.G., Ramanujam, S., Kamnev, A., Harne, S., Chapa-y-Lazo, B., Hogg, R., Sevugan, M., Mishra, M., Gayathri, P. \& Balasubramanian, M.K. (2017). Motor Activity Dependent and Independent Functions of Myosin II Contribute to Actomyosin Ring Assembly and Contraction in Schizosaccharomyces pombe. Current Biology, vol. 27 (5), pp. 751-757

Papadakis, M.A. \& Workman, C.T. (2015). Oxidative stress response pathways: Fission yeast as archetype. Critical Reviews in Microbiology, vol. 41 (4), pp. 520-535

Pelham, R.J. \& Chang, F. (2002). Actin dynamics in the contractile ring during cytokinesis in fission yeast. Nature, vol. 419 (6902), pp. 82-86

Perez, P. \& Cansado, J. (2010). Cell Integrity Signaling and Response to Stress in Fission Yeast. Current Protein \& Peptide Science, vol. 11 (8), pp. 680-692

Perez, P., Cortés, J.C.G., Cansado, J. \& Ribas, J.C. (2018). Fission yeast cell wall biosynthesis and cell integrity signalling. The Cell Surface, vol. 4, pp.1-9

Perez, P., Portales, E. \& Santos, B. (2015). Rho4 interaction with exocyst and septins regulates cell separation in fission yeast. Microbiology (Reading, England), vol. 161 (Pt 5), pp. 948959

Perez, P. \& Rincón, S.A. (2010). Rho GTPases: regulation of cell polarity and growth in yeasts. The Biochemical Journal, vol. 426 (3), pp. 243-253

Perez, P., Soto, T., Gómez-Gil, E. \& Cansado, J. (2019). Functional interaction between Cdc42 and the stress MAPK signaling pathway during the regulation of fission yeast polarized growth. International Microbiology: The Official Journal of the Spanish Society for Microbiology, 
Piala, A.T., Humphreys, J.M. \& Goldsmith, E.J. (2014). MAP kinase modules: the excursion model and the steps that count. Biophysical Journal, vol. 107 (9), pp. 2006-2015

Pinar, M., Coll, P.M., Rincón, S.A. \& Pérez, P. (2008). Schizosaccharomyces pombe Pxl1 is a paxillin homologue that modulates Rho1 activity and participates in cytokinesis. Molecular Biology of the Cell, vol. 19 (4), pp. 1727-1738

Plouffe, S.W., Meng, Z., Lin, K.C., Lin, B., Hong, A.W., Chun, J.V. \& Guan, K.-L. (2016). Characterization of Hippo Pathway Components by Gene Inactivation. Molecular Cell, vol. 64 (5), pp. 993-1008

Pollard, L.W., Onishi, M., Pringle, J.R. \& Lord, M. (2012). Fission yeast Cyk3p is a transglutaminase-like protein that participates in cytokinesis and cell morphogenesis. Molecular biology of the cell, vol. 23 (13), pp. 2433-2444

Pollard, T.D. (2017). Nine unanswered questions about cytokinesis. The Journal of Cell Biology, vol. 216 (10), pp. 3007-3016

Pollard, T.D. \& O'Shaughnessy, B. (2019). Molecular Mechanism of Cytokinesis. Annual Review of Biochemistry, vol. 88 (1), p. annurev-biochem-062917-012530

Pommier, Y. (2006). Topoisomerase I inhibitors: camptothecins and beyond. Nature Reviews. Cancer, vol. 6 (10), pp. 789-802

Proctor, S.A., Minc, N., Boudaoud, A. \& Chang, F. (2012). Contributions of Turgor Pressure, the Contractile Ring, and Septum Assembly to Forces in Cytokinesis in Fission Yeast. Current Biology, vol. 22 (17), pp. 1601-1608

$\mathrm{Pu}$, K.-M., Akamatsu, M. \& Pollard, T.D. (2015). The septation initiation network controls the assembly of nodes containing Cdr2p for cytokinesis in fission yeast. Journal of Cell Science, vol. 128 (3), pp. 441-446

Quinn, J., Findlay, V.J., Dawson, K., Millar, J.B.A., Jones, N., Morgan, B.A. \& Toone, W.M. (2002). Distinct regulatory proteins control the graded transcriptional response to increasing $\mathrm{H}(2) \mathrm{O}(2)$ levels in fission yeast Schizosaccharomyces pombe. Molecular Biology of the Cell, vol. 13 (3), pp. 805-816

Rachfall, N., Johnson, A.E., Mehta, S., Chen, J.-S. \& Gould, K.L. (2014). Cdk1 promotes cytokinesis in fission yeast through activation of the septation initiation network. Molecular Biology of the Cell, vol. 25 (15), pp. 2250-2259

Ren, L., Willet, A.H., Roberts-Galbraith, R.H., McDonald, N.A., Feoktistova, A., Chen, J.-S., Huang, H., Guillen, R., Boone, C., Sidhu, S.S., Beckley, J.R. \& Gould, K.L. (2015). The Cdc15 and Imp2 SH3 domains cooperatively scaffold a network of proteins that redundantly ensure efficient cell division in fission yeast. (Lew, D. J., ed.) Molecular Biology of the Cell, vol. 26 (2), pp. 256-269

Revilla-Guarinos, M.T., Martín-García, R., Villar-Tajadura, M.A., Estravís, M., Coll, P.M. \& Pérez, P. (2016). Rga6 is a Fission Yeast Rho GAP Involved in Cdc42 Regulation of Polarized Growth. Molecular Biology of the Cell,

Ribas, J.C. \& Cortés, J.C.G. (2016). Imaging Septum Formation by Fluorescence Microscopy. Methods in Molecular Biology (Clifton, N.J.), vol. 1369, pp. 73-85

Ribas, J.C., Diaz, M., Duran, A. \& Pere, P. (1991). Isolation and characterization of Schizosaccharomyces pombe mutants defective in cell wall (1-3)beta-D-glucan. Journal of Bacteriology, vol. 173 (11), pp. 3456-3462

Riedl, J., Crevenna, A.H., Kessenbrock, K., Yu, J.H., Neukirchen, D., Bista, M., Bradke, F., Jenne, D., Holak, T.A., Werb, Z., Sixt, M. \&Wedlich-Soldner, R. (2008). Lifeact: a versatile marker to visualize F-actin. Nature Methods, vol. 5 (7), pp. 605-607

Rincon, S.A., Bhatia, P., Bicho, C., Guzman-Vendrell, M., Fraisier, V., Borek, W.E., Alves, F. de L., Dingli, F., Loew, D., Rappsilber, J., Sawin, K.E., Martin, S.G. \& Paoletti, A. (2014). Pom1 regulates the assembly of Cdr2-Mid1 cortical nodes for robust spatial control of cytokinesis. The Journal of Cell Biology, vol. 206 (1), pp. 61-77

Rincon, S.A., Estravis, M., Dingli, F., Loew, D., Tran, P.T. \& Paoletti, A. (2017). SIN-Dependent Dissociation of the SAD Kinase Cdr2 from the Cell Cortex Resets the Division Plane. Current biology: $C B$, vol. 27 (4), pp. 534-542 
Rincon, S.A. \& Paoletti, A. (2016). Molecular control of fission yeast cytokinesis. Seminars in Cell \& Developmental Biology, vol. 53, pp. 28-38

Rispail, N., Soanes, D.M., Ant, C., Czajkowski, R., Grünler, A., Huguet, R., Perez-Nadales, E., Poli, A., Sartorel, E., Valiante, V., Yang, M., Beffa, R., Brakhage, A.A., Gow, N.A.R., Kahmann, R., Lebrun, M.-H., Lenasi, H., Perez-Martin, J., Talbot, N.J., Wendland, J. \& Di Pietro, A. (2009). Comparative genomics of MAP kinase and calcium-calcineurin signalling components in plant and human pathogenic fungi. Fungal genetics and biology: $F G \& B$, vol. 46 (4), pp. 287-298

Roberts-Galbraith, R.H., Chen, J.-S., Wang, J. \& Gould, K.L. (2009). The SH3 domains of two PCH family members cooperate in assembly of the Schizosaccharomyces pombe contractile ring. The Journal of Cell Biology, vol. 184 (1), pp. 113-127

Roberts-Galbraith, R.H., Ohi, M.D., Ballif, B.A., Chen, J.-S., McLeod, I., McDonald, W.H., Gygi, S.P., Yates, J.R. \& Gould, K.L. (2010). Dephosphorylation of F-BAR protein Cdc15 modulates its conformation and stimulates its scaffolding activity at the cell division site. Molecular Cell, vol. 39 (1), pp. 86-99

Rodríguez-Gabriel, M.A. \& Russell, P. (2005). Distinct signaling pathways respond to arsenite and reactive oxygen species in Schizosaccharomyces pombe. Eukaryotic Cell, vol. 4 (8), pp. $1396-1402$

Roncero, C. \& Durán, A. (1985). Effect of Calcofluor white and Congo red on fungal cell wall morphogenesis: in vivo activation of chitin polymerization. Journal of Bacteriology, vol. 163 (3), pp. 1180-1185

Roncero, C. \& Sánchez, Y. (2010). Cell separation and the maintenance of cell integrity during cytokinesis in yeast: the assembly of a septum. Yeast (Chichester, England), vol. 27 (8), pp. 521-530

Rosenberg, J.A., Tomlin, G.C., McDonald, W.H., Snydsman, B.E., Muller, E.G., Yates, J.R. \& Gould, K.L. (2006). Ppc89 links multiple proteins, including the septation initiation network, to the core of the fission yeast spindle-pole body. Molecular Biology of the Cell, vol. 17 (9), pp. 3793-3805

Rossman, K.L., Der, C.J. \& Sondek, J. (2005). GEF means go: turning on RHO GTPases with guanine nucleotide-exchange factors. Nature Reviews. Molecular Cell Biology, vol. 6 (2), pp. $167-180$

Rossman, K.L. \& Sondek, J. (2005). Larger than Dbl: new structural insights into RhoA activation. Trends in Biochemical Sciences, vol. 30 (4), pp. 163-165

Rüthnick, D. \& Schiebel, E. (2016). Duplication of the Yeast Spindle Pole Body Once per Cell Cycle. Molecular and Cellular Biology, vol. 36 (9), pp. 1324-1331

Sabatinos, S.A. \& Forsburg, S.L. (2010). Molecular Genetics of Schizosaccharomyces pombe. Methods in Enzymology. Academic Press, pp. 759-795.

Salas-Pino, S. \& Daga, R.R. (2019). Spatiotemporal control of spindle disassembly in fission yeast. Cellular and molecular life sciences: CMLS, vol. 76 (18), pp. 3543-3551

Salat-Canela, C., Paulo, E., Sánchez-Mir, L., Carmona, M., Ayté, J., Oliva, B. \& Hidalgo, E. (2017). Deciphering the role of the signal- and Sty1 kinase-dependent phosphorylation of the stress-responsive transcription factor Atf1 on gene activation. The Journal of Biological Chemistry, vol. 292 (33), pp. 13635-13644

Sánchez-Mir, L., Franco, A., Madrid, M., Vicente-Soler, J., Villar-Tajadura, M.A., Soto, T., Pérez, P., Gacto, M. \& Cansado, J. (2012). Biological Significance of Nuclear Localization of Mitogen-activated Protein Kinase Pmk1 in Fission Yeast. Journal of Biological Chemistry, vol. 287 (31), pp. 26038-26051

Sánchez-Mir, L., Soto, T., Franco, A., Madrid, M., Viana, R.A., Vicente, J., Gacto, M., Pérez, P. \& Cansado, J. (2014). Rho1 GTPase and PKC ortholog Pck1 are upstream activators of the cell integrity MAPK pathway in fission yeast. PloS One, vol. 9 (1), p. e88020

Satoh, R., Morita, T., Takada, H., Kita, A., Ishiwata, S., Doi, A., Hagihara, K., Taga, A., Matsumura, Y., Tohda, H. \& Sugiura, R. (2009). Role of the RNA-binding protein Nrd1 and Pmk1 mitogen-activated protein kinase in the regulation of myosin mRNA stability in fission yeast. Molecular Biology of the Cell, vol. 20 (9), pp. 2473-2485 
Schindelin, J., Arganda-Carreras, I., Frise, E., Kaynig, V., Longair, M., Pietzsch, T., Preibisch, S., Rueden, C., Saalfeld, S., Schmid, B., Tinevez, J.-Y., White, D.J., Hartenstein, V., Eliceiri, K., Tomancak, P. \& Cardona, A. (2012). Fiji: an open-source platform for biological-image analysis. Nature Methods, vol. 9 (7), pp. 676-682

Schmidt, S., Sohrmann, M., Hofmann, K., Woollard, A. \& Simanis, V. (1997). The Spg1p GTPase is an essential, dosage-dependent inducer of septum formation in Schizosaccharomyces pombe. Genes \& Development, vol. 11 (12), pp. 1519-1534

Sengar, A.S., Markley, N.A., Marini, N.J. \& Young, D. (1997). Mkh1, a MEK kinase required for cell wall integrity and proper response to osmotic and temperature stress in Schizosaccharomyces pombe. Molecular and Cellular Biology, vol. 17 (7), pp. 3508-3519

Sethi, K., Palani, S., Cortés, J.C.G., Sato, M., Sevugan, M., Ramos, M., Vijaykumar, S., Osumi, M., Naqvi, N.I., Ribas, J.C. \& Balasubramanian, M. (2016). A New Membrane Protein Sbg1 Links the Contractile Ring Apparatus and Septum Synthesis Machinery in Fission Yeast. PLoS Genetics, vol. 12 (10). DOI: https://doi.org/10.1371/journal.pgen.1006383

Shimoda, C. (2004). Forespore membrane assembly in yeast: coordinating SPBs and membrane trafficking. Journal of Cell Science, vol. 117 (Pt 3), pp. 389-396

Shiozaki, K. \& Russell, P. (1995). Cell-cycle control linked to extracellular environment by MAP kinase pathway in fission yeast. Nature, vol. 378 (6558), pp. 739-743

Shiozaki, K. \& Russell, P. (1996). Conjugation, meiosis, and the osmotic stress response are regulated by Spc1 kinase through Atf1 transcription factor in fission yeast. Genes \& Development, vol. 10 (18), pp. 2276-2288

Shiozaki, K., Shiozaki, M. \& Russell, P. (1998). Heat stress activates fission yeast Spc1/StyI MAPK by a MEKK-independent mechanism. Molecular Biology of the Cell, vol. 9 (6), pp. 13391349

Simanis, V. (2015). Pombe's thirteen - control of fission yeast cell division by the septation initiation network. Journal of Cell Science, vol. 128 (8), pp. 1465-1474

Skau, C.T. \& Kovar, D.R. (2010). Fimbrin and tropomyosin competition regulates endocytosis and cytokinesis kinetics in fission yeast. Current biology: CB, vol. 20 (16), pp. 1415-1422

Sohrmann, M., Schmidt, S., Hagan, I. \& Simanis, V. (1998). Asymmetric segregation on spindle poles of the Schizosaccharomyces pombe septum-inducing protein kinase Cdc7p. Genes \& Development, vol. 12 (1), pp. 84-94

Soto, T., Beltrán, F.F., Paredes, V., Madrid, M., Millar, J.B.A., Vicente-Soler, J., Cansado, J. \& Gacto, M. (2002). Cold induces stress-activated protein kinase-mediated response in the fission yeast Schizosaccharomyces pombe. European Journal of Biochemistry, vol. 269 (20), pp. 5056-5065

Soto, T., Villar-Tajadura, M.A., Madrid, M., Vicente, J., Gacto, M., Pérez, P. \& Cansado, J. (2010). Rga4 Modulates the Activity of the Fission Yeast Cell Integrity MAPK Pathway by Acting as a Rho2 GTPase-activating Protein. Journal of Biological Chemistry, vol. 285 (15), pp. $11516-11525$

Sparks, C.A., Morphew, M. \& McCollum, D. (1999). Sid2p, a spindle pole body kinase that regulates the onset of cytokinesis. The Journal of Cell Biology, vol. 146 (4), pp. 777-790

Stachowiak, M.R., Laplante, C., Chin, H.F., Guirao, B., Karatekin, E., Pollard, T.D. \& O'Shaughnessy, B. (2014). Mechanism of cytokinetic contractile ring constriction in fission yeast. Developmental Cell, vol. 29 (5), pp. 547-561

Stark, B.C., Sladewski, T.E., Pollard, L.W. \& Lord, M. (2010). Tropomyosin and myosin-II cellular levels promote actomyosin ring assembly in fission yeast. Molecular biology of the cell, vol. 21 (6), pp. 989-1000

Sugawara, T., Takahashi, S., Osumi, M. \& Ohno, N. (2004). Refinement of the structures of cellwall glucans of Schizosaccharomyces pombe by chemical modification and NMR spectroscopy. Carbohydrate Research, vol. 339 (13), pp. 2255-2265

Sugiura, R., Kita, A., Shimizu, Y., Shuntoh, H., Sio, S.O. \& Kuno, T. (2003). Feedback regulation of MAPK signalling by an RNA-binding protein. Nature, vol. 424 (6951), pp. 961-965

Sugiura, R., Toda, T., Dhut, S., Shuntoh, H. \& Kuno, T. (1999). The MAPK kinase Pek1 acts as a phosphorylation-dependent molecular switch. Nature, vol. 399 (6735), pp. 479-483 
Sugiura, R., Toda, T., Shuntoh, H., Yanagida, M. \& Kuno, T. (1998). pmp1+, a suppressor of calcineurin deficiency, encodes a novel MAP kinase phosphatase in fission yeast. The EMBO Journal, vol. 17 (1), pp. 140-148

Swulius, M.T., Nguyen, L.T., Ladinsky, M.S., Ortega, D.R., Aich, S., Mishra, M. \& Jensen, G.J. (2018). Structure of the fission yeast actomyosin ring during constriction. Proceedings of the National Academy of Sciences of the United States of America, vol. 115 (7), pp. E1455E1464

Taira, K., Umikawa, M., Takei, K., Myagmar, B.-E., Shinzato, M., Machida, N., Uezato, H., Nonaka, S. \& Kariya, K. (2004). The Traf2- and Nck-interacting kinase as a putative effector of Rap2 to regulate actin cytoskeleton. The Journal of Biological Chemistry, vol. 279 (47), pp. 49488-49496

Tajadura, V. (2004). Caracterización de rgf3+: regulador de Rho1p en Schizosaccharomyces pombe. (Tesis doctoral). Universidad de Salamanca.

Tajadura, V., García, B., García, I., García, P. \& Sánchez, Y. (2004). Schizosaccharomyces pombe Rgf3p is a specific Rho1 GEF that regulates cell wall beta-glucan biosynthesis through the GTPase Rho1p. Journal of Cell Science, vol. 117 (Pt 25), pp. 6163-6174

Takada, H., Nishida, A., Domae, M., Kita, A., Yamano, Y., Uchida, A., Ishiwata, S., Fang, Y., Zhou, X., Masuko, T., Kinoshita, M., Kakehi, K. \& Sugiura, R. (2010). The Cell Surface Protein Gene ecm33+ Is a Target of the Two Transcription Factors Atf1 and Mbx1 and Negatively Regulates Pmk1 MAPK Cell Integrity Signaling in Fission Yeast. Molecular Biology of the Cell, vol. 21 (4), pp. 674-685

Takada, H., Nishimura, M., Asayama, Y., Mannse, Y., Ishiwata, S., Kita, A., Doi, A., Nishida, A., Kai, N., Moriuchi, S., Tohda, H., Giga-Hama, Y., Kuno, T. \& Sugiura, R. (2007). Atf1 Is a Target of the Mitogen-activated Protein Kinase Pmk1 and Regulates Cell Integrity in Fission Yeast. Molecular Biology of the Cell, vol. 18 (12), pp. 4794-4802

Tanaka, K., Petersen, J., MacIver, F., Mulvihill, D.P., Glover, D.M. \& Hagan, I.M. (2001). The role of Plo1 kinase in mitotic commitment and septation in Schizosaccharomyces pombe. The EMBO Journal, vol. 20 (6), pp. 1259-1270

Tasto, J.J., Morrell, J.L. \& Gould, K.L. (2003). An anillin homologue, Mid2p, acts during fission yeast cytokinesis to organize the septin ring and promote cell separation. The Journal of cell biology, vol. 160 (7), pp. 1093-1103

Tebbs, I.R. \& Pollard, T.D. (2013). Separate roles of IQGAP Rng2p in forming and constricting the Schizosaccharomyces pombe cytokinetic contractile ring. Molecular Biology of the Cell, vol. 24 (12), pp. 1904-1917

Thiyagarajan, S., Munteanu, E.L., Arasada, R., Pollard, T.D. \& O'Shaughnessy, B. (2015). The fission yeast cytokinetic contractile ring regulates septum shape and closure. Journal of Cell Science, vol. 128 (19), pp. 3672-3681

Toda, T., Dhut, S., Superti-Furga, G., Gotoh, Y., Nishida, E., Sugiura, R. \& Kuno, T. (1996). The fission yeast pmk1+ gene encodes a novel mitogen-activated protein kinase homolog which regulates cell integrity and functions coordinately with the protein kinase $\mathrm{C}$ pathway. Molecular and Cellular Biology, vol. 16 (12), pp. 6752-6764

Toda, T., Shimanuki, M. \& Yanagida, M. (1993). Two novel protein kinase C-related genes of fission yeast are essential for cell viability and implicated in cell shape control. The EMBO journal, vol. 12 (5), pp. 1987-1995

Trautmann, S. \& McCollum, D. (2005). Distinct Nuclear and Cytoplasmic Functions of the S. pombe Cdc14-like Phosphatase Clp1p/Flp1p and a Role for Nuclear Shuttling in Its Regulation. Current Biology, vol. 15 (15), pp. 1384-1389

Trautmann, S., Wolfe, B.A., Jorgensen, P., Tyers, M., Gould, K.L. \& McCollum, D. (2001). Fission yeast Clp1p phosphatase regulates G2/M transition and coordination of cytokinesis with cell cycle progression. Current Biology, vol. 11 (12), pp. 931-940

Ueyama, T. (2019). Rho-Family Small GTPases: From Highly Polarized Sensory Neurons to Cancer Cells. Cells, vol. 8 (2) 
Vavylonis, D., Wu, J.-Q., Hao, S., O’Shaughnessy, B. \& Pollard, T.D. (2008). Assembly mechanism of the contractile ring for cytokinesis by fission yeast. Science (New York, N.Y.), vol. 319 (5859), pp. 97-100

Vetter, I.R. \& Wittinghofer, A. (2001). The guanine nucleotide-binding switch in three dimensions. Science (New York, N.Y.), vol. 294 (5545), pp. 1299-1304

Viana, R.A., Pinar, M., Soto, T., Coll, P.M., Cansado, J. \& Pérez, P. (2013). Negative functional interaction between cell integrity MAPK pathway and Rho1 GTPase in fission yeast. Genetics, vol. 195 (2), pp. 421-432

Villar-Tajadura, M.A., Coll, P.M., Madrid, M., Cansado, J., Santos, B. \& Pérez, P. (2008). Rga2 is a Rho2 GAP that regulates morphogenesis and cell integrity in S. pombe. Molecular Microbiology, vol. 70 (4), pp. 867-881

Wachowicz, P., Chasapi, A., Krapp, A., Cano Del Rosario, E., Schmitter, D., Sage, D., Unser, M., Xenarios, I., Rougemont, J. \& Simanis, V. (2015). Analysis of S. pombe SIN protein association to the SPB reveals two genetically separable states of the SIN. Journal of Cell Science, vol. 128 (4), pp. 741-754

Wagner, E. \& Glotzer, M. (2016). Local RhoA activation induces cytokinetic furrows independent of spindle position and cell cycle stage. The Journal of Cell Biology, vol. 213 (6), pp. 641649

Wang, N., Wang, M., Zhu, Y.-H., Grosel, T.W., Sun, D., Kudryashov, D.S. \& Wu, J.-Q. (2015). The Rho-GEF Gef3 interacts with the septin complex and activates the GTPase Rho4 during fission yeast cytokinesis. Molecular Biology of the Cell, vol. 26 (2), pp. 238-255

Warbrick, E. \& Fantes, P.A. (1991). The wis1 protein kinase is a dosage-dependent regulator of mitosis in Schizosaccharomyces pombe. The EMBO journal, vol. 10 (13), pp. 4291-4299

Wennerberg, K., Rossman, K.L. \& Der, C.J. (2005). The Ras superfamily at a glance. Journal of Cell Science, vol. 118 (Pt 5), pp. 843-846

Wilkinson, M.G., Samuels, M., Takeda, T., Toone, W.M., Shieh, J.C., Toda, T., Millar, J.B. \& Jones, N. (1996). The Atf1 transcription factor is a target for the Sty1 stress-activated MAP kinase pathway in fission yeast. Genes \& Development, vol. 10 (18), pp. 2289-2301

Willet, A.H., DeWitt, A.K., Beckley, J.R., Clifford, D.M. \& Gould, K.L. (2019). NDR Kinase Sid2 Drives Anillin-like Mid1 from the Membrane to Promote Cytokinesis and Medial Division Site Placement. Current biology: CB, vol. 29 (6), pp. 1055-1063.e2

Willet, A.H., McDonald, N.A. \& Gould, K.L. (2015). Regulation of contractile ring formation and septation in Schizosaccharomyces pombe. Current Opinion in Microbiology, vol. 28, pp. 46-52

Wood, E. \& Nurse, P. (2015). Sizing up to divide: mitotic cell-size control in fission yeast. Annual Review of Cell and Developmental Biology, vol. 31, pp. 11-29

Wu, J.-Q., Kuhn, J.R., Kovar, D.R. \& Pollard, T.D. (2003). Spatial and temporal pathway for assembly and constriction of the contractile ring in fission yeast cytokinesis. Developmental Cell, vol. 5 (5), pp. 723-734

Wu, J.-Q. \& Pollard, T.D. (2005). Counting cytokinesis proteins globally and locally in fission yeast. Science (New York, N.Y.), vol. 310 (5746), pp. 310-314

Wu, J.-Q., Sirotkin, V., Kovar, D.R., Lord, M., Beltzner, C.C., Kuhn, J.R. \& Pollard, T.D. (2006). Assembly of the cytokinetic contractile ring from a broad band of nodes in fission yeast. The Journal of Cell Biology, vol. 174 (3), pp. 391-402

Xu, W. \& He, X. (2010). DEEP Insights through the DEP Domain. Structure (London, England: 1993), vol. 18 (10), pp. 1223-1225

Yamashita, A., Sakuno, T., Watanabe, Y. \& Yamamoto, M. (2017). Analysis of Schizosaccharomyces pombe Meiosis. Cold Spring Harbor Protocols, vol. 2017 (9), p. pdb.top079855

Yang, P., Qyang, Y., Bartholomeusz, G., Zhou, X. \& Marcus, S. (2003). The novel Rho GTPaseactivating protein family protein, Rga8, provides a potential link between Cdc42/p21activated kinase and Rho signaling pathways in the fission yeast, Schizosaccharomyces pombe. The Journal of Biological Chemistry, vol. 278 (49), pp. 48821-48830 
Ye, Y., Lee, I.-J., Runge, K.W. \& Wu, J.-Q. (2012). Roles of putative Rho-GEF Gef2 in division-site positioning and contractile-ring function in fission yeast cytokinesis. Molecular Biology of the Cell, vol. 23 (7), pp. 1181-1195

Yeung, T., Gilbert, G.E., Shi, J., Silvius, J., Kapus, A. \& Grinstein, S. (2008). Membrane phosphatidylserine regulates surface charge and protein localization. Science (New York, N.Y.), vol. 319 (5860), pp. 210-213

Zaitsevskaya-Carter, T. \& Cooper, J.A. (1997). Spm1, a stress-activated MAP kinase that regulates morphogenesis in S.pombe. The EMBO Journal, vol. 16 (6), pp. 1318-1331

Zambon, P., Palani, S., Kamnev, A. \& Balasubramanian, M.K. (2017). Myo2p is the major motor involved in actomyosin ring contraction in fission yeast. Current biology: $C B$, vol. 27 (3), pp. R99-R100

Zheng, S., Dong, F., Rasul, F., Yao, X., Jin, Q., Zheng, F. \& Fu, C. (2018). Septins regulate the equatorial dynamics of the separation initiation network kinase Sid2p and glucan synthases to ensure proper cytokinesis. The FEBS Journal, vol. 285 (13), pp. 2468-2480

Zhou, X., Ma, Y., Kato, T. \& Kuno, T. (2012). A Measurable Activation of the bZIP Transcription Factor Atf1 in a Fission Yeast Strain Devoid of Stress-activated and Cell Integrity Mitogen-activated Protein Kinase (MAPK) Activities. The Journal of Biological Chemistry, vol. 287 (28), pp. 23434-23439

Zhou, Z., Munteanu, E.L., He, J., Ursell, T., Bathe, M., Huang, K.C. \& Chang, F. (2015). The contractile ring coordinates curvature-dependent septum assembly during fission yeast cytokinesis. Molecular Biology of the Cell, vol. 26 (1), pp. 78-90

Zhu, Y.-H., Ye, Y., Wu, Z. \& Wu, J.-Q. (2013). Cooperation between Rho-GEF Gef2 and its binding partner Nod1 in the regulation of fission yeast cytokinesis. Molecular Biology of the Cell, vol. 24 (20), pp. 3187-3204 